NISTIR 8256

\title{
Measurement of Airborne Emissions from Extinguished Cigarettes: Final Report
}

\author{
Dustin Poppendieck \\ Mengyan Gong
}

This publication is available free of charge from:

https://doi.org/10.6028/NIST.IR.8256

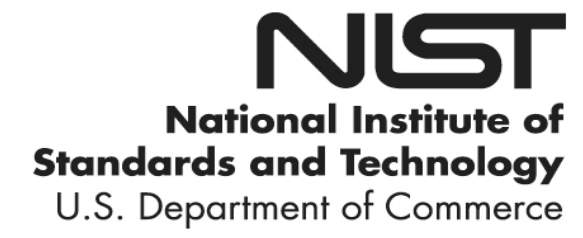




\title{
Measurement of Airborne Emissions from Extinguished Cigarettes: Final Report
}

\author{
Dustin Poppendieck \\ Mengyan Gong \\ Energy and Environment Division \\ Engineering Laboratory
}

This publication is available free of charge from:

https://doi.org/10.6028/NIST.IR.8256

December 2019

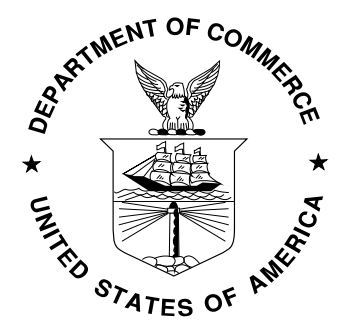

U.S. Department of Commerce Wilbur L. Ross, Jr., Secretary

National Institute of Standards and Technology Walter Copan, NIST Director and Undersecretary of Commerce for Standards and Technology 
Certain commercial entities, equipment, or materials may be identified in this document in order to describe an experimental procedure or concept adequately. Such identification is not intended to imply recommendation or endorsement by the National Institute of Standards and Technology, nor is it intended to imply that the entities, materials, or equipment are necessarily the best available for the purpose.

National Institute of Standards and Technology Interagency Report 8256

Natl. Inst. Stand. Technol. Interag. Rep. 8256, 135 pages (December 2019)

This publication is available free of charge from:

https://doi.org/10.6028/NIST.IR.8256 


\section{EXECUTIVE SUMMARY}

Globally, around five trillion cigarette butts are disposed of per year (Novotny and Zhao 1999, Chapman 2006, Healton et al. 2011, Bonanomi et al. 2015). Cigarette butts are found in buildings, in cars, on beaches, and near streams, night clubs, bus stops, roads and streets. The environmental impact of cigarette butts due to air emissions is not well studied. This report summarizes activities conducted by the National Institute of Standards and Technology (NIST) to better understand the airborne emissions from non-smoldering cigarette butts by determining the initial distributions of chemicals in a cigarette butt, the influence of environmental parameters on the emissions from butts conditioned in different environments, and airborne emission rates from butts in a simulated indoor environment.

Consistent cigarette butts were generated using a custom-built smoking apparatus. Airborne emissions of eight target chemicals were quantified in each experiment: furfural, ethylbenzene, styrene, 2-methyl-2-cyclopenten-1-one, limonene, naphthalene, triacetin, and nicotine. Chemicals were selected based on consistency and size of analytical response areas, and/or if the chemical was listed in the United States Food and Drug Administration (FDA) Harmful and Potentially Harmful Constituents (HPHC) list for tobacco products and tobacco smoke. Three series of experiments were conducted in this study. First, studies were performed to determine the relative distributions of the target chemicals in freshly smoked butts by analyzing six types of samples consisting of different parts of the butts, i.e. unburned filter, unburned tobacco, burned filter, burned ash, cut cigarette butt, and uncut cigarette butt. Each sample was analyzed using headspacethermal desorption (TD) gas chromatograph mass spectrometry (GC-MS). The goal of the headspace analysis was not to fully extract all chemicals remaining on the cigarette butt, rather to provide a consistent basis to compare potential chemical emissions into the air from the cigarette butts. Second, the butts were placed in a range of controlled conditioning environments for $2 \mathrm{~h}$ to $144 \mathrm{~h}$ to examine the influence of various factors on emissions: temperature, relative humidity $(\mathrm{RH})$, ultraviolet (UV) radiation, water saturation and air change rate. Butts were also conditioned outdoors in summer and winter to investigate emissions in real environments. After outdoor conditioning, each cigarette butt was also analyzed using headspace-TD-GC-MS. Lastly, one experiment was conducted to directly measure the chemical emission rates from cigarette butts in a walk-in chamber. Air samples were collected from the chamber up to $27 \mathrm{~h}$ after butts were placed in the chamber and were analyzed using TD-GC-MS.

In examining the emissions of the target chemicals in the butts, it was determined that most of the target chemicals were not emitted from the unburned cigarettes and were likely formed as a result of the burning process. Burning increased the emitted masses for triacetin and nicotine, the two target chemicals present in unburned cigarettes. Most of the target chemicals were primarily emitted from the burned filter.

Results from the conditioning experiments showed discarded butts are likely to be measurable sources of furfural, ethylbenzene, styrene, 2-methyl-2-cyclopenten-1-one, limonene, and naphthalene in the first $48 \mathrm{~h}$ after smoking. After $48 \mathrm{~h}$, the measured emitted mass of these 
chemicals decreased to less than $5 \%$ of the initial values, except when butts were conditioned on rooftop in winter with temperatures lower than $5{ }^{\circ} \mathrm{C}$. Triacetin and nicotine decayed more slowly and more erratically in most environments. Butts are likely to be sources of airborne triacetin and nicotine for prolonged periods (greater than $48 \mathrm{~h}$ ), which may be relevant for butts disposed in indoor spaces like cars.

Higher temperatures increased the rate at which all target chemicals were emitted from the butts in both chamber conditioning and outdoor experiments. Water vapor also had considerable influence on the emission rates from butts. Seven of the eight chemicals were emitted faster from butts at a $50 \%$ RH compared to a $25 \%$ RH. For butts discarded in dry environments, increasing the relative humidity may result in water competing for sorption sites in the butts with the target chemicals, which would enhance the emission rate of target chemicals. During butt saturation in a rain event, chemicals with high water solubility and water-to-air partitioning coefficients ( $\left.\mathrm{K}_{w a}\right)$, like triacetin and nicotine, may migrate into the surrounding environment via aqueous rather than airborne routes. Other less soluble chemicals likely emit from saturated butts into air to greater extents as $K_{w a}$ decreases. For these chemicals, the ratios of initial emitted mass for dry and wet butts/filters decrease with increasing $K_{\text {wa. }}$. Water saturation enhanced the decay rate of emitted mass measured in headspace analysis for the two carbonyl chemicals: furfural and 2-methyl-2cyclopenten-1-one, while it decreased the decay rate for the three hydrocarbons (styrene, limonene, and naphthalene). Exposure to intense UV light (wavelength from $295 \mathrm{~nm}$ to $400 \mathrm{~nm}$ ) can increase the emission by either increasing the temperature of the butt or enhancing the degradation of cellulose acetate. The air change rate under test conditions only influenced the emissions of triacetin and nicotine in the first 24 hours.

One experiment has been conducted to measure the average emission rates of target chemicals from cigarette butts in a walk-in chamber at $25^{\circ} \mathrm{C}$ and $50 \% \mathrm{RH}$. The average emitted mass of the target chemicals over the first $24 \mathrm{~h}$ ranged from $2.5 \mu \mathrm{g} / \mathrm{butt}$ to $120 \mu \mathrm{g} / \mathrm{butt}$. The $24 \mathrm{~h}$ emitted mass for nicotine from a cigarette butt in this study could be up to $15 \%$ of emitted mass of nicotine from a burning cigarette as reported in the literature. Hence, the long-term nicotine emissions could be comparable to the mainstream and side stream smoke if the cigarette butt were left longer than $24 \mathrm{~h}$ in a room. In addition, while not measured in this study, temperatures higher than $25^{\circ} \mathrm{C}$ may increase the relative importance of the nicotine emission from butts compared to the mainstream and side stream smoke.

The association between the emission rates from the large chamber emission test and the emitted masses from the headspace analysis were examined. Furfural, ethylbenzene, styrene, 2-methyl-2cyclopenten-1-one, limonene, and naphthalene demonstrated significant correlations. These correlations indicate that for these chemicals the trends of environmental conditions on emitted mass by headspace analysis should be similar to the trends of environmental conditions on emission rates under real indoor conditions.

This study has several limitations. Only one brand of cigarette was tested in this study. The cigarette butts were produced using a custom-built smoking apparatus and thus the cigarette butts tested in this study may be different from the real butts produced by human smoking. When 
examining the influence of various factors, the emitted mass into the headspace of a vial were measured, not the actual emission rate into the air. In addition, the emission rate test was only conducted once for 24 hours. Also, literature adsorption parameters were used for calculating the emission rates for nicotine.

Nonetheless, this work does demonstrate that cigarette butts may be a significant source of the target chemicals to the environments in which they are disposed, although further studies of emissions are warranted. The emission rates and relevant risk to receptors will be dependent upon environmental factors including temperature, relative humidity, and water saturation.

KEYWORDS: Cigarette butts; emission rate; environmental conditions, nicotine; triacetin. 


\section{CONTENTS}

1 Introduction 1

1.1 Background__ 1

1.2 Objectives _ 3

1.3 Project overview _ 3

2 Methods 5

2.1 Cigarette butt generation __ 5

2.1.1 Cigarette brand and butt length survey __ 5

2.1.2 Cigarette butt mass __ 6

2.1.3 Smoking apparatus __ 7

2.1.4 Smoking procedure _ 10

2.1.5 Quality assurance and quality control __ 11

2.2 Target chemicals 11

2.3 Chemical distribution in cigarette butt__ 14

2.4 Headspace analysis of conditioned cigarette butts 15

2.4.1 Summary of experiments _ 15

2.4.2 SPHERE__ 17

2.4.3 Large chamber _ 21

2.4.4 Rooftop__ 22

2.4.5 Headspace analysis _ 26

2.4.6 Quality assurance and quality control __ 27

2.5 Emission test in large chamber 35

2.5.1 Experimental setup___ 35

2.5.2 Air sample analysis __ 36

2.5.3 Quality assurance and quality control __ 36

2.5.4 Emission rates calculation __ 38

3 Results and discussion $\quad 40$

3.1 Chemical distribution in cigarette butts__ 40

3.2 Measured mass emitted from conditioned cigarette butts__ 46

3.2.1 Data analysis _ 46

3.2.2 Conditioning in SPHERE Chambers _ 48

3.2.2.1 Influence of UV_ 48 
3.2.2.2 Influence of temperature and relative humidity _ 54

3.2.2.3 Influence of water saturation _ 61

3.2.3 Conditioning in large chamber __ 69

3.2.3.1 Influence of air change rate __ 69

3.2.4 Conditioning on rooftop __ 75

3.2.4.1 Comparison of winter and summer _ 75

3.2.4.2 Impacts of Water Saturation__ 80

3.2.5 Conditioning Experiments Summary __ 84

3.3 Emission rates from cigarette butts in large chamber ___ 85

3.3.1 Air sample concentrations in the chamber ___ 85

3.3.2 Calculated emission rates ___ 88

3.3.3 Association of chamber emission rates and headspace analysis mass measurements

4 Conclusions 94

5 Disclaimer 96

6 Acknowledgements $\quad 96$

7 References__ 96

Appendix A Method development data__ 101

A.1 Chemicals identified emitting from four fresh cigarette butts _ $\quad 101$

A.2 Evaluation of injection time on emitted masses from cigarette butts_ 105

A.3 Evaluation of transportation on emitted masses from cigarette butts _ 108

A.4 Measurement of air change rate in the large chamber ___ 111

A.5 Evaluation of breakthrough during air sampling in the chamber emission test

114

Appendix B Experimental data

B.1 Measured mass emitted from fresh cigarette butts __ 116

B.2 Headspace analysis curve fitting parameters _ 117

B.3 Air sample concentrations in the chamber 120 


\section{TABLES}

Table 1.1 Six types of samples analyzed to determine chemical distributions in cigarette butts. Butts were cut at the boundary of the filter and tobacco. Greyed out cells were not part of this analysis.

Table 2.1: Number of different cigarette butts of each brand sampled 6

Table 2.2: $\quad$ Comparison of smoking parameters defined by ISO 3308 and the apparatus and protocol used in the current study. Puff duration error for the apparatus is the standard deviation of seven measurements. Puff volume and puff volume error are calculated from the flow rate and puff duration.

Table 2.3: $\quad$ List of target chemicals and their chemical properties ${ }^{a}$

Table 2.4: $\quad$ Summary of conditioning experiments. Standard deviations appear in parenthesis. Each experimental condition was tested for a range of durations (typically nine tests: $2 \mathrm{~h}$ to $144 \mathrm{~h}$.). For all experiments, except the rooftop experiments, the standard deviations shown in parenthesis are of the average values over the varying duration experiments. 16

Table 2.5: Instrument detection limits and quantification limits for headspace analysis (ng) .28

Table 2.6: Ratio of backup Tenax tube to front Tenax tube. Values larger than $5 \%$ are highlighted in bold.

Table 2.7: Instrument and method detection limits for air sample analysis in emission tests.

Table 3.1: $\quad$ Ratios of measured emitted mass between different samples types. Each sample type was tested more than seven times and the average mass emitted was determined. Bold values signify significant differences between the average masses emitted used to calculate the ratios (Student's t test, $\mathrm{p}<0.05$ ).

Table 3.2: $\quad$ Measured initial mass for dry and wet butts and filters (mean \pm SD, ng) .

Table 3.3: $\quad$ Dry-to-wet ratios of mass emitted from butts and filters. Chemical properties were calculated at $25^{\circ} \mathrm{C}$ using sparc online calculator (http://archemcalc.com/sparc-web/calc) on 11/7/2018.

Table 3.4: Mass of chemical emitted from a cigarette butt (this study, $\mu \mathrm{g} /$ cigarette butt, first row) compared mass of chemicals emitted during active cigarette burning ( $\mu \mathrm{g} /$ cigarette)

Table A.1: $\quad$ Number of chemicals identified in four fresh cigarette butts with peak response larger than $1 \%$ of the largest peak.

Table A.2: $\quad$ Summary of observed chemicals in four fresh cigarette butts that had response areas ranking in the top 30 response area plus chemicals listed in HPHC by FDA (target chemicals are highlighted in bold). 102

Table A.3: $\quad$ Summary of number of identified chemicals with response areas ranking the top 30 105

Table A.4: $\quad$ Breakthrough data for air sampling with Tenax tube. 114

Table B.1: $\quad$ Measured emitted mass from each set of fresh cigarette butts (mean (standard deviation)).

Table B.2: $\quad$ Curve fitting parameters for experimental data examining influence of UV.......117 
Table B.3: $\quad$ Curve fitting parameters for experimental data examining influence of temperature $(T)$ and relative humidity $(R H)$

Table B.4: $\quad$ Curve fitting parameters for experimental data examining influence of water saturation.

Table B.5: Curve fitting parameters for experimental data examining influence of air change rate $(\lambda)$

Table B.6: Curve fitting parameters for experimental data comparing summer and winter.

Table B.7: Chemical concentrations in chamber air at different locations and different times for emission test in large chamber. 


\section{FIGURES}

Figure 1.1: $\quad$ Cigarette butts in a Maryland parking lot. ................................................

Figure 1.2: Overview of conditioning environments and headspace analysis

experiments. Cigarette butt generation details are shown in Figure 2.2 ............. 4

Figure 1.3: Illustration of emission test in a walk-in chamber. ......................................... 4

Figure 2.1: $\quad$ Measured lengths of cigarette butts collected at NIST ................................. 6

Figure 2.2: Diagram of smoking machine for cigarette butt generation. ............................. 9

Figure 2.3: $\quad$ Cigarettes holder above ash catching tray (left). Smoking apparatus, extinguishing sand, lighters and wrench for knocking off ash (right).................. 9

Figure 2.4 Structures of the eight target chemicals. Figures were downloaded from sparc online calcualtor (http://archemcalc.com/sparc-web/calc) on

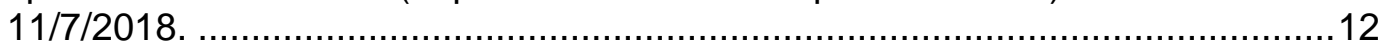

Figure 2.5: Cutting cigarette butts with 3D printed cutter. Butts were cut at the boundary of the filter and tobacco.

Figure 2.6: Cigarette butt samples from left to right: unburned filter - filter from unburned cigarette (1); unburned tobacco- tobacco from unburned cigarette (2); burned filter- filter from burned cigarette (3), burned ash unburned tobacco and ash from burned cigarette (4); cut cigarette butt filter, tobacco and ash from burned cigarette (5); uncut cigarette butt (6).......... 15

Figure 2.7: Cigarette butt holder for conditioning in SPHERE. ..................................... 18

Figure 2.8: Cigarette butts conditioned in two different types of SPHERE chambers.

(a) dark chamber; (b) UV chamber. The outer enclosure and copperwrapped water bath are used to maintain the temperature and $\mathrm{RH}$ of the inner dark and UV chambers where the cigarette butt holders are located. The UV enters the UV chamber through the glass window, which is closed for the photograph.

Figure 2.9: Example of disintegration of paper wrapper around unburned tobacco and ash after rain event during conditioning on the roof. A stainless-steel wire was used to hold butts down during outdoor rooftop exposure..........................19

Figure 2.10: Condition of cigarette butt in (a) dry petri dish; (b) in a wet petri dish with

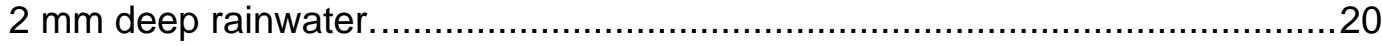

Figure 2.11: Mass change of cigarette butts with soaking time .........................................20

Figure 2.12: Condition of filter of cigarette butt in (a) dry petri dish, (b) wet petri dish with $2 \mathrm{~mm}$ deep simulated rainwater.

Figure 2.13: (a) Large stainless-steel walk-in chamber; (b) Cigarette butts being conditioned in large chamber.

Figure 2.14: Cigarette butts conditioned on the roof of the NIST laboratory building. Solar tracking system on left, weather station in center, and protective mesh cover shown on right.

Figure 2.15: Temperature profiles during four rooftop experiments. .....................................23

Figure 2.16: Relative humidity profiles during four rooftop experiments............................24

Figure 2.17: Global horizontal solar radiation profiles during four rooftop experiments. ........24

Figure 2.18: Wind profiles during four rooftop experiments. One-minute data displayed every $15 \mathrm{~min}$. .25 
Figure 2.19: Rain and snow profiles during four rooftop experiments. Constant lines on Winter 1 at $46 \mathrm{~h}$ through $62 \mathrm{~h}$ indicate when sensor was covered with

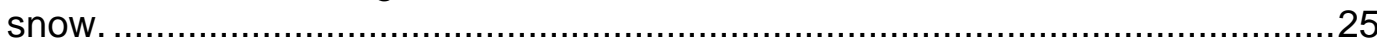

Figure 2.20: Atmospheric pressure profiles during four rooftop experiments.......................26

Figure 2.21: Measured emitted mass from fresh cigarette butts (ng). Right axis is for limonene. Left axis is for all other chemicals. T: temperature; $\mathrm{RH}$ : relative humidity; $\mathrm{n}$ : the number.

Figure 2.22: Distribution of the storage time of butts between removal from conditioning environment and TD-GC-MS analysis.

Figure 2.23: Percent of average initial concentration for Limonene and Naphthalene mass emitted during headspace analysis conducted $0 \mathrm{~h}$ to $46 \mathrm{~h}$ after butt generation.

Figure 2.24 Distribution of the relative humidity (\%) in the fume hood during smoking.........32

Figure 2.25 Correlation between emitted mass for nicotine and relative humidity in the burning environment.

Figure 2.26 Distribution of the amount of time the butts were in the $20 \mathrm{~mL}$ vials between extinguishing and placement in the conditioning environment. 34

Figure 2.27: Cigarette butts, aluminum-foil-lined, stainless-steel mesh basket (left). Location of basket in walk-in chamber (right).

Figure 2.28: Changing the sorption tube sampling at one of the walk-in chamber inlets.

Figure 3.1: $\quad$ Measured emitted mass from six different types of samples. Calculated ash + filter equals the sum of emitted masses from burned ash and burned filter; In (b) left axis is for limonene, right axis is for naphthalene, triacetin, and nicotine. Error bars show one standard deviation.

Figure 3.2: $\quad$ Example of measured emitted mass from each cigarette butt conditioned in UV chambers at different temperature $(T)$ and relative humidity $(R H)$.

Figure 3.3: $\quad$ Measured emitted mass of target chemicals from each cigarette butt conditioned in SPHERE UV chamber with UV on and with UV off. Samples for UV on and off at $30{ }^{\circ} \mathrm{C}$ were intended to be conditioned for 2 h, 5 h, 18 h, 24 h, 48 h, 72 h, 96 h, 120 h and 144 h. Samples for UV off at $37^{\circ} \mathrm{C}$ were intended to be conditioned for $2 \mathrm{~h}, 5 \mathrm{~h}, 18 \mathrm{~h}, 24 \mathrm{~h}, 48 \mathrm{~h}$, and $72 \mathrm{~h}$. Note that the actual conditioning time shown in the figure deviated somewhat from the intended time.

Figure 3.4: $\quad$ Exposure time required for the mass emitted into the headspace vial to be (a) $5 \%$ of the initial emitted mass under UV on and off conditions; (b) $25 \%$ of the initial emitted mass under UV on and off conditions.

Figure 3.5: $\quad$ Measured emitted masses and curve fits for target chemicals from each cigarette butt conditioned in dark chambers at different temperature $(T)$ and relative humidity $(\mathrm{RH})$. Samples were intended to be conditioned for $2 \mathrm{~h}, 5 \mathrm{~h}, 18$ h, 24 h, 48 h, 72 h, 96 h, 120 h and 144 h. Note that the actual conditioning time shown in the figure deviated somewhat from the intended time.

Figure 3.6: Amount of exposure time required for the mass emitted into the headspace vial to be $5 \%$ or $25 \%$ of the initial emitted mass. Left-hand values demonstrate the impacts of a temperature change in the conditioning chamber. Right-hand values demonstrate the impact of a relative humidity change in the conditioning chamber. 
Figure 3.7: $\quad$ Measured emitted masses of target chemicals from each dry and wet cigarette filter conditioned in dark chambers.

Figure 3.8: $\quad$ Amount of exposure time required for the masses emitted into the headspace vial to be $5 \%$ of the initial emitted masses for dry and wet filters. The decay time was not calculated for triacetin and nicotine, since their mass change with time didn't follow an exponential decay.

Figure 3.9: Measured emitted mass of the target chemicals from each cigarette butt conditioned in the large walk-in chamber at the same temperature $(T)$ and relative humidity $(\mathrm{RH})$, but different air change rate $\left(\lambda_{\mathrm{o}}\right)$. $\lambda_{\mathrm{o}}$ : flow rate from outdoor air divided by chamber volume; $\lambda_{r}$ : recirculation flow rate divided by chamber volume.

Figure 3.10: Exposure time required for the masses emitted into the headspace vial to be $5 \%$ or $25 \%$ or $30 \%$ of the initial emitted masses under conditions with $\lambda_{0}$ (flow rate from outdoor air divided by chamber volume) of $0.5 \mathrm{~h}^{-1}$ and $1 \mathrm{~h}^{-1}$. Note that $30 \%$ decay times were calculated for triacetin and nicotine, instead of $25 \%$ decay times. This is because the curve fit for triacetin mass change in Figure $3.9 \mathrm{~g}$ ) shows that the mass would reach steady state at $27 \%$ of the initial mass emitted.

Figure 3.11: Measured emitted masses of target chemicals from each cigarette butt conditioned on roof of a NIST building in both summer and winter.

Figure 3.12: Exposure time required for the masses emitted into the headspace vial to be $5 \%$ of the initial emitted masses. Left-hand values are from the Roof Winter 1 samples. Right-hand values are from the Roof Winter 2 samples. 80

Figure 3.13: Change in butt mass between placement on roof and removal from roof. No data for Roof Summer 2 or Roof Winter 1 at $48 \mathrm{~h}$. Vertical bars show major rain and snow events. The pink bar is for the Summer 1 sample. The green bar for the Summer 2 sample. The blue bar is for the Winter 1 sample. The yellow bar is for the Winter 2 sample.

Figure 3.14: Change in butt appearance after rain event on roof. 82

Figure 3.15: Change in butt mass between placement on roof and removal from roof. No data for Roof Summer 2 or Roof Winter 1 at $48 \mathrm{~h}$. Vertical bars show minor rain and snow events. The pink bar is for the Summer 1 sample. The green bar for the Sumer 2 sample. The purple bar is for the Summer 1 and Winter 1 sample

Figure 3.16 Target chemical concentrations in the middle (mid) and outlet (out) of the chamber. The time corresponding to each concentration point is the middle of the sampling period.

Figure 3.17. Calculated emission rates for six chemicals per cigarette butt in a walk-in chamber (ng/h).

Figure 3.18: Correlation between calculated emission rates and measured emitted masses by headspace analysis.

Figure A.1: $\quad$ Percent of average initial concentration for furfural and ethylbenzene mass emitted during headspace analysis conducted $0 \mathrm{~h}$ to $46 \mathrm{~h}$ after butt generation.

Figure A.2: $\quad$ Percent of average initial concentration for styrene and 2-methyl-2cyclopenten-1-one mass emitted during headspace analysis conducted $0 \mathrm{~h}$ to $46 \mathrm{~h}$ after butt generation. 106 
Figure A.3: $\quad$ Percent of average initial concentration for triacetin and nicotine mass emitted during headspace analysis conducted $0 \mathrm{~h}$ to $46 \mathrm{~h}$ after butt generation.

Figure A.4: $\quad$ Percent of average initial concentration for furfural and ethylbenzene mass emitted during headspace analysis conducted $0 \mathrm{~h}$ to $4 \mathrm{~h}$ after butt generation.

Figure A.5: $\quad$ Percent of average initial concentration for styrene and 2 methyl-2cyclopenten-1-one mass emitted during headspace analysis conducted $0 \mathrm{~h}$ to $4 \mathrm{~h}$ after butt generation.

Figure A.6: Percent of average initial concentration for limonene and naphthalene mass emitted during headspace analysis conducted $0 \mathrm{~h}$ to $4 \mathrm{~h}$ after butt generation.

Figure A.7: $\quad$ Percent of average initial concentration for triacetin and nicotine mass emitted during headspace analysis conducted $0 \mathrm{~h}$ to $4 \mathrm{~h}$ after butt generation.

Figure A.8: Measurement locations in the large chamber/ESPEC system

Figure A.9: $\mathrm{SF}_{6}$ concen

Figure A.10: Relation between outdoor air change rate and opening of recirculation damper. 


\section{INTRODUCTION}

An environmental consequence of the use of tobacco products, including conventional and rollyour-own cigarettes, is the disposal of discarded cigarette filters or butts. Globally, around five trillion cigarette butts are generated per year (Novotny and Zhao 1999, Chapman 2006, Healton et al. 2011, Bonanomi et al. 2015). These cigarette butts can persist in the environment for more than 18 months (Novotny and Zhao 1999). Cigarette butts are some of the most common forms of litter found on beaches (Claereboudt 2004, Smith et al. 2014), near streams, night clubs (Becherucci and Pon 2014), bus stops (Wilson et al. 2014), roads and streets (Healton et al. 2011, Patel et al. 2013). Cigarette butts have been found at densities averaging more than 4 butts $\mathrm{m}^{-2}$ in urban environments (Figure 1.1) (Seco Pon and Becherucci 2012).

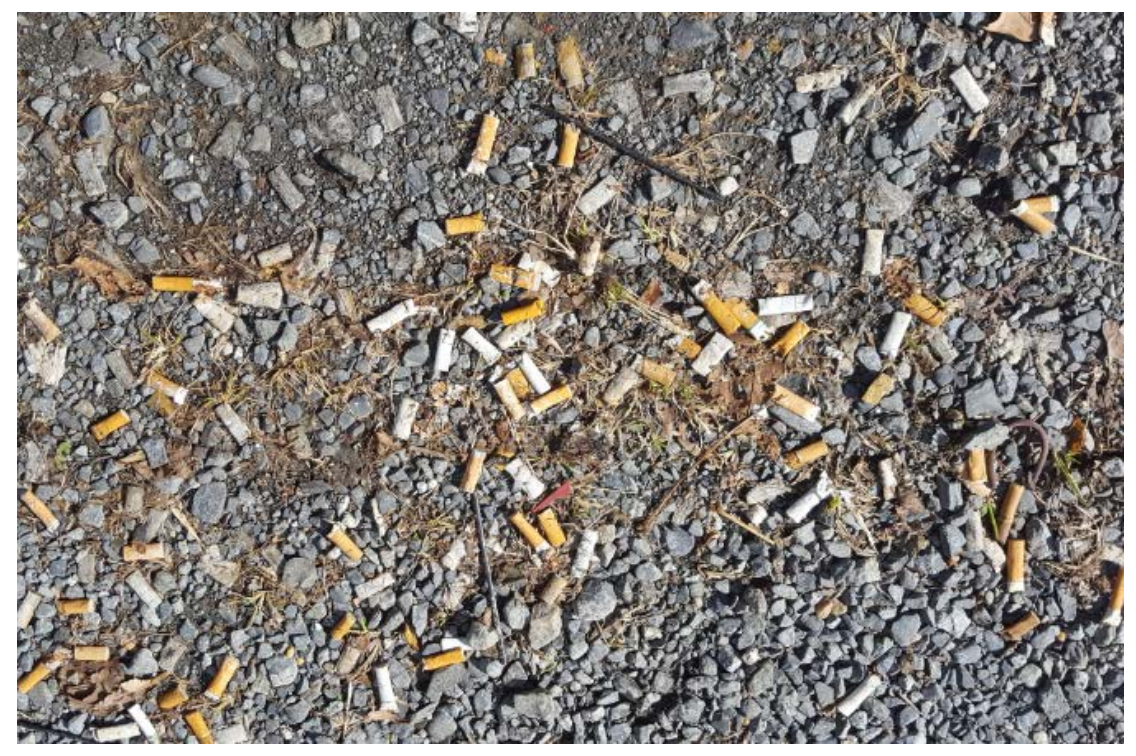

Figure 1.1: $\quad$ Cigarette butts in a Maryland parking lot.

The Family Smoking Prevention and Tobacco Control Act (United States Food and Drug Administration 2009) was signed into law on June 22, 2009, amending the Food, Drug and Cosmetic Act and providing the Food and Drug Administration (FDA) the authority to regulate the manufacturing, distribution, and marketing of tobacco products. More specifically, the Tobacco Control Act gives FDA the authority to, among other things, establish science and research programs to inform the development of tobacco product regulations and better understand the risks associated with tobacco use. One risk FDA seeks to quantify is the airborne emission from non-smoldering cigarette butts.

\subsection{BACKGROUND}

FDA entered into an interagency agreement with the National Institute of Standards and Technology (NIST) to conduct a two-part investigation into airborne emissions of non-smoldering cigarette butts. Non-smoldering cigarette butts are defined in this research as butts that are at 
ambient temperature and are assumed to no longer be emitting particles. The first phase of this study was a comprehensive literature review conducted to gather and analyze existing research related to airborne emissions from non-smoldering cigarette butts (Poppendieck et al. 2016). In summary, although there is a reasonable body of knowledge on aqueous emissions from cigarette butts, the environmental impact of cigarette butts due to air emissions has not been well studied (Gong et al. 2017). There are four studies that measured the emissions from cigarette butts into the airborne headspace of test vials.

Fukuhara et al. (1985) detected a range of volatile components (e.g., carbonyls, hydrocarbons, pyrroles and terpenes) in the headspace of vessels that contained cigarette butts, and found that these compounds were also found in mainstream smoke. They also indicated that the tar-like odors in butts may result from 2,3-pentanedione, $\mathrm{N}$-methyl pyrrole, 3-methyl pyrrole, isocapronitrile, pyrrole, and 2-methyl pyrrole. You et al. (2014) developed a static headspace gas chromatographyflame ionization detector (GC-FID) method for quantifying menthol concentrations in the cigarette filter and cigarette papers in a mentholated cigarette. The samples were first heated at $100{ }^{\circ} \mathrm{C}$ for $30 \mathrm{~min}$ in a headspace sampler, and then measured by GC-FID. The methanol concentration in the cigarette papers ranged from $3.0 \mathrm{mg} \mathrm{g}^{-1}$ paper to $4.1 \mathrm{mg} \mathrm{g}^{-1}$ paper, while the methanol concentration in the cigarette filter was $13.7 \mathrm{mg} \mathrm{g}^{-1}$ paper to $27.2 \mathrm{mg} \mathrm{g}^{-1}$ paper. Huang et al. (2014) measured the emissions from cigarette tipping paper (which attaches the filter to the tobacco column) into the headspace of vials. The samples were first incubated at $80^{\circ} \mathrm{C}$ for $45 \mathrm{~min}$, and then 20 volatile organic compounds (VOCs) were quantified using gas chromatography-mass spectrometry (GCMS). Among the 20 target VOCs, methanol, ethanol, isopropanol, ethyl acetate, 1-methoxy-2propanol, and n-propyl acetate were the most abundant, with concentrations ranging from below detection to $20.7 \mathrm{mg} \mathrm{m}^{-2}$ paper. A recent study developed a static headspace GC-MS method to quantify benzene, toluene, $\mathrm{m}$-xylene, $\mathrm{p}$-xylene, o-xylene, styrene and ethylbenzene concentrations in cigarette filters (Ji et al. 2015). The method heated the cigarette filters at $120^{\circ} \mathrm{C}$ for $30 \mathrm{~min}$ in the headspace vials. The measured concentrations for benzene, toluene, ethylbenzene, p-xylene, m-xylene, o-xylene, and styrene ranged from $0.4 \mu \mathrm{g} /$ filter to $5.7 \mu \mathrm{g} /$ filter.

These four studies provide some basis for understanding the potential airborne emissions into indoor and outdoor environments. However, the study reported by Fukuhara et al. (1985) was limited in the number of cigarette butts tested and not quantifying the identified chemicals. For the three more recent studies (Huang et al. 2014, You et al. 2014, Ji et al. 2015), the types of chemicals detected were limited and only cigarette filters or tipping papers were studied. These studies did not include the unburned tobacco or ash of cigarette butts, which may emit different chemicals from the filters and tipping papers. In addition, the high incubation temperatures $\left(>80^{\circ} \mathrm{C}\right)$ would enhance the emission of some non-volatile chemicals that may not be emitted to a significant degree at more typical indoor and outdoor temperatures. Finally, all these studies only measured freshly generated cigarette butts, or part of the unburned cigarette, and didn't examine the influence of environmental factors that could impact the emissions from cigarette butts, such as temperature, relative humidity, water saturation, ultraviolet (UV) radiation and air change rate. 


\subsection{OBJeCtIVES}

FDA is seeking to gather more information regarding airborne emissions from cigarette butts to help assess the cumulative environmental impact of filtered tobacco products. This report summarizes activities conducted between September 2016 and December 2018 by NIST. The objective of this effort was to measure the airborne emissions from non-smoldering cigarette butts and determine the influence of environmental factors on cigarette butt emissions. Specifically, this effort sought to 1) determine the initial distributions of the emitted target chemicals in a cigarette butts, 2) determine the influence of environmental parameters (temperature, relative humidity, water saturation, UV, and air change rate) on airborne cigarette butt emissions, and 3) determine airborne emission rates for target chemicals from cigarette butts in a simulated indoor environment.

\subsection{Project OVERVIEW}

Consistent cigarette butts were generated using a custom-built smoking apparatus. Three series of experiments were conducted in this study. First, the distributions of the target chemicals in the cigarette butts were determined by analyzing six types of samples consisting of different parts of a cigarette butt.

Table 1.1 Six types of samples analyzed to determine chemical distributions in cigarette butts. Butts were cut at the boundary of the filter and tobacco. Greyed out cells were not part of this analysis.

\begin{tabular}{|c|c|c|c|c|}
\hline Sample & Filter & Tobacco/ Ash & $\begin{array}{c}\text { Cut Cigarette } \\
\text { Butt }\end{array}$ & $\begin{array}{c}\text { Uncut } \\
\text { Cigarette Butt }\end{array}$ \\
\hline Unburned & $(1)$ & $(2)$ & & \\
\hline Burned & $(3)$ & $(4)$ & $(5)$ & $(6)$ \\
\hline
\end{tabular}

Second, the cigarette butts were placed in a conditioning environment for up to one week. Three conditioning environments were used (Figure 1.2):

1) Simulation Photo-degradation via High Energy Radiation Emission (SPHERE) chambers where the impacts of ultraviolet (UV) radiation, temperature, relative humidity and water saturation of the butts were examined.

2) Walk-in chamber where the impacts of indoor air change rates were examined.

3) Roof where the impacts of summer and winter outdoor exposure were examined. 


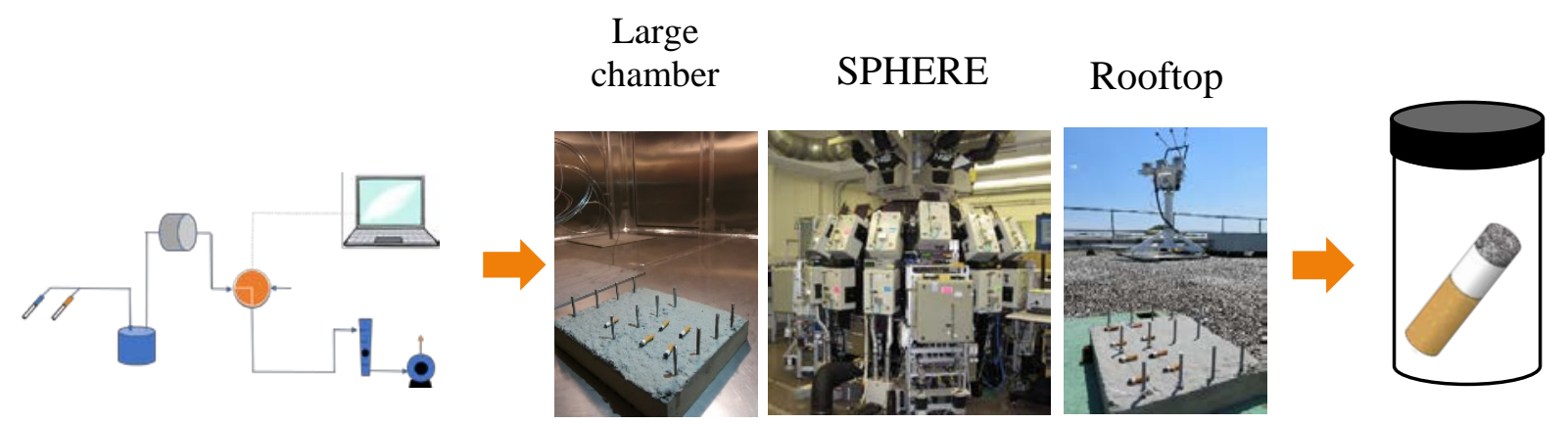

\section{Cigarette butt generation}

Conditioning

Headspace analysis

Figure 1.2: $\quad$ Overview of conditioning environments and headspace analysis experiments. Cigarette butt generation details are shown in Figure 2.2.

After conditioning, each cigarette butt was analyzed using headspace-thermal desorption (TD) GC-MS. The goal of the headspace analysis was not to fully extract all chemicals remaining on the cigarette butt, but to provide a consistent basis to compare chemical emissions into the air after the cigarette butts had been conditioned in different environments.

Third, a set of experiments was conducted to measure the chemical emission rates from cigarette butts in the walk-in chamber (Figure 1.3). Air samples were collected up to $24 \mathrm{~h}$ after butts were placed in the walk-in chamber and were analyzed using TD-GC-MS.

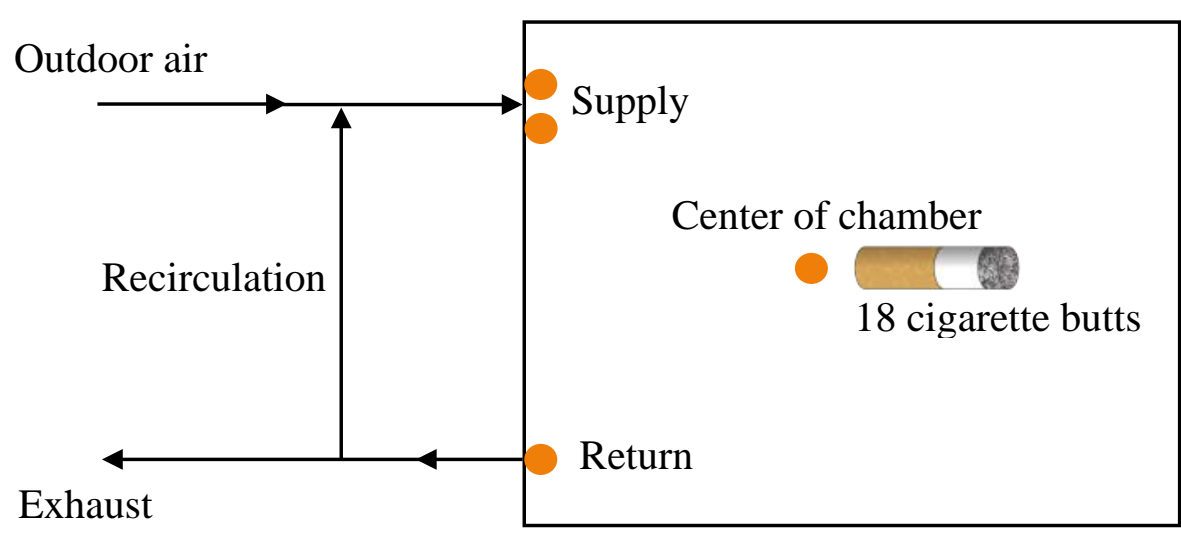

Air sampling points

Figure 1.3: Illustration of emission test in a walk-in chamber. 


\section{METHODS}

This section describes the methods used to achieve the study objectives to measure the airborne emissions from non-smoldering cigarette butts and determine the influence of environmental factors on cigarette butt emissions. Section 2.1 describes the cigarette butt generation methods. The target chemicals considered in this study are described next (Section 2.2). The methods used to determine the chemical distributions in the butts are presented in Section 2.3. The details of the conditioning environments (Section 2.4), including a detailed discussion of the headspace analysis method in Section 2.4.5, and the emission rate test (Section 2.5) follow.

\subsection{Cigarette butt generation}

Over 1,600 cigarette butts were generated using a custom-built system for this study. The primary objective of the generation system was to create cigarette butts that have relatively consistent chemical content of target chemicals. In order to achieve this consistently, only one brand of cigarettes was used, and a single smoking protocol was employed. Hence, the generated butts were not necessarily representative of butts that might exist in the environment. However, the relative consistency of each generated cigarette butt allows for comparison among different conditioning environments.

\subsubsection{Cigarette brand and butt length survey}

As a first step in developing the generation protocol, a survey of butts collected on the NIST campus were studied in terms of their length and mass. Cigarette butts were collected from the ground at two outdoor locations on NIST campus where cigarette butts are often discarded over four different sampling events from 10-7-2016 to 1-31-2017. Six different brands were identified from this sample (Table 2.1). The lengths of over 230 collected cigarette butts were measured to the nearest millimeter. The measured lengths were lognormally distributed as shown in Figure 2.1. 


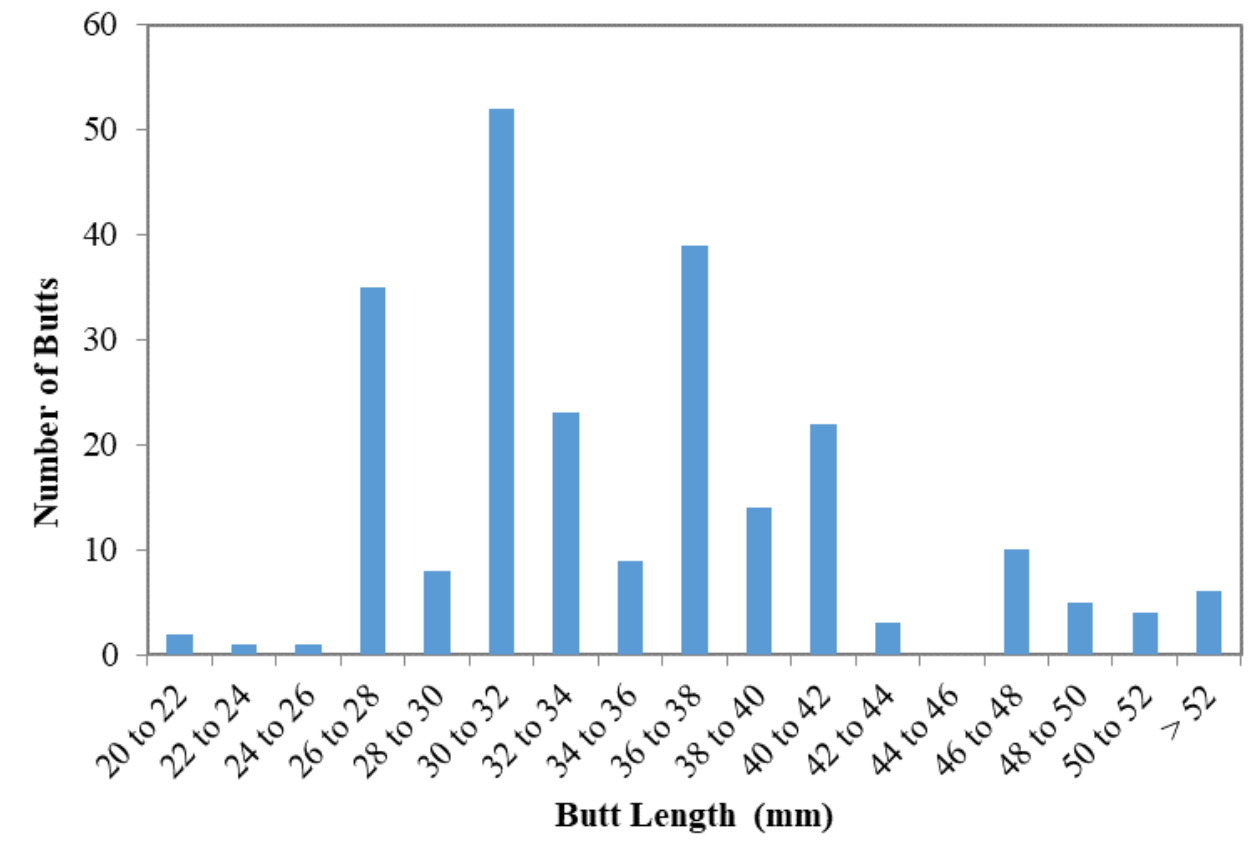

Figure 2.1: $\quad$ Measured lengths of cigarette butts collected at NIST.

Table 2.1: Number of different cigarette butts of each brand sampled.

\begin{tabular}{|c|c|c|c|}
\hline Brand & Number & $\begin{array}{c}\text { Geometric } \\
\text { Average Length } \\
\text { (cm) }\end{array}$ & $\begin{array}{c}\text { Standard } \\
\text { Deviation of } \\
\text { Length (cm) }\end{array}$ \\
\hline Unknown & 122 & 3.04 & 0.57 \\
\hline Brand 1 & 38 & 3.60 & 0.90 \\
\hline Brand 2 & 27 & 3.39 & 0.31 \\
\hline Brand 3 & 22 & 4.01 & 0.56 \\
\hline Brand 4 & 10 & 4.10 & 0.71 \\
\hline Brand 5 & 9 & 3.22 & 0.57 \\
\hline Brand 6 & 6 & 3.30 & 0.90 \\
\hline \hline Total & 234 & 3.30 & 0.71 \\
\hline
\end{tabular}

Marlboro was the brand most frequently identified in the collected butts. This brand has also identified by the United States Center of Disease Control and Prevention (2017) as the leading cigarette brand consumed in the United States market. Hence, Marlboro Class A Filter cigarettes were chosen as the target cigarette to be used in the remainder of this research.

\subsubsection{Cigarette butt mass}

The mass of butts collected outdoors can be highly variable due to potential exposure to rain, snow or dew (see Section 3.2.4.2). Hence, the variability in the mass of the field collected butts means that mass is not an ideal criterion for screening of butts generated in the lab. Instead, a target length for lab generated cigarette butts was set to be the average length measured for Marlboro cigarettes from the field, $3.60 \mathrm{~cm}$ (Table 2.1). 
However, it was difficult to measure the length of a butt accurately in a timely manner immediately after generation in the smoking systems without impacting the consistency of the butt emissions, since chemicals may be emitted from butts inconsistently during the length measurement period. Unlike field collected butts, butts produced in the lab are not exposed to the elements and have less mass variability. Hence, mass was used in the lab as a quality control metric to verify that the generation system was producing relatively consistent cigarette butts. The target mass was chosen based on the mass of lab produced butts that were approximately the length of the field collected butts.

Specifically, a total of 101 butts were generated in preliminary experiments with the smoking procedures described in Sections 2.1.3 and 2.1.4 to determine mass criteria for butts used in the study. The average mass was $0.421 \mathrm{~g}$ (standard deviation $=0.035 \mathrm{~g}$, relative standard deviation $=$ $8.6 \%$ ). To make sure the butts used for this study were consistent, only those generated cigarette butts, which had a mass within one standard deviation of the preliminary average mass ( $0.386 \mathrm{~g}$ to $0.457 \mathrm{~g}$ ), were intended to be used. However, due to the omission of some of the mass data in the initial calculations, the actual range used was $0.370 \mathrm{~g}$ to $0.442 \mathrm{~g}$. Despite this slightly lower mass, this mass criteria typically resulted in butts between $3.9 \mathrm{~cm}$ and $4.4 \mathrm{~cm}$ in length (the average length of the field-collected Marlboro butts was $3.6 \mathrm{~cm}$ with a standard deviation of $0.9 \mathrm{~cm}$ ). Out of 1,121 butts generated for the experiments described below, $77 \%$ met the mass criteria. The remainder were discarded and not used in conditioning or emission experiments.

Through trial and error, it was discovered that to produce cigarette butts with a mass in the range of $0.370 \mathrm{~g}$ to $0.442 \mathrm{~g}$, the unsmoked cigarettes ideally should have a mass between $0.850 \mathrm{~g}$ and $0.870 \mathrm{~g}$. The average initial mass of unsmoked cigarettes used in this study was $0.861 \mathrm{~g}$ (standard deviation $=0.014 \mathrm{~g}$, number of unsmoked cigarettes with mass data collected $=1437$ ). Unsmoked cigarettes outside of this range were not used in this study. The percentage of excluded unsmoked cigarettes depended upon the carton, ranging from approximately $30 \%$ to $60 \%$ for each carton.

\subsubsection{Smoking apparatus}

The need for data regarding the health impacts of smoking has led to the development of complex smoking machines, with their operation guided by ISO 3308:2012: Routine analytical cigarettesmoking machine - Definitions and standard conditions (ISO3308 2012). The standard contains a single set of operating conditions for smoking machines, though in reality smoking habits can impact emissions (Nelson et al. 1998, Purkis et al. 2010, St Charles et al. 2010). Hence, there may be differences in emissions from a cigarette butt generated using a smoking machine compared to a cigarette butt generated by a smoker. The difference between emissions with smoking machines and actual smokers is out of the scope of this study.

Given the objective of this study to measure the airborne emissions from non-smoldering cigarette butts, it was important that the butts were generated consistently. An apparatus was constructed that can burn two cigarettes at a time and simulates the puff sequence outlined in ISO 3308 (Table 2.2). Detailed comparison of the smoking parameters defined by ISO 3308 and the apparatus and protocol used in the current study are shown in Table 2.2. The smoking apparatus used in this study consists of a computer, vacuum pump, rotameter, solenoid valve, filter, condensate knockout, 
cigarette stand, cigarette holder, ash catching tray, tubing and fittings (Table 2.2, Figure 2.2 and Figure 2.3).

Table 2.2: Comparison of smoking parameters defined by ISO 3308 and the apparatus and protocol used in the current study. Puff duration error for the apparatus is the standard deviation of seven measurements. Puff volume and puff volume error are calculated from the flow rate and puff duration.

\begin{tabular}{|c|c|c|c|c|c|c|c|}
\hline & $\begin{array}{c}\text { Flow rate per } \\
\text { cigarette } \\
\left(\mathbf{L} \text { min }^{-1}\right)\end{array}$ & $\begin{array}{c}\text { Puff } \\
\text { duration } \\
(\mathbf{s})\end{array}$ & $\begin{array}{c}\text { Puff } \\
\text { volume } \\
(\mathbf{m L})\end{array}$ & $\begin{array}{c}\text { Puff } \\
\mathbf{( \# )}\end{array}$ & $\begin{array}{c}\text { Puff } \\
\text { reoccurrence } \\
\mathbf{( s )}\end{array}$ & $\begin{array}{c}\text { Ash } \\
\text { knocks } \\
(\#)\end{array}$ & $\begin{array}{c}\text { Extinguish } \\
\text { method }\end{array}$ \\
\hline ISO 3308 & $\begin{array}{c}\text { Bell-shaped puff } \\
\text { profile with maximum } \\
\text { flow rate within 1.5 L } \\
\text { min }^{-1} \text { and 1.8 L min }\end{array}$ & 2 & 35 & 10 & 60 & None & None \\
\hline $\begin{array}{c}\text { Apparatus } \\
\text { used in } \\
\text { this study }\end{array}$ & 1.0 & $2.7 \pm 0.1$ & $45.5 \pm 1.5$ & 6 & 60 & 6 & Sand \\
\hline
\end{tabular}

The flow rate was measured using a bubble flow meter placed in line between the filter and solenoid valve. The bubble flow meter was removed from the flow path prior to igniting the cigarettes. The initial flow rate in the apparatus was set to an average value $1.001 \mathrm{~L} \mathrm{~min}^{-1}$ per cigarette $\left(n=1104\right.$, standard deviation $\left.=0.003 \mathrm{~L} \mathrm{~min}^{-1}\right)$ at the beginning of each experiment. However, the filter collected on average $3.89 \mu \mathrm{g}$ of particles per cigarette ( $n=7$, standard deviation $=0.11 \mu \mathrm{g})$ on the filter $(0.45$ micron polytetrafluoroethene), which reduced the flow rate (and puff volume) with every puff. By the last puff, the flow rate was typically reduced to approximately $0.90 \mathrm{~L} \mathrm{~min}^{-1}$. The combination of the opening of the solenoid valve and condensate knockout jar (240 mL volume) made the flow rate vary during each puff. Although the shape of puff profile was not precisely measured, flow appeared to increase exponentially to the initial flow rate $\left(1.0 \mathrm{~L} \mathrm{~min}^{-1}\right)$ in less than $0.5 \mathrm{~s}$ and decrease to zero at the end of each puff in the same manner. 


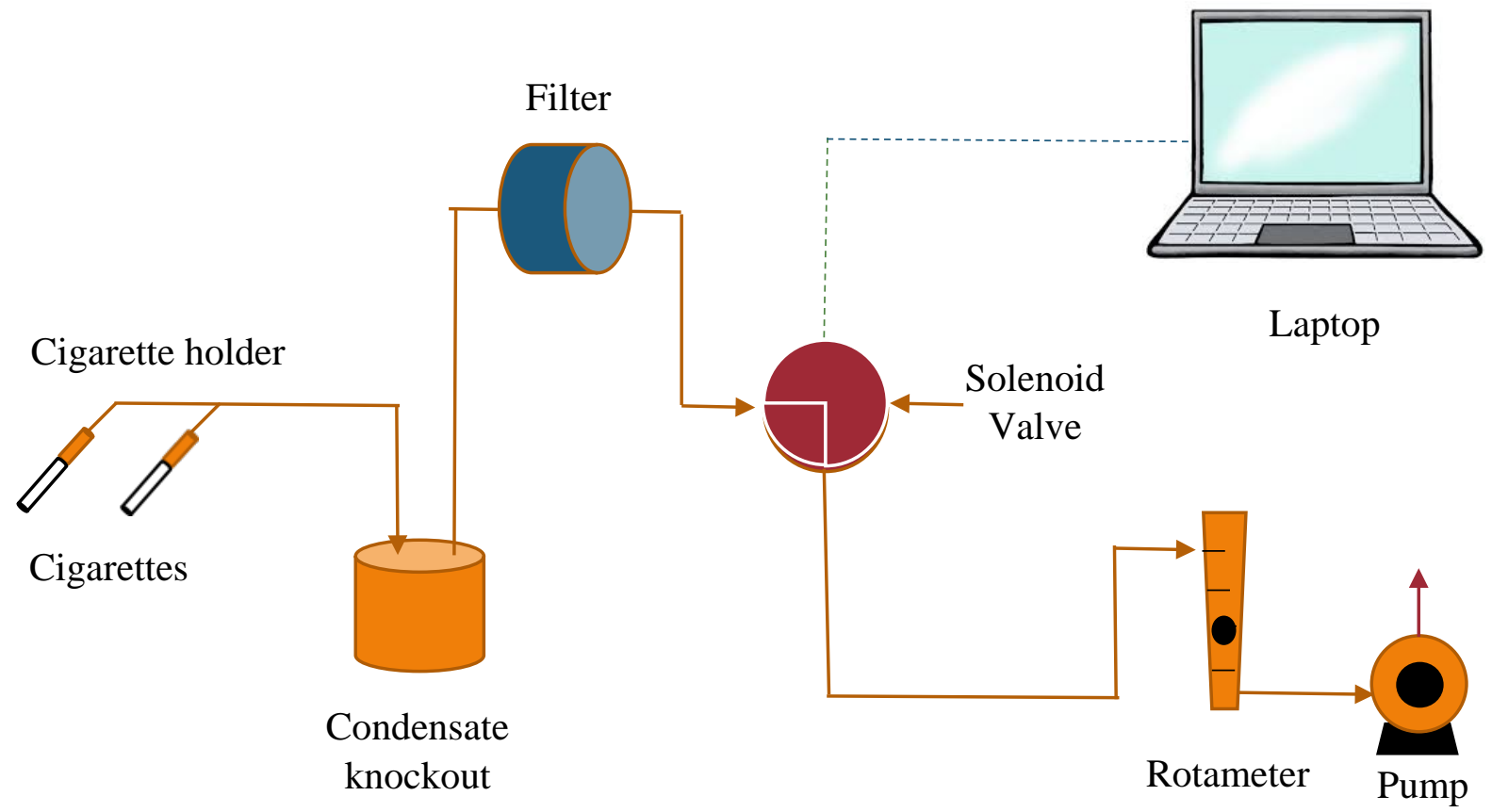

Figure 2.2: $\quad$ Diagram of smoking machine for cigarette butt generation.
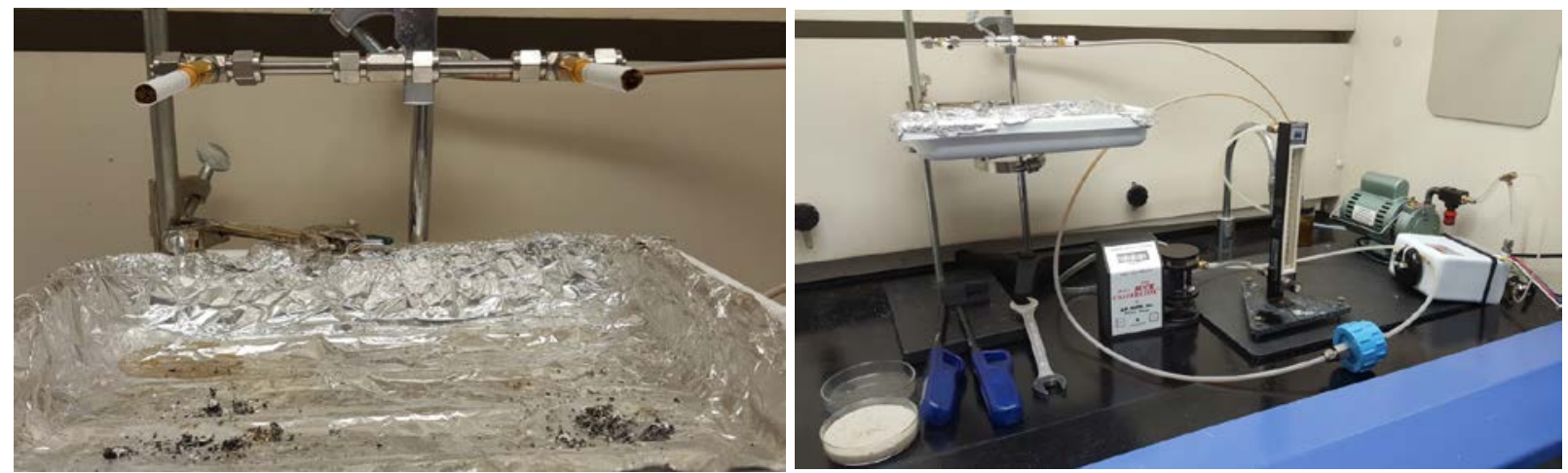

Figure 2.3: $\quad$ Cigarettes holder above ash catching tray (left). Smoking apparatus, extinguishing sand, lighters and wrench for knocking off ash (right).

Six puffs were chosen based on preliminary testing, which showed that the lengths of cigarette butts produced with six puffs were the most consistent and close to the desired butt length $(3.6 \mathrm{~cm})$. The initial puff lasted $4.5 \mathrm{~s}$ to enable lighting of both cigarettes, while the next five puffs lasted 2.7 s each.

Cigarettes were burned in the center of a fume hood. Cigarettes were held in modified filter holders (the golden part of a Sukragraha cigarette holder). The filter holders were located $13 \mathrm{~cm}$ from the back of the fume hood and $16.5 \mathrm{~cm}$ apart from each other. The holders were centered $14 \mathrm{~cm}$ above a $25 \mathrm{~cm}$ x $30 \mathrm{~cm}$ ash catching tray (Figure 2.3). The tray was raised $27 \mathrm{~cm}$ above the base of the fume hood. The opening of the fume hood $(10 \mathrm{~cm})$ was not changed after lighting the cigarettes to keep the flow in the fume hood relatively consistent. Air velocities near the position where cigarettes were held during burning were monitored for 5 min 6 times using a VelociCalc Plus air 
velocity meter at a sample time resolution of $2 \mathrm{~s}$. The air velocities ranged from $0.00 \mathrm{~m} \mathrm{~s}^{-1}$ to $0.19 \mathrm{~m} \mathrm{~s}^{-1}$ with an average of $0.034 \mathrm{~m} \mathrm{~s}^{-1}(\mathrm{n}=900)$; the standard deviation of the average values for each test was $0.004 \mathrm{~m} \mathrm{~s}^{-1}(\mathrm{n}=6)$.

The temperature and relative humidity $(\mathrm{RH})$ in the fume hood were not controlled but were monitored during smoking using a HOBO data logger with manufacture specified temperature accuracy of $\pm 0.24{ }^{\circ} \mathrm{C}$ and $\mathrm{RH}$ accuracy of $\pm 2.5 \%$ at a resolution of $15 \mathrm{~s}$. The temperatures were relatively consistent with an average of $24.2^{\circ} \mathrm{C}$ and a standard deviation of $0.6{ }^{\circ} \mathrm{C}(\mathrm{n}=459)$. The average relative humidity was $39.4 \%$ with a standard deviation of $8.8 \%(n=481)$. The relative humidity in the fume hood varied from $15.2 \%$ to $52.9 \%$ depending on the season and weather. Relative humidity values ranged from $39.0 \%$ to $52.9 \%$ between June and September and were lower during other months.

\subsubsection{Smoking procedure}

A procedure to generate cigarette butts was developed in recognition of the fact that the mass of chemicals in the cigarette butts can be influenced by various factors, including

- the temperature and relative humidity of the cigarette storage environment prior to smoking,

- the temperature and relative humidity of the fume hood when the cigarettes are burned,

- the weight of the cigarette prior to burning,

- the puffing duration,

- the number of puffs,

- the flow rate through the cigarette during burning,

- the amount of time required to extinguish the cigarette butt,

- the handling method to transport the cigarette butts the conditioning environment, and

- the weight and length of cigarette butts.

To increase the consistency of the target chemicals in the freshly smoked butts, the following procedures were followed to generate cigarette butts:

- The cigarettes were stored in a $50 \mathrm{~L}$ chamber with a flow rate equivalent to one air change per hour at $25^{\circ} \mathrm{C}$ and with relative humidity of $50 \%$ for at least $24 \mathrm{~h}$ prior to burning. During storage, the butts were laid out in aluminum foil trays at the bottom of the chamber. While this process was intended to produce more consistent butts, it also means that the cigarettes may be different from cigarettes removed from a freshly opened package.

- Cigarettes were labeled and pre-weighed to make sure they were within the ideal mass range.

- Empty $20 \mathrm{~mL}$ headspace vials were pre-weighed.

- Two cigarettes were placed in the cigarette holders.

- The used filter was replaced with a fresh filter.

- The bubble flow meter was connected in-line between the filter and the rotameter. The flow was adjusted using the rotameter to the desired range. The bubble flow meter was removed from the system.

- The cigarettes were simultaneously lit with two long-reach butane utility lighters during the initial puff. 
- After each puff, the ash was knocked off the burning cigarette by tapping the cigarette stand once with a metal wrench and collected by the ash catching tray (the collected ash was thrown away and not analyzed for chemical emissions).

- After the sixth puff, each cigarette was immediately placed in a sand ashtray for $60 \mathrm{~s}$ to extinguish the butt. When the butts were removed from the sand, they were at ambient temperature and no longer visibly emitting particles (defined in this project as nonsmoldering). The sand used to extinguish the butts was replaced roughly every 100 butts to 200 butts.

- While the butts were in the sand, the solenoid valve was opened to allow the venting of the condensate knockout for $60 \mathrm{~s}$ prior to smoking the next set of cigarettes.

- After $60 \mathrm{~s}$ in the sand, each extinguished butt was sealed in a pre-weighed $20 \mathrm{~mL}$ headspace vial.

- The weight of the butt was determined as the difference of the weight of bottle with the butt and the weight of bottle without the butt.

- The butts were then transported to the conditioning environment in the headspace vial or analyzed in the headspace vial via TD-GC-MS (Section 2.4.5).

\subsubsection{Quality assurance and quality control}

To ensure the cigarette butts were as consistent as possible, the following quality assurance and quality control measures were taken:

- The weight of cigarettes prior to burning were limited to cigarettes between $0.850 \mathrm{~g}$ and $0.870 \mathrm{~g}$.

- Only generated butts with mass between $0.370 \mathrm{~g}$ and $0.442 \mathrm{~g}$ were further conditioned and analyzed.

\subsection{TARGET CHEMICALS}

Four fresh cigarette butts were analyzed using headspace analysis (Section 2.4.5) to develop a list of target chemicals that were considered in this study. The peaks in the chromatograms were identified using Agilent Mass Hunter Qualitative Analysis with W10N14 library. Over 157 different chemicals were identified in each of the butts (Table A.1). The target chemicals were primarily selected from chemicals with response areas ranking in the top 30 among the identified chemicals. A total of 44 different chemicals were in the top 30 responses for each of the four cigarette butts analyzed. These chemicals can by characterized by structural groups: clyclohexenes (3 different chemicals), pyridines (6), benzenes (12), clyclohexanes (2), clyclopentanes (2), furans (2), pyrazoles (2), indene (2), and others (13).

The criteria for selection of the target chemicals for quantification were that the chemical represented one of the classes of chemicals listed above, its response areas among four different butts were consistent with relative standard deviation less than $30 \%$, and/or it was listed in the FDA Harmful and Potentially Harmful Constituents (HPHC) list (United States Food and Drug Administration 2012). Naphthalene and triacetin were the only chemicals that were not in the top 30 response area list but were still included in the list of target chemicals. Naphthalene was 
included because it is on the HPHC list. Triacetin is not on the HPHC list or the top 30 list, but it is a commonly used plasticizer in filters and can account for about $6 \%$ to $10 \%$ of the filter weight (Branton et al. 2017). Therefore, triacetin could be a good indicator for long term emissions.

Two chemicals met the above criteria but were not included as they did not have readilyavailable standards: 1H-pyrazole-3-ethanamine (pyrazole group) and 1-methyl-3-(1methylethenyl)-cis-cyclohexane, (cyclohexane group). The eight chemicals selected for analysis and their chemical properties are shown in Table 2.3, and their chemical structures are shown in Figure 2.4. These eight chemicals were confirmed to be identified correctly by spectral comparison with purchased standards.

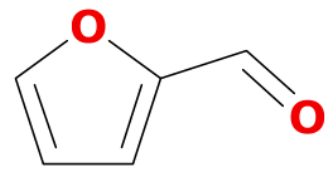

furfural<smiles>C=C(C)C1CC=C(C)CC1</smiles>

limonene

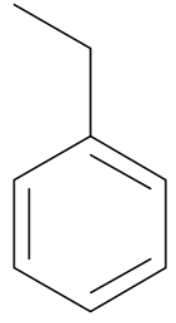

ethylbenzene

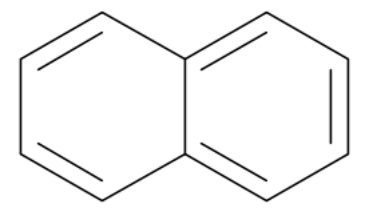

naphthalene

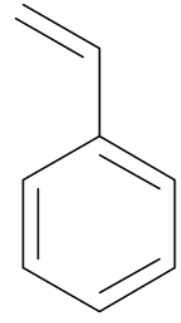

styrene

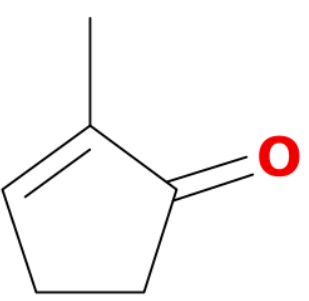

2-methyl-2cyclopenten-1-one<smiles>CC(=O)OCC(COC(C)=O)OC(C)=O</smiles>

triacetin<smiles>CN1CCCC1c1cccnc1</smiles>

nicotine

Figure 2.4 Structures of the eight target chemicals. Figures were downloaded from sparc online calcualtor (http://archemcalc.com/sparc-web/calc) on 11/7/2018. 
Table 2.3: List of target chemicals and their chemical properties ${ }^{a}$

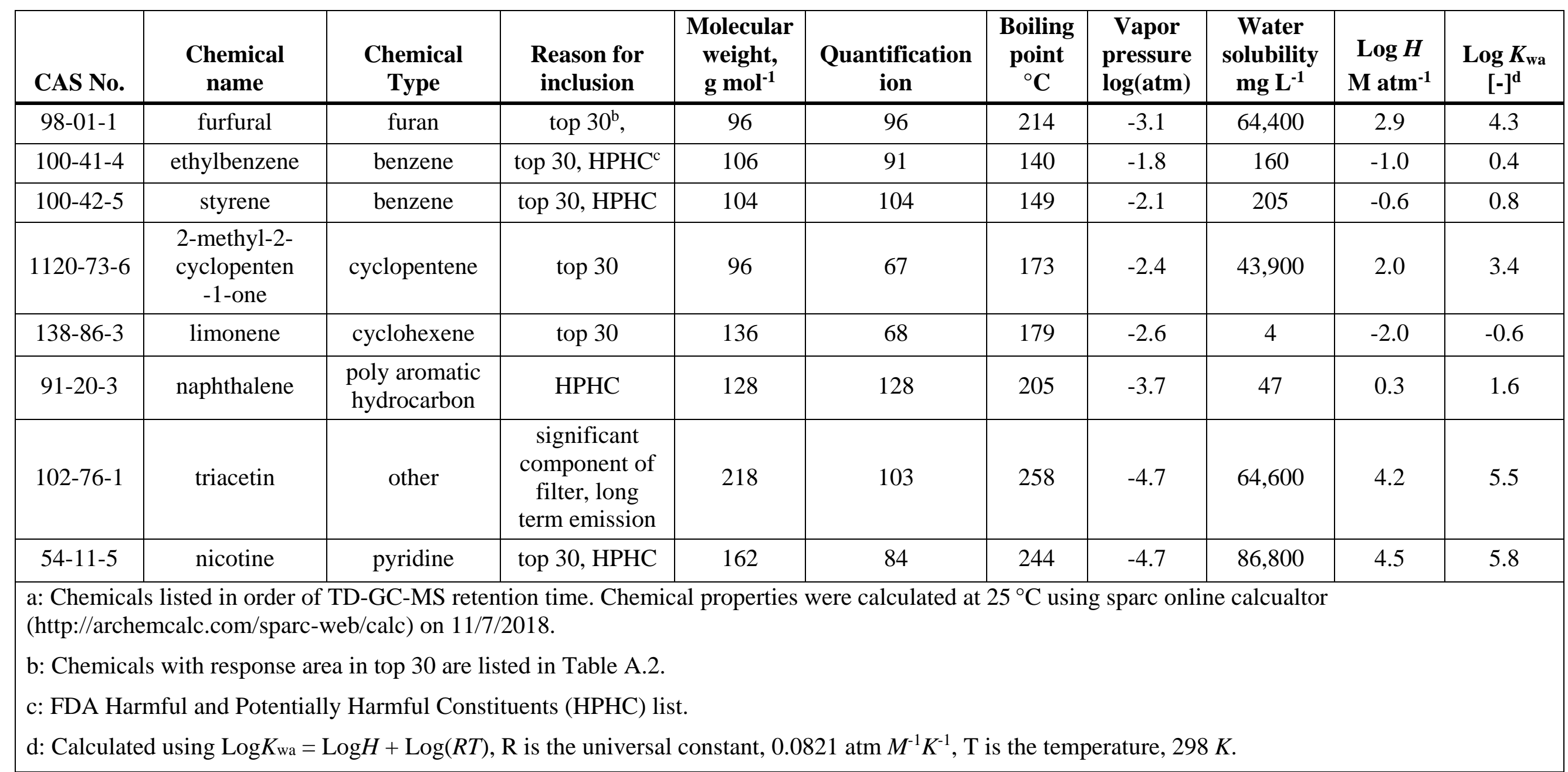




\subsection{Chemical DISTRIBUtion In CIGARETtE BUTT}

Chemicals may not be uniformly distributed in the cigarette butt due to the different materials, structures and functions of different parts of the cigarette. To better understand the emission characteristics of cigarette butts, it is helpful to determine the chemical distributions of the target chemicals in different parts of the cigarette butt. Therefore, several cigarette butts were cut into two parts, i.e. filter and ash (the ash included unburned tobacco) using a razor blade and a 3Dprinted cutting guide (Figure 2.5). The butts were cut and placed in headspace vials within $60 \mathrm{~s}$ of removal from the sand (120 s after removal from the smoking apparatus). The cutting guide components were wiped with a methanol-soaked laboratory Kimwipe after cutting each butt.

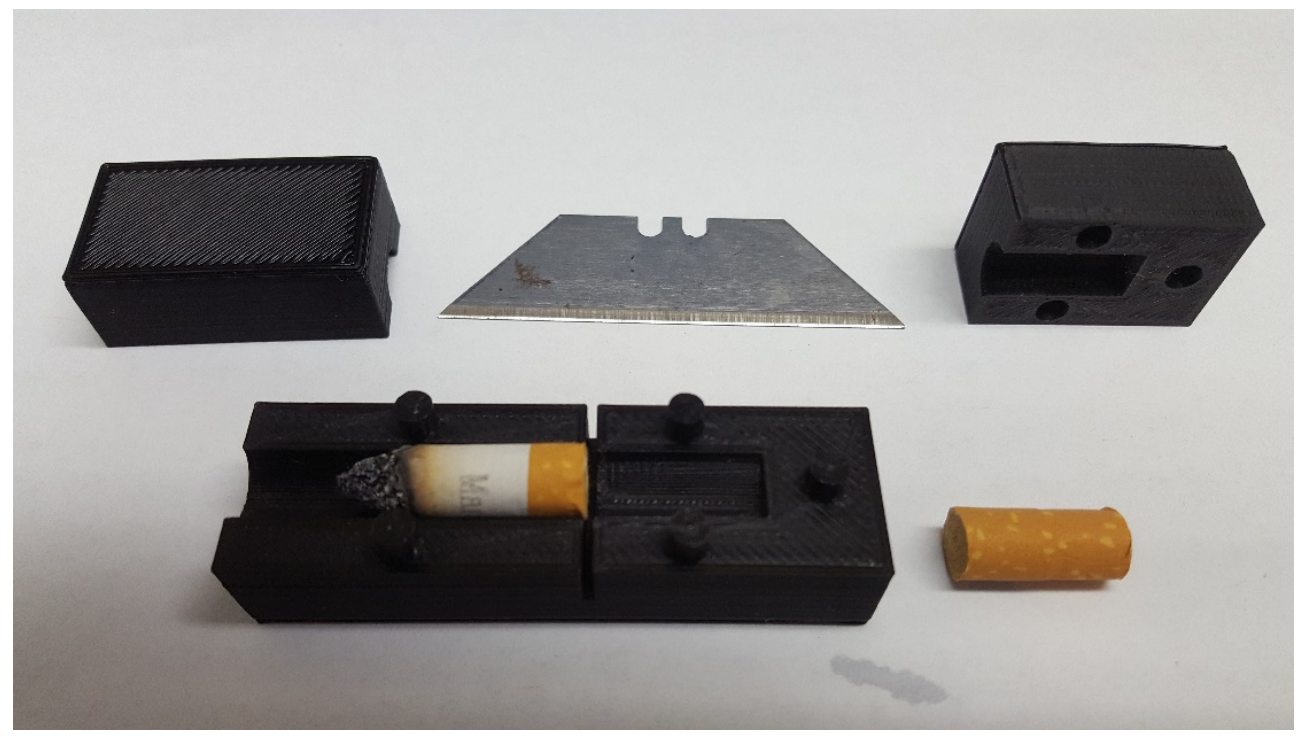

Figure 2.5: $\quad$ Cutting cigarette butts with 3D printed cutter. Butts were cut at the boundary of the filter and tobacco.

Six types of samples, shown in Table 1.1 and Figure 2.6, were prepared and analyzed in headspace vials (analysis described in Section 2.4.5). More specifically, seven unburned cigarettes were cut to each produce two parts (filter, Sample (1), and tobacco, Sample (2)). For consistency the tobacco sample was produced with the same length as the cut ash (Sample (4)). Twelve burned cigarette butts were also cut to produce two components. Their filter and ash components were analyzed with headspace analysis separately (burned filter, Sample (3), and ash, Sample (4)). The ash component includes both the unburned tobacco and ash from the burned cigarette. To determine the impact of the extra exposed surface area of the cut butts, another seven burned cigarette butts were cut, and each paired filter and ash component was placed together in one vial for headspace analysis (Sample (5)). As a comparison, eighteen uncut, burned cigarette butts were also tested (Sample (6)). 


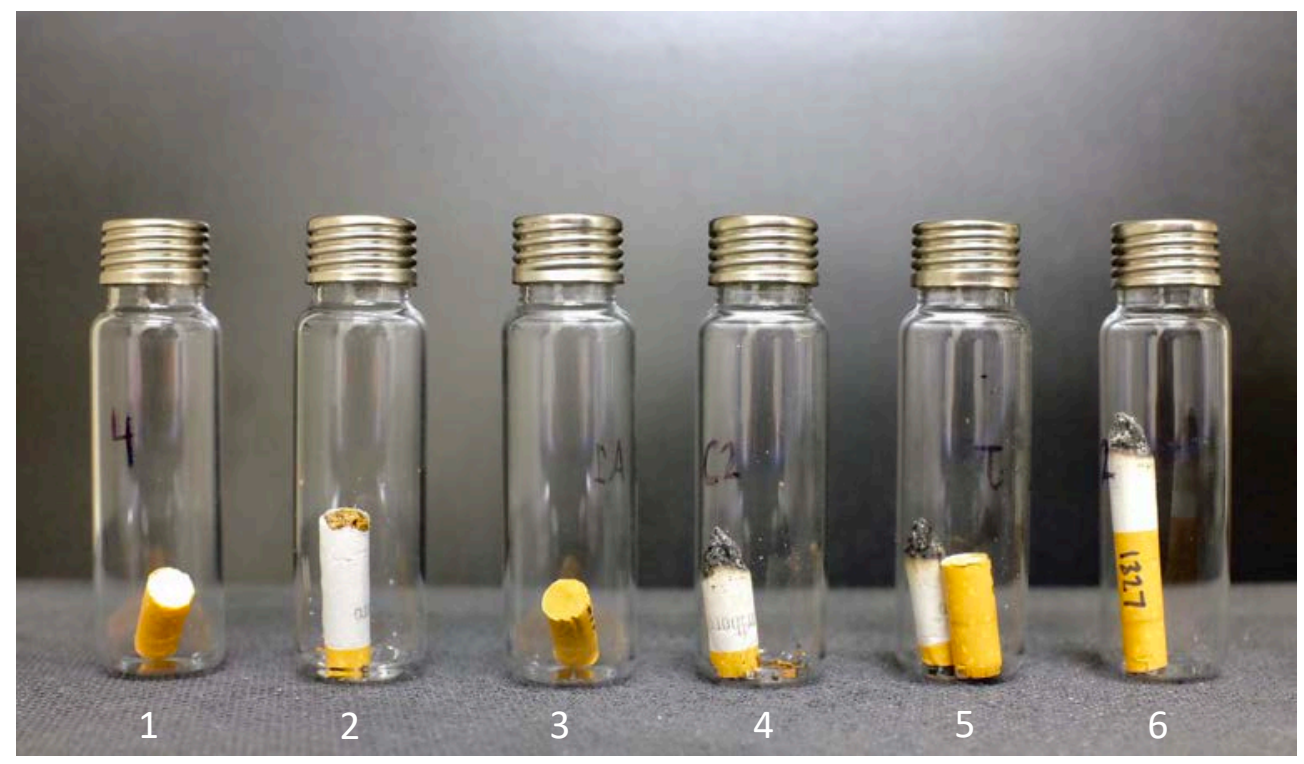

Figure 2.6: $\quad$ Cigarette butt samples from left to right: unburned filter - filter from unburned cigarette (1); unburned tobaccotobacco from unburned cigarette (2); burned filter- filter from burned cigarette (3), burned ash - unburned tobacco and ash from burned cigarette (4); cut cigarette butt - filter, tobacco and ash from burned cigarette (5); uncut cigarette butt (6).

\subsection{HEADSPACE ANALYSIS OF CONDITIONED CIGARETTE BUTTS}

To examine the influence of environmental factors on airborne cigarette butt emissions, the butts were placed in a range of environmental conditions for up to one week at a time. At the end of the conditioning period, the butts were taken out from the conditioning environment and placed in $20 \mathrm{~mL}$ headspace vials, and then the mass of chemicals emitted into the headspace were determined using TD-GC-MS analysis.

\subsubsection{Summary of experiments}

Freshly smoked cigarette butts were taken out of the $20 \mathrm{~mL}$ headspace vials and placed in different environments for different times (Table 2.4). The SPHERE experiments investigated the influence of temperature (Experiments 1 versus 2, and 3 versus 4), relative humidity ( 1 versus 3, and 2 versus 4), saturation of filters by artificial rainfall (5 versus 6 ) and exposure to enhanced simulated solar UV radiation (7 versus 8 and 9). The one-week rooftop experiments compared the influence of ambient conditions during summer (10 and 11) and winter (12 and 13). The large chamber experiments examined the influence of air change rate (14 and 15). 
Table 2.4: Summary of conditioning experiments. Standard deviations appear in parenthesis. Each experimental condition was tested for a range of durations (typically nine tests: $2 \mathrm{~h}$ to $144 \mathrm{~h}$.). For all experiments, except the rooftop experiments, the standard deviations shown in parenthesis are of the average values over the varying duration experiments.

\begin{tabular}{|c|c|c|c|c|c|c|}
\hline & $\begin{array}{c}\text { Condition } \\
\text { environment }\end{array}$ & $\begin{array}{l}\text { Temperature } \\
\quad\left({ }^{\circ} \mathrm{C}\right)\end{array}$ & $\begin{array}{l}\text { Relative } \\
\text { humidity (\%) }\end{array}$ & 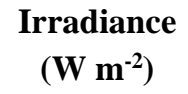 & $\begin{array}{l}\text { Airflow rate or wind } \\
\text { velocity }\end{array}$ & $\begin{array}{l}\text { Rainfall } \\
\left(\mathbf{m m} \text { min }^{-1}\right)\end{array}$ \\
\hline 1 & SPHERE ${ }^{\mathrm{a}}$ chamber & $31.1( \pm 0.2)$ & $49.6( \pm 1.2)$ & Off & $350 \mathrm{~mL} / \mathrm{min}^{\mathrm{b}}$ & N/A \\
\hline 2 & SPHERE chamber & $40.3( \pm 0.2)$ & $50.5( \pm 1.8)$ & Off & $344.7( \pm 14.0) \mathrm{mL} / \mathrm{min}$ & N/A \\
\hline 3 & SPHERE chamber & $30.8( \pm 0.2)$ & $25.4( \pm 0.6)$ & Off & $357.3( \pm 5.2) \mathrm{mL} / \mathrm{min}$ & N/A \\
\hline 4 & SPHERE chamber & $40.3( \pm 0.2)$ & $25.3( \pm 0.6)$ & Off & $347.3( \pm 14.9) \mathrm{mL} / \mathrm{min}$ & N/A \\
\hline 5 & SPHERE chamber & $30.9( \pm 0.2)$ & $51.7( \pm 4.2)$ & Off & $357.8( \pm 8.2) \mathrm{mL} / \mathrm{min}$ & Wet $^{\mathrm{c}}$ \\
\hline 6 & SPHERE chamber & $30.6( \pm 0.2)$ & $50.9( \pm 0.5)$ & Off & $359.8( \pm 6.3) \mathrm{mL} / \mathrm{min}$ & Dry $^{\mathrm{c}}$ \\
\hline 7 & SPHERE chamber & $30.5( \pm 0.01)^{d}$ & $51.5( \pm 1.3)$ & $144( \pm 2.7)^{\mathrm{e}}$ & $258.3( \pm 5.5) \mathrm{mL} / \mathrm{min}$ & N/A \\
\hline 8 & SPHERE chamber & $31.0( \pm 0.3)^{d}$ & $51.2( \pm 1.3)$ & Off & $252.0( \pm 5.9) \mathrm{mL} / \mathrm{min}$ & N/A \\
\hline 9 & SPHERE chamber & $37.3( \pm 0.0)^{\mathrm{d}}$ & $49.8( \pm 0.6)$ & Off & $252.2( \pm 8.3) \mathrm{mL} / \mathrm{min}$ & N/A \\
\hline 10 & Rooftop summer & $25.1( \pm 3.0)$ & $72.6( \pm 14.1)$ & $230( \pm 319)^{\mathrm{e}}$ & $1.8( \pm 1.1) \mathrm{m} \mathrm{s}^{-1}$ & $0.001( \pm 0.011)$ \\
\hline 11 & Rooftop summer & $24.4( \pm 3.3)$ & $72.8( \pm 12.1)$ & $216( \pm 290)^{\mathrm{e}}$ & $2.1( \pm 1.1) \mathrm{m} \mathrm{s}^{-1}$ & $0.001( \pm 0.029)$ \\
\hline 12 & Rooftop winter & $3.7( \pm 2.7)$ & $64.6( \pm 14.2)$ & $75( \pm 135)^{\mathrm{e}}$ & $3.2( \pm 1.9) \mathrm{m} \mathrm{s}^{-1}$ & $0.002( \pm 0.013)^{\mathrm{f}}$ \\
\hline 13 & Rooftop winter & $3.5( \pm 4.2)$ & $64.5( \pm 17.1)$ & $64( \pm 123)^{\mathrm{e}}$ & $3.7( \pm 2.9) \mathrm{m} \mathrm{s}^{-1}$ & $0.001( \pm 0.008)$ \\
\hline 14 & Large chamber & $25.0( \pm 0.0)$ & $48.1( \pm 0.0)$ & Off & $16.7 \mathrm{~m}^{3} \mathrm{~h}^{-1} \mathrm{~g}$ & N/A \\
\hline 15 & Large chamber & $25.0( \pm 0.2)$ & $48.1( \pm 0.2)$ & Off & $30.7 \mathrm{~m}^{3} \mathrm{~h}^{-1} \mathrm{~g}$ & N/A \\
\hline \multicolumn{6}{|c|}{$\begin{array}{l}\text { 'Cigarette butts that were soaked in a petri dish with artificial rainwater before being placed into the dark chamber were considered "wet”, } \\
\text { while cigarette butts that were placed in an empty petri dish before placed into the dark chamber were considered "dry”. }\end{array}$} & sidered “wet”, \\
\hline \multicolumn{7}{|c|}{$\begin{array}{l}\text { d Air temperatures during the experiments averaged } 30.5( \pm 0.1)^{\circ} \mathrm{C} \text {. Butt temperatures measured by placing thermocouple in the cigarette butts } \\
\text { while the butts were exposed to the UV source averaged } 37.3( \pm 0.3){ }^{\circ} \mathrm{C} \text {. }\end{array}$} \\
\hline \multicolumn{7}{|c|}{$\begin{array}{l}\text { eThe wavelength of UV in the SPHERE ranged from } 295 \mathrm{~nm} \text { to } 400 \mathrm{~nm} \text {. Irradiance values on the rooftop are measured for the full sun } \\
\text { spectrum, not just the UV range. }\end{array}$} \\
\hline \multicolumn{7}{|c|}{ fValue may be elevated due to snow on the sensor for over $24 \mathrm{~h}$. } \\
\hline \multicolumn{7}{|c|}{$\begin{array}{l}\text { 'The flow rates for the large chamber were the flow rate for outdoor air and calculated by multiplying the measured air change rate (in inverse } \\
\text { time) by the chamber volume. The air change rates for the large chamber were measured based on ASTM E741-11 (2017) (ASTM 2017), as } \\
\text { described in Appendix A.4. }\end{array}$} \\
\hline
\end{tabular}




\subsubsection{SPHERE}

To study the influence of temperature, relative humidity, UV and water saturation on airborne cigarette butt emissions, cigarette butts were placed in two different types of SPHERE chambers (Figure 2.8), i.e., dark chambers and a UV chamber. The dark chambers (Experiments 1 through 6 in Table 2.4) had a rectangular cuboid shape and a volume of $590 \mathrm{~mL}$ with no UV exposure, and were used to examine the influence of temperature, relative humidity and water saturation on cigarette butt emissions. A cylindrical UV chamber was used to investigate the influence of UV exposure on cigarette butt emissions (Experiments 7 and 8 in Table 2.4). The cylindrical UV chamber had a volume of $99 \mathrm{~mL}$. More information on the UV chamber system is provided in Chin et al. (2004). The measured temperatures, relative humidities and flow rates of the dark and UV chambers for each set of experiments are summarized in Table 2.4.

In the dark chambers, cigarette butts were conditioned under four settings with the same chamber flow rate of $350 \mathrm{~mL} \mathrm{~min}{ }^{-1}$ but different temperature and relative humidity combinations: $30{ }^{\circ} \mathrm{C}$ and $50 \%, 40{ }^{\circ} \mathrm{C}$ and $50 \%, 30{ }^{\circ} \mathrm{C}$ and $25 \%$, and $40{ }^{\circ} \mathrm{C}$ and $25 \%$ (Experiments 1 through 4 in Table 2.4). The temperature and relative humidity were recorded automatically every minute, while the flow rates were checked at the beginning and end of each experiment with a bubble flow meter. For each test, three freshly smoked cigarette butts were placed in the chamber with a specially designed holder (Figure 2.7) for eight different time durations (2 h, 5 h, 18 h, 24 h, 48 h, 72 h, 96 h, $120 \mathrm{~h}$ and $144 \mathrm{~h}$ ). The filter holder had $1.7 \mathrm{~mm}$ diameter pegs to mount the butts onto the vertical butt holder. The pegs made two holes in the filter area of each butt that remained present for the headspace TD-GC-MS analysis.

In the UV chamber (Experiments 7 and 8 in Table 2.4), cigarette butts were conditioned with a UV exposure of $144 \mathrm{~W} \mathrm{~m}^{-2}$ (wavelength from $295 \mathrm{~nm}$ to $400 \mathrm{~nm}$ ) and without UV at a relative humidity of $50 \%$ and a flow rate of $250 \mathrm{~mL} \mathrm{~min}^{-1}$. The UV was intended to simulate the solar UV radiance range described in ASTM G173-03 (2012) (ASTM 2012), i.e., $295 \mathrm{~nm}$ to $400 \mathrm{~nm}, 46 \mathrm{~W}$ $\mathrm{m}^{-2}$. When conditioning the butts with UV radiation, the butt temperature $\left(37.5^{\circ} \mathrm{C}\right)$ was higher than the temperature in the chamber air $\left(30.5^{\circ} \mathrm{C}\right)$ due to the energy associated with the UV exposure. The chamber was also set to be $37.5^{\circ} \mathrm{C}$ when UV was off (Experiment 9). Samples were analyzed with UV on and off at 2 h, 5 h, 18 h, 24 h, and 48 h (Experiments 7, 8 and 9). Additional samples were collected with UV on at 72 h, 96 h, 120 h and 144 h (Experiment 7). 


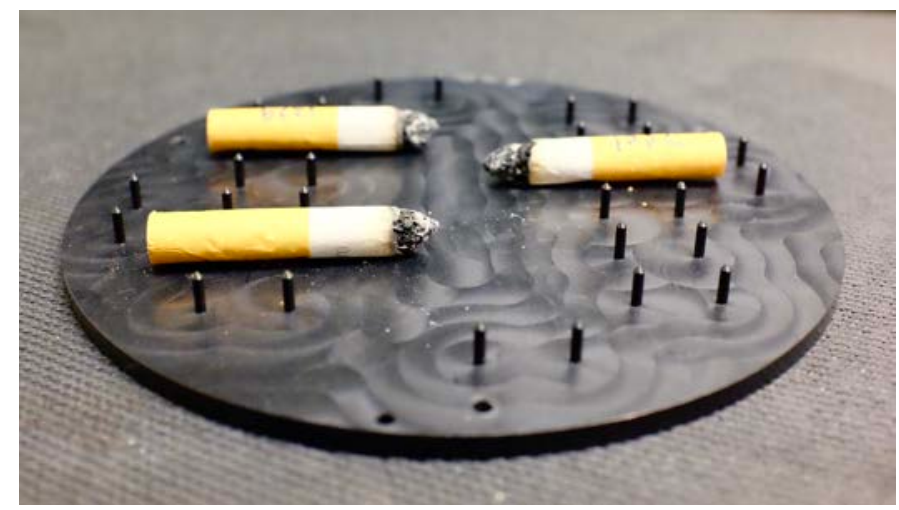

Figure 2.7: $\quad$ Cigarette butt holder for conditioning in SPHERE.

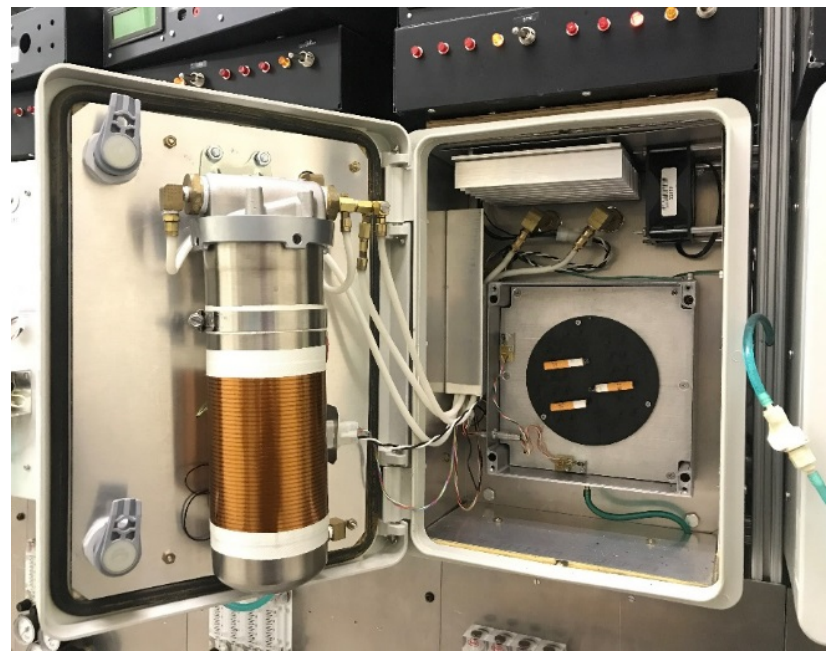

(a)

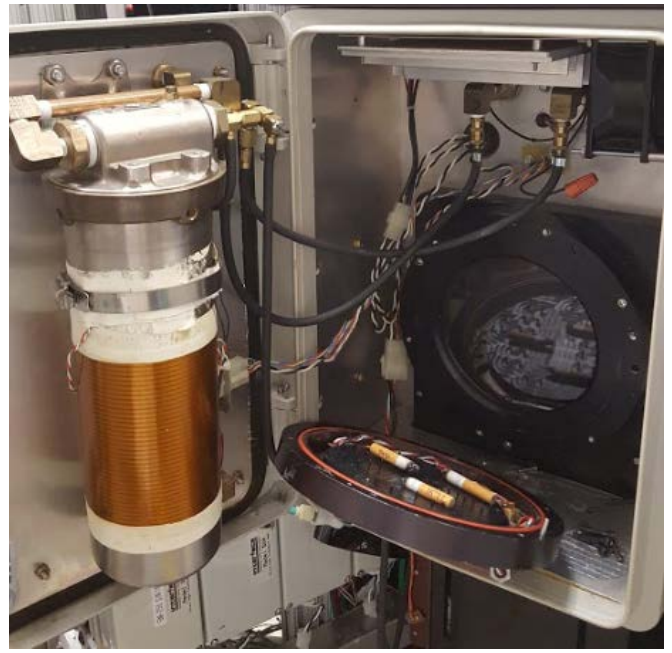

(b)

Figure 2.8: $\quad$ Cigarette butts conditioned in two different types of SPHERE chambers. (a) dark chamber; (b) UV chamber. The outer enclosure and copper-wrapped water bath are used to maintain the temperature and RH of the inner dark and UV chambers where the cigarette butt holders are located. The UV enters the UV chamber through the glass window, which is closed for the photograph.

To study the influence of rainwater saturation on emissions from cigarette butts, freshly smoked cigarette butts were preconditioned before being placed into dark chambers (Experiments 5 and 6 in Table 2.4). An artificial rainwater concentrate solution previously used for cigarette butt aqueous leaching experiments (Chevalier et al. 2018) was prepared by dissolving the following components in $1 \mathrm{~L}$ of distilled water: $\mathrm{NaCl}(3.24 \mathrm{~g}), \mathrm{KCl}(0.36 \mathrm{~g}), \mathrm{CaCl}_{2} \cdot 2 \mathrm{H}_{2} \mathrm{O}(1.65 \mathrm{~g})$, $\left(\mathrm{NH}_{4}\right) 2 \mathrm{SO}_{4}$ (3.41 g), $\mathrm{MgSO}_{4} \cdot 7 \mathrm{H}_{2} \mathrm{O}$ (2.98 g), and $\mathrm{NaNO}_{3}$ (4.08 g). Following Chevalieret al (2018), the solution was then diluted by a factor of 1000 prior to use.

Preliminary experiments showed that once the cigarette butts were saturated, the paper surrounding the ash and tobacco could disintegrate erratically when handled and placed in chambers. In addition, butts placed on the roof shortly before heavy rain events had similar fates, and it was 
challenging to recover the entire butt intact (Figure 2.9). In contrast to the degradation of the ash and tobacco when exposed to water, cigarette filters typically contain plasticized cellulose acetate fibers that show minimal degradation after two years of outdoor exposure (Bonanomi et al. 2015). In fact, filters can persist up to ten years in the environment (Novotny and Zhao 1999, Puls et al. 2011, Bonanomi et al. 2015). In addition, experiments in this study (Section 3.1) demonstrated that the emitted masses of the target chemicals from burned filters were comparable to the entire emitted mass from the burned cigarette butt for most of the target chemicals.

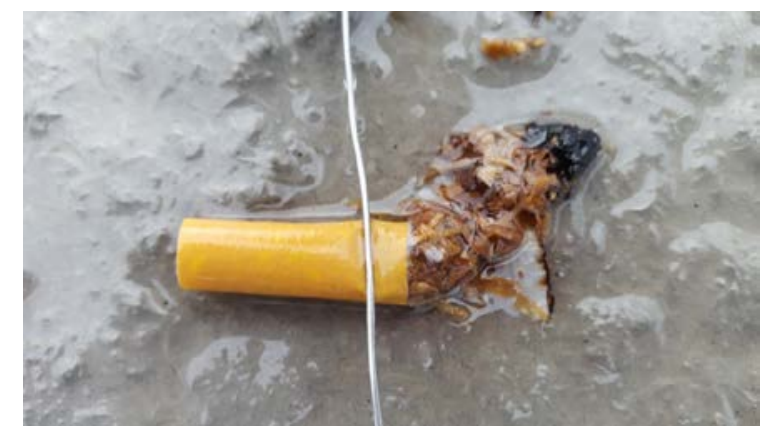

Figure 2.9: $\quad$ Example of disintegration of paper wrapper around unburned tobacco and ash after rain event during conditioning on the roof. A stainless-steel wire was used to hold butts down during outdoor rooftop exposure.

Given these questions, two sets of water saturation experiments were conducted, one with the entire butt and one with just the filter. In the first set of experiments, seven butts were wet using the procedure below and then directly placed in the headspace vials for TD-GC-MS analysis conditioning to determine the impact of rainwater saturation on the initial emitted mass into headspace. For each pair of freshly smoked cigarette butts, one was placed in a dry petri dish while the other was soaked in $30 \mathrm{~mL}$ diluted rainwater solution in another petri dish (Figure 2.10). Experiments showed that 3 min was enough to saturate the cigarette butts (Figure 2.11). Hence, after 3 min of conditioning, the butts were transferred onto a wire mesh rack using tweezers. Each butt was left on the rack for $30 \mathrm{~s}$ to remove any residual water that wasn't absorbed by the cigarette butt, and then placed into a pre-weighed $20 \mathrm{~mL}$ vial using tweezers. For this first set of experiments, the butts were directly analyzed via headspace TD-GC-MS analysis after determining the water mass gained in each butt. 


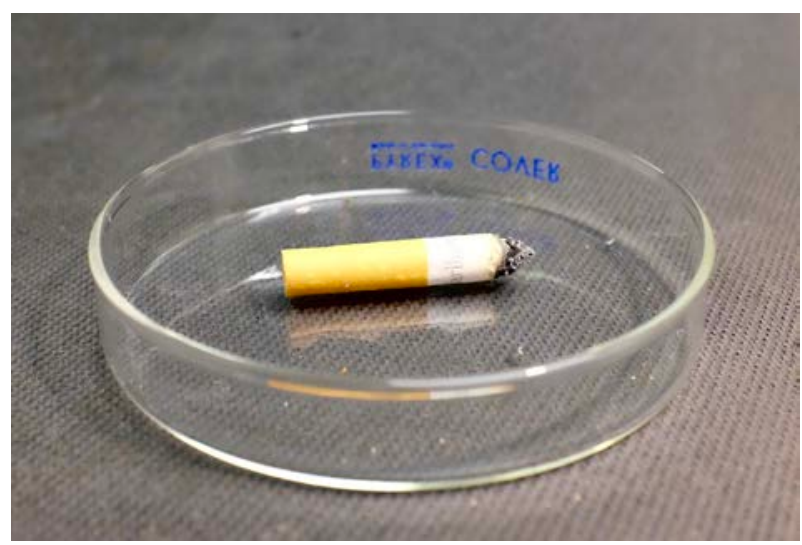

(a)

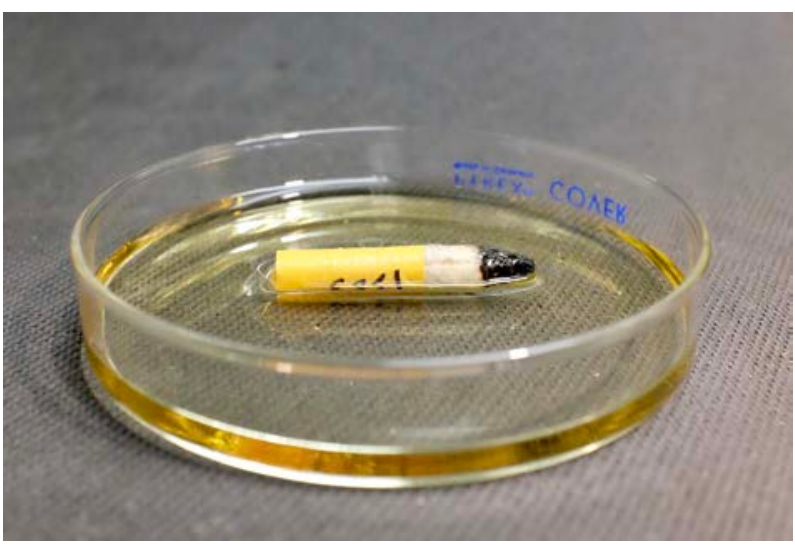

(b)

Figure 2.10: Condition of cigarette butt in (a) dry petri dish; (b) in a wet petri dish with 2 mm deep rainwater.

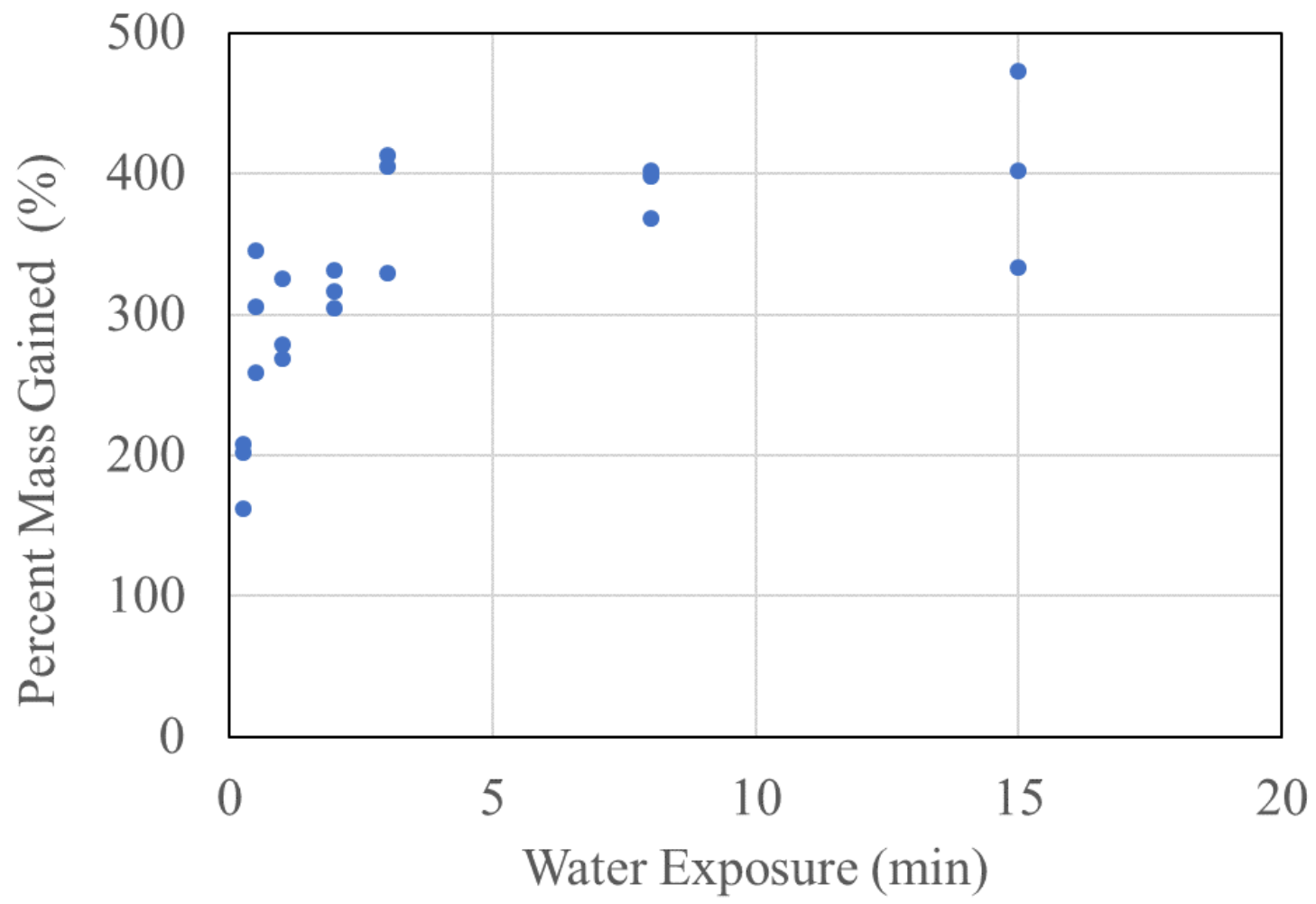

Figure 2.11: $\quad$ Mass change of cigarette butts with soaking time.

In the second set of experiments, butts were cut using the apparatus described in Section 2.3. The ash and unburned tobacco were discarded. After cutting, three filters were wet following the same procedure as above, while three other filters were handled in the same manner but kept dry (Figure 2.12). The dry and wet filters were then conditioned in dark chambers at $30^{\circ} \mathrm{C}$ and $50 \% \mathrm{RH}$ (Experiment 5 and 6 in Table 2.4). The measured temperatures, relative humidifies and flow rates of the dark chambers for each set of experiments are summarized in Table 2.4. The dry filters were 
analyzed after five different conditioning times, i.e., 2 h, 5 h, 18 h, 24 h and 120 h, while the wet filters were analyzed after four different conditioning times, i.e., 5 h, 18 h, 24 h and 120 h.

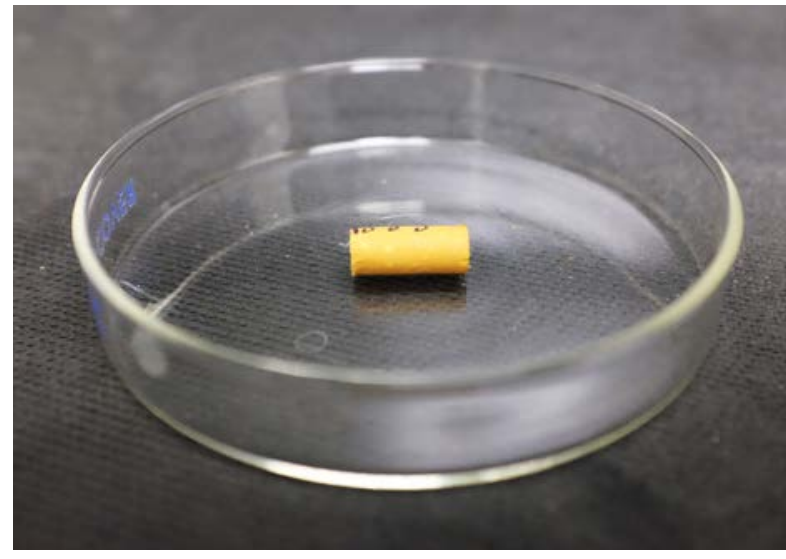

(a)

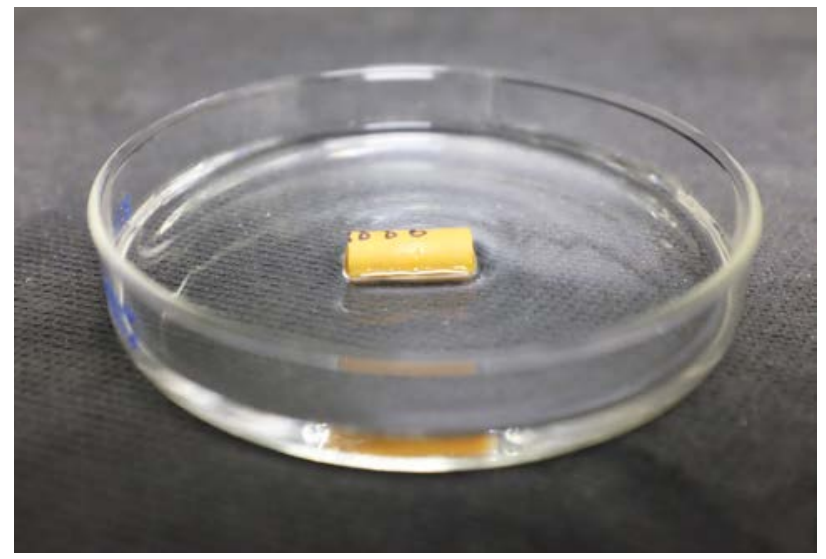

(b)

Figure 2.12: Condition of filter of cigarette butt in (a) dry petri dish, (b) wet petri dish with 2 mm deep simulated rainwater.

\subsubsection{Large chamber}

To mimic indoor conditions, cigarette butts were also conditioned in a large stainless-steel, $31 \mathrm{~m}^{3}$ walk-in chamber (Experiment 14 and 15 in Table 2.4), which was designed consistent to ASTM D6670-18 (ASTM 2018). The chamber, shown in Figure 2.13 (a), has its own heating, cooling, and ventilation system, which allows control of temperature, relative humidity, outdoor air change rate and recirculation airflow rate. Both outdoor makeup air and recirculated air are cleaned with high efficiency particulate air (HEPA) and charcoal filters. Background tests described in Section 2.5 showed none of the target chemicals were present in significant quantities in the air entering the chamber.

Cigarette butts were conditioned in the large chamber under two settings with the same temperature and relative humidity of $25^{\circ} \mathrm{C}$ and $50 \%$, but different outdoor airflow rates. The first conditioning experiment used $16.7 \mathrm{~m}^{3} \mathrm{~h}^{-1}$ outdoor air (equivalent to an air change rate of $0.54 \mathrm{~h}^{-1}$ ) plus $109.3 \mathrm{~m}^{3} \mathrm{~h}^{-1}$ of recirculated air (equivalent to recirculation rate of $3.3 \mathrm{~h}^{-1}$ ). The second experiment used $30.7 \mathrm{~m}^{3} \mathrm{~h}-1$ outdoor air (equivalent to an air change rate of approximately $0.99 \mathrm{~h}^{-1}$ ) plus $93.3 \mathrm{~m}^{3} \mathrm{~h}^{-1}$ recirculated air (equivalent to a recirculation rate of $3.0 \mathrm{~h}^{-1}$ ). The determination of the outdoor air change rate and recirculation rate is described in Section A.4. In this study, the air change rate is used as a surrogate for the impact of both outdoor air dilution and local air movement over the surface of the cigarette butt on emission rate.

For each test, a freshly smoked cigarette butt was placed on each of three different concrete blocks placed on the chamber floor (Figure 2.13). The concrete blocks used were the same as in the rooftop experiments (Section 2.4.4). The duration of the nine experiments was from $2 \mathrm{~h}$ to $144 \mathrm{~h}$. The measured temperatures, relative humidities, and flow rates of the walk-in chamber for each set of experiment were recorded every minute and are summarized in Table 2.4. 


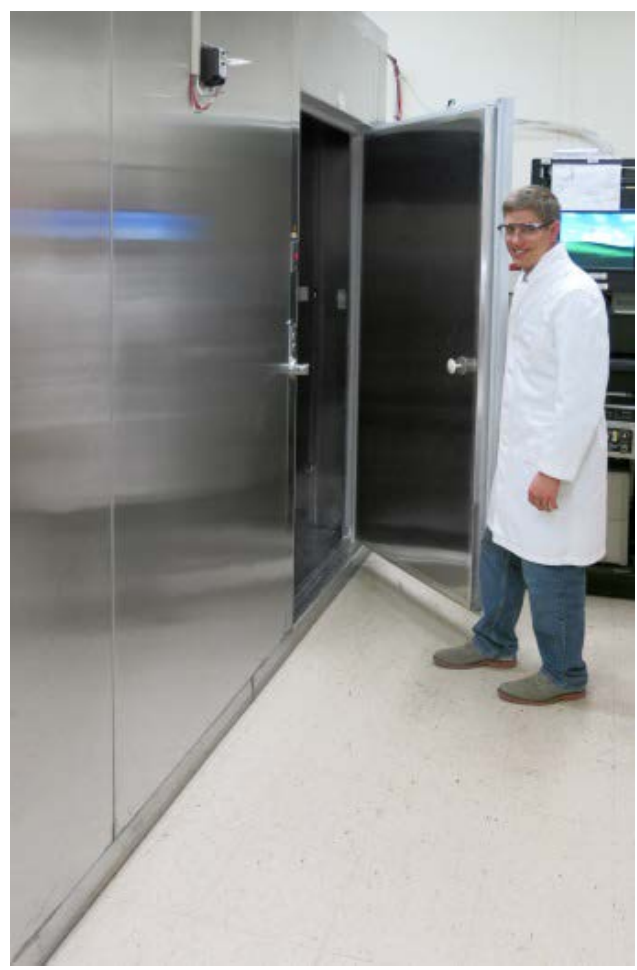

(a)

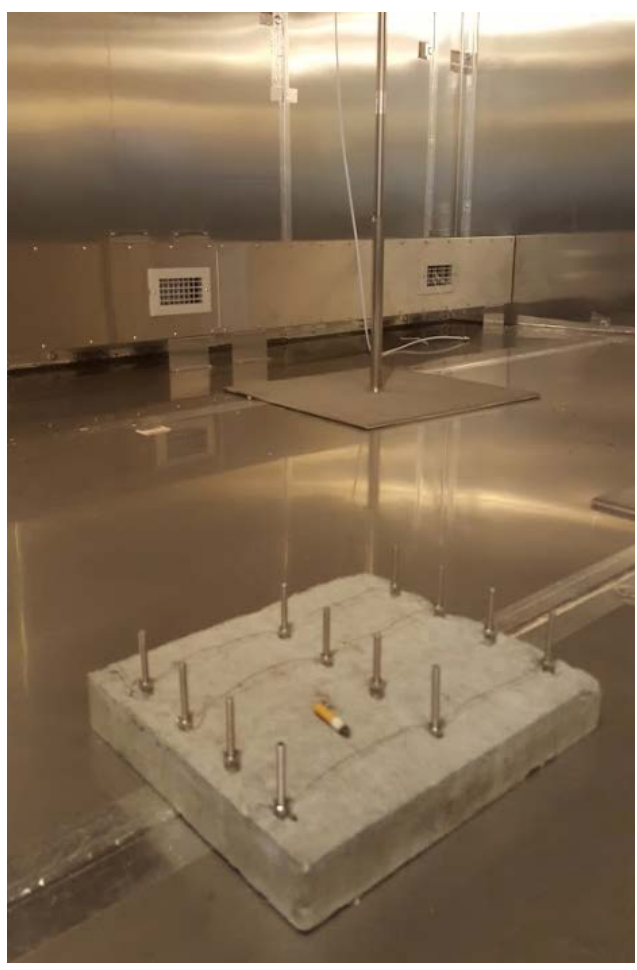

(b)

Figure 2.13: (a) Large stainless-steel walk-in chamber; (b) Cigarette butts being conditioned in large chamber.

\subsubsection{Rooftop}

Experiments were also conducted by conditioning cigarette butts on the roof of a five story NIST laboratory building (Experiments 10 through 13 in Table 2.4, shown in Figure 2.14). The roof consists of a melted asphalt membrane covered by a layer of pebbles. This environment was chosen to keep the butts safe from the interference of people and animals other than birds. In addition, the roof hosts an existing solar PV panel logging and weather station (Figure 2.14); more information on this system can be found in (Boyd 2016). The butts were placed on concrete blocks to mimic the thermal properties of a butt discarded on a street or in a parking lot. 

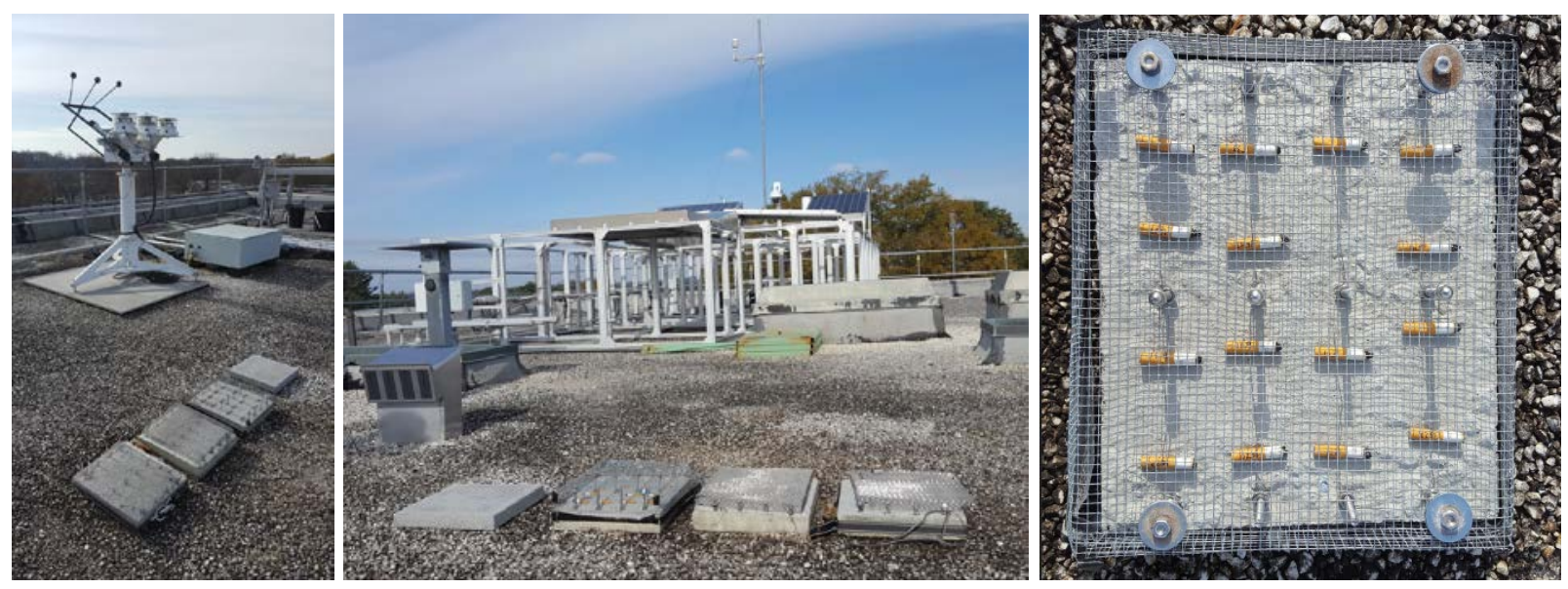

Figure 2.14: Cigarette butts conditioned on the roof of the NIST laboratory building. Solar tracking system on left, weather station in center, and protective mesh cover shown on right.

Two sets of experiments were conducted in summer (August 2018, Experiments 10 and 11 in Table 2.4) and two sets of experiments were conducted in winter (November 2018, Experiments 12 and 13 in Table 2.4). Rain occurred during each sampling event. The butts were placed beneath wires to pin them to a concrete block. In addition, a wire mesh was placed on top of the blocks to prevent interference from birds (Figure 2.14). For each test, three freshly smoked cigarette butts were placed on the roof for nine different time durations, ranging from $2 \mathrm{~h}$ to $144 \mathrm{~h}$. The solar radiation, precipitation, temperature, relative humidity, wind velocity, and atmospheric pressure were recorded every minute during the experiments, shown in Figure 2.15 through Figure 2.20.

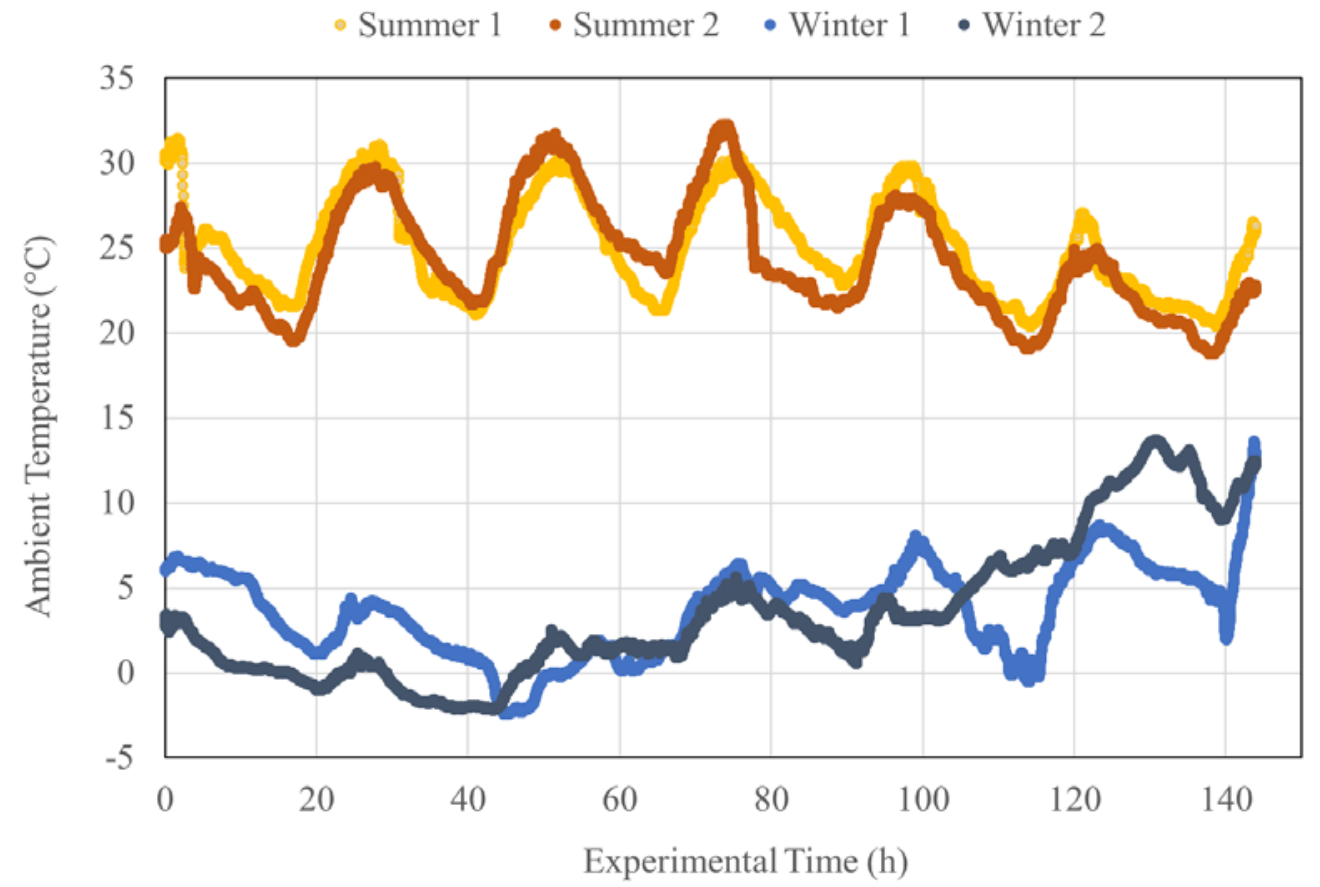

Figure 2.15: Temperature profiles during four rooftop experiments. 


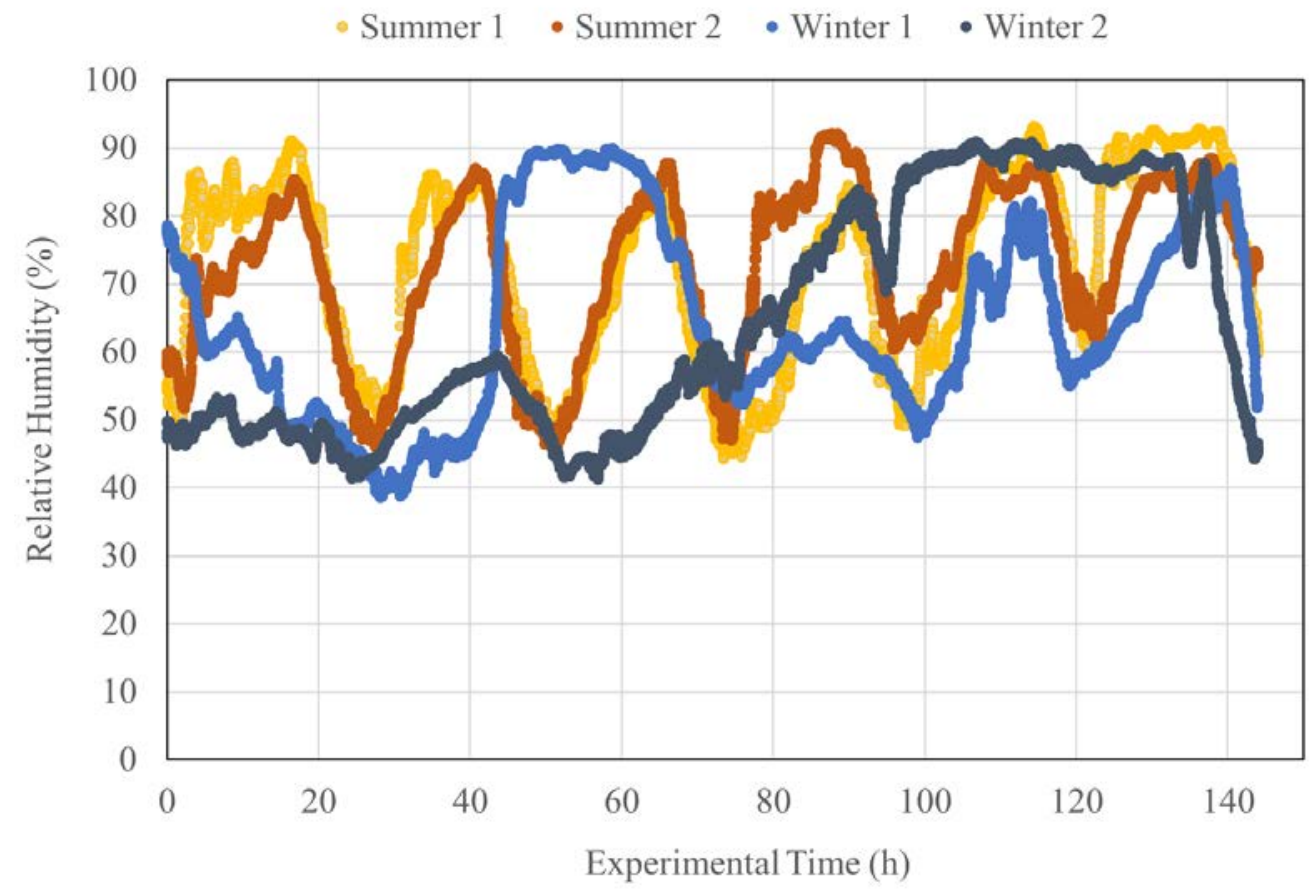

Figure 2.16: Relative humidity profiles during four rooftop experiments.

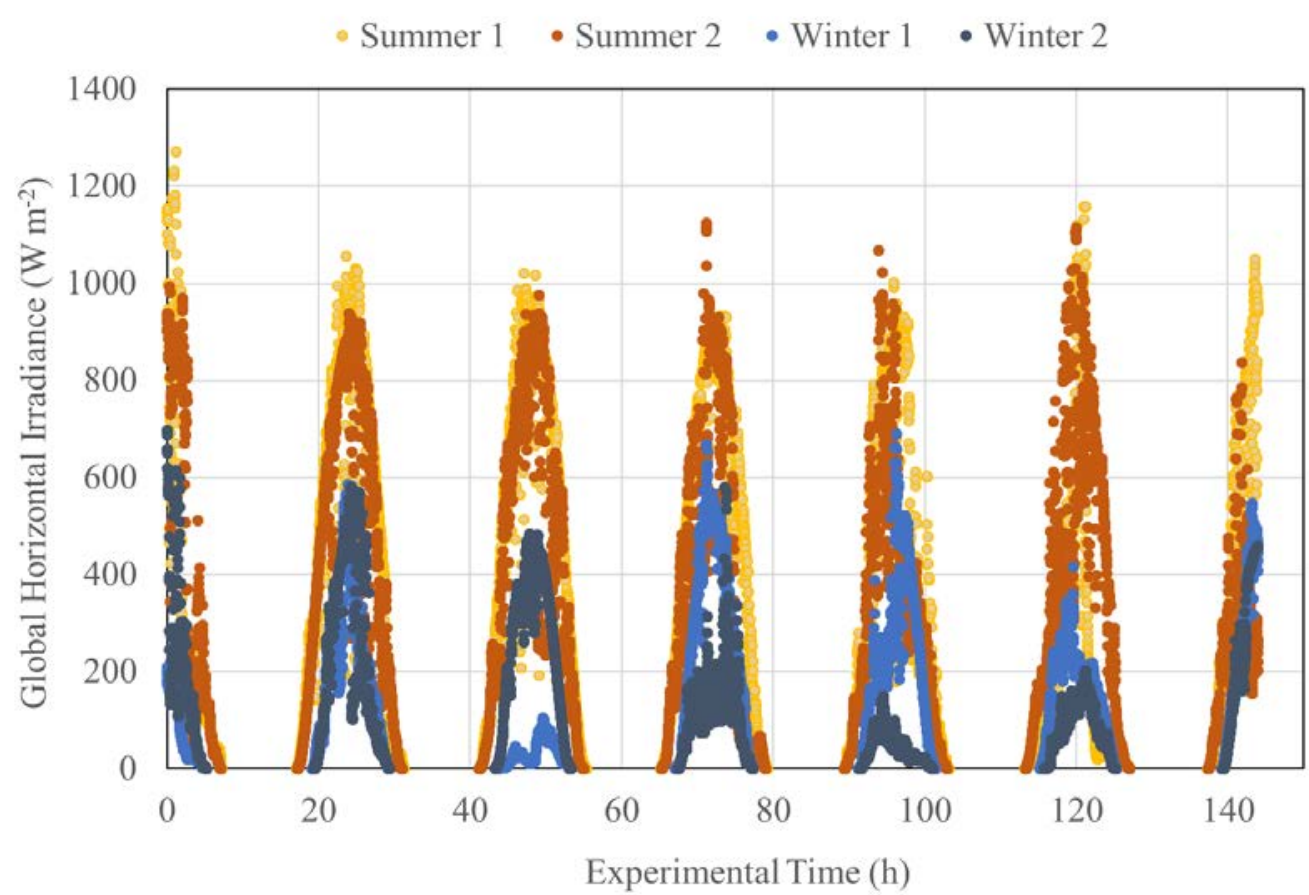

Figure 2.17: Global horizontal solar radiation profiles during four rooftop experiments. 


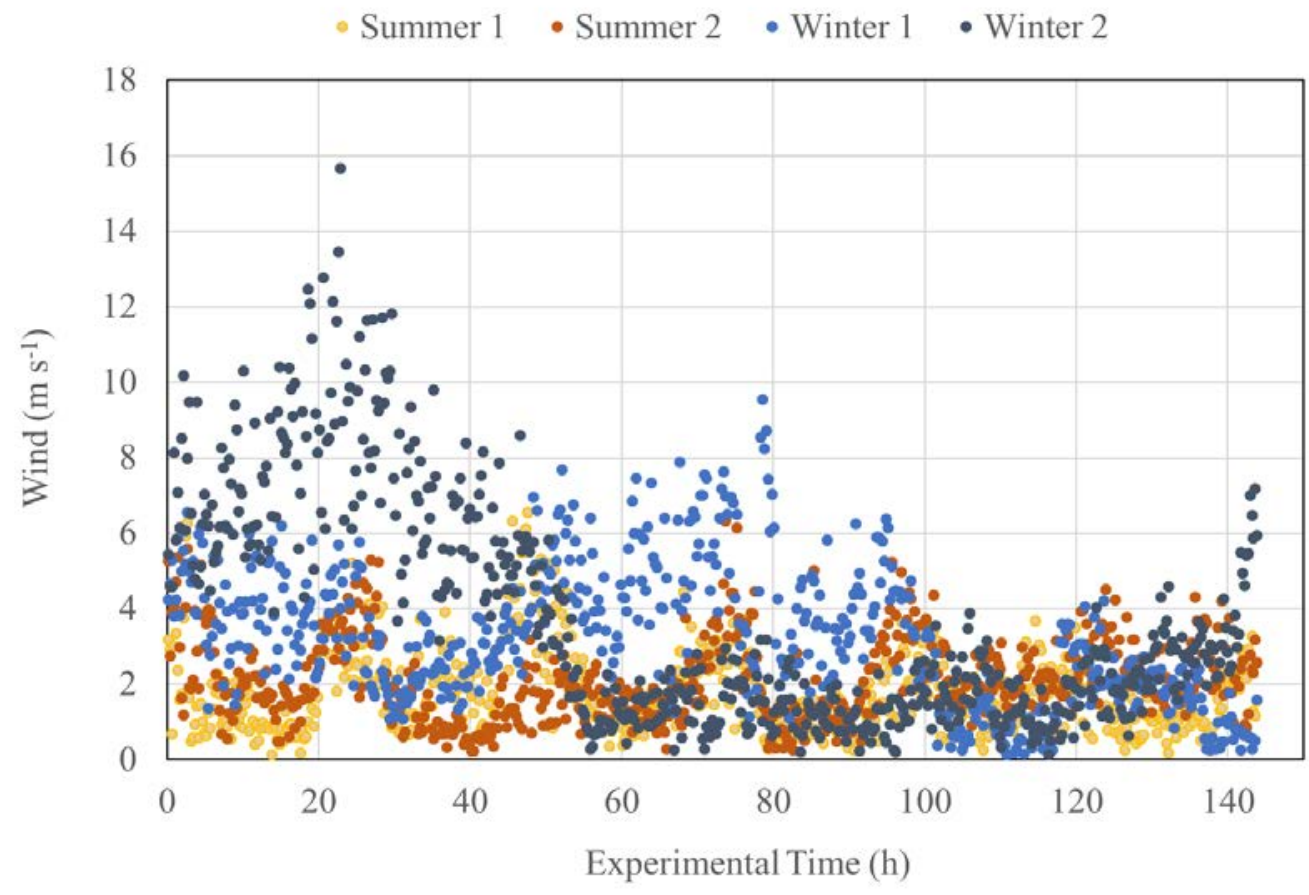

Figure 2.18: Wind profiles during four rooftop experiments. One-minute data displayed every 15 min.

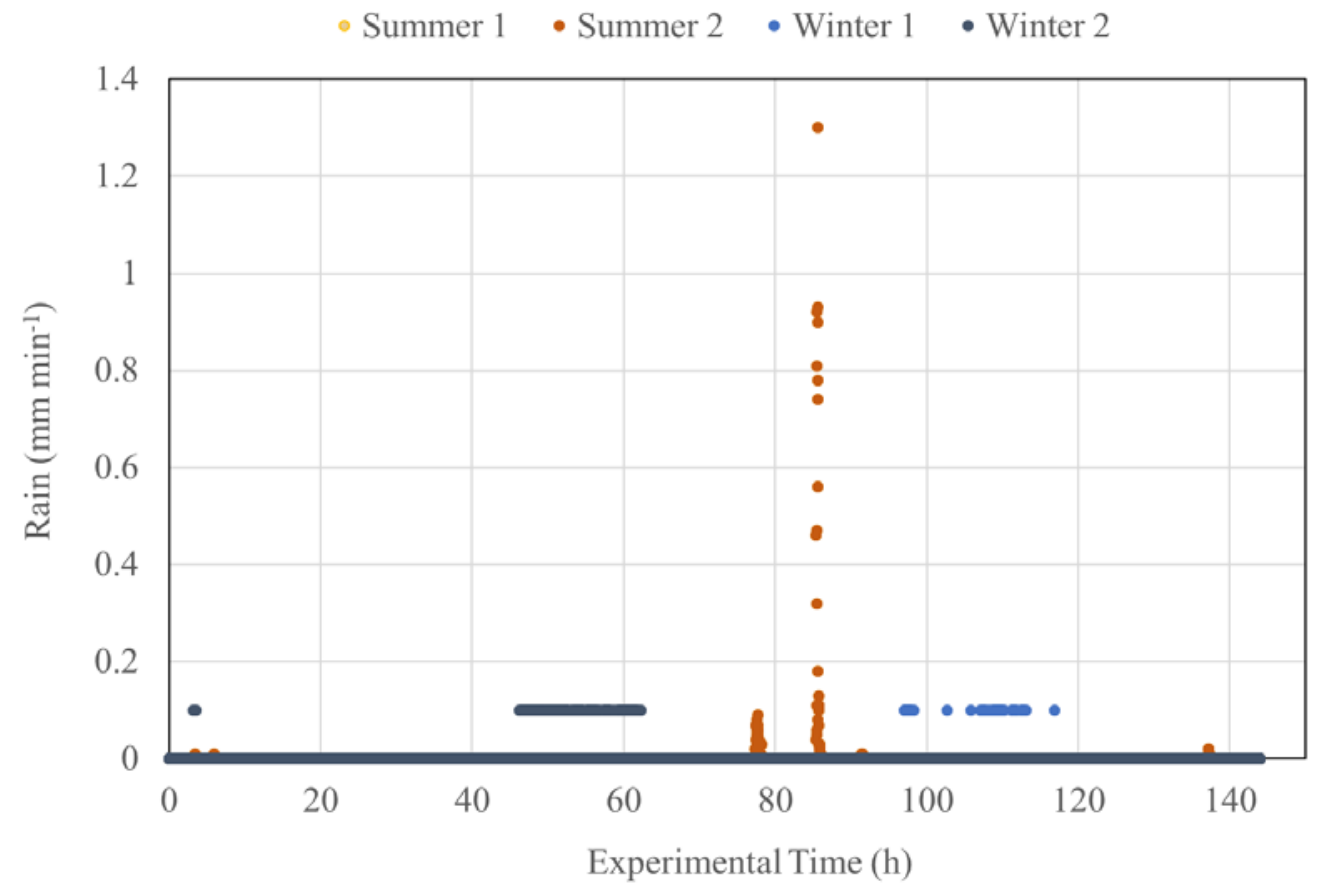

Figure 2.19: Rain and snow profiles during four rooftop experiments. Constant lines on Winter 1 at 46 h through 62 h indicate when sensor was covered with snow. 


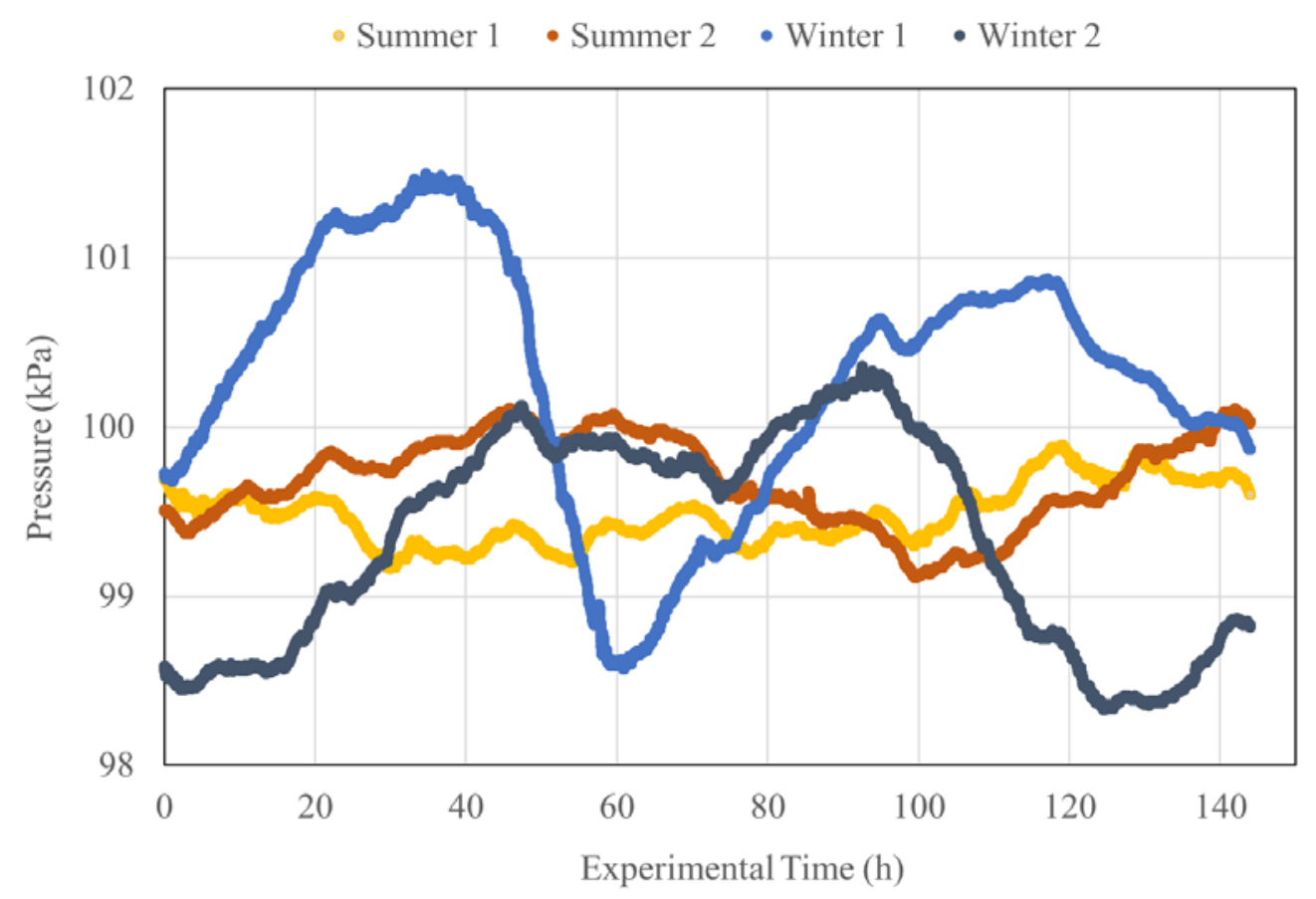

Figure 2.20: Atmospheric pressure profiles during four rooftop experiments.

\subsubsection{Headspace analysis}

Fresh and conditioned cigarette butt samples were analyzed with headspace analysis to determine the mass emitted from the butts. The objective of the headspace analysis was not to fully extract all the mass from the butts, but rather to establish a repeatable method that would allow comparison of chemical emissions into the headspace air after the cigarette butts were conditioned in the different environments. In summary, the headspace analysis method equilibrated the butt in a headspace vial at $30^{\circ} \mathrm{C}$. The headspace of the vial was then flushed onto a thermal desorption tube. The tube was then desorbed into the GC-MS, and the chemical mass in the tube was analyzed. To increase the repeatability and sensitivity, ensure full desorption from the thermal desorption tube, and reduce the analysis time of the method, experiments were conducted to optimize key parameters, including incubation time, sampling volume, thermal desorption program, and GC oven temperature program.

After optimization, all the samples were run using the method as described below. Each cigarette butt was placed in a $20 \mathrm{~mL}$ vial and conditioned for $10 \mathrm{~min}$ at $30^{\circ} \mathrm{C}$. After conditioning, a Tenax tube was used to sample the headspace air from the vial at a flow rate of $100 \mathrm{~mL} / \mathrm{min}$ for $1 \mathrm{~min}$. The Tenax tube was then automatically transported to a thermal desorption unit (TD). The thermal desorption started at $40^{\circ} \mathrm{C}$ for $0.5 \mathrm{~min}$, ramped up to $300^{\circ} \mathrm{C}$ at a rate of $12^{\circ} \mathrm{C} \mathrm{s}^{-1}$ and held for $8 \mathrm{~min}$, while the desorbed chemicals were captured by a cooled injection system (CIS) at $-120^{\circ} \mathrm{C}$. After desorption, the CIS temperature ramped up to $280^{\circ} \mathrm{C}$ at a rate of $12{ }^{\circ} \mathrm{C} \mathrm{s}^{-1}$ and held for $3 \mathrm{~min}$, and the desorbed chemicals were transferred to a gas chromatograph (GC) column with a split 
ratio of $15: 1$. The transfer temperature to the gas chromatograph was $280{ }^{\circ} \mathrm{C}$. The gas chromatograph used a $30 \mathrm{~m}, 0.25 \mathrm{~mm}$ ID, and $0.25 \mu \mathrm{m}$ film thickness column with a flow of $1 \mathrm{~mL} \mathrm{~min}{ }^{-1}$ of helium. The column oven temperature started at $30^{\circ} \mathrm{C}$ for $1 \mathrm{~min}$, ramped up at $10^{\circ} \mathrm{C}$ $\min ^{-1}$ to $200^{\circ} \mathrm{C}$, then ramped up at $20^{\circ} \mathrm{C} \min ^{-1}$ to $300{ }^{\circ} \mathrm{C}$ and held for $2 \mathrm{~min}$. The mass spectrometer was operated in full scan mode. The mass-to-charge ratios for quantification of the target chemicals (quantification ion) are listed in Table 2.3 in Section 2.2.

Standards curves were made by spiking $0.2 \mu \mathrm{L}$ to $4 \mu \mathrm{L}$ of standard solutions of the eight target chemicals (Section 2.2) in methanol, with $1 \mu \mathrm{L}$ of ethylbenzene-d8 as an internal standard (quantification ion: 116) directly onto the bottom of the glass frit of the sorption tube. Nitrogen gas was passed from the bottom to the top of the sorption tube for 2 min prior to analysis to remove the methanol. Three five-point evenly-spaced standard curves with the following concentration ranges were used: $0.04 \mathrm{ng}$ to $80 \mathrm{ng}$ per injection for naphthalene, $1 \mathrm{ng}$ to $2000 \mathrm{ng}$ per injection for limonene, and $0.4 \mathrm{ng}$ to $800 \mathrm{ng}$ per injection for the other target chemicals.

For an internal standard, each sample tube was also spiked with $1 \mu \mathrm{L}$ of ethylbenzene-d8 in methanol directly on to the bottom of the glass frit of the sorption tube prior to sampling the headspace vial. To minimize chromatography interferences, nitrogen gas was passed from the bottom to the top of the sorption tube for 2 min prior to analysis to remove the methanol. A blank thermal desorption sample tube spiked with an internal standard was run after each set of triplicate butt samples.

\subsubsection{Quality assurance and quality control}

Six quality assurance and quality control issues were addressed during the headspace analysis: (1) Reliability of the TD-GC-MS analysis; (2) Detection limit of the method; (3) Consistency of the butt production over the course of the experiments; (4) Loss of chemicals while butts were in the $20 \mathrm{~mL}$ analysis vial waiting to be analyzed by the TD-GC-MS; (5) Consistency of chemical emissions from the butts before they were placed in the conditioning environments; and, (6) Consistency of the conditioning environments.

(1) Reliability of the TD-GC-MS analysis. During cigarette butt analysis, standard curves were run in each sequence, and only data from sequences where the standard curves had linear $\mathrm{R}^{2}$ values larger than 0.98 were used. A total of 23 experiments were repeated due to inadequate standard curves to ensure adequate quantification of detected peaks. Blank sorption tubes were run in every sequence to check if there was any crossover contamination. No target chemicals were detected in any of the blanks.

(2) Detection limit of the method. Instrument detection limits of the target chemicals on sorbent tubes were determined by spiking the target chemicals in a $1 \mu \mathrm{L}$ methanol solution onto the bottom of the sorbent tubes. The instrument detection limits for each target chemical were determined by multiplying three times the standard deviation of seven replicates at a concentration that was less than five times the determined method detection limit (Code of Federal Regulations 2003). The quantification limits were determined by multiplying the 
above determined standard deviation by ten. The instrument detection limits and quantification limits for headspace analysis are shown in Table 2.5.

Table 2.5: Instrument detection limits and quantification limits for headspace analysis (ng)

\begin{tabular}{|c|c|c|}
\hline & $\begin{array}{c}\text { Instrument detection limit for } \\
\text { headspace analysis (ng) }\end{array}$ & $\begin{array}{c}\text { Quantification limit for } \\
\text { headspace analysis (ng) }\end{array}$ \\
\hline Furfural & 0.88 & 2.93 \\
\hline Ethylbenzene & 0.40 & 1.35 \\
\hline Styrene & 0.31 & 1.04 \\
\hline 2-methyl-2-Cyclopenten-1-one & 0.40 & 1.33 \\
\hline Limonene & 1.00 & 3.32 \\
\hline Naphthalene & 0.11 & 0.36 \\
\hline Triacetin & 0.46 & 1.52 \\
\hline Nicotine & 0.42 & 1.40 \\
\hline
\end{tabular}

(3) Consistency of the butt production over the course of the experiments. The emitted masses from freshly smoked butts were measured for 6 sets of at least 12 cigarette butts by TD-GCMS. Figure 2.21 shows the average masses for the eight target chemicals, and the average temperature $(\mathrm{T})$ and relative humidity $(\mathrm{RH})$ in the fume hood where the cigarettes were burned. The detailed values are shown in Table B.1. These fresh butts were analyzed after they were stored in the vials for different times ranging from $0 \mathrm{~h}$ to $46 \mathrm{~h}$. 


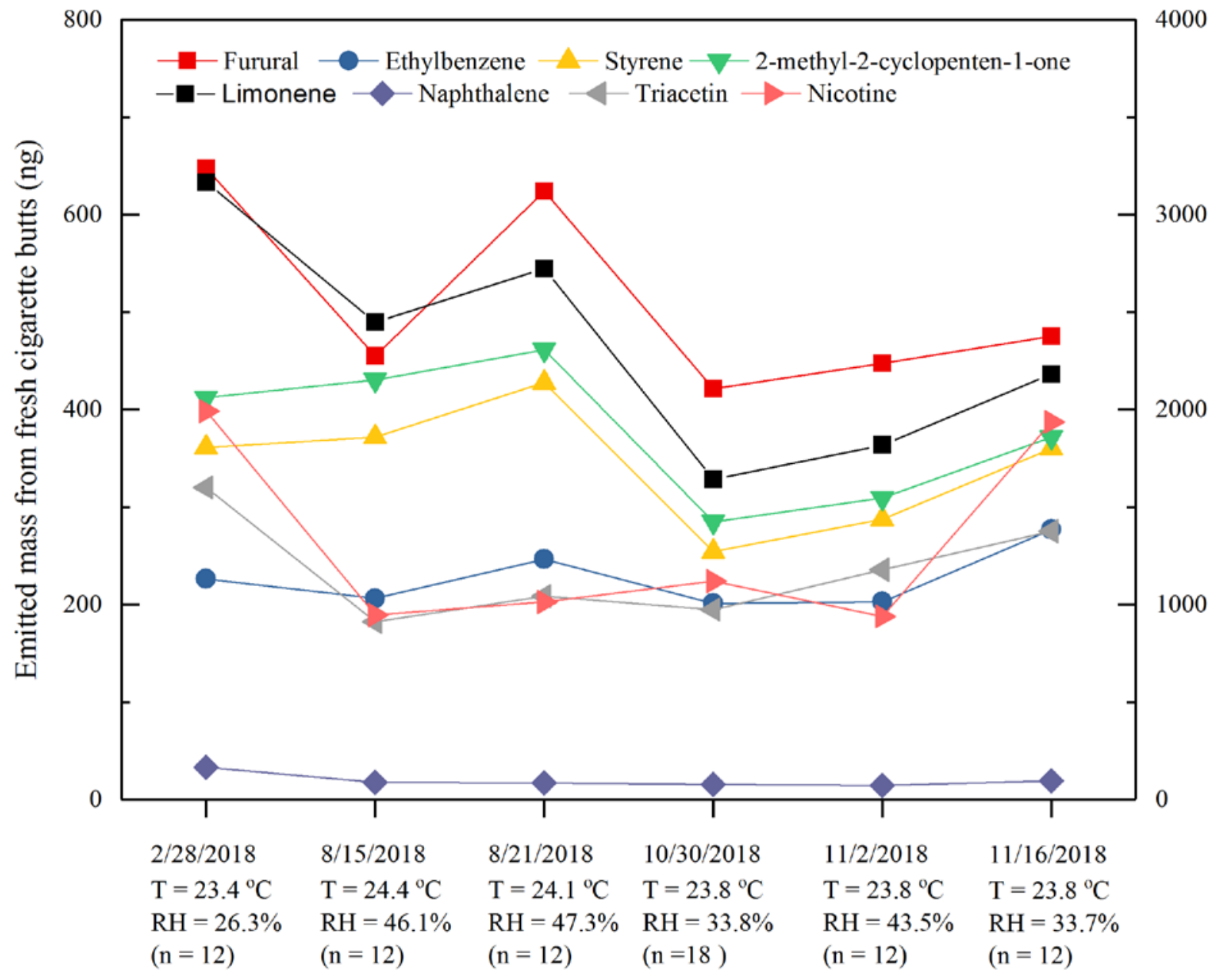

Figure 2.21: $\quad$ Measured emitted mass from fresh cigarette butts (ng). Right axis is for limonene. Left axis is for all other chemicals. T: temperature; $R H$ : relative humidity; $n$ : the number.

The relative standard deviations (RSDs) within each set of the data shown in Figure 2.21 are within $25 \%$, except ethylbenzene (28\%) and nicotine (27\%) in the set tested on 11/2/2018, while the RSDs between different sets are within $25 \%$ except naphthalene (33\%) and nicotine (34\%). Some of the variations between dates shown in Figure 2.21 may be due to the time between the butt being placed in the bottle and the analysis as discussed below.

(4) Loss of chemicals while the butts were in the $20 \mathrm{~mL}$ analysis vial waiting to be analyzed by the TD-GC-MS. The TD-GC-MS system could only analyze one vial at a time, with each run taking roughly $55 \mathrm{~min}$. For all conditioning experiments the average storage time of butts in the headspace vials between removal from a conditioning environment and the start of the TD-GC-MS run was $21.4 \mathrm{~h}$ (number of sets of cigarettes burned with data recorded $=497$, standard deviation $=11.6 \mathrm{~h}$ ). The frequency distribution of the time in the transport vials is shown in Figure 2.22. 


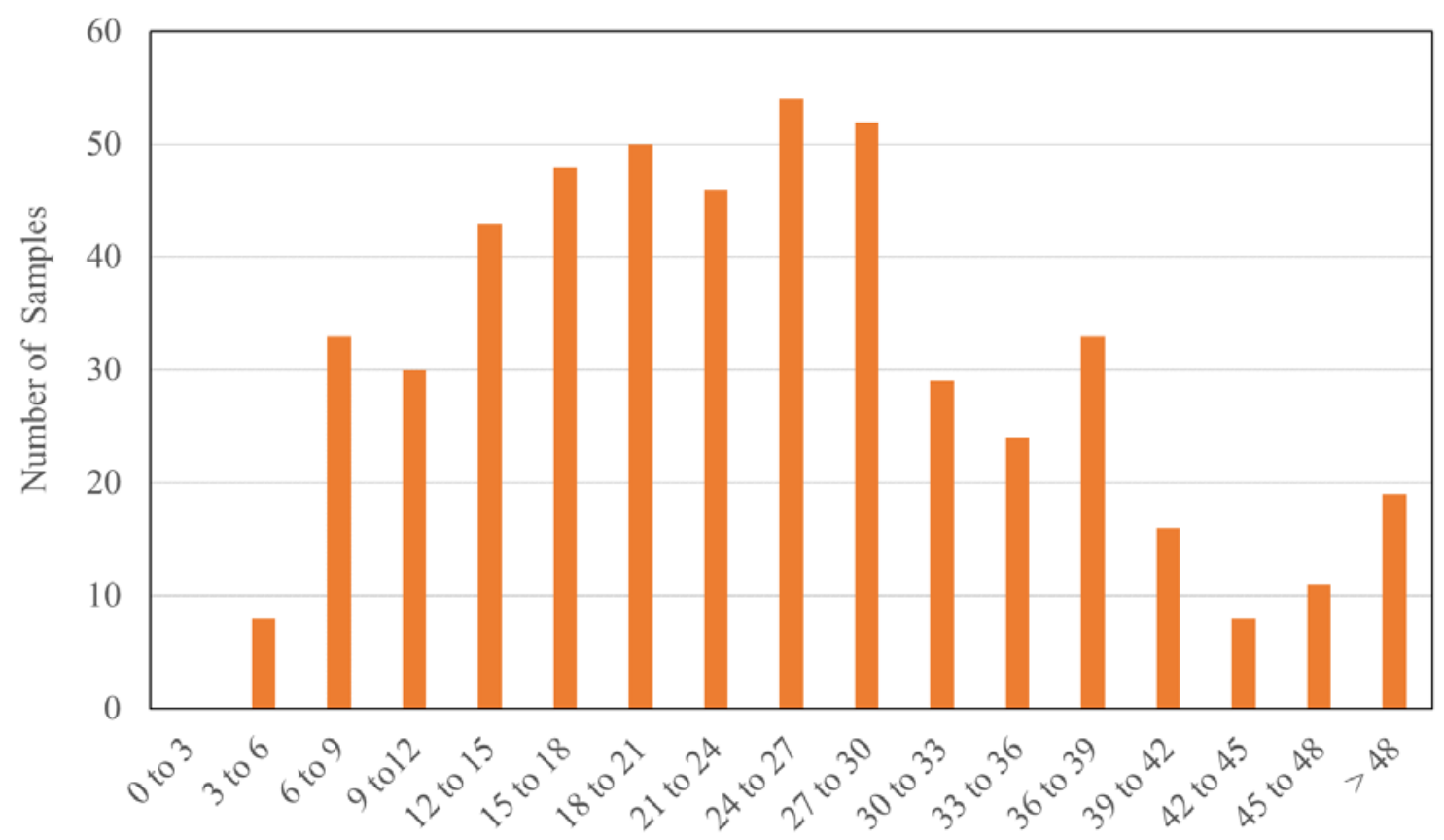

Time between removal from conditioning environment and TD-GC-MS analysis (h)

Figure 2.22: Distribution of the storage time of butts between removal from conditioning environment and TD-GC-MS analysis.

Figure 2.23 is an example of the measured emitted mass change with time for limonene and naphthalene; the remaining data can be found in Appendix A.3, Figure A.1 through Figure A.3. The data are normalized by the average concentration for each chemical for all samples measured between 8/15/2018 and 11/16/2018 (the time between generation and analysis was not recorded for the 2/28/2018 data). Overall, the emitted masses do not show a trend for triacetin and nicotine but do show a decay over the $46 \mathrm{~h}$ of sampling time for the other six target chemicals. 


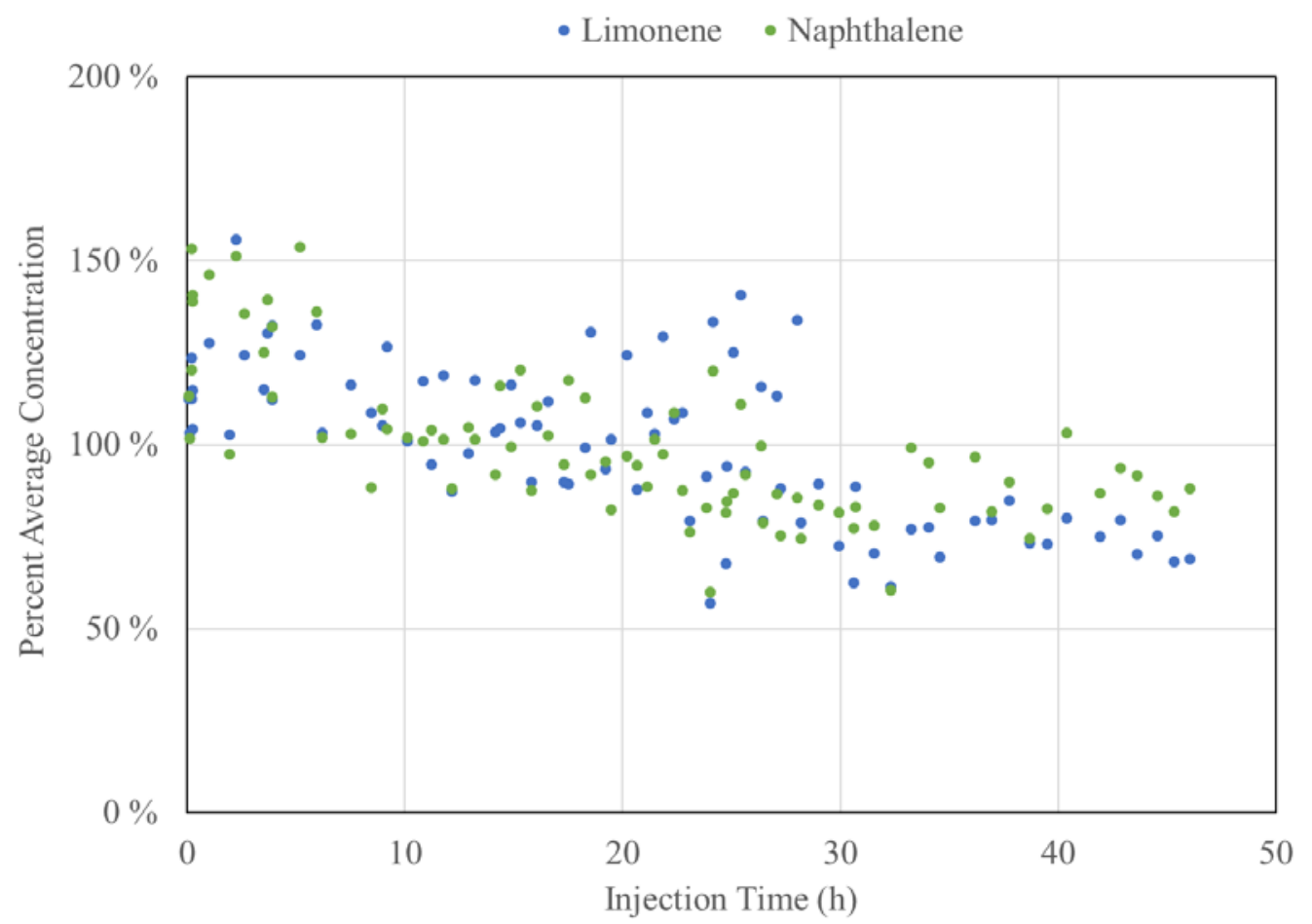

Figure 2.23: Percent of average initial concentration for Limonene and Naphthalene mass emitted during headspace analysis conducted $0 \mathrm{~h}$ to $46 \mathrm{~h}$ after butt generation.

Correcting for this decay is complicated as the 66 initial mass butts (from 8/15/2018 and $11 / 16 / 2018$ ) were smoked on five days over four months with varying relative humidity in the hood. However, most of the butts ( $\mathrm{n}=349$ out of 497) were analyzed during a period ranging from $5 \mathrm{~h}$ to $35 \mathrm{~h}$, and the mass analyzed during that period was relatively consistent, with relative standard deviation of less than $25 \%$ for those samples, except for triacetin (27 \%) and nicotine (41\%). Hence, no adjustment for the influence of the storage time on the sample mass was made in this report.

(5) Consistency of the chemical emissions from the butts before they were placed in the conditioning environments. As described in section 2.1.4, the masses of target chemicals in the cigarette butts can be influenced by various factors, including the condition of the cigarette prior to burning, smoking parameters, the conditions of the environment where the cigarettes were burned, weight and length of the cigarette butts, and the handling method used to transport the butt to the conditioning environment. Among these potential influential factors, the relative humidity of the fume hood where the cigarettes were burned, and the transportation time between extinguishing the cigarette butts and placing them into the conditioning environment were not controlled. The other factors were controlled as stated in Sections 2.1.4 and 2.1.5. Hence, six sets of data described in Table B.1 were analyzed to address the two uncontrolled factors.

a. Influence of relative humidity in the burning environment. The relative humidity in the fume hood impacts the burning conditions of the cigarettes. The average relative 
humidity in the fume hood during smoking was $38.8 \%(\mathrm{n}=738$, standard deviation $=$ $8.9 \%$ ). However, the relative humidity was not normally distributed (Figure 2.24) with most samples near $33 \% \mathrm{RH}$ or $45 \% \mathrm{RH}$. Almost half of the butts used for conditioning experiments were generated when relative humidity was between $42.5 \%$ and $50 \%$. Roughly one-third of the butts were generated when relative humidity was between $30 \%$ and $35 \%$.

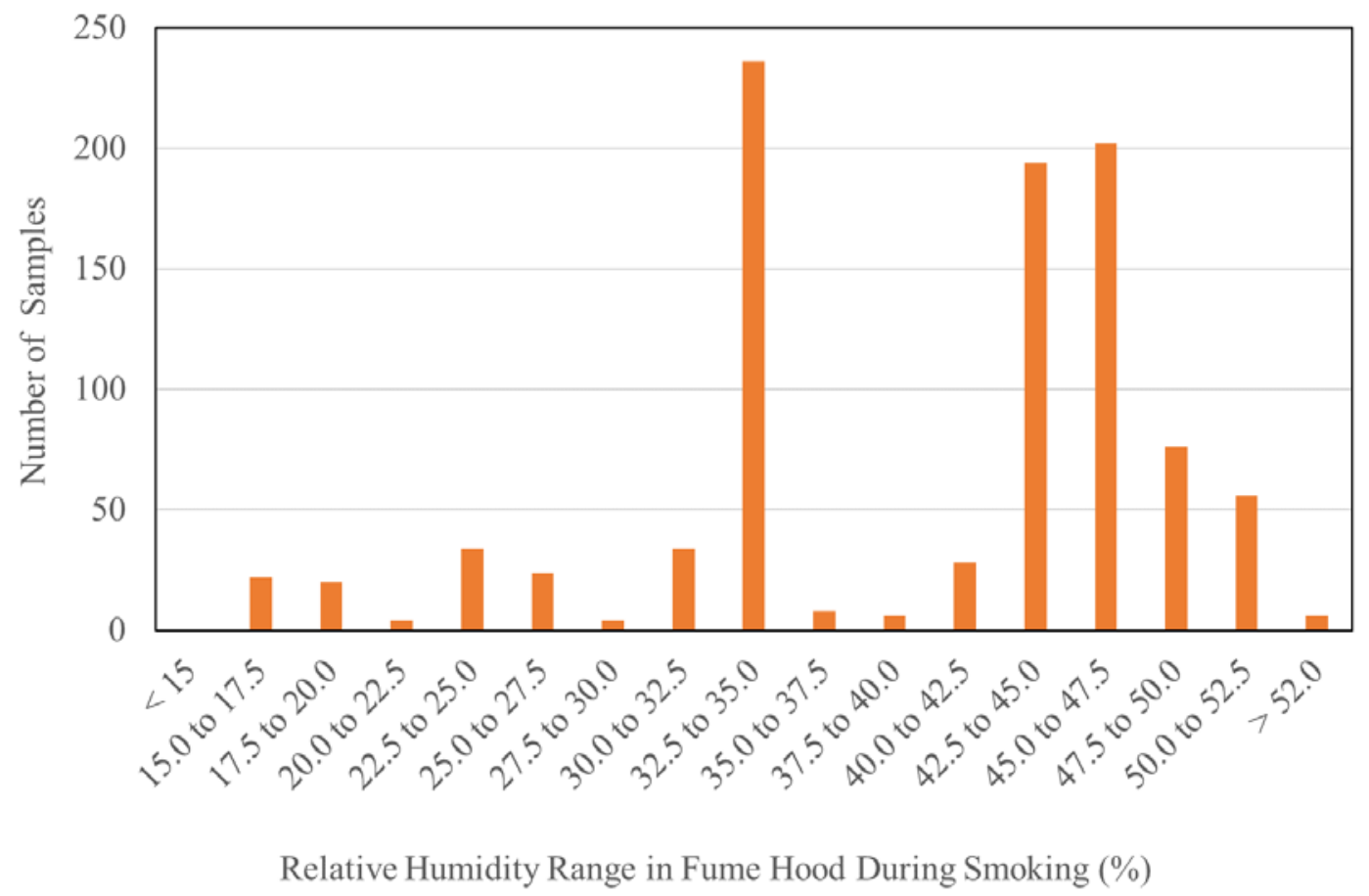

Figure 2.24 Distribution of the relative humidity (\%) in the fume hood during smoking.

Only average initial emitted mass for the six data sets shown in Figure 2.21 were used to examine the impact of the fume hood relative humidity on initial emitted mass of the eight target chemicals. Pearson correlation analysis shows that the emitted mass for nicotine is significantly linearly correlated with relative humidity (coefficient $=0.84, \mathrm{p}<0.05$ ), while the correlations between relative humidity and emitted mass for the other seven target chemicals are insignificant $(\mathrm{p}>0.05)$ based on both Pearson and Spearman correlation analysis. The linear regression for relative humidity and nicotine emitted mass is shown in Figure 2.25.

Other researchers have shown that nicotine partitions more to the particle phase relative to the gas phase at lower relative humidities (John et al. 2018). In this research, the larger fraction of nicotine in the ash phase at higher relative humidity may hinder the emission of nicotine into headspace during the headspace analysis, which would result in lower measured emitted mass for nicotine at higher relative humidity. 


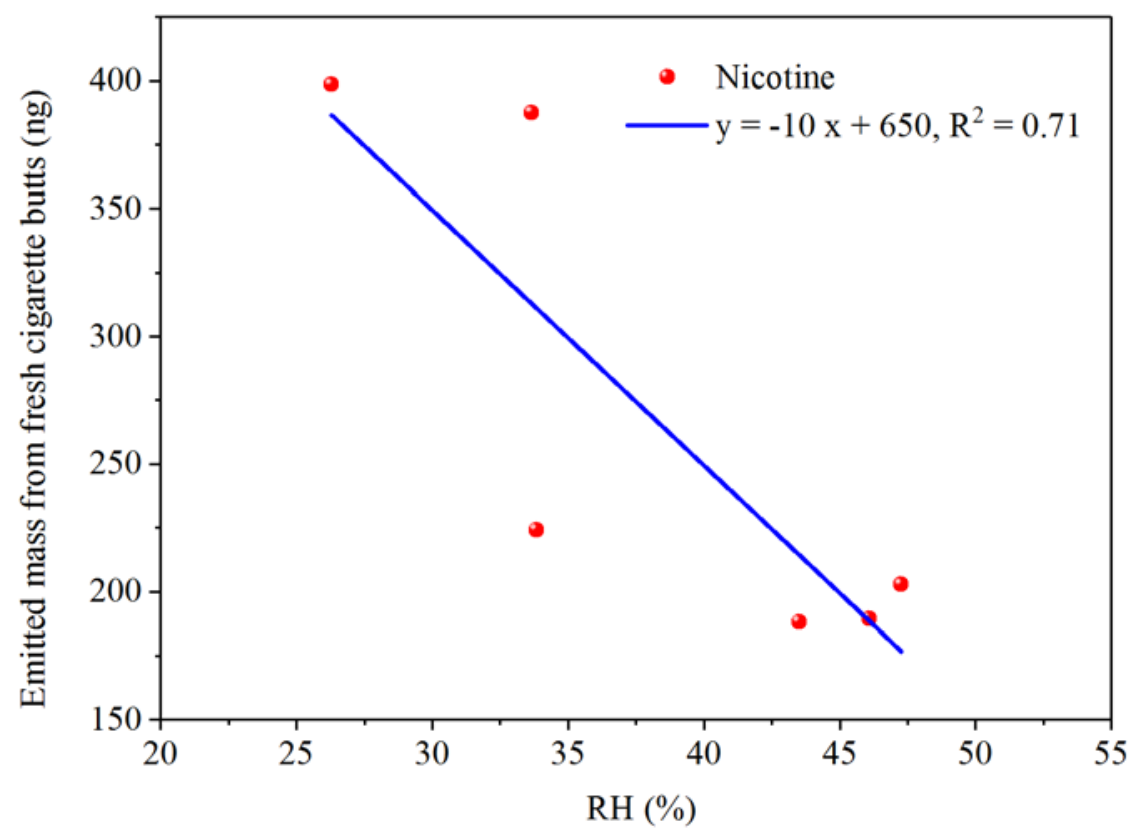

Figure 2.25 Correlation between emitted mass for nicotine and relative humidity in the burning environment.

The cause for the scatter in the data at 33\% RH in Figure 2.25 was not attributable to the conditioning time of the cigarettes prior to burning, the time between generation and analysis, or internal standard variations. Since it is unknown what caused the high variation of the nicotine initial masses at $33 \% \mathrm{RH}$ and because the data were limited (six data sets), the initial nicotine mass data was not adjusted for the measured relative humidity during burning. The other seven chemicals did not vary significantly with the fume hood relative humidity. Hence, for all eight target chemicals, the average values for each data set were used as the initial mass for data analysis in Section 3.1 and Section 3.2.

b. Influence of transportation time between extinguishing of cigarette butt and placement into the conditioning environment. Each cigarette butt was placed into a headspace vial immediately after removal from the sand. These vials were then used to transport the cigarette butts to the various conditioning environments. Due to the limitation of smoking two butts at a time and the conditioning environments requiring between 3 butts and 27 butts being placed in the environment at the same time, the amount of time that the butts were stored for in the $20 \mathrm{~mL}$ vials between smoking and placement in the conditioned environment varied. The average butt storage time in these transport vials for all experiments was $2.1 \mathrm{~h}$ (number of duplicate butts with data recorded $=518$, standard deviation $=1.6 \mathrm{~h}$ ). The frequency distribution of the time in the transport vials is shown in Figure 2.26. 


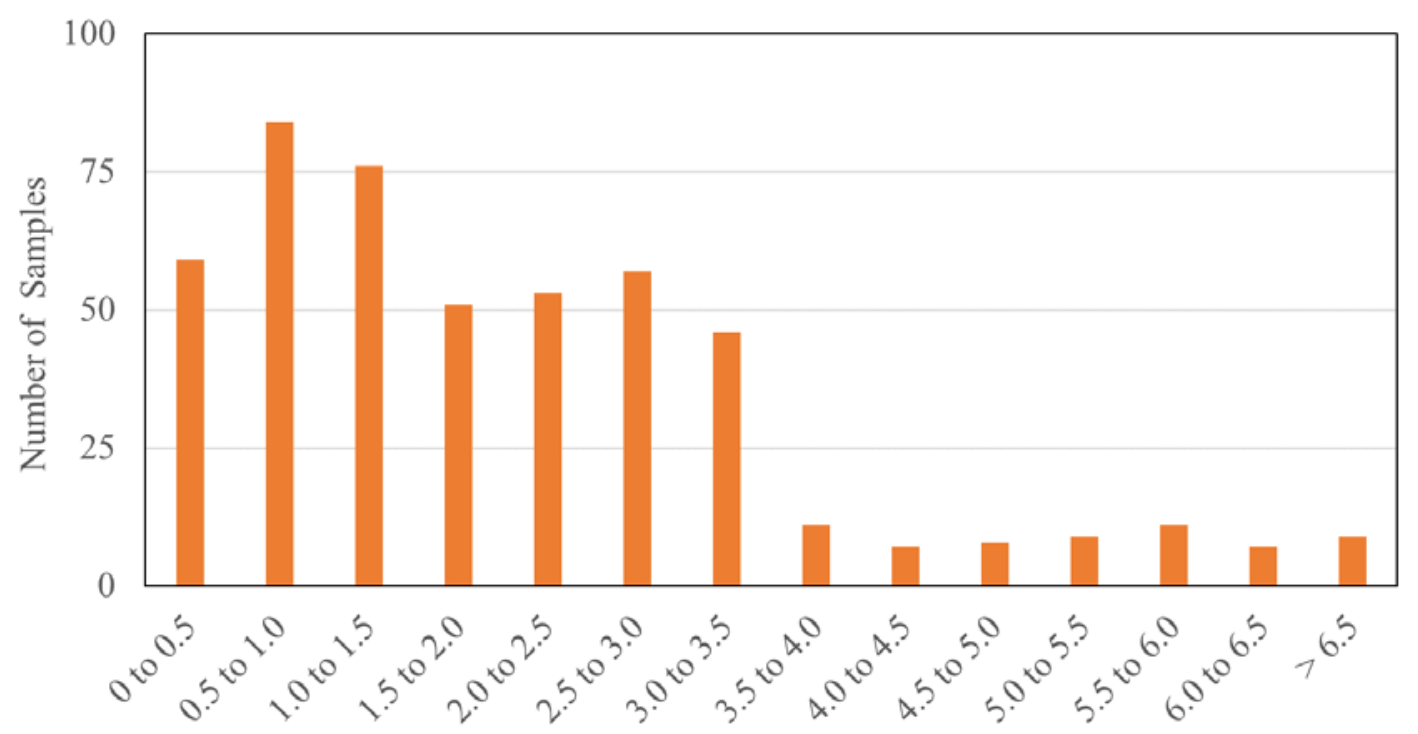

Time between smoking and placement in conditiong enviornment $(\mathrm{h})$

Figure 2.26 Distribution of the amount of time the butts were in the 20mL vials between extinguishing and placement in the conditioning environment.

Only data with a transportation time ranging from $0 \mathrm{~h}$ to $4 \mathrm{~h}$ were used, since more than $88 \%$ of the butts' storage times were in this range. The variation in the masses of chemicals emitted by the butts during headspace analysis (Section 2.4.5) were within $25 \%$, except for triacetin (39\%) and nicotine (32 \%) in the first $4 \mathrm{~h}$ of storage (Appendix A.3, Figure A.4 through Figure A.7). In addition, there was no significant correlation between the emitted mass and transportation time $(\mathrm{p}>0.05)$. This indicates placing the butts in the transport vials for less than $4 \mathrm{~h}$ prior to placing in the conditioning environment had minimal impact on the future emissions.

Overall, the relative humidity in the burning environment had moderate influence on the measured mass from cigarette butts for nicotine but not for other target chemicals, and the transportation time didn't influence the emitted mass within the first $4 \mathrm{~h}$. The consistency of the chemical emissions from the butts before they were placed in the conditioning environments was considered acceptable.

(6) Consistency of the conditioning environments. The temperature, flow, and relative humidity were recorded for the dark, UV and walk-in chambers. Data from an individual experiment was not used if the relative standard deviation of the temperature during the conditioning period was greater than $1 \%$, or the relative standard deviation of relative humidity and flow were greater than $5 \%$. Four experiments where three butts were placed in a chamber for a single defined sampling time ( $2 \mathrm{~h}$ to $144 \mathrm{~h}$ ) were repeated due to temperature variations. Eight experiments were repeated due to relative humidity variations. Seven experiments were repeated due to flow variations. 


\subsection{EMISSION TEST IN LARGE CHAMBER}

One experiment was conducted in a walk-in chamber to measure the emission rates for the target chemicals from cigarette butts in a simulated indoor environment. To determine emission rates in such an environment, the room air needs to be sampled, rather than using the headspace analysis done in the other tests. To avoid detection limit issues in the room air, 18 butts were placed in the walk-in chamber and a $24 \mathrm{~h}$ sampling event was conducted.

\subsubsection{Experimental setup}

Before emission testing, $3 \mathrm{~h}$ air samples were taken to measure the background concentrations in the chamber and inlet air. During the emission test, 18 freshly smoked cigarette butts were first placed on an aluminum-foil-lined, stainless-steel mesh basket (Figure 2.27) in the center of the chamber. The basket was hung in the center of the walk-in chamber to facilitate mixing of the emissions with the chamber air. In addition, moving the butts off the floor (as they were placed for the headspace experiments (Section 2.4.3)) avoided impacts of the concrete surface on the emissions and increased the distance to chamber surfaces to which contaminants might be adsorbed.
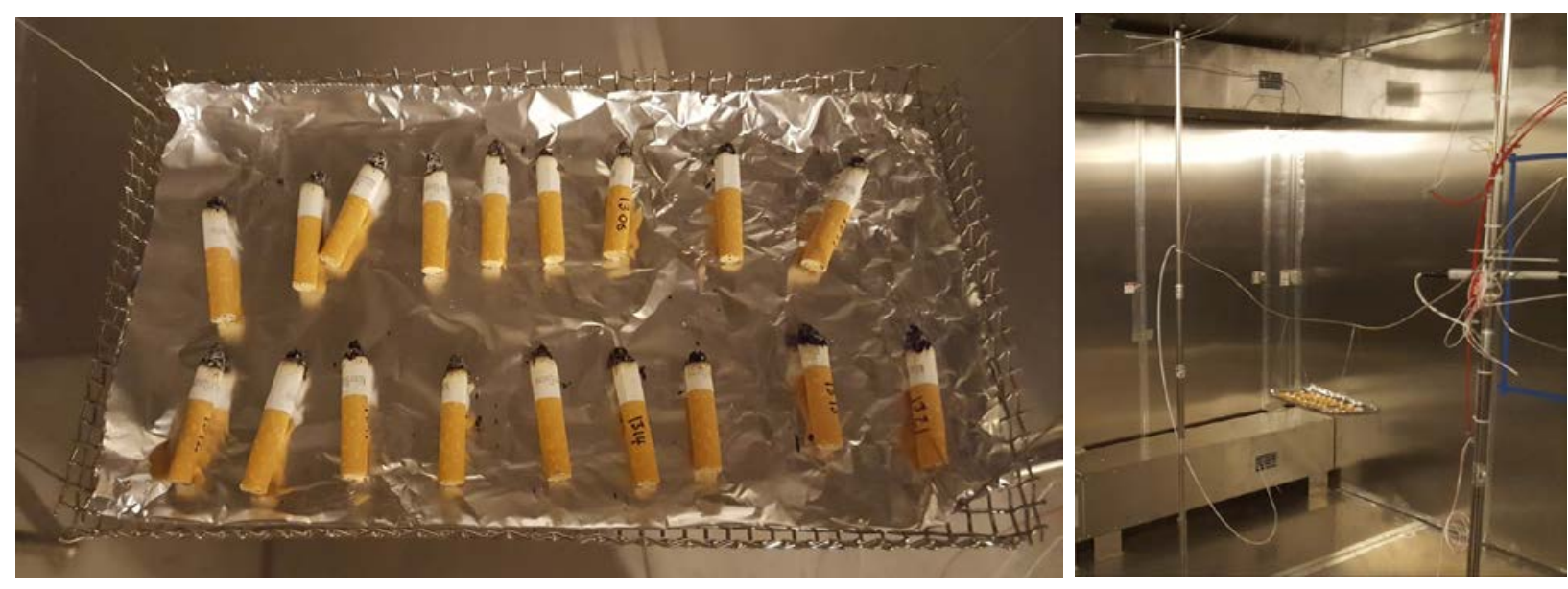

Figure 2.27:

Cigarette butts, aluminum-foil-lined, stainless-steel mesh basket (left). Location of basket in walk-in chamber (right).

The chamber was run at $25^{\circ} \mathrm{C}, 50 \% \mathrm{RH}$, with $16.7 \mathrm{~m}^{3} \mathrm{~h}^{-1}$ outdoor air supply (equivalent to an air change rate of $0.54 \mathrm{~h}^{-1}$ ) and $109.3 \mathrm{~m}^{3} \mathrm{~h}^{-1}$ of recirculated air (equivalent to $3.3 \mathrm{~h}^{-1}$ ). Appendix A.4 summarizes the measurements used to determine the airflow rates. Air samples were taken for $3 \mathrm{~h}$ at the supply inlet, return outlet, and the middle of the chamber (Figure 2.28) at $2 \mathrm{~h}, 5 \mathrm{~h}, 8 \mathrm{~h}, 11 \mathrm{~h}$, $15 \mathrm{~h}, 18 \mathrm{~h}, 21 \mathrm{~h}, 24 \mathrm{~h}$ and $27 \mathrm{~h}$ after the butts were placed in the chamber. A $2 \mathrm{~h}$ air sample was also taken at $0 \mathrm{~h}$ after they were placed. Flow rates through the sampling tubes were controlled with mass flow controllers at $100 \mathrm{~mL} \mathrm{~min}{ }^{-1}$ and confirmed with a calibrated bubble flow meter before and after sampling. All pumps and mass flow controllers were located outside the chamber. The chamber was entered in conjunction with each sampling event to change the sampling tubes. 


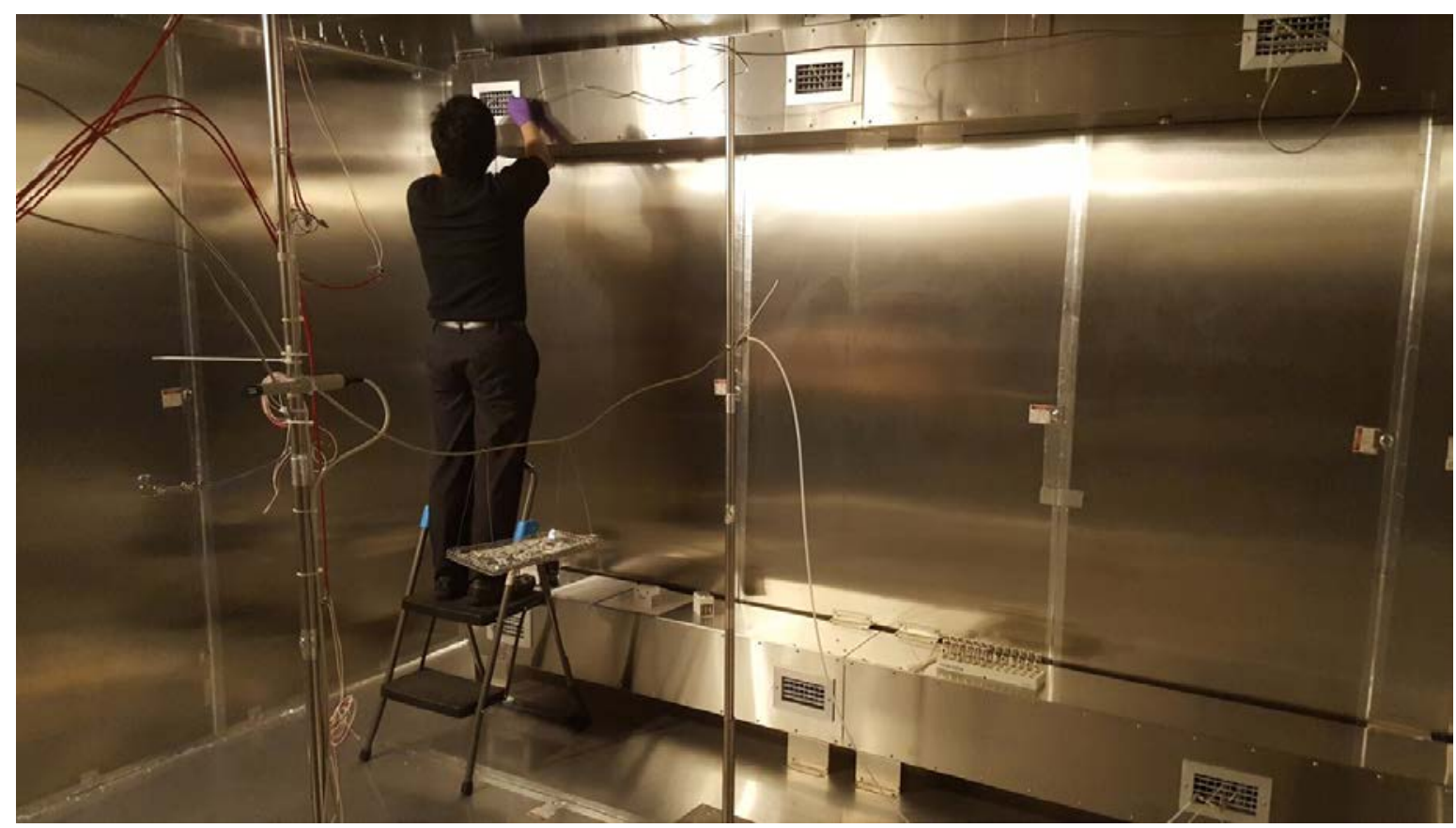

Figure 2.28: Changing the sorption tube sampling at one of the walk-in chamber inlets.

To examine the relation of the emitted mass measured by headspace analysis described in Section 2.4.5, and the emission rate measured in the walk-in chamber, cigarette butt samples were analyzed using headspace vials after conditioning the butts in the chamber by placing it in the same basket under the same condition as the emission rate experiment for 2 h, 5 h, 8 h, 11 h, 15 h, 18 h, 21 h, and $24 \mathrm{~h}$. Like the headspace analysis described in Section 2.4.3, each time point was a separate experiment applied to three conditioned cigarette butts.

\subsubsection{Air sample analysis}

The air samples were analyzed by TD-GC-MS. The TD-GC-MS running conditions were the same as the headspace analysis described in section 2.4.5, except that the headspace analysis used a CIS split ratio of 15:1 while the chamber air sample analysis was conducted in a splitless mode. Standards curves were made using the same method as described in described in section 2.4.5. A five-point standard curve was used, evenly spaced from $0.02 \mathrm{ng}$ to $0.4 \mathrm{ng}$ for naphthalene, $0.5 \mathrm{ng}$ to $50 \mathrm{ng}$ for limonene, and $0.2 \mathrm{ng}$ to $4 \mathrm{ng}$ for other target chemicals per injection. Blank thermal desorption sample tubes spiked with internal standards were run after each set of air samples.

\subsubsection{Quality assurance and quality control}

There were three quality assurance and quality control issues addressed during the chamber emission test analysis: 1) Reliability of the TD-GC-MS analysis, 2) Breakthrough of the target chemicals through the sorbent tube during the $3 \mathrm{~h}$ sampling, 3) Detection limit of the method.

(1) Reliability of TD-GC-MS analysis. During emission testing, analyses of the standard curves had linear $\mathrm{R}^{2}$ values larger than 0.98 . Blanks sorption tubes were run in every sequence to check if there was any contamination. No target chemicals were detected in any of the blanks. 
(2) Breakthrough of the target chemicals through the sorbent tube during the $\mathbf{3} \mathrm{h}$ sampling. Experiments were conducted to check if there was breakthrough during the air sampling. First, $1 \mu \mathrm{L}$ of standard ( $2 \mathrm{ng} / \mu \mathrm{L}$ for naphthalene, $50 \mathrm{ng} / \mu \mathrm{L}$ for limonene, and $20 \mathrm{ng} / \mu \mathrm{L}$ for the other six chemicals) were spiked onto a Tenax tube (roughly 50 to 100 times the instrument quantification limits in Table 2.7). Then, the spiked Tenax tube was connected to a clean Tenax tube as a backup tube and purged with $99.99 \%$ nitrogen for $3 \mathrm{~h}$ at the same flow rate used during air sampling, i.e., $100 \mathrm{~mL} \mathrm{~min}{ }^{-1}$. A total of four tube pairs were analyzed. The detailed breakthrough test data are shown in Table A.4 of Section A.5. The masses of most chemicals that were detected in the back-up tubes were less than $5 \%$ of the masses in the front tubes (Table 2.6), except the mass of furfural in one tube, ethylbenzene in one tube, and naphthalene in three tubes. However, the breakthrough mass in these cases was less than $10 \%$ of the masses in corresponding spiked front tubes. Except for furfural, the maximum masses of chemicals in the air samples from the emissions tests were two to ten times lower than the spiked masses in the breakthrough test. Hence, it is expected that the sampling breakthrough during emission testing would be less than that seen in the breakthrough test. Consequently, breakthrough of chemicals during air sampling for the emission tests was considered to be negligible.

Table 2.6: $\quad$ Ratio of backup Tenax tube to front Tenax tube. Values larger than 5\% are highlighted in bold.

\begin{tabular}{|c|c|c|c|c|c|c|c|c|}
\hline Sample & Furfural & Ethylbenzene & Styrene & $\begin{array}{c}\text { 2-methyl-2- } \\
\text { cyclopenten- } \\
\text { 1-one }\end{array}$ & Limonene & Naphthalene & Triacetin & Nicotine \\
\hline $\begin{array}{c}\text { Back-up 1/ } \\
\text { Front 1 }\end{array}$ & $2.9 \%$ & $2.6 \%$ & $0.0 \%$ & $0.0 \%$ & $0.0 \%$ & $\mathbf{6 . 2} \%$ & $2.0 \%$ & $1.9 \%$ \\
\hline $\begin{array}{c}\text { Back-up 2/ } \\
\text { Front 2 }\end{array}$ & $3.8 \%$ & $3.2 \%$ & $0.8 \%$ & $0.0 \%$ & $0.0 \%$ & $\mathbf{5 . 7} \%$ & $2.5 \%$ & $3.3 \%$ \\
\hline $\begin{array}{c}\text { Back-up 3/ } \\
\text { Front 3 }\end{array}$ & $4.5 \%$ & $3.7 \%$ & $1.6 \%$ & $0.0 \%$ & $0.0 \%$ & $\mathbf{5 . 4} \%$ & $0.0 \%$ & $1.5 \%$ \\
\hline $\begin{array}{c}\text { Back-up 4/ } \\
\text { Front 4 }\end{array}$ & $\mathbf{7 . 9} \%$ & $\mathbf{9 . 1} \%$ & $3.6 \%$ & $1.8 \%$ & $1.4 \%$ & $4.3 \%$ & $0.0 \%$ & $1.8 \%$ \\
\hline
\end{tabular}

(3) Detection limit of the method. The mass of target chemicals on sorbent tubes in emission test were typically lower than the mass on sorbent tubes in the headspace analyses. Hence, the sorbent tubes from the emission tests were analyzed in a splitless mode, while the headspace analysis used a 15:1 split ratio. This difference in the method required determination of a separate set of detection limits, which was done in the same manner as described in Section 2.4.6. The detection and quantification limits are shown in Table 2.7. 
Table 2.7: $\quad$ Instrument and method detection limits for air sample analysis in emission tests.

\begin{tabular}{|c|c|c|c|}
\hline & $\begin{array}{c}\text { Instrument } \\
\text { detection limit for } \\
\text { air sampling } \\
\text { analysis, ng }\end{array}$ & $\begin{array}{c}\text { Quantification limit } \\
\text { for air sample } \\
\text { analysis, ng }\end{array}$ & $\begin{array}{c}\text { Method quantification } \\
\text { limit for air sampling } \\
\text { analysis }{ }^{\mathrm{a}}, \mathrm{ng} \mathrm{m}^{-3}\end{array}$ \\
\hline Furfural & 0.12 & 0.39 & 21.4 \\
\hline Ethylbenzene & 0.05 & 0.15 & 8.4 \\
\hline Styrene & 0.07 & 0.24 & 13.2 \\
\hline $\begin{array}{c}\text { 2-methyl-2- } \\
\text { Cyclopenten-1-one }\end{array}$ & 0.06 & 0.20 & 11.3 \\
\hline Limonene & 0.14 & 0.45 & 25.2 \\
\hline Naphthalene & 0.02 & 0.06 & 3.5 \\
\hline Triacetin & 0.09 & 0.29 & 16.4 \\
\hline Nicotine & 0.07 & 0.23 & 13.0 \\
\hline
\end{tabular}

\subsubsection{Emission rates calculation}

Emission rates in the chamber were calculated based on a mass balance analysis that considers emissions, airflow into the chamber, and deposition to and emissions from the chamber walls (Van Loy et al. 1997):

$$
\begin{gathered}
V \frac{d C}{d t}=\dot{E}+Q C_{i n}-Q C-S \frac{d M}{d t} \\
\frac{d M}{d t}=v_{d} C^{n_{a}}-k_{d} M^{n_{d}}
\end{gathered}
$$

Where:

$V$ is the volume of the chamber, $31 \mathrm{~m}^{3}$;

$C$ is the chemical concentration in the chamber air, $\mathrm{ng} \mathrm{m}^{-3}$;

$\dot{E}$ is the chemical emission rate of the cigarette butts, $\mathrm{ng} \mathrm{h}^{-1}$;

$Q$ is the flow rate of supply air, $126 \mathrm{~m}^{3} \mathrm{~h}^{-1}$;

$C_{i n}$ is the chemical concentration in the supply air, $\mathrm{ng} \mathrm{m}^{-3}$;

$S$ is the surface area of the chamber walls, $\mathrm{m}^{2}$;

$M$ is the surface concentration on the chamber walls, $\mathrm{ng} \mathrm{m}^{-2}$;

$v_{d}$ is the deposition velocity, with units a function of the dimensionless constants, $n g^{1-n_{a}} m^{3 n_{a}-2} h^{-1}$

$k_{d}$ is the reemission rate constant, with units a function of the dimensionless constants, $n g^{1-n_{d}} m^{3 n_{d}-2} h^{-1}$

$n_{a}$ and $n_{d}$ are the dimensionless constants.

When used the deposition velocity $\left(v_{d}\right)$, reemission rate constant $\left(k_{d}\right)$ and dimensionless constants $\left(n_{a}\right.$ and $\left.n_{d}\right)$ were determined from literature values. 
In performing this mass balance analysis, the chemical concentration at the midpoint of the sampling period was set to be equal to the measured concentration during the $2 \mathrm{~h}$ or $3 \mathrm{~h}$ period. For more volatile chemicals, adsorption to the stainless-steel chamber walls can be ignored (Equation 2). For these chemicals, the emission rate at the midpoint between $t_{1}$ and $t_{2}$ can be calculated as follows:

$$
\dot{E}=V \frac{C_{2}-C_{1}}{t_{2}-t_{1}}+Q \frac{C_{1}+C_{2}}{2}-Q \frac{C_{i n, 1}+C_{i n, 2}}{2}
$$

where $C_{1}$ and $C_{2}$ are the concentrations in the chamber at two sequential sampling time periods; $C_{i n, 1}$ and $C_{i n, 2}$ are the concentrations at the inlet at two sequential sampling time periods; and, $t_{1}$ and $t_{2}$ are the mid points of the two sequential sampling time periods.

For less volatile chemicals, like nicotine, adsorption to the stainless-steel chamber walls may be important to the mass balance. For these chemicals, the adsorption mass at $t_{1}$ and $t_{2}$ can be calculated first by solving the following equation (derived from equation (2)):

$$
M_{2}-M_{1}=v_{d} \frac{C_{2}{ }^{n_{a}}+C_{1}{ }^{n} a}{2}\left(t_{2}-t_{1}\right)-k_{d} \frac{{M_{2}}^{{ }^{n}} d+M_{1}{ }^{n} d}{2}\left(t_{2}-t_{1}\right)
$$

where $M_{1}$ and $M_{2}$ are the masses of chemical adsorbed onto the chamber wall at two sequential time periods. The adsorption mass is assumed to be zero during the first sampling period.

Once the adsorption mass at $\mathrm{t}_{1}$ and $\mathrm{t}_{2}$ is calculated, the emission rate at the midpoint of $\mathrm{t}_{1}$ and $\mathrm{t}_{2}$ can be calculated as follows:

$$
\dot{E}=V \frac{C_{2}-C_{1}}{t_{2}-t_{1}}+Q \frac{C_{1}+C_{2}}{2}-Q \frac{C_{i n, 1}+C_{i n, 2}}{2}+S \frac{M_{2}-M_{1}}{t_{2}-t_{1}}
$$




\section{RESULTS AND DISCUSSION}

The objective of this research was to characterize the airborne emissions from non-smouldering cigarette butts. Specifically, this effort sought to 1) determine the initial distribution of the target chemicals emitted from cigarette butts, 2) determine the influence of environmental parameters (temperature, relative humidity, water saturation, UV, and air change rate) on airborne cigarette butt emissions, and 3) determine airborne emission rates for target chemicals from cigarette butts in a simulated indoor environment.

\subsection{ChEMICAL DISTRIBUTION IN CIGARETTE BUTTS}

The chemical masses emitted during headspace analysis were measured for six different types of samples (Table 1.1). Comparing the emitted masses (Figure 3.1) and the ratios of emitted masses (Table 3.1) from the different type of samples yields insights to the target chemical content in each part of the butt and the influence of emission surface area for each type of sample. In the discussion below, samples described as burned ash contain some unburned tobacco as shown in Table 1.1 and Figure 2.6.

Most of the target chemicals released from the butts were the result of the burning process. Chemicals in cigarette butts can be the original chemicals in the unburned cigarettes or the combustion, pyrolysis, and distillation products deposited in the cigarette butts during the smoking process. Collectively, the combustion, pyrolysis, and distillation phases are referred to as the burning process in this document. Depending on the burning conditions, the combustion temperature in a cigarette can reach up to $800{ }^{\circ} \mathrm{C}$ (Hertz et al. 2012). Different chemicals are produced at different temperatures and times during the burning process. Hydrocarbons (e.g., benzene, naphthalene) are formed by pyrolysis above $600^{\circ} \mathrm{C}$, while phenols are generated at $400{ }^{\circ} \mathrm{C}$. In contrast, nicotine is released by distillation at temperatures below $300^{\circ} \mathrm{C}$ (Baker 1987).

Six of the eight target chemicals (furfural, ethylbenzene, styrene, 2-methyl-2-Cyclopenten-1-one, limonene, naphthalene) were not detected in either the unburned filter or the unburned tobacco (Figure 3.1). The ratio between both unburned filter/burned filter and the unburned tobacco/burned ash is zero for these six chemicals (row 2 and row 3 of Table 3.1). The fact that these chemicals were only detected in samples after the burning process is consistent with previous work. Ohara et al. (2003) showed that limonene was present at levels below $143 \mathrm{ng}$ (g tobacco) ${ }^{-1}$ in tobacco that had been genetically engineered to produce limonene. In contrast, the emitted limonene in this study was at levels of 2,100 ng (g cigarette) $)^{-1}$ to 3,600 $\mathrm{ng}$ (g cigarette) ${ }^{-1}$ which is much higher than the levels that had been genetically engineered specifically to produce limonene, indicating it may be mainly generated during the burning process. Cardoso and Ataíde (2013) demonstrated that limonene and furfural are tobacco residue pyrolysis products. Torikai et al. (2004) showed pyrolysis formation of styrene in tobacco at temperatures above $400{ }^{\circ} \mathrm{C}$. The collected data and literature indicate that these six chemicals were not initially present in the cigarettes at measurable levels, and their presence is primarily be the result of the burning processes. 


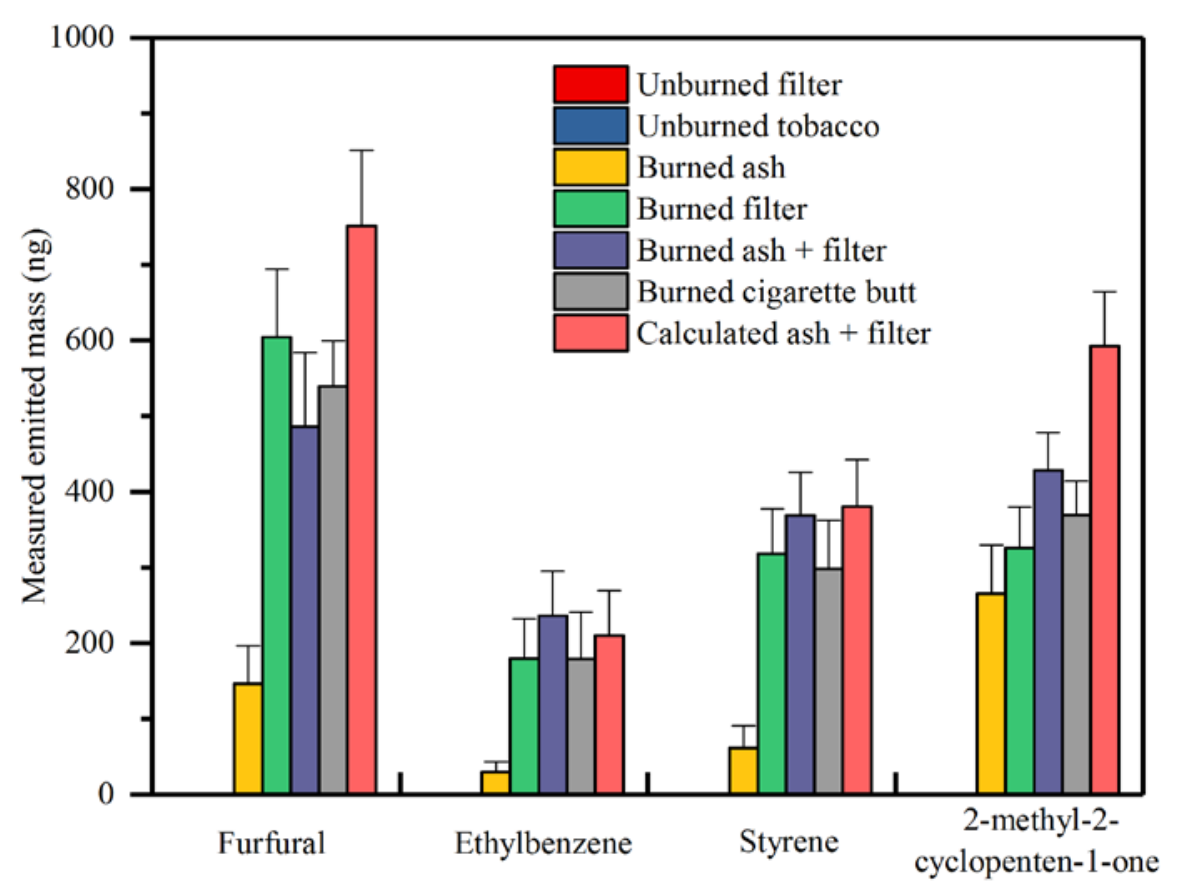

(a)

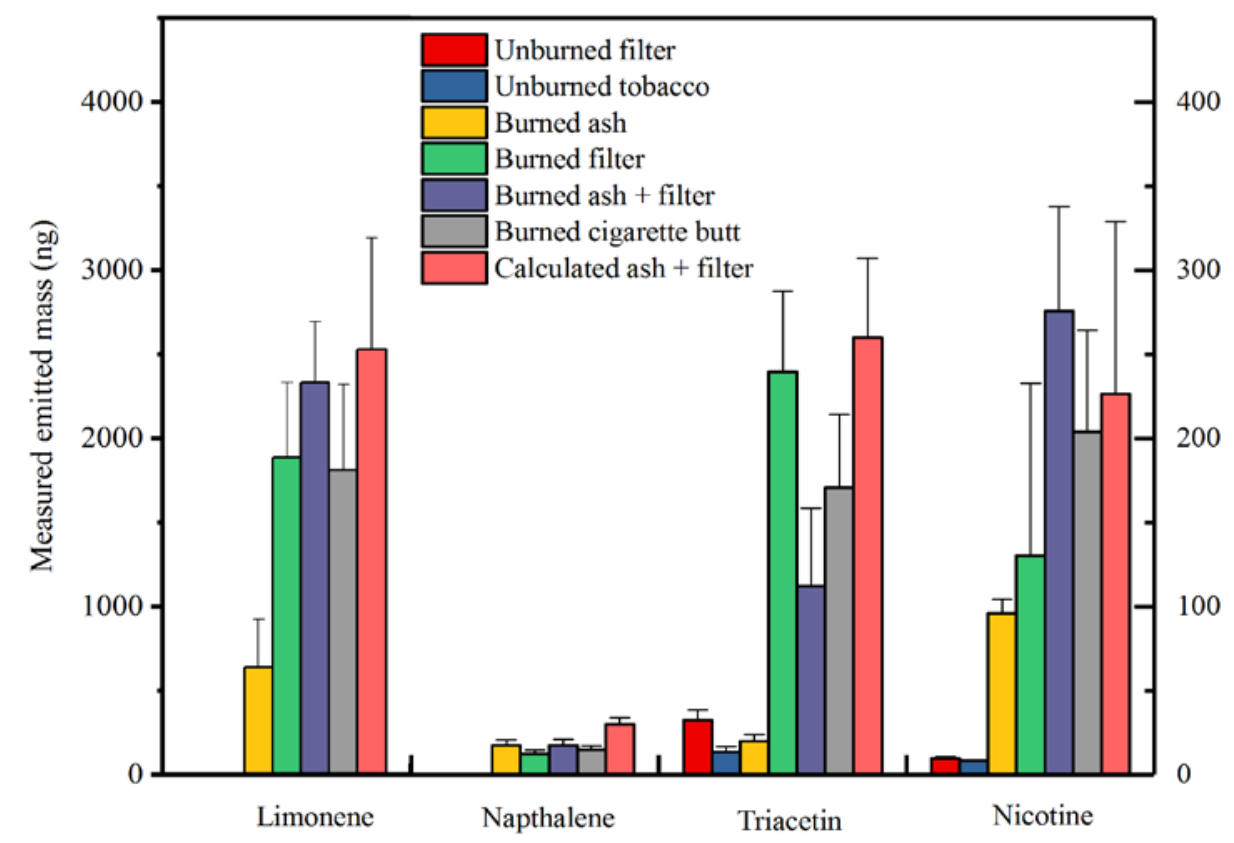

(b)

Figure 3.1: $\quad$ Measured emitted mass from six different types of samples. Calculated ash + filter equals the sum of emitted masses from burned ash and burned filter; In (b) left axis is for limonene, right axis is for naphthalene, triacetin, and nicotine. Error bars show one standard deviation. 
Table 3.1:

Ratios of measured emitted mass between different samples types. Each sample type was tested more than seven times and the average mass emitted was determined. Bold values signify significant differences between the average masses emitted used to calculate the ratios (Student's $t$ test, $p<0.05$ ).

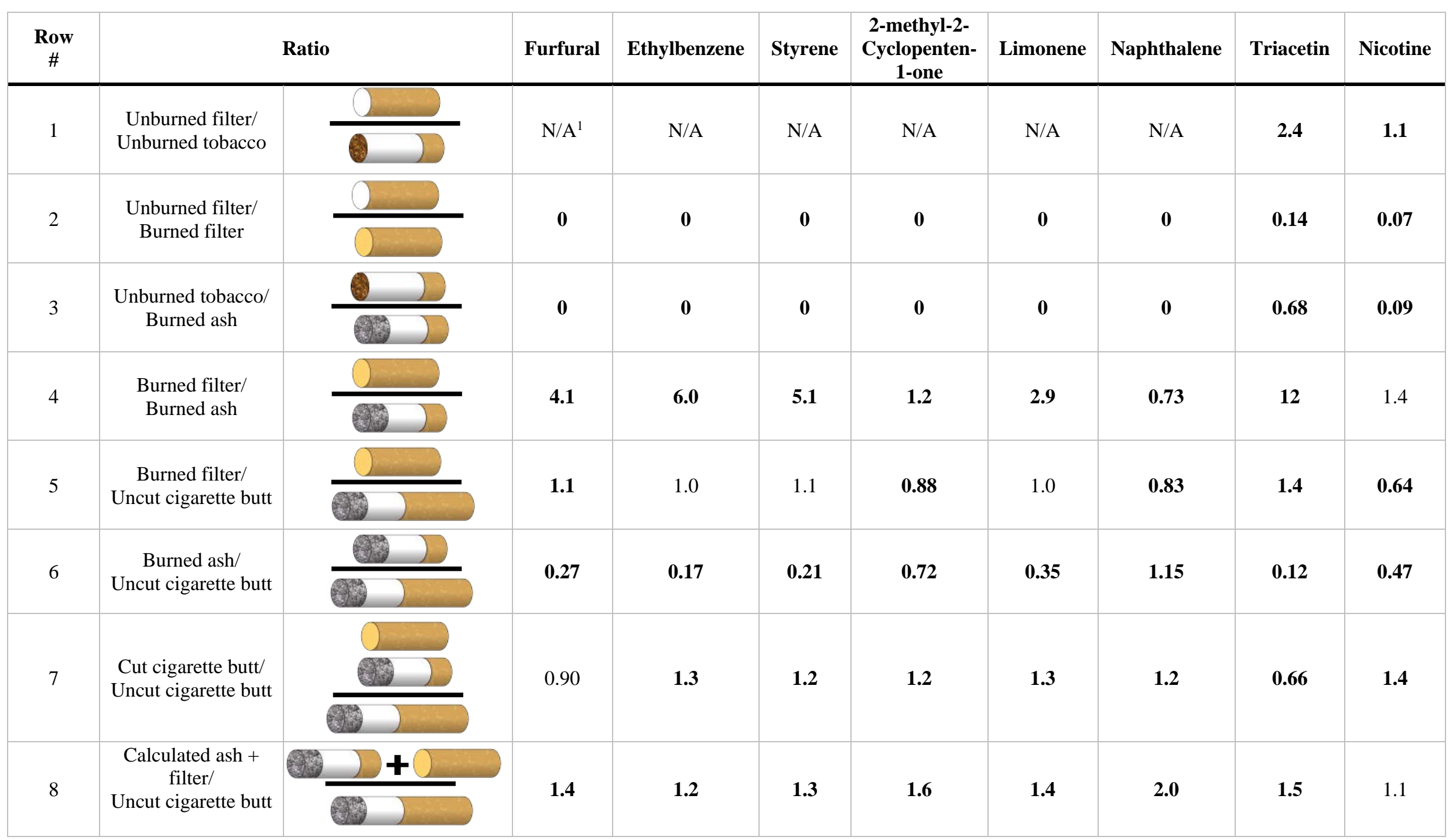

${ }^{1}$ N/A: Not applicable since the emitted mass of the chemical from unburned tobacco was below the quantification limit and thus the denominator was zero. 
The two exceptions to this trend of zero concentration in the unburned sample are triacetin and nicotine (Figure 3.1), both of which are normally components of unburned cigarettes and were measured in both the unburned filter and unburned tobacco (row 1 and 2 of Table 3.1). Triacetin has been shown to be used as plasticizer in filters (Clark et al. 2017). Hence, the fact that the unburned filter emitted 2.4 times more triacetin than the unburned tobacco with the same length is not unexpected. Nicotine is a natural component of unburned tobacco. Nicotine emitted from the unburned filter and unburned tobacco were roughly the same, with a mass ratio of 1.1, indicating that nicotine may have migrated from the tobacco to the filter after it was manufactured. It is possible that this migration also occurred during the conditioning of the cigarettes in the $50 \% \mathrm{RH}$ chamber prior to burning.

Burning increased the emitted masses for triacetin and nicotine. The average mass of triacetin emitted from the unburned filter was only $14 \%$ of the mass from the burned filter (row 2, Table 3.1), and the triacetin mass from unburned tobacco was $68 \%$ of its mass from burned ash (row 3). This indicates that the burning process enhanced triacetin emission from butts, perhaps because the competition for sorption sites from other smoke components produced during burning decreased the sorption sites for triacetin.

The fact that the average mass of nicotine emitted from the unburned filter and unburned tobacco samples was less than one tenth the mass from the respective burned filter and burned ash samples may be the result of the migration of nicotine from the tobacco to the filter during the burning process. Unlike triacetin, the unburned filter samples initially emitted a similar amount of nicotine as the unburned tobacco samples. During the burning process, nicotine migrates through the remaining butt via each puff and is partially adsorbed by the filter. This concentrating transport process may be why the burned filter samples emitted ten times more nicotine than the unburned filter samples (row 2, Table 3.1). Another hypothesis is that the burning process enhances nicotine emission from the burned ash and burned filter due to competitive sorption.

Most of the target chemicals were primarily emitted from the burned filter. For all target chemicals other than naphthalene, the emitted masses from the burned filter samples ranged from 1.2 to 6.0 times the emitted masses from the burned ash samples (row 4, Table 3.1), which indicates that most of these chemicals are adsorbed onto the burned filter, not the burned ash. For furfural, ethylbenzene, styrene and limonene, the emitted masses from the burned filter samples ranged from 1.0 to 1.1 times the emitted masses from the entire butt (row 5, Table 3.1). For the same chemicals, the emitted mass from the burned ash samples ranged from 0.17 to 0.35 times the mass emitted from the entire butt (row 6). Together, for these four chemicals, these results indicate that most of the emitted target chemicals were likely from the burned filter.

The ratio of emitted mass from the burned filter and the burned ash for nicotine was 1.4 (row 4, Table 3.1), indicating that the burned filter was a larger source (roughly $40 \%$ ) of nicotine for airborne emissions from cigarette butts than the ash. However, this increase was not statistically significant (Student's t test, $\mathrm{p}>0.05$ ). The ratio of the nicotine mass emitted from the burned filter to entire cigarette butts was 0.64 (row 5 , Table 3.1). The ratio of the nicotine mass emitted from the burned ash to the mass from entire cigarette butts was 0.47 (row 6, Table 3.1). Together, these 
two results indicate that the emission of nicotine from the burned filter may be slightly higher than the emissions from the burned ash. This could be the result of concentrating nicotine on the filter during each puff or the potentially greater affinity of the nicotine to the ash and unburned tobacco compared to the filter under the headspace analysis conditions.

For triacetin, the emitted mass from the burned filter was 12 times higher (row 4, Table 3.1) than the mass from the burned ash. In addition, ratio of triacetin mass emitted from the burned ash to the mass from entire cigarette butts was 0.12 . Together, these two results demonstrate that the filter is the primary emission source for triacetin and reflects the much higher initial content of triacetin in the filter. The ratio of triacetin mass emitted from the burned filter to the mass from entire cigarette butts was 1.4 (row 5, Table 3.1). The fact that this ratio is greater than one indicates that exposing more surface area of the filter by cutting the butt impacted the triacetin emissions. The impact of cutting the butts is discussed more below.

Both 2-methyl-2-cyclopenten-1-one and naphthalene emitted more evenly from different parts of the butt than the other chemicals. Roughly $20 \%$ more of 2-methyl-2-cyclopenten-1-one was emitted from the burned filter compared to the burned ash (ratio of 1.2, row 5, Table 3.1). In addition, both the ratio of mass from burned filters to mass emitted from entire cigarette butts, and the ratio of burned ash to entire cigarette butts ( 0.88 and 0.72 respectively) were closer to 0.5 than the other chemicals. This ratio would be 0.5 if the chemical distribution was perfectly uniform in the butt. The fact the ratios for these two chemicals are not 0.5 may be a function of cutting the butts as discussed below.

Naphthalene was the only chemical where there was less mass emitted from the burned filter compared to the burned ash (ratio of 0.83 , row 5 , Table 3.1). This may be a result of the affinity of non-polar naphthalene to the burned ash as compared to the burned filter. The ratio of naphthalene mass emitted from the burned ash to the mass from entire cigarette butts was 1.15. The fact that this ratio is greater than one indicates that exposing more surface area of the ash by cutting may have increased the naphthalene emission.

Cutting butts enhanced the emissions for most chemicals. Row 7 in Table 3.1 compares two sets of cigarette butts each analyzed in one headspace vial, one cut in half and one uncut (Figure 2.6). Row 8 in Table 3.1 compares two sets of analysis: in the numerator, the cut components were analyzed in two different headspace vials, and in the denominator, the uncut butts were analyzed in one vial. These comparisons provide insights on the impact of cutting butts on the emissions of target chemicals. Cutting the butts increased the exposed emission surface area for the burned filter and burned ash. In addition, compared to analysing the entire cigarette butt in one vial, placing the cut component in separate vials also increased the total air volume in the headspace, which could allow more chemicals to be emitted into the headspace air when reaching equilibrium with the sample in the vial. The influence of cutting the butts on the emitted mass of the target chemicals was a combination of the change of the exposed emission surface area and the air volume in the headspace vial. 
For ethylbenzene, styrene and limonene, the ratios for comparing the cut and uncut butts in different headspace vials ranged between 1.2 and 1.4 (Rows 7 and 8 in Table 3.1). The difference between analysing the cut components within one vial and two separated vials was minimal for these three chemicals, as the ratios in row 7 and row 8 differed only by 0.1 for each chemical. Combining these observations indicates cutting the butts enhanced emissions for these three chemicals. This may be due to the extra surface area resulting from the cut and not the extra volume in the headspace vials.

For 2-methyl-2-cyclopenten-1-one and naphthalene, the ratio between the mass from the cut components in a single headspace vial and the mass from the uncut butts was 1.2 (row 7, Table 3.1). In addition, the ratios of the mass from the cut components in two headspace vials to the mass from uncut butts increased from 1.2 to 1.6 (2-methyl-2-cyclopenten-1-one) and 2.0 (naphthalene). These data indicate that emissions of these chemicals may be enhanced because (a) of the extra surface area resulting from the cut and/or (b) the emission of these chemicals from an entire butt into the headspace might be limited by the vial volume. For the samples placed in two separate vials (row 8), the volume of the headspace air was larger than the volume of the headspace air for samples where both components were placed in one vial (row 7). This difference could allow more chemicals to be emitted into the headspace air when reaching equilibrium with the sample in the vial, resulting in the higher ratios shown in row 8 (Table 3.1).

For nicotine, the ratio between the mass from cut butts in a single headspace vial and the mass from the uncut butts was 1.4 (row 7, Table 3.1). However, when the cut components were placed in two headspace vials, the ratio decreased to 1.1, which was not statistically significant (Student $\mathrm{t}$ test, $\mathrm{p}>0.05$ ). This lower ratio maybe a function of noise in the data as the relative standard deviations of the masses from the burned ash and burned filters that were used to calculate the ratio are $30 \%$ and $45 \%$ respectively. Regardless, it still appears there is some nicotine emission enhancement due to cutting.

Lower masses of furfural and triacetin were emitted when comparing the cut components in a single headspace vial with the uncut butt ( 0.90 and 0.66 respectively). The difference was not significant for furfural, but it was for triacetin. It is not clear why the triacetin values were lower. For three of the seven samples with the burned ash and filter in a single bottle, the average mass emitted was $63 \mathrm{ng}$ (6\% relative standard deviation), while the average for the other four samples was $148 \mathrm{ng}$ (7\% relative standard deviation). This discrepancy could indicate some unknown measurement issues for the triacetin mass for these samples. In contrast, when the cut components were placed into two separate vials, the ratios for furfural and triacetin were 1.4 and 1.5 respectively (row 8 , Table 3.1), which indicates that there may be emission enhancement for furfural and triacetin because (a) of the extra surface area resulting from the cut, and/or (b) the emission of these chemicals from an entire butt into the headspace might be limited by the vial volume. 


\subsection{MEASURED MASS EMITTED FROM CONDITIONED CIGARETTE BUTTS}

Cigarette butts are discarded in a wide range of environments, both indoors and outdoors. The chemical masses emitted from cigarette butts conditioned in controlled environments were measured using headspace analysis. The influence of five different parameters on the emitted masses was examined, including temperature, relative humidity, water saturation, UV, and air change rate. The emitted masses were also measured after the cigarette butts were conditioned on a roof exposed to outdoor weather (uncontrolled environment) in both summer and winter.

\subsubsection{Data analysis}

The mass of target chemicals emitted in the vial headspace decreased rapidly in the first $24 \mathrm{~h}$ of exposure to a conditioned environment, as Figure 3.2 illustrates for limonene using typical data. SC in the figures in this section (3.2) refers to data collected in small chambers (either dark or UV). The LC label in the figures in this section (3.2) refers to data collected in the large walk-in chamber.

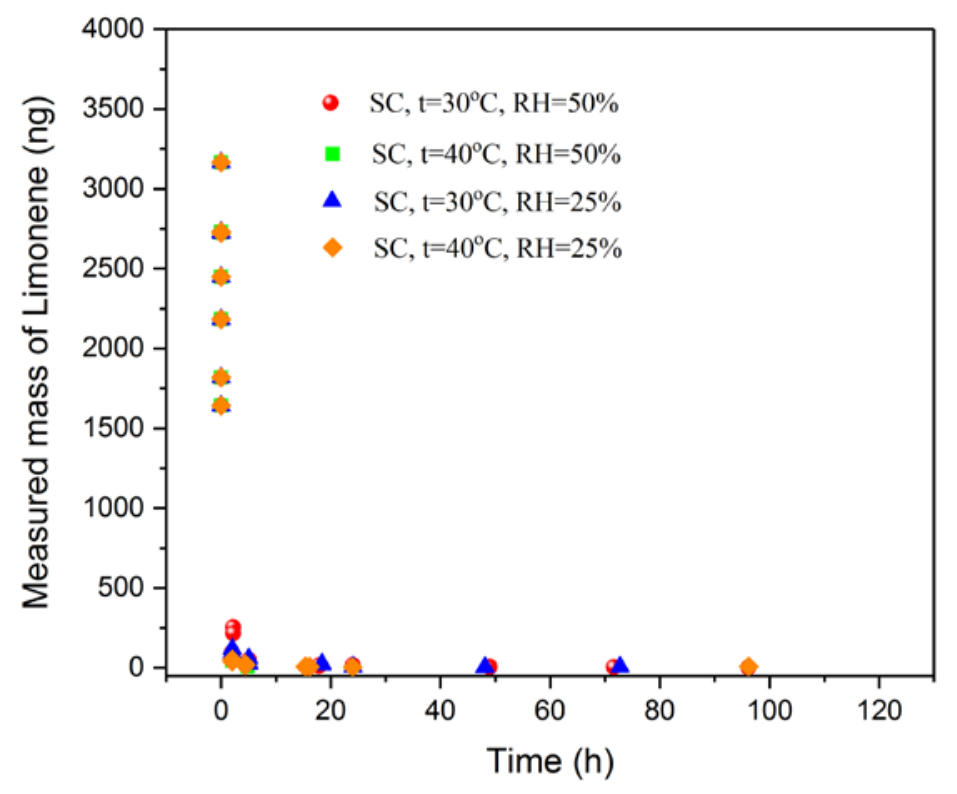

Figure 3.2: $\quad$ Example of measured emitted mass from each cigarette butt conditioned in UV chambers at different temperature (T) and relative humidity $(\mathrm{RH})$.

To mathematically characterize the emission of each chemical, an empirical two-stage emission model was used to fit the measured mass as below:

$$
M=M_{0}\left(F \cdot e^{-k_{1} t}+(1-F) \cdot e^{-k_{2} t}\right)
$$

In this model, the decay of measured mass $(M)$ is partitioned into two components: a fast emitting fraction $(F)$ that emits at a rate of $k_{1}$, and a slow emitting fraction $(1-F)$ that emits at a rate of $k_{2}$ (Hawthorne et al. 2001). $M_{0}$ is the initial measured mass emitted before conditioning. Although empirical, the two-stage model has some physical basis given the composition of the butts. As 
shown in Section 3.1, the target chemicals are distributed in the butts between the filter and the ash/unburned tobacco. The chemical emission rate from each component of a butt may be different for each chemical. Hence, conceptually a two-stage model is a reasonable approach to characterize the emission of the target chemicals from these two portions of the butt.

Other than fitting the data examining the influence of water saturation in section 3.2.2.3, the average values of measured initial masses shown in Table B. 1 were used as $M_{0}$. During the fitting, $M o$ was fixed so that the three fitting parameters were $F, k_{1}$, and $k_{2}$. Boundaries were set for the parameters with $0 \leq F \leq 1, k_{1} \geq 0$, and $k_{2} \geq 0$. The non-linear model in equation (6) was fitted using the Levenberg Marquardt method in OriginPro (2017). The $\mathrm{R}^{2}$ values of the curve fits averaged 0.89 with a range of 0.62 to 1.0 (Appendix B.2, Table B.2 through Table B.6).

The butt samples were tested using headspace analysis after they were conditioned for one of nine durations ( 2 h, 5 h, 18 h, 24 h, 48 h, 72 h, 96 h, 120 h and 144 h). For each designated time, if there are no data points for the chemical in a figure in Section 3.2, it means that the emitted mass for the chemical was below the quantification limit. Under some conditions, e.g. the ethylbenzene mass from cigarette butts conditioned at $30{ }^{\circ} \mathrm{C}$ and $50 \% \mathrm{RH}$, the number of time points that have masses higher than the quantification limit were fewer than three. Curve fitting was not conducted when the number of time points was fewer than three. In addition, in some cases the curve fits resulted in a $k_{2}$ value of zero, which makes the last term of equation (6) a constant.

As discussed in Section 2.4.2, due to the physical decay of the ash portion when saturated, only filters were placed in the chambers when investigating water saturation. Given that the filter is a relatively uniform media, the physical reason for using a two-stage model was no longer valid. Hence, a simple exponential decay model was used when curve fitting to examine the influence of water saturation used a simple exponential decay model:

$$
M=M_{0} \cdot e^{-k t}
$$

During the fitting, $M_{0}$ was fixed as the average value of the measured masses from the saturated unconditioned filters (Table B.4) so that the only fitting parameter was $k$ (rate constant). The boundary set for the parameter $k$ was $k \geq 0$. The non-linear model in equation (7) was also fitted using the Levenberg Marquardt method in OriginPro (2017).

The curve fitting to Equation 6 resulted in three parameters that did not consistently reveal trends in the data (Appendix B.2) for the varying exposure conditions. This may be due to the scatter in the data or that the two-stage non-linear model is over-parameterized for the data collected. Regardless, the curve fits do allow comparison of the impacts of the binary levels (e.g., $30{ }^{\circ} \mathrm{C}$ and $40^{\circ} \mathrm{C}$ ) that were tested for each conditioned environment. For six of the target chemicals (furfural, ethylbenzene, styrene, 2-methyl-2-cyclopenten-1-one, limonene, naphthalene), the curve fits were used to determine the amount of exposure time in the conditioned environment required for the mass emitted into the headspace vial to be $5 \%$ of the initial emitted mass. This was defined as the decay time. Triacetin and nicotine did not always reach $5 \%$ of the initial mass within the experimental period, so a $25 \%$ decay time was used for these two chemicals. A longer decay time indicates a smaller emission rate in the conditioned environment. These decay times were compared for the upper and lower levels of the experimental conditions. Using a single parameter 
decay time allows for more direct comparisons of data sets than the three-parameter values in the fitted curve.

\subsubsection{Conditioning in SPHERE Chambers}

To study the influence of UV, temperature, relative humidity and water saturation on airborne cigarette butt emissions, cigarette butts were placed in two different types of SPHERE chambers (i.e. dark chambers and a UV chamber). The dark chambers were used to examine the influence of temperature, relative humidity and water saturation on cigarette butt emissions. The UV chamber was used to investigate the influence of enhanced UV.

\subsubsection{Influence of UV}

Cigarette butts were conditioned with UV exposure of $144 \mathrm{~W} \mathrm{~m}^{-2}$ (wavelength from $295 \mathrm{~nm}$ to $400 \mathrm{~nm}$ ) and without $\mathrm{UV}$ at an air temperature of $30^{\circ} \mathrm{C}$ and a relative humidity of $50 \%$. However, when conditioning the butts at $30^{\circ} \mathrm{C}$ with UV on, the butt temperatures $\left(37^{\circ} \mathrm{C}\right)$ were higher than the temperature in the chamber air $\left(30^{\circ} \mathrm{C}\right)$ due to the UV exposure. Hence, another set of experiments was conducted at a temperature of $37^{\circ} \mathrm{C}$ and relative humidity of $50 \%$ when the UV was off. The measured masses for the eight target chemicals from cigarette butts conditioned in the SPHERE UV chamber (UV on at $30^{\circ} \mathrm{C}$, UV off at $30^{\circ} \mathrm{C}$, and $\mathrm{UV}$ off at $37^{\circ} \mathrm{C}$ ) and their curve fits are shown in Figure 3.3 (a) through (h). The relative standard deviations (RSDs) of each triplicate data are within $30 \%$ for $87 \%$ of time points in Figure 3.3, while the RSDs for data at the other $13 \%$ range from $30 \%$ to $47 \%$.

By $48 \mathrm{~h}$ the emitted masses decayed to less than $5 \%$ of the initial emitted masses in the conditioned environments for all chemicals except triacetin and nicotine. In contrast, the emitted masses of nicotine and triacetin decayed slower, with the measured mass at $48 \mathrm{~h}$ being $24 \%$ to $44 \%$ of the initial mass. The $\mathrm{R}^{2}$ values of the curve fits are higher than 0.89 for furfural, ethylbenzene, styrene, 2-cyclopenten-1-one, 2-methyl and limonene. However, the curve fit $\mathrm{R}^{2}$ values for the other three chemicals, i.e. naphthalene, triacetin, and nicotine, are all lower, ranging from 0.69 to 0.84 . The RSDs of each triplicate data set at a given sampling time for these three chemicals are similar to the RSDs for the other five chemicals. But the data for these three chemicals tend to have more scatter, e.g., the emitted masses can be higher than the emitted mass at an earlier time point. For example, the mass of triacetin emitted at $120 \mathrm{~h}$ was 1.6 times higher than the mass emitted at $96 \mathrm{~h}$ under the condition of UV off at $30^{\circ} \mathrm{C}$. The cause of the erratic data for these three chemicals is unknown. 


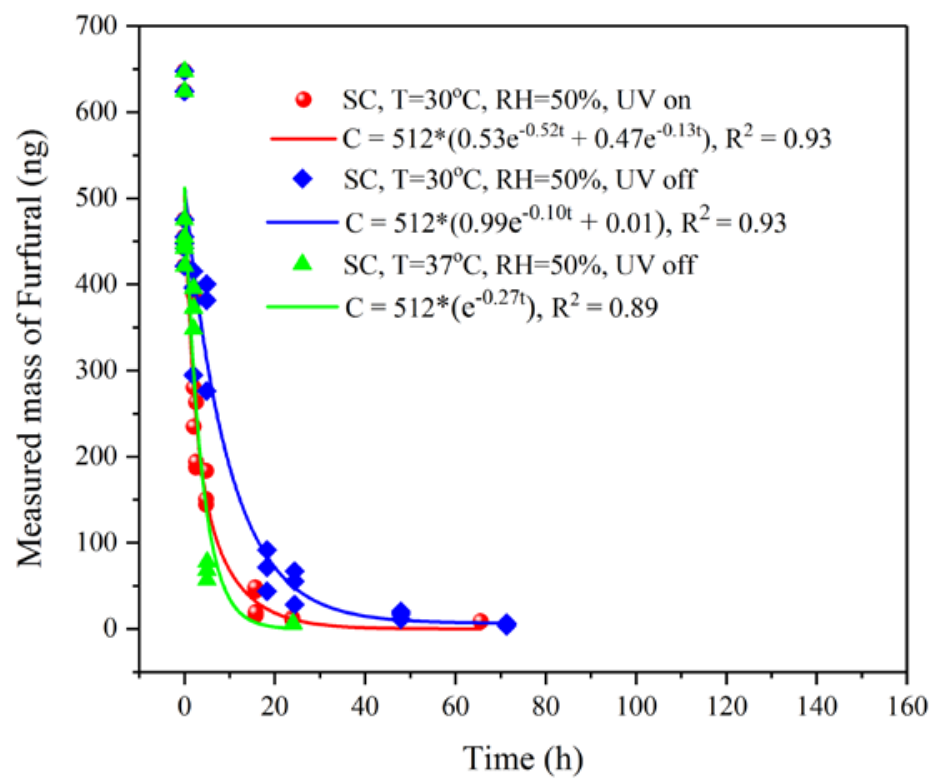

(a)

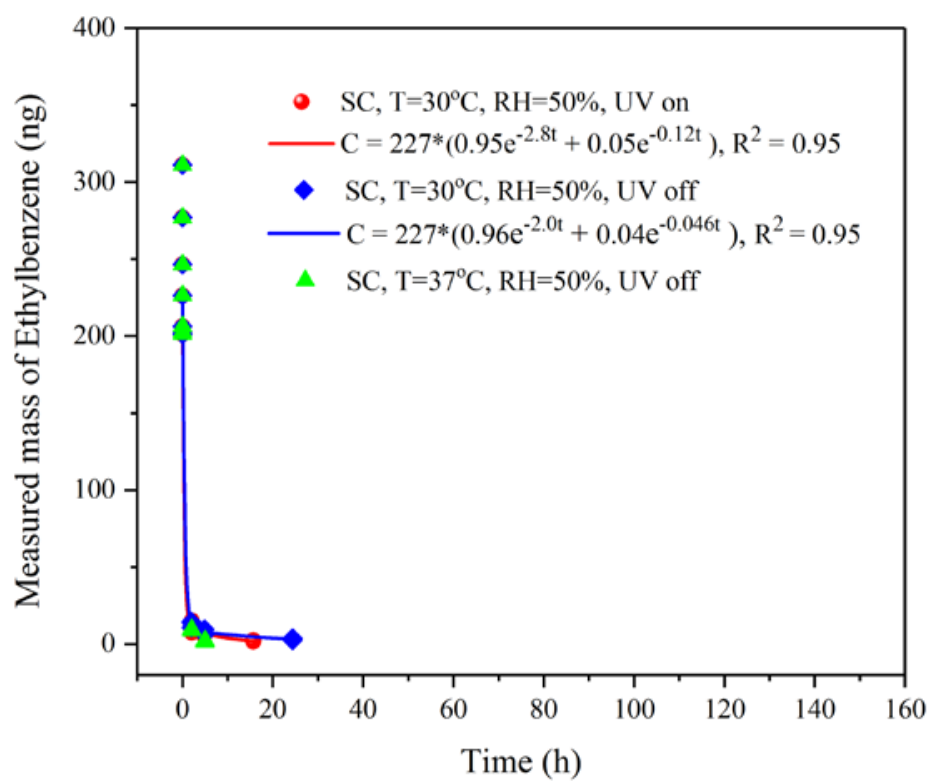

(b) 


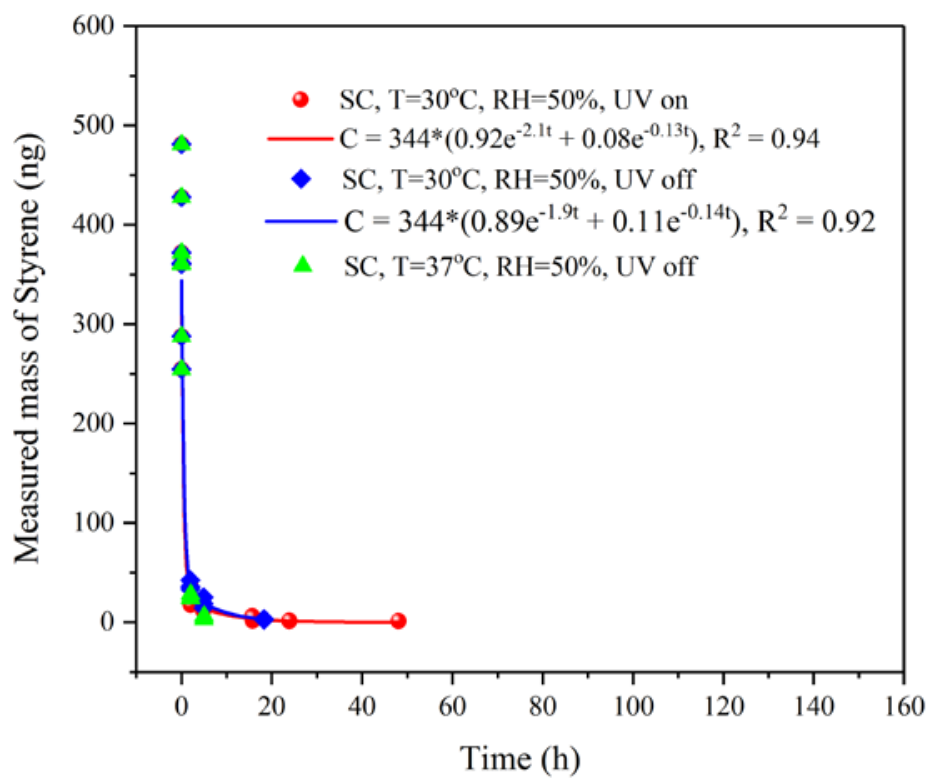

(c)

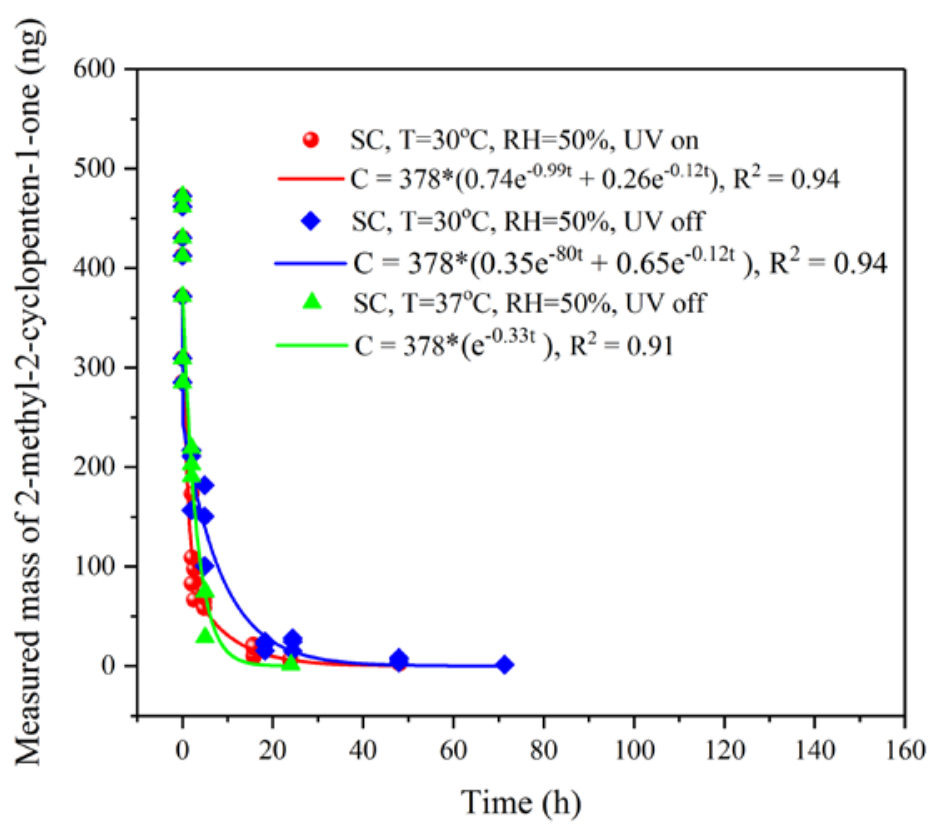

(d) 


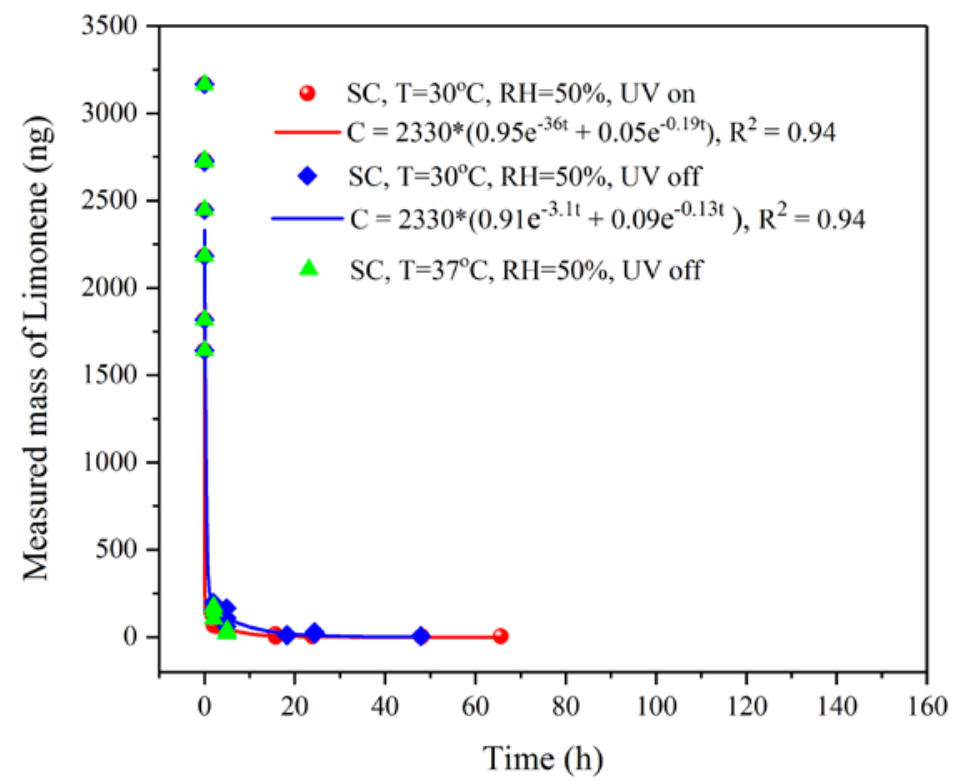

(e)

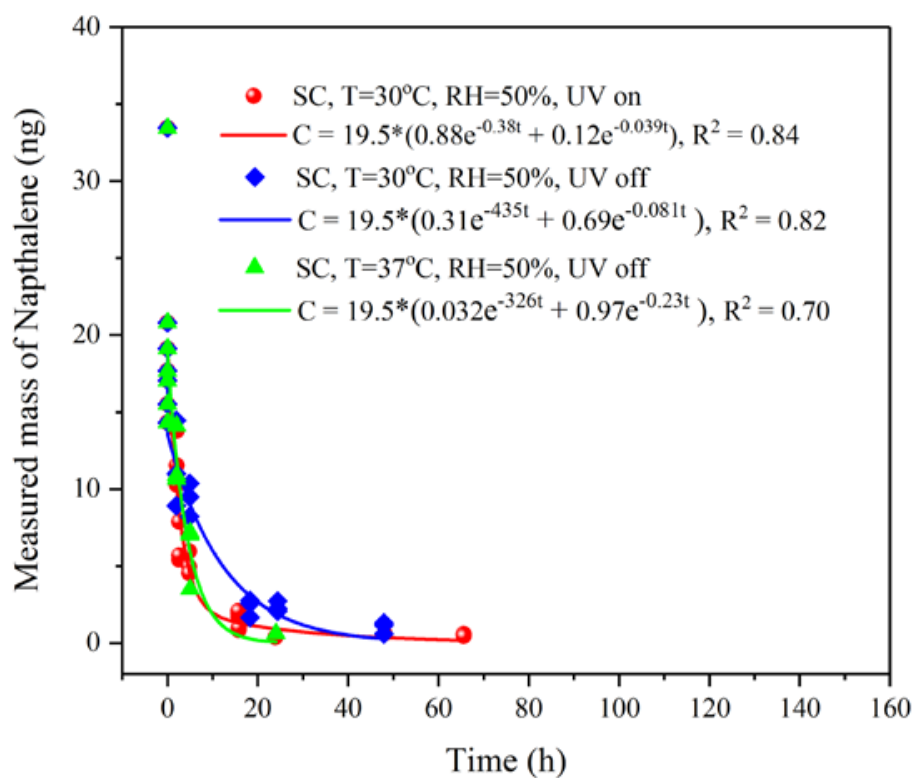

(f) 


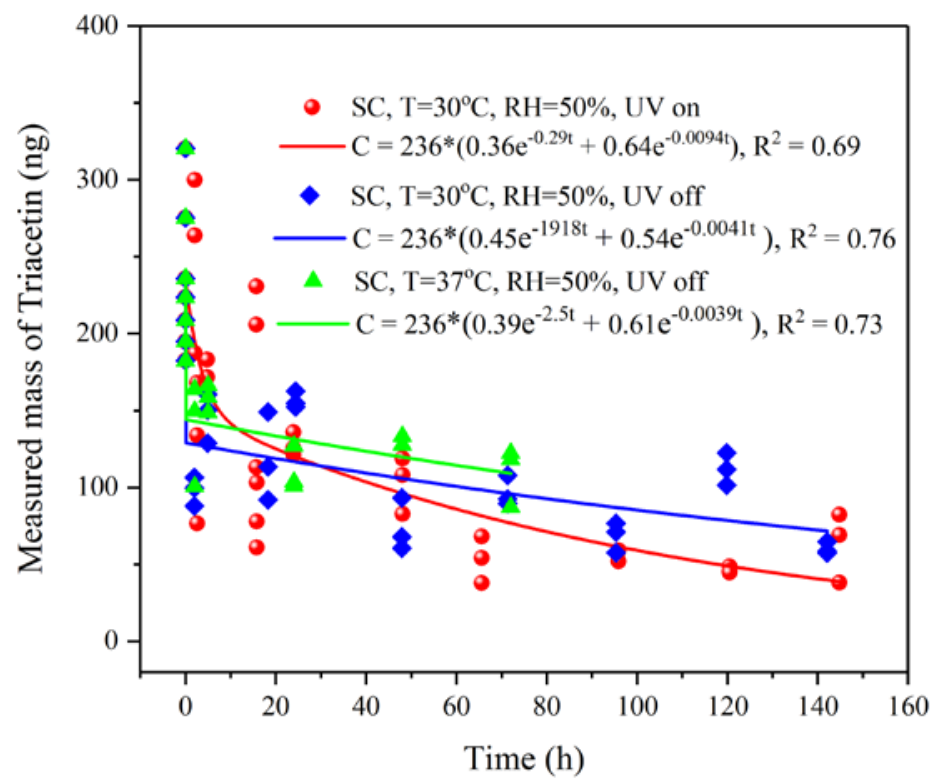

(g)

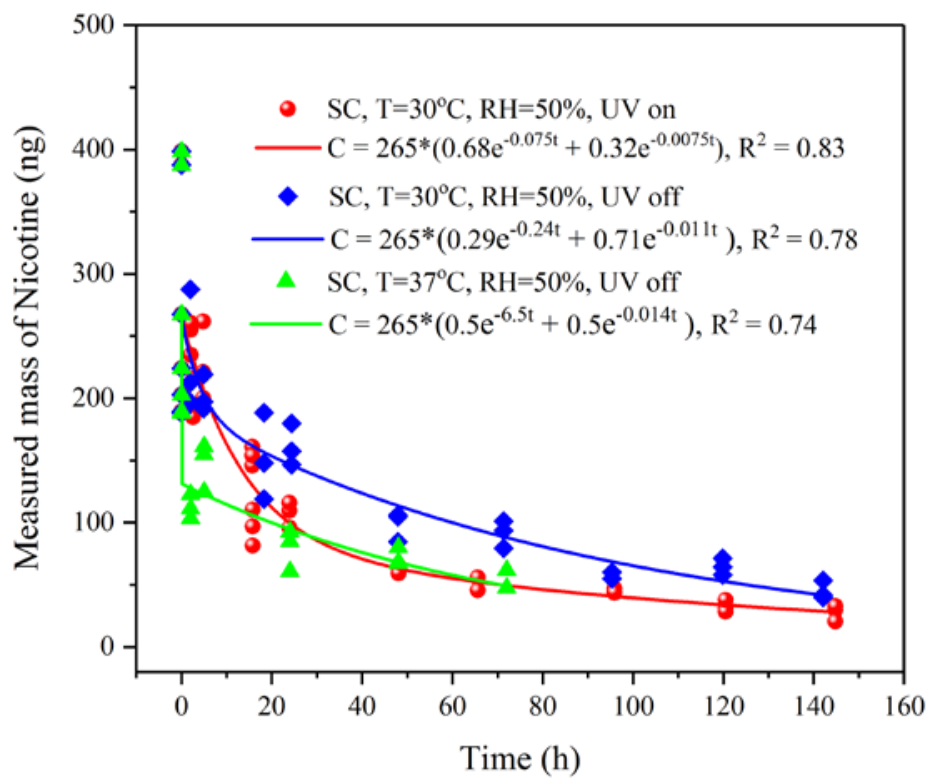

(h)

Figure 3.3: $\quad$ Measured emitted mass of target chemicals from each cigarette butt conditioned in SPHERE UV chamber with $U V$ on and with UV off. Samples for UV on and off at $30^{\circ} \mathrm{C}$ were intended to be conditioned for $2 \mathrm{~h}, 5 \mathrm{~h}, 18 \mathrm{~h}$, $24 \mathrm{~h}, 48 \mathrm{~h}, 72 \mathrm{~h}, 96 \mathrm{~h}, 120 \mathrm{~h}$ and $144 \mathrm{~h}$. Samples for UV off at $37^{\circ} \mathrm{C}$ were intended to be conditioned for $2 \mathrm{~h}, 5 \mathrm{~h}$, $18 \mathrm{~h}, 24 \mathrm{~h}, 48 \mathrm{~h}$, and $72 \mathrm{~h}$. Note that the actual conditioning time shown in the figure deviated somewhat from the intended time. 
To examine the influence of UV on the emitted mass, the decay times were calculated from the curve fits. The decay times are compared in Figure 3.4 (a) and (b) for $5 \%$ and $25 \%$ decay times respectively. For all eight of the target chemicals, the decay time for UV on at $30{ }^{\circ} \mathrm{C}$ was smaller than the decay time for UV off at $30^{\circ} \mathrm{C}$. The percentage change of the decay time ranged from $24 \%$ for ethylbenzene to $185 \%$ for limonene. This trend is consistent with the fact that the measured mass emitted from butts conditioned with UV on were lower than the mass from butts conditioned with UV off at the same time point (Figure 3.3). This indicates that UV under the test condition ( $30{ }^{\circ} \mathrm{C}, 50 \% \mathrm{RH}, 280 \mathrm{~nm}$ to $400 \mathrm{~nm} \mathrm{UV}$ with intensity of $140 \mathrm{~W} \mathrm{~m}^{-2}$ ) in this study enhanced the emission of chemicals into air in the conditioned environment. As stated above, when $\mathrm{UV}$ was on, the cigarette butt temperature $\left(37^{\circ} \mathrm{C}\right)$ was higher than the temperature in the chamber air $\left(30^{\circ} \mathrm{C}\right)$ due to UV exposure. Hence, the higher emissions with UV on may be a result of enhanced degradation of cellulose acetate by UV, but it may also be due to the increased temperature of the butts. The impact of temperature on emissions are discussed in more detail in section 3.2.2.2.

Filters typically consist of plasticized cellulose acetate fibers, which can take years to degrade (Puls et al. 2011). The degradation depends on the degree of acetylation, types of plasticizers, and the environmental conditions, including UV exposure, which has been reported to play an important role in cigarette butt degradation (Puls et al. 2011). UV induces photodegradation by initiating formation of radicals after UV absorption. Cellulose acetate itself normally doesn't have a significant absorption of near-UV light (300 nm to $400 \mathrm{~nm}$ ), which is the major part of sunlight reaching earth's surface and the UV light used in this study (280 nm to $400 \mathrm{~nm}$ ). However, photosensitizers (such as benzophenone (Hosono et al. 2007)) can be added to cigarettes to enhance degradation. These additives have been shown to enhance the degradation from exposure to near-UV light by acting through energy transfer or initial radical abstraction. Also, higher temperatures and higher humidity may influence UV photodegradation (Egerton and Shah 1968). It is unknown if the tested cigarettes contained these additives.

The decay time for the testing condition of UV off at $37^{\circ} \mathrm{C}$ was less than the decay time for UV on at $30{ }^{\circ} \mathrm{C}$ by $41 \%, 43 \%$ and $54 \%$ for 2-methyl-2-cyclopenten-1-one, furfural, and naphthalene, respectively. Note that the butt temperatures for both conditions (UV on at air temperature $30{ }^{\circ} \mathrm{C}$ and UV off at air temperature $37^{\circ} \mathrm{C}$ ) were $37^{\circ} \mathrm{C}$. The higher air temperature could decrease the partition between the butts and air, which would increase the emission rate from the cigarette butts. Even though UV may enhance the emission by increasing the degradation of cellulose acetate, it may not compensate for the influence of air temperature. For nicotine, the decay time for the UVoff condition at $37{ }^{\circ} \mathrm{C}$ and the UV on condition at $30{ }^{\circ} \mathrm{C}$ were close, with an $8 \%$ relative percentage difference. Hence, the higher air temperature for the UV-off condition didn’t significantly increase the nicotine emission compared to the UV on condition. For triacetin, the decay time for UV off at $37{ }^{\circ} \mathrm{C}$ was $78 \%$ higher compared to UV on at $30{ }^{\circ} \mathrm{C}$. This increase may be due to the data scatter, which resulted in a low $\mathrm{R}^{2}$ value for the curve fit (Figure $3.3(\mathrm{~g})$ ), or it may be due to the UV exposure.

Overall, when the air temperatures were the same in the conditioned environment, UV increased the emissions from butts by either increasing the temperature of the butts or enhancing the 
degradation of cellulose acetate. However, it is unknown which effect is more important based on these data. More studies examining airborne emissions under more temperature, humidity and UV combinations would help to better understand the mechanisms of UV influence on the degradation of cigarette butts.

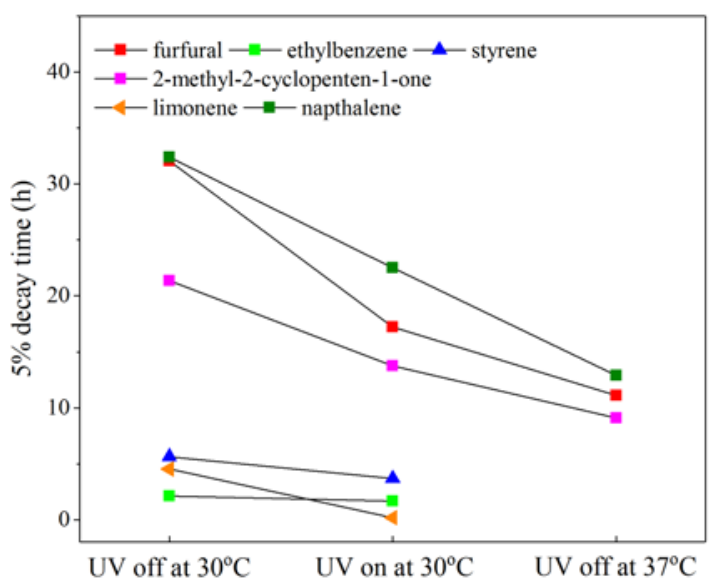

(a)

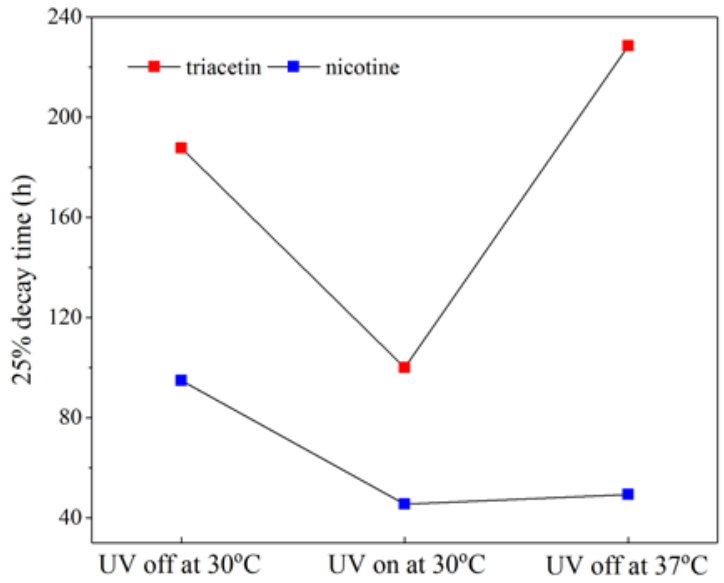

(b)

Figure 3.4: $\quad$ Exposure time required for the mass emitted into the headspace vial to be (a) $5 \%$ of the initial emitted mass under UV on and off conditions; (b) $25 \%$ of the initial emitted mass under UV on and off conditions.

\subsubsection{Influence of temperature and relative humidity}

The measured masses of the eight target chemicals from cigarette butts conditioned in dark chambers under four different conditions $\left(30^{\circ} \mathrm{C}\right.$ and $25 \% \mathrm{RH}, 30^{\circ} \mathrm{C}$ and $50 \% \mathrm{RH}, 40^{\circ} \mathrm{C}$ and $25 \% \mathrm{RH}, 40^{\circ} \mathrm{C}$ and $50 \% \mathrm{RH}$ ) and their curve fits are shown in Figure 3.5 (a) through (h). The relative standard deviations (RSDs) of each triplicate data set for $90 \%$ of the time points in Figure 3.5 are within $30 \%$, while the RSDs for the other $10 \%$ range from $31 \%$ to $51 \%$.

Similar to the experiments examining the influence of UV, after $48 \mathrm{~h}$ the emitted masses of the six chemicals other than triacetin and nicotine decayed to less than $5 \%$ of the initial masses in all four conditioned environments. In contrast, the emitted masses of nicotine and triacetin decayed more slowly with the measured mass at $48 \mathrm{~h}$ being $18 \%$ to $51 \%$ of the initial mass for all conditions. The $\mathrm{R}^{2}$ values of the curve fits are higher than 0.92 for furfural, ethylbenzene, styrene, 2-cyclopenten-1-one, 2-methyl and limonene. However, the $\mathrm{R}^{2}$ values for the other three chemicals, i.e., naphthalene, triacetin, and nicotine, are all lower, ranging from 0.62 to 0.90 . The lower $R^{2}$ value may result from erratic data, similar to the datasets in Figure 3.3 (f) through (h). 


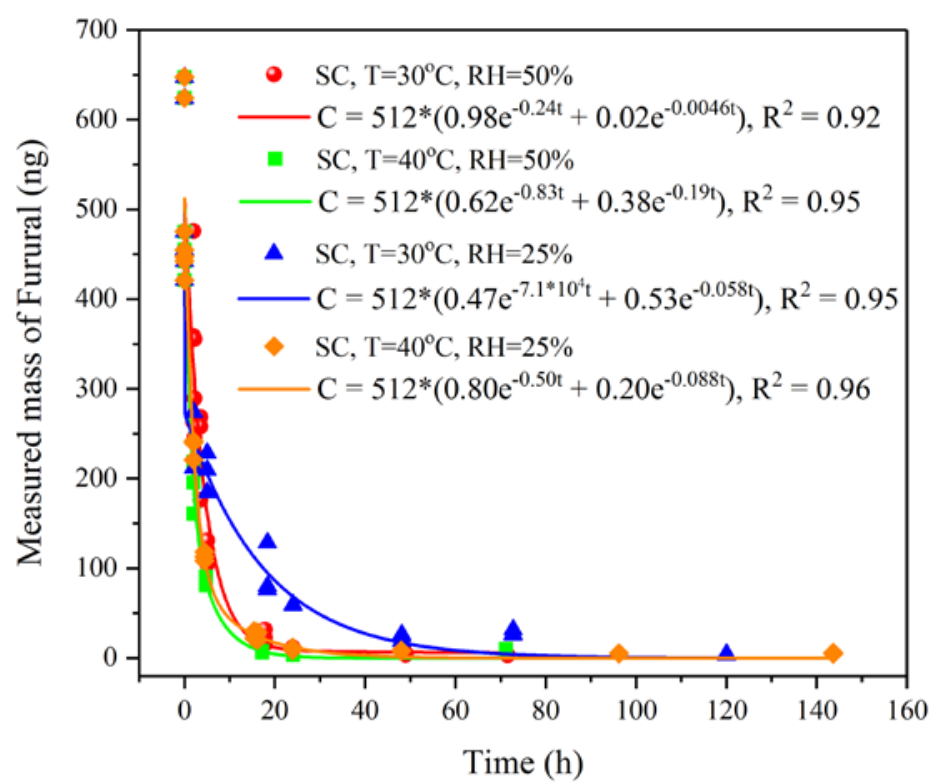

(a)

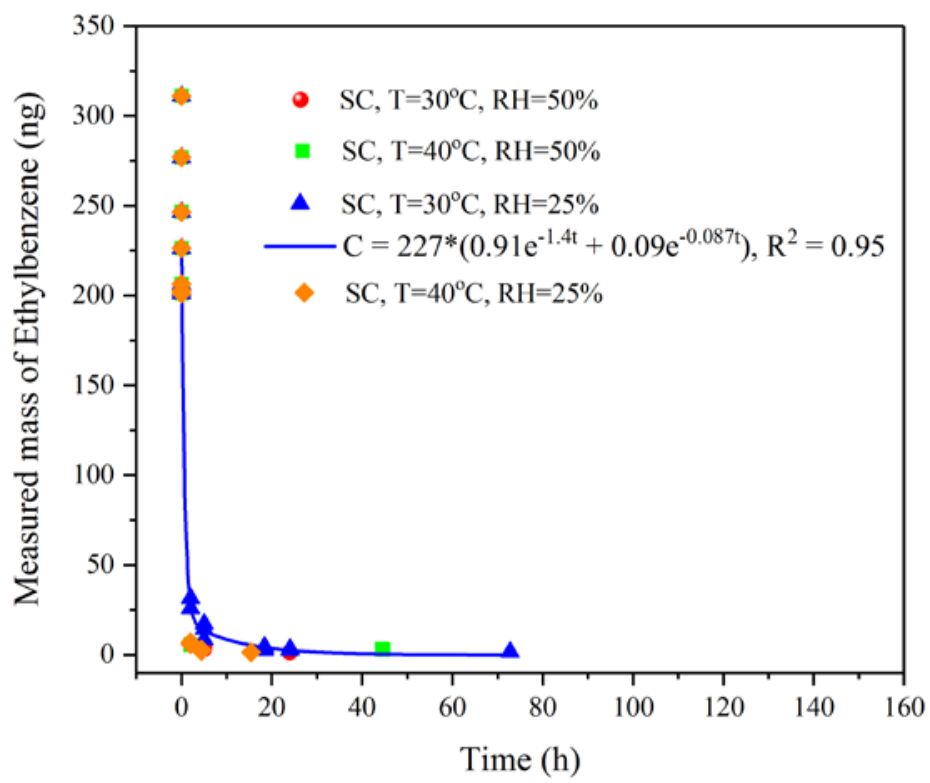

(b) 


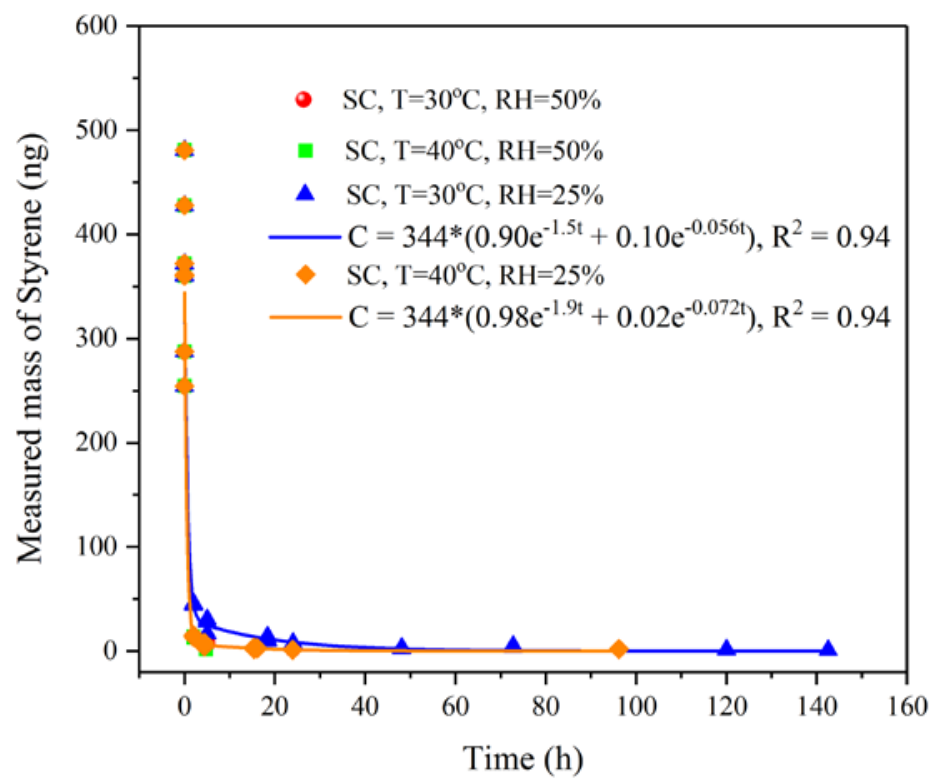

(c)

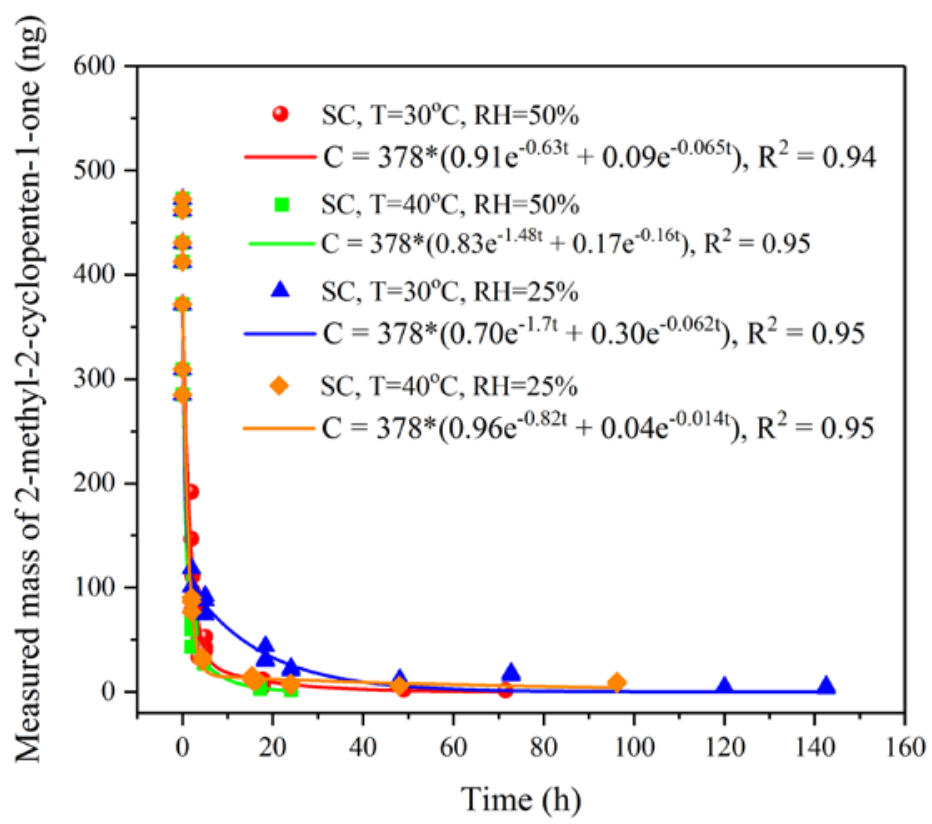

(d) 


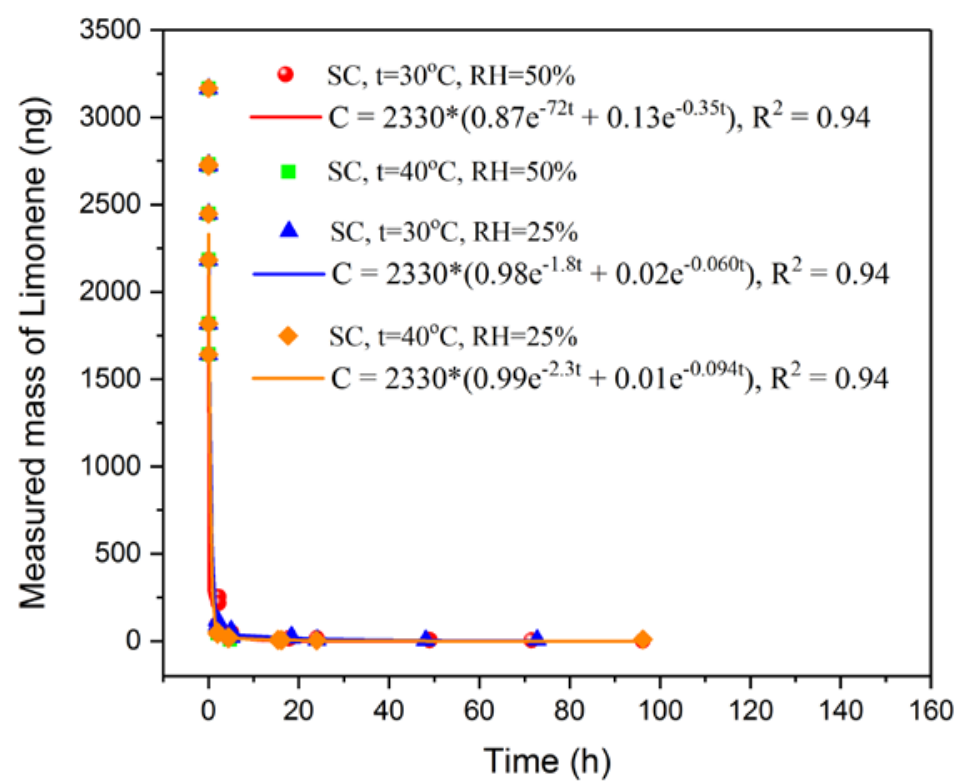

(e)

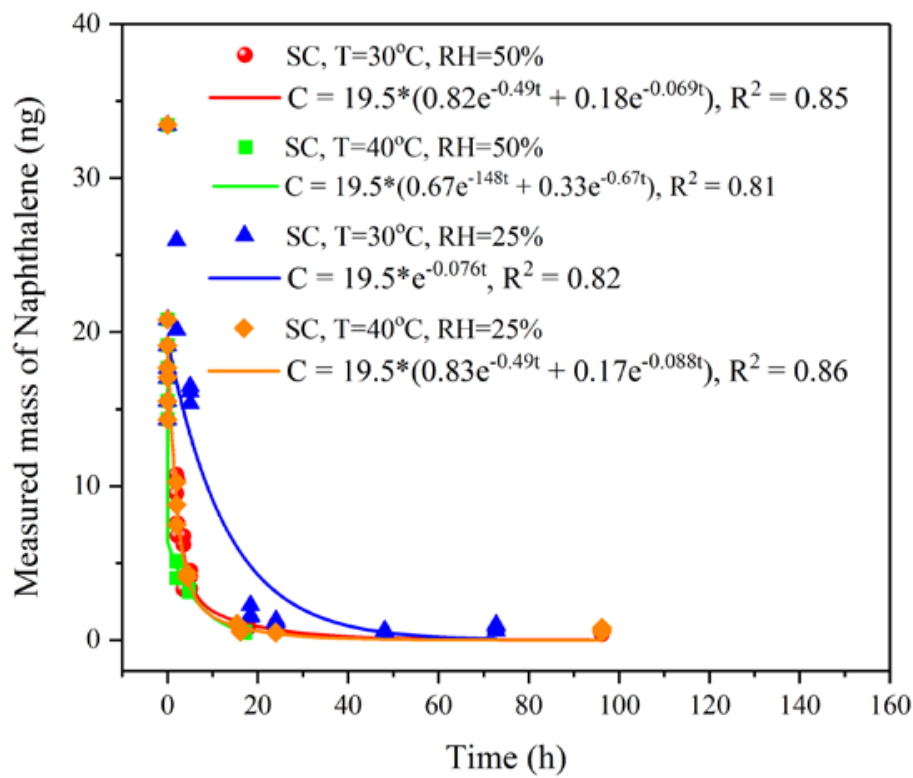

(f) 


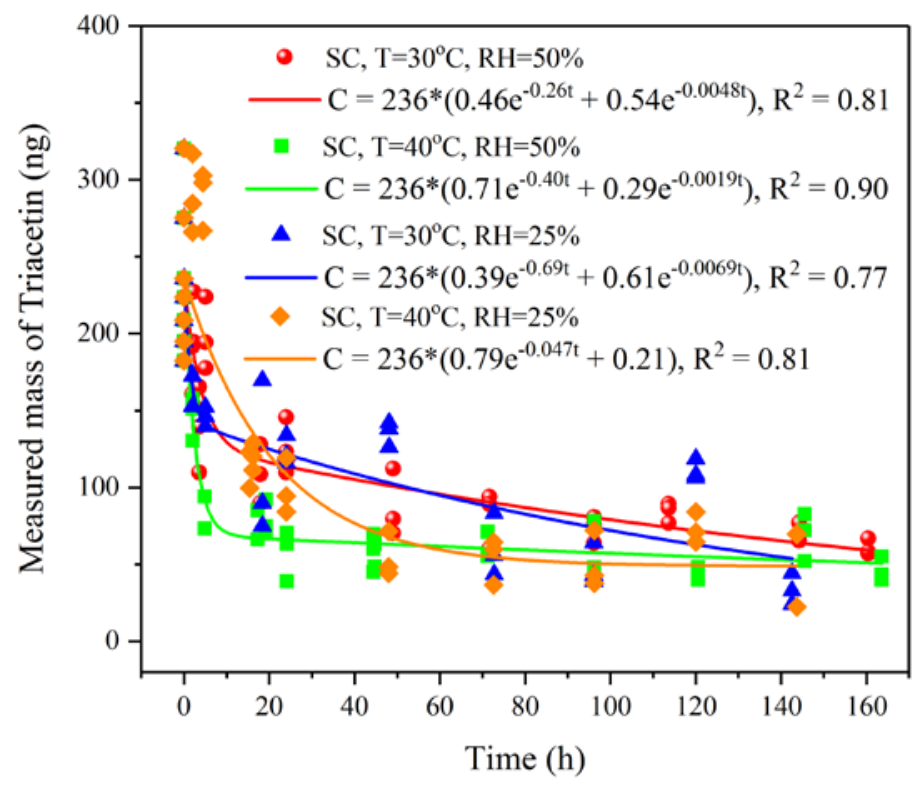

(g)

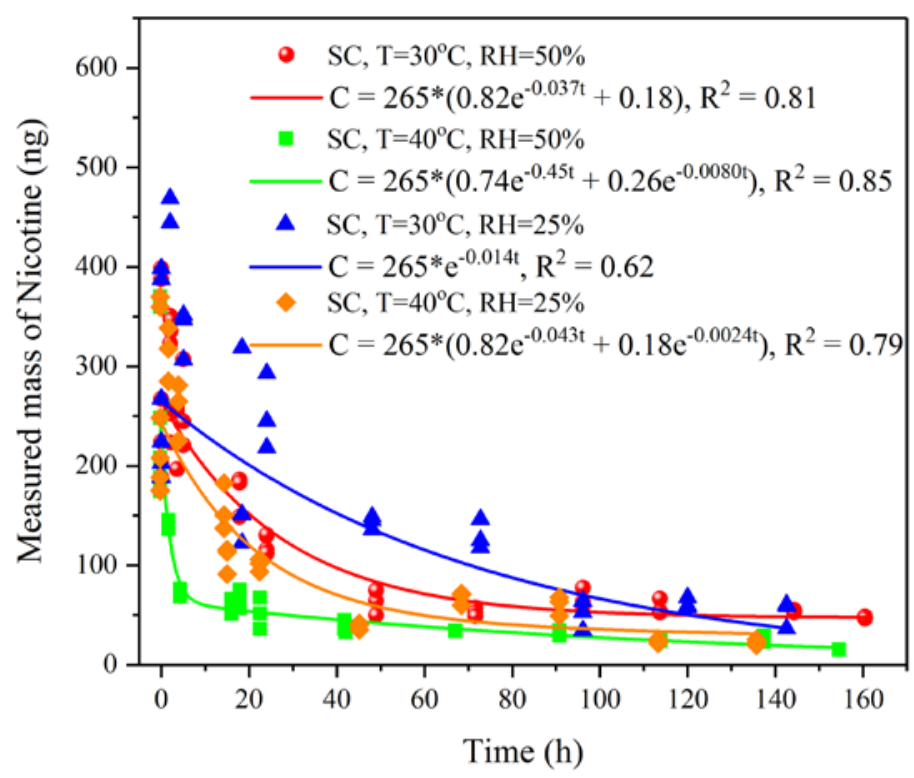

(h)

Figure 3.5: $\quad$ Measured emitted masses and curve fits for target chemicals from each cigarette butt conditioned in dark chambers at different temperature $(T)$ and relative humidity $(R H)$. Samples were intended to be conditioned for $2 \mathrm{~h}, 5 \mathrm{~h}, 18 \mathrm{~h}, 24 \mathrm{~h}, 48 \mathrm{~h}, 72 \mathrm{~h}, 96 \mathrm{~h}, 120 \mathrm{~h}$ and $144 \mathrm{~h}$. Note that the actual conditioning time shown in the figure deviated somewhat from the intended time. 
To examine the influence of a $10^{\circ} \mathrm{C}$ temperature change and a $25 \% \mathrm{RH}$ change, decay times were calculated using the curve fits shown in Figure 3.5. Only one of the four conditioning environments resulted in a curve fit for ethylbenzene. Styrene only had curve fits for the $25 \% \mathrm{RH}$ environments. Hence, ethylbenzene and styrene are not included in this analysis based on the three-point limit for curve fitting mentioned earlier.

Temperature The decay times are shown in in Figure 3.6 (a) through (f). The decay time changes due to a $10{ }^{\circ} \mathrm{C}$ temperature change show similar trends for the six compounds. The $10^{\circ} \mathrm{C}$ increase decreased the decay time by $21 \%$ to $92 \%$ at $25 \% \mathrm{RH}$ and by $48 \%$ to $82 \%$ at $50 \% \mathrm{RH}$. The trend for decay time is consistent with the fact that the measured emitted mass at higher temperature is generally lower than the mass emitted at lower temperature at the same time point and same relative humidity (Figure 3.5). A decrease of the decay time indicates that more mass has been emitted during the conditioning phase prior to headspace analysis. This is consistent with the fact that as the temperature increases, the vapor pressures of the target chemicals increase so that the chemical concentrations at the surface of the cigarette butts increases, and the chemical emission rates increase. For reference, increasing the temperature from $30^{\circ} \mathrm{C}$ to $40{ }^{\circ} \mathrm{C}$ increases the vapor pressures of the chemicals by $51 \%$ to $163 \%$ (vapor pressures were calculated using the sparc online calcualtor, http://archemcalc.com/sparc-web/calc).

Relative Humidity In general, the change in decay times for a $25 \%$ increase of relative humidity was similar to the change in decay times with a $10{ }^{\circ} \mathrm{C}$ temperature increase. For furfural, limonene, naphthalene, and nicotine, the influence of increasing relative humidity by $25 \%$ showed similar trends, decreasing the decay time by $33 \%$ to $71 \%$ at $30{ }^{\circ} \mathrm{C}$ and $32 \%$ to $90 \%$ at $40{ }^{\circ} \mathrm{C}$. This trend in decay time is consistent with the fact that the measured masses emitted at higher relative humidity were lower than the masses emitted at the same time point and same temperature (Figure 3.5). Changes in relative humidity would impact the adsorbed water layer in the butts. When conditioning the butts in the chamber with relative humidity of $50 \%$, more water would be adsorbed onto the porous surface of the butts compared to conditioning in the chamber with relative humidity of $25 \%$. The greater water layer at $50 \% \mathrm{RH}$ can result in fewer adsorption sites for other chemicals, enhancing the target chemical emissions from the butts to air. To our knowledge, no other studies have examined the influence of relative humidity on airborne emissions from cigarette butts. But, a similar influence of increase in relative humidity increasing emissions have been observed for volatile organic chemical (VOC) emissions from a variety of materials. Markowicz and Larsson (2015) indicated that VOC emissions from gypsum, wood, and concrete were higher when the relative humidity in the chamber was $85 \%$ compared to $45 \%$. Specifically that study showed limonene and styrene concentrations increased from below detection at $40 \% \mathrm{RH}$ to quantifiable at $85 \% \mathrm{RH}$. Laskar et al. (2019) demonstrated a faster breakthrough of 2-propanol in activated carbon adsorbed at $95 \% \mathrm{RH}$ compared to $50 \% \mathrm{RH}$, attributing the difference to the competitive adsorption of water vapor with 2-propanol. 


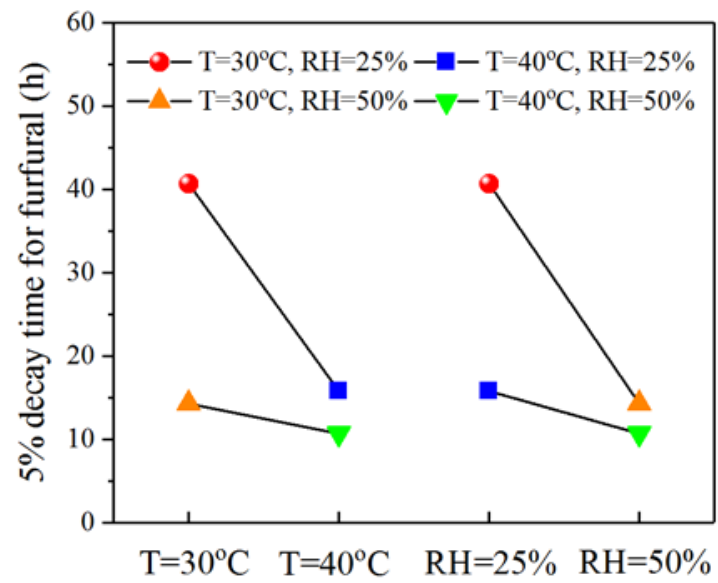

(a)

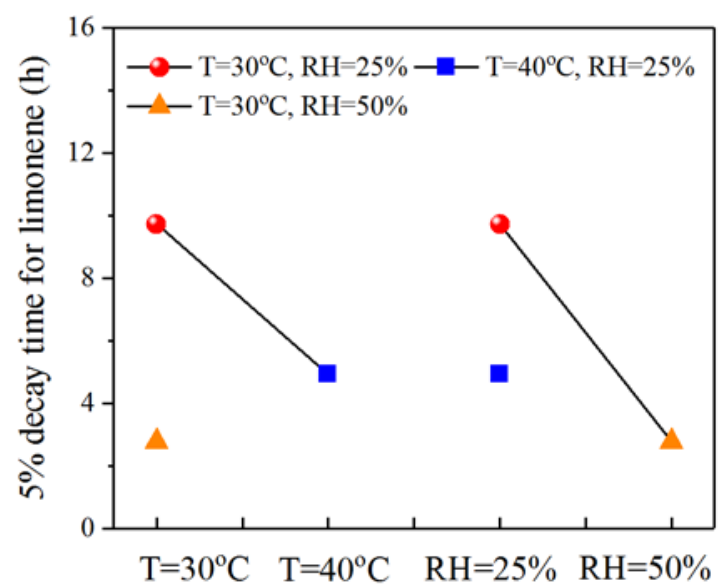

(c)

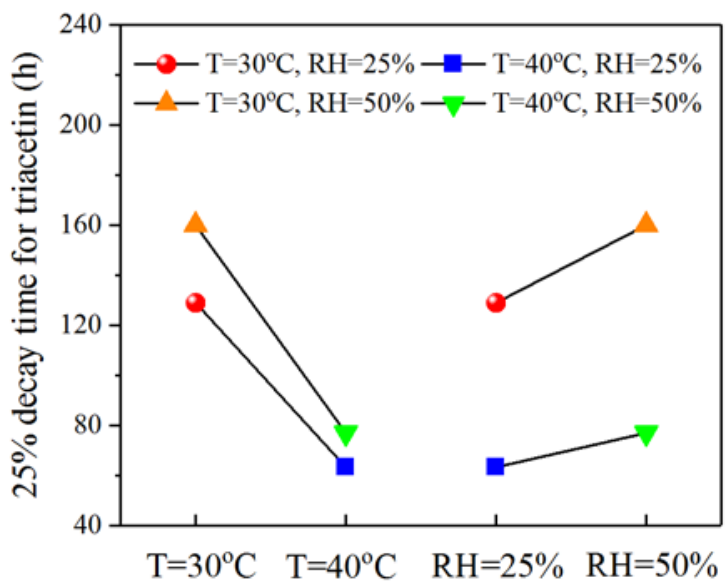

(e)

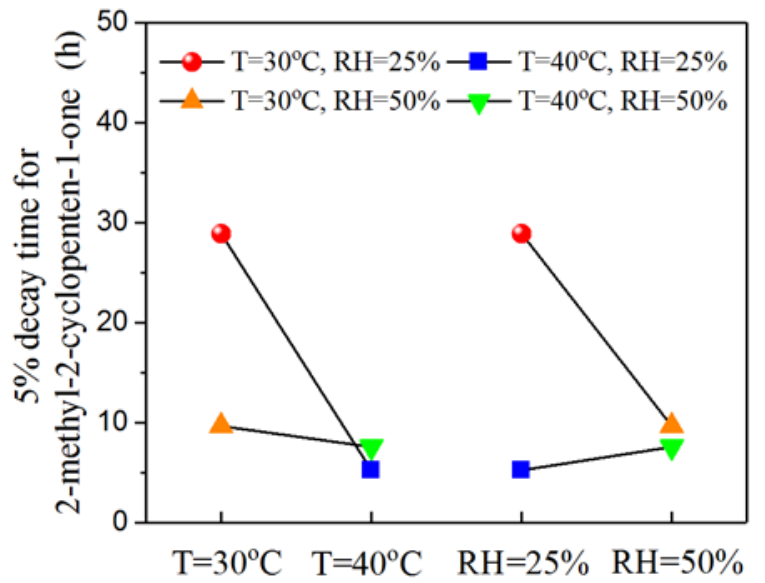

(b)

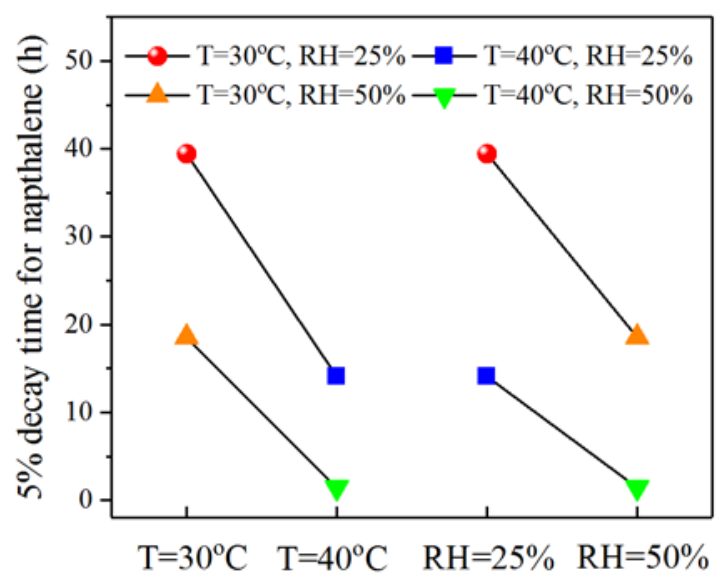

(d)

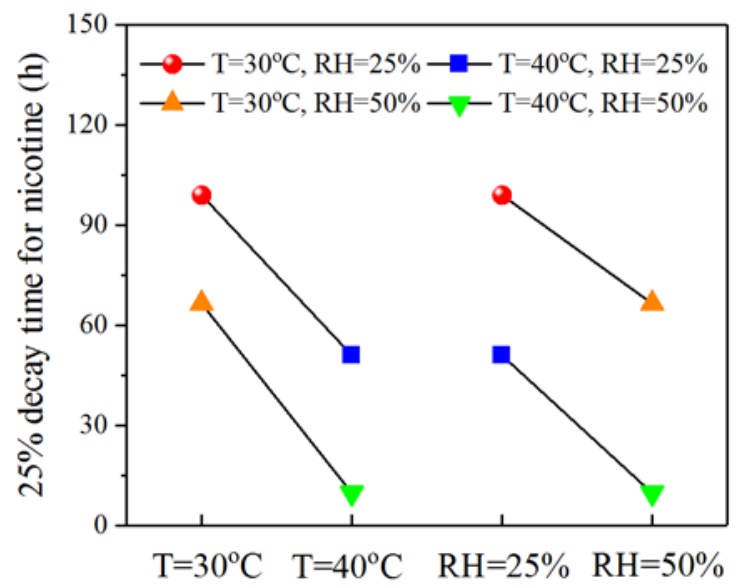

(f)

Figure 3.6: $\quad$ Amount of exposure time required for the mass emitted into the headspace vial to be $5 \%$ or $25 \%$ of the initial emitted mass. Left-hand values demonstrate the impacts of a temperature change in the conditioning chamber. Right-hand values demonstrate the impact of a relative humidity change in the conditioning chamber. 
Two chemicals don't follow the trend of decreasing decay time with increasing relative humidity. For 2-methyl-2-cyclopenten-1-one, even though the decay time decreased by $66 \%$ at $30{ }^{\circ} \mathrm{C}$ with a $25 \% \mathrm{RH}$ increase, the decay time increased by $45 \%$ at $40{ }^{\circ} \mathrm{C}$. And for triacetin, the decay time increased $24 \%$ at $30{ }^{\circ} \mathrm{C}$ and $21 \%$ at $40{ }^{\circ} \mathrm{C}$ with a $25 \% \mathrm{RH}$ increase. The relatively small number of time points $(n=5)$ for curve fitting for 2-methyl-2-cyclopenten-1-one at $40{ }^{\circ} \mathrm{C}$ and $50 \% \mathrm{RH}$ may result in an inaccurate estimate of the decay time, while curve fits with low $\mathrm{R}^{2}$ value $(0.77$ to 0.90) may contribute to the opposite trend of relative humidity influence for triacetin. Another possibility is these chemicals are two of the most water soluble (Table 2.3) among the target chemicals, and their structures (Figure 2.4) may make them more amenable to positively interacting with an increased water layer than the other target chemicals. More experiments need to be conducted to understand the influence of relative humidity on emissions of these two chemicals.

\subsubsection{Influence of water saturation}

Changes in relative humidity impact the adsorbed water layer in butts in a non-linear manner. Butts placed in chambers at $25 \% \mathrm{RH}$ and $50 \% \mathrm{RH}$ did not change appreciably in mass during conditioning. Butts placed on the roof increased mass by up to $20 \%$ when exposed to relative humidity above $90 \%$. In contrast, butts saturated with liquid water can increase mass by up to $300 \%$ (Figure 2.11).

As discussed in Section 3.2.2.2, water can influence the chemical emissions from cigarette butts due to competitive adsorption with a change in relative humidity. In contrast to vapor water adsorption from the atmosphere, when butts were saturated with liquid water (rain or artificially), there was no longer a water layer on porous surfaces as the pore spaces in the butts are filled with water. Hence, the influence of water saturation on cigarette butt emissions are expected to be different from the influence of relative humidity. These experiments examined the impact of saturation on the emitted mass from the butts. The saturation of the butts' pore spaces with liquid water makes the chemical partitioning between the butts, water and air important in determining the fate of a chemical.

Initial Concentrations. To understand the influence of water saturation on the initial emitted mass, two sets of experiments were conducted. In the first set of experiments, seven butts were wet for 3 min in petri dishes as described in Section 2.4.2 (wet butt sample), dried for 0.5 min, and then placed in the headspace vials for TD-GC-MS analysis. A paired set of seven dry butts (dry butt sample) was conditioned in petri dishes without water for the same time. In the second set of experiments, three butts were cut using the apparatus described in Section 2.2. The ash and unburned tobacco were discarded. The filters were then wet and analyzed in a similar manner as the complete butts (wet filter sample). A paired set of filters were also conditioned without water for the same time (dry filter sample).

Table 3.2 reports the initial emitted masses for the target chemicals from the tested butts and filters (dry and wet). Although the dry butts and filters were not prepared identically to the butts and filters in Section 3.1 (these dry butts and filters were exposed to air for 3.5 min longer prior to placement in headspace vials), it is useful to compare the ratios as a quality control step. In general, 
the ratios of emitted masses from the dry filters to the dry butts (shown in Table 3.2) follow the trends in Table 3.1 row 5 . The dry filter mass to dry butt mass ratio is equal to or less than one for 2-methyl-2-cyclopenten-1-one, naphthalene, and nicotine, and greater than one for the remaining chemicals. However, the ratios for ethylbenzene, limonene, and triacetin are more than $50 \%$ higher in these tests than for the data in Table 3.1 Row 5.

Table 3.2: $\quad$ Measured initial mass for dry and wet butts and filters (mean $\pm S D, n g$ )

\begin{tabular}{|c|c|c|c|c|c|}
\hline Chemical & $\begin{array}{c}\text { dry butt } \\
(\mathbf{n}=\mathbf{7})\end{array}$ & $\begin{array}{c}\text { wet butt } \\
(\mathbf{n}=\mathbf{7})\end{array}$ & $\begin{array}{c}\text { dry filter } \\
(\mathbf{n}=\mathbf{3})\end{array}$ & $\begin{array}{c}\text { wet filter } \\
(\mathbf{n}=\mathbf{3})\end{array}$ & $\begin{array}{c}\text { dry filter/ } \\
\text { dry butt }\end{array}$ \\
\hline Furfural & $542 \pm 71$ & $420 \pm 72$ & $689 \pm 31$ & $777 \pm 63$ & 1.3 \\
\hline Ethylbenzene & $140 \pm 29$ & $93 \pm 17$ & $301 \pm 43$ & $191 \pm 7$ & 2.2 \\
\hline Styrene & $294 \pm 52$ & $182 \pm 26$ & $402 \pm 37$ & $291 \pm 15$ & 1.4 \\
\hline 2-methyl-2-cyclopenten-1-one & $368 \pm 68$ & $210 \pm 28$ & $358 \pm 20$ & $301 \pm 39$ & 1.0 \\
\hline Limonene & $1380 \pm 350$ & $699 \pm 86$ & $2320 \pm 55$ & $1448 \pm 63$ & 1.7 \\
\hline Naphthalene & $16 \pm 1.9$ & $12 \pm 1.3$ & $14 \pm 0.4$ & $12 \pm 0.3$ & 0.88 \\
\hline Triacetin & $166 \pm 84$ & $242 \pm 80$ & $373 \pm 50$ & $159 \pm 18$ & 2.2 \\
\hline Nicotine & $175 \pm 75$ & $52 \pm 25$ & $146 \pm 77$ & $13 \pm 3$ & 0.83 \\
\hline
\end{tabular}

Table 3.3 shows the ratios of emitted mass from dry and wet butts/filters. The chemical masses emitted from the dry samples are larger for seven of the eight target chemicals in each case. These differences indicate that either 1) during the 3.5 min when the filters were in the petri dishes, more chemicals were emitted from the wet filter and butts (either to the air or the water solution) than the dry filter and butts, or 2) less chemicals were emitted into the headspace vials during analysis due to partitioning into the water phase in the filter.

Table 3.3: $\quad$ Dry-to-wet ratios of mass emitted from butts and filters. Chemical properties were calculated at $25^{\circ} \mathrm{C}$ using sparc online calculator (http://archemcalc.com/sparc-web/calc) on 11/7/2018.

\begin{tabular}{|c|c|c|c|c|c|c|c|}
\hline Chemical & $\begin{array}{c}\text { dry butt/ } \\
\text { wet butt }\end{array}$ & $\begin{array}{c}\text { dry filter/ } \\
\text { wet filter }\end{array}$ & $\begin{array}{c}\text { filter ratio/ } \\
\text { butt ratio }\end{array}$ & $\begin{array}{c}\text { Water } \\
\text { solubility, } \\
\text { mg } \mathbf{~ L}^{-1}\end{array}$ & Log $\boldsymbol{K}_{\text {wa }}$ & Log $\boldsymbol{K}_{\boldsymbol{o a}}$ & Log $\boldsymbol{K}_{\boldsymbol{o w}}$ \\
\hline Furfural & 1.3 & 0.9 & 0.7 & 64,400 & 4.3 & 4.58 & 0.30 \\
\hline Ethylbenzene & 1.5 & 1.6 & 1.0 & 160 & 0.4 & 3.47 & 3.09 \\
\hline Styrene & 1.6 & 1.4 & 0.9 & 205 & 0.8 & 3.74 & 2.95 \\
\hline 2-methyl-2-cyclopenten-1-one & 1.8 & 1.2 & 0.7 & 43,900 & 3.4 & 4.29 & 0.86 \\
\hline Limonene & 2.0 & 1.6 & 0.8 & 4 & -0.6 & 4.12 & 4.71 \\
\hline Naphthalene & 1.3 & 1.1 & 0.9 & 47 & 1.6 & 5.06 & 3.41 \\
\hline Triacetin & 0.7 & 2.4 & 3.5 & 64,600 & 5.5 & 6.22 & 0.68 \\
\hline Nicotine & 3.4 & 11.2 & 3.3 & 86,800 & 5.8 & 7.92 & 2.07 \\
\hline
\end{tabular}

Structurally (Figure 2.4), furfural and 2-methyl-2-cyclopenten-1-one both have a polar carbonyl group, making them both relatively soluble in water (Table 3.3). Triacetin has three polar carboxylic ester groups, which makes it also relatively soluble in water. Nicotine is an amine (a 
weak base), also making it relatively soluble. The other four target chemicals are relatively nonpolar hydrocarbons, making them comparatively insoluble.

For the four non-polar hydrocarbons, the ratio of the dry to wet emitted mass (dry/wet ratio) for the butts and filters negatively correlates with the water/air partition coefficient $\left(K_{\text {wa }}\right.$, butt $\mathrm{R}^{2}$ value $=0.89$, filter $\mathrm{R}^{2}$ value $=0.85$ ). These correlations indicate that these four hydrocarbons in the wet butts and filter mainly migrated to the air, not the water solution during the saturation process. Chemicals in the wet butts and filters with smaller $K_{\text {wa }}$ values (e.g. ethylbenzene) emitted more mass into the air during the $3.5 \mathrm{~min}$ saturation time leading to larger dry-to-wet ratios for the emitted masses. The two carbonyl chemicals (furfural and 2-methyl-2-cyclopenten-1-one) followed the same correlation trends as the hydrocarbons (negative with $K_{\mathrm{wa}}$ ). Due to its higher $K_{\text {wa }}$ value, the dry/wet ratios for furfural were larger than the ratios for 2-methyl-2-cyclopenten-1one. However, the carbonyls didn't fall on the same curve fits as the hydrocarbons, as the structural differences result in $K_{\text {wa }}$ values at least two orders of magnitude higher than the hydrocarbons. Given there are only two carbonyl target chemicals, no $\mathrm{R}^{2}$ values for the correlation with $K_{\text {wa }}$ could be calculated. Hence, as with the hydrocarbons, for carbonyl chemicals with smaller $K_{\text {wa }}$ values, more chemical mass was released into the air during the 3.5 min saturation time.

In general, the dry/wet ratios for butts are greater than the ratios for filters indicating that the addition of the ash and unburned tobacco impacts the relative partitioning between the air/water/solid phases of cigarette butts. Interestingly, the carbonyl containing chemicals both had a filter ratio/butt ratio of 0.7 , indicating that cutting and removing the ash/tobacco had a consistent negative impact on the ratios. The four non-polar hydrocarbons were not impacted as much by the presence of ash/tobacco with an average filter ratio/butt ratio of 0.9.

The reason that furfural and 2-methyl-2-cyclopenten-1-one were impacted more is likely because furfural and 2-methyl-2-cyclopenten-1-one have high water solubility and the filters were more hydrophilic than the butts. The filters therefore gained relatively more water than the butts. The masses of the wet filters after conditioning in petri dishes increased by an average of $420 \% \pm 80 \%$ $(n=9)$. The masses of the wet butts after conditioning in petri dishes increased by an average of $273 \% \pm 54 \%(n=7)$. The filter ratio/butt ratio was positively impacted for both triacetin and nicotine (average value 3.4) by the presence of ash/tobacco.

Triacetin is the only ester among the target chemicals. More triacetin was emitted from the wet butts than the dry butts. In contrast, more triacetin was emitted from the dry filters than the wet filters. Given the large $K_{\text {wa }}$, large $K_{\text {oa }}$, low vapor pressure, and high-water solubility, triacetin emissions from the wet filters may be due to dissolution into the water solution in the petri dish, not emissions into air. The high dissolution of triacetin in the wet filters into water solution in the petri dish would decrease triacetin's mass in the headspace vial for the wet filters. This difference is consistent with the visual migration of the chemicals seen on the saturated roof butts (discussion in Section 3.2.4.2). The reason that the relative magnitude of triacetin mass in wet and dry butts is opposite to the relative magnitude of triacetin mass in wet and dry filter is not clear. However, the relative standard deviations on the triacetin butt data (33\% wet and $50 \%$ dry) could limit the ability to make accurate conclusions. 
For nicotine, the dry/wet ratios ( 3 for butts and 11 for filters) were much higher than the ratios for the other chemicals ( 0.7 to 2.0 for butts, 0.9 to 2.4 for filters). Nicotine is the only target chemical that can protonate, meaning it can add a proton to the molecule. Also, nicotine can exist in three forms: 1) a diprotonated molecule that exists when in contact with envrionments with $\mathrm{pH}<3,2$ ) a monoprotonated molecule that can exist in a tobacco filter (where $5<\mathrm{pH}<6$ ), and 3 ) a free-base molecule (deprotanted conjugate base) (Liang and Pankow 1996, Ishizu and Ishizu 2013). Only the free-base species is volatile (Liang and Pankow 1996). Free-base nicotine is the dominant form of nicotine on the cigarette filter when freshly smoked, although the $\mathrm{pH}$ and nicotine species can change with environmental exposures. The artificial rainwater solution has been measured by Chevalier et al. (2018) to have a $\mathrm{pH}$ of 5.2, indicating that most of the nicotine in the aqueous phase is likely to be in the non-volatile monopronated form. Nicotine is also fairly water soluble, so a significant amount of nicotine in the wet filters and butts would likely disolve into the aqueous phase and then protonate, making it non-volatile. In addition, some of the nicotine could have migrated into the water in the petri dish, also contributing to its low mass in the wet filters and butts.

Emission Decay from Saturated Butts. The water saturation of the filters pore spaces impacted the total initial mass of the target chemicals in the filters. To determine if temporary saturation (e.g., rain) can impact the decay rate of the emitted masses for the target chemicals in headspace analysis, saturated filters were placed in dark chambers at $30^{\circ} \mathrm{C}$ and $50 \% \mathrm{RH}$ for $5 \mathrm{~h}, 18 \mathrm{~h}, 24 \mathrm{~h}$, and $144 \mathrm{~h}$ (dry filters were analyzed at the same times, plus an additional sample at $2 \mathrm{~h}$ ). The saturated filters dried during the experiment. The $5 \mathrm{~h}$ wet filters averaged a $9 \% \pm 21 \%$ mass increase from their pre-saturation mass $(n=3$, decreasing from $420 \% \pm 80 \%$ immediately after saturation). The $24 \mathrm{~h}$ wet filters averaged a $-3 \% \pm 5 \%$ mass change from their pre-saturation mass $(\mathrm{n}=3)$. These wet filters may initially experience conditions where pore spaces were saturated with water, and then after five hours water may be mainly adsorbed on the porous surface layers and competed for sorption sites with the target chemicals. The limited number of samples prevents a full understanding of the rate of drying.

The measured masses of the eight target chemicals emitted from the cigarette filters conditioned in the dark chamber and their curve fits are shown in Figure 3.7 (a) through (h). The curves for the drying wet filter were similar to the dry filters, with all chemicals other than triacetin and nicotine decaying to less than $5 \%$ of the initial masses within $10 \mathrm{~h}$. The decay times for the drying wet filters and the dry filters for six of the eight target chemicals are compared in Figure 3.8. The decay times were lower for the wet filters as compared to the dry filters for the two carbonyl chemicals: furfural and 2-methyl-2-cyclopenten-1-one. The decay time increased for the three hydrocarbons (styrene, limonene, and naphthalene). Hence, the wetting/drying process enhances the emission of furfural and 2-methyl-2-cyclopenten-1-one from the filter. These two chemicals have the highest water solubility and $K_{\text {wa }}$ values compared to the other chemicals in Figure 3.8 (three orders of magnitude higher in Table 3.3). In contrast, the wetting/drying process may retard the emission of the hydrocarbons from filters. These chemicals have the lowest solubility and $K_{\text {wa }}$ values. Saturating a filter retards the emission of these chemicals (initial dry/wet ratios are 1.1 to 1.6) for the first few hours. Once the filters dried out, the emission rates elevated for the hydrocarbons. 
This indicates that both the water solubility and $K_{\text {wa }}$ are important to the chemical fate in temporarily saturated butts.

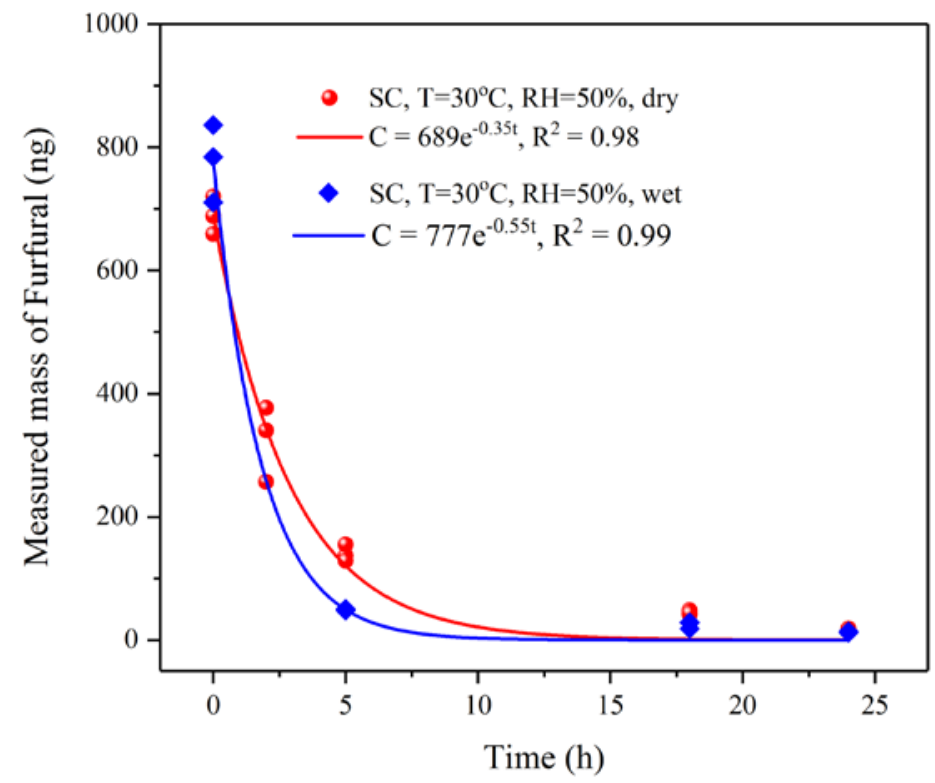

(a)

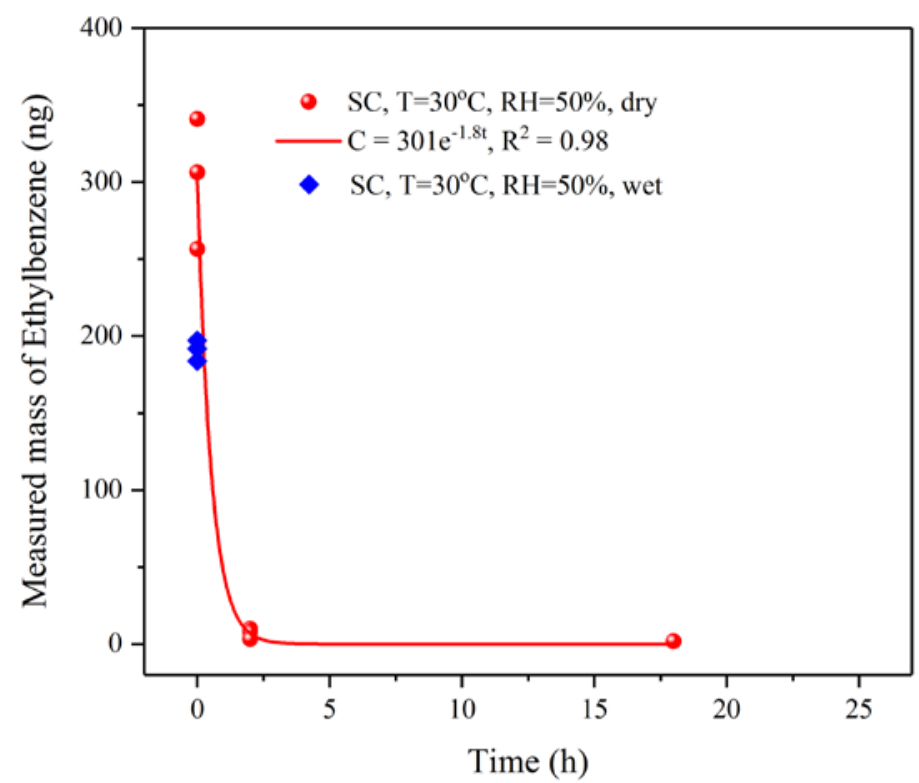

(b) 


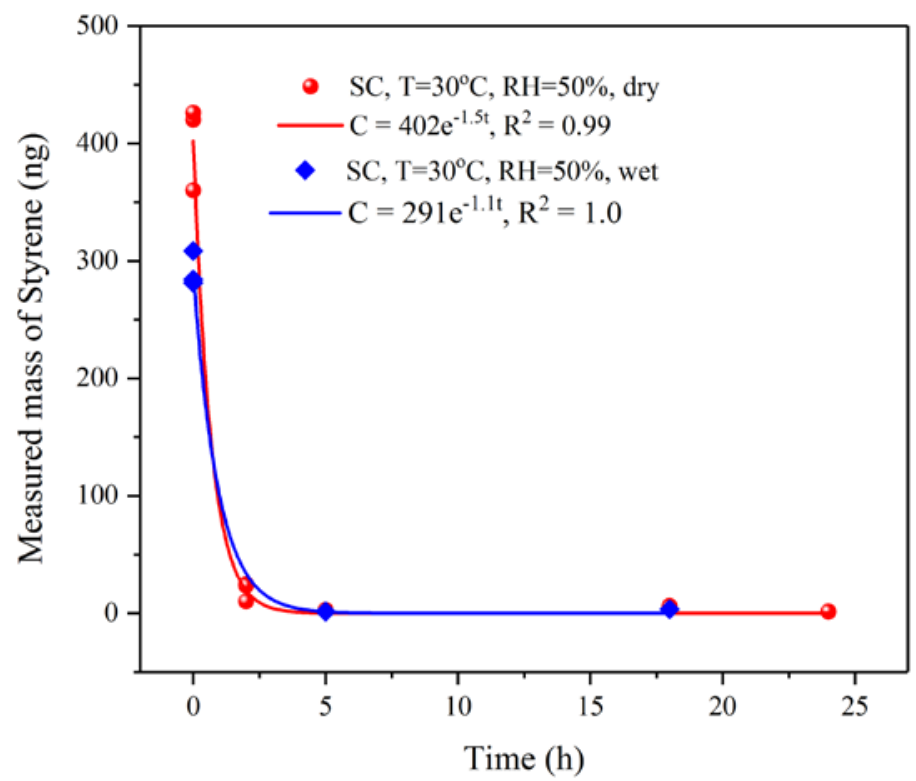

(c)

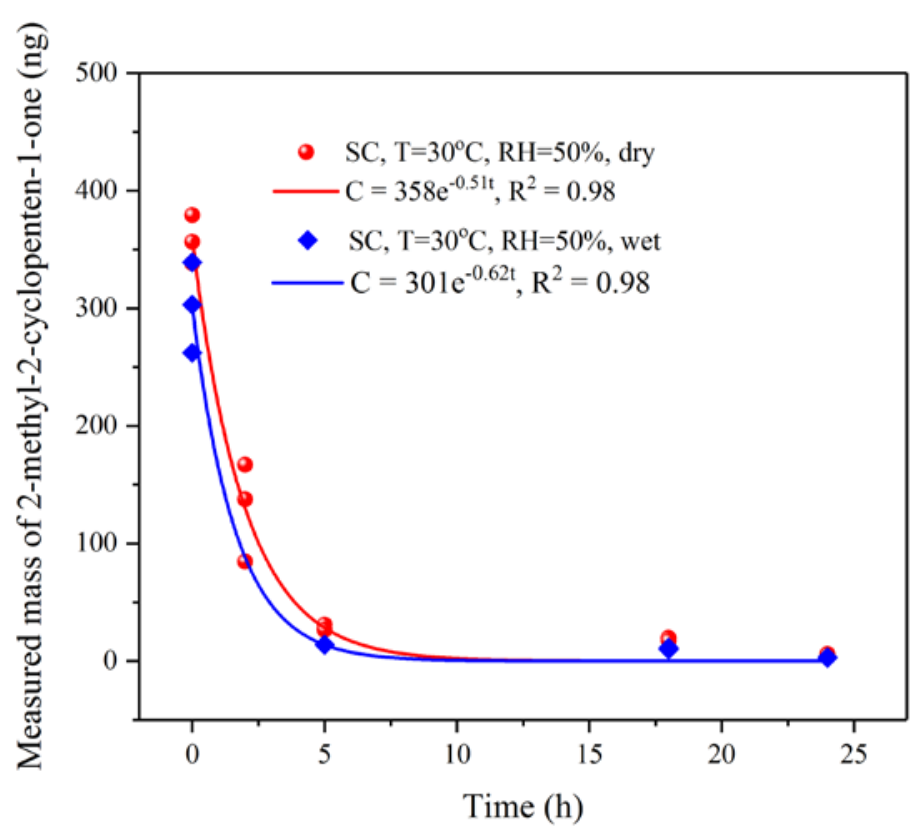

(d) 


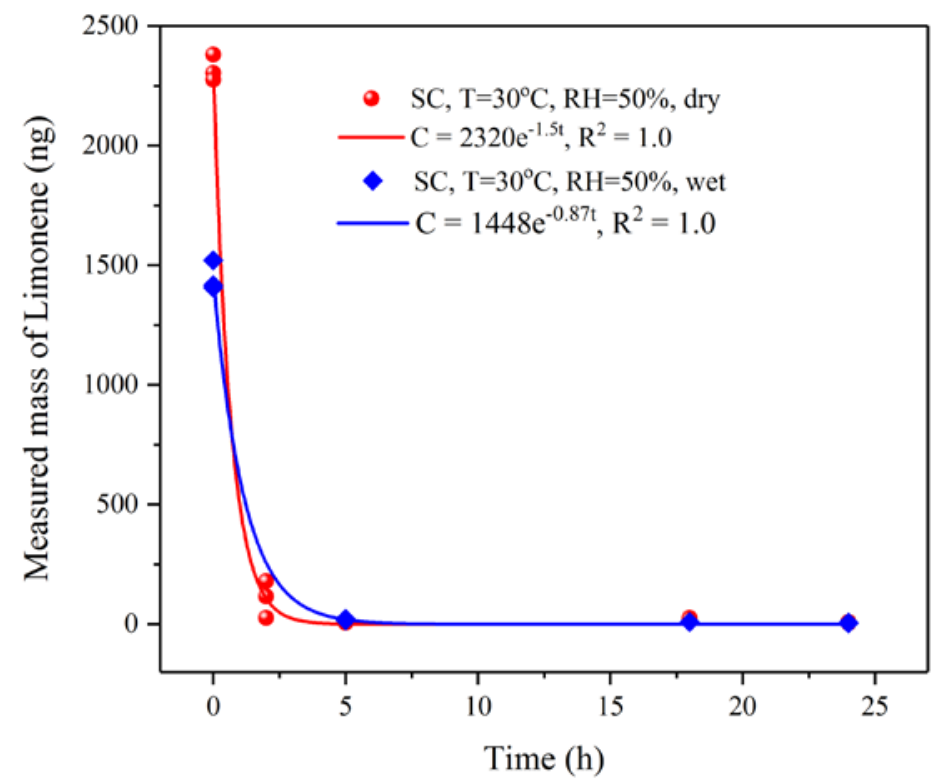

(e)

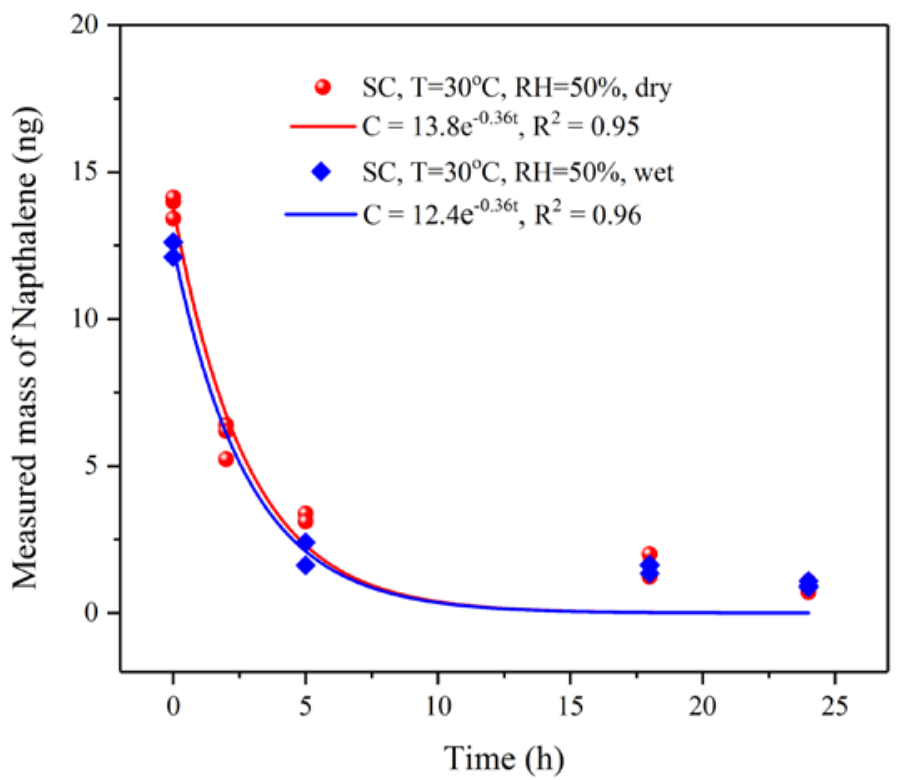

(f) 


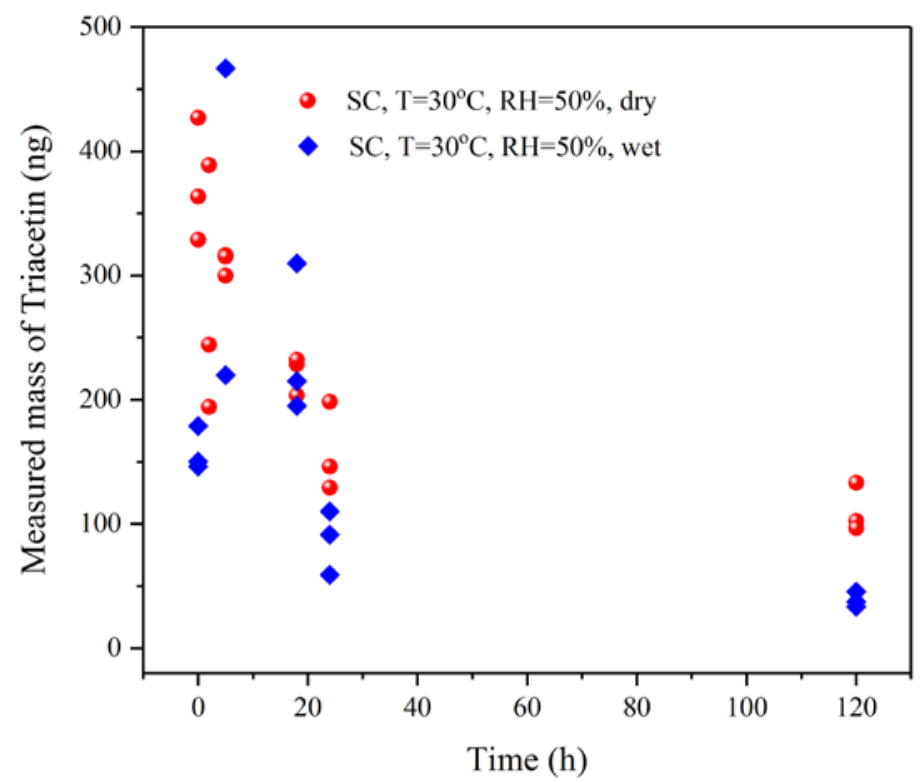

(g)

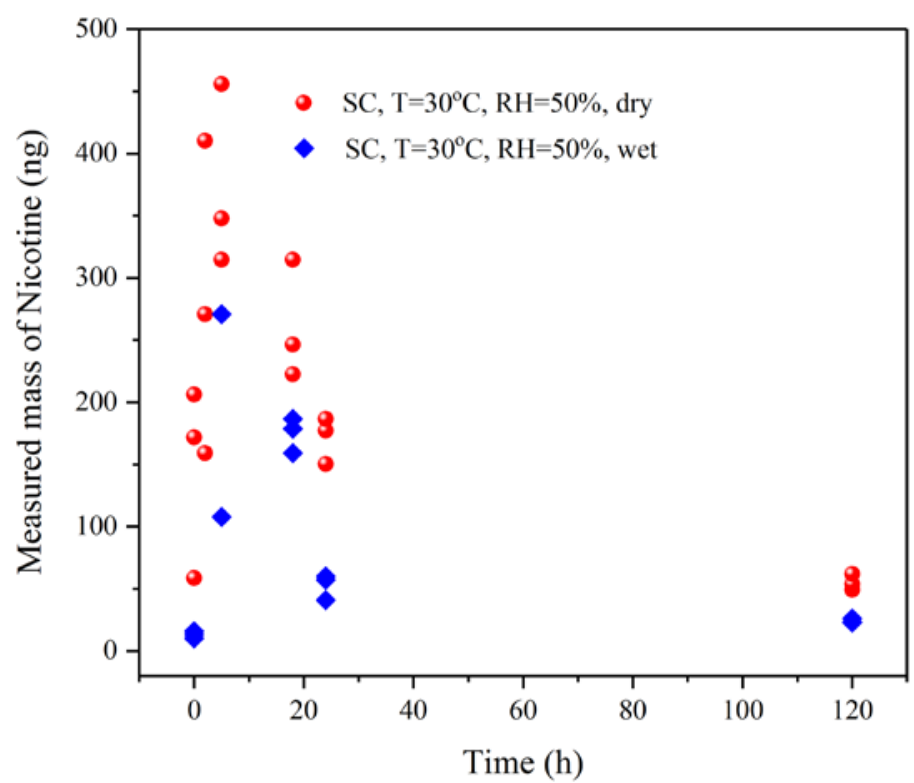

(h)

Figure 3.7: $\quad$ Measured emitted masses of target chemicals from each dry and wet cigarette filter conditioned in dark chambers. 
The other two chemicals that have high water solubility and $K_{\text {wa }}$ are triacetin and nicotine (Table 3.3). For both chemicals, the emitted mass from the wet filters increased for the $5 \mathrm{~h}$ and $18 \mathrm{~h}$ samples and then decayed. In the saturated butts, nicotine was likely present primarily in the nonvolatile, monoprotonated form. As the butts dried in the dark chamber, nicotine likely reverted to the free-base form. Hence, more nicotine was emitted into the headspace vial at the $5 \mathrm{~h}$ sample than the initial sample. The reason triacetin also increased from the $5 \mathrm{~h}$ and $18 \mathrm{~h}$ samples compared to the initial sample is unknown.

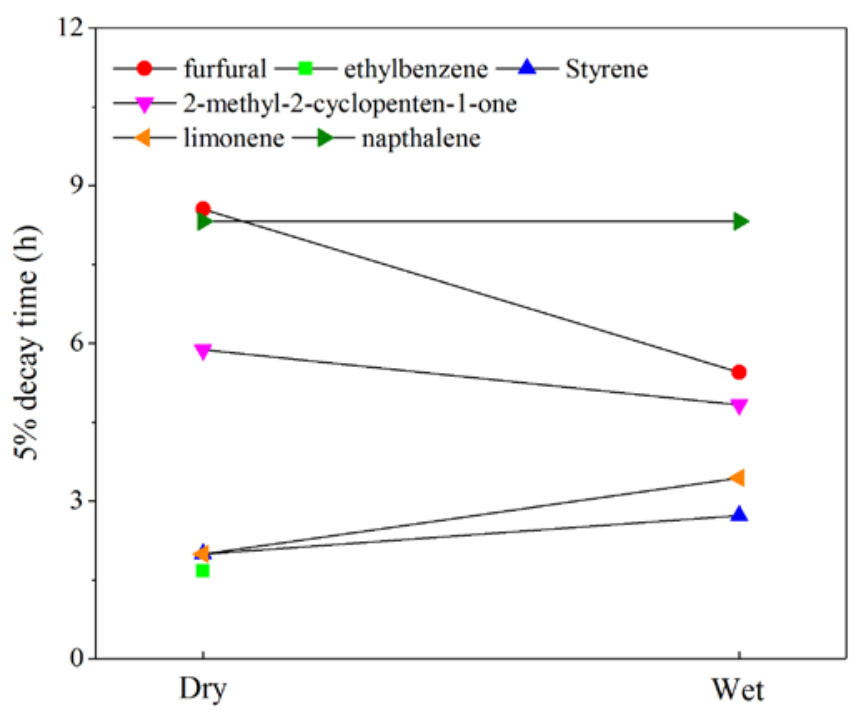

Figure 3.8: $\quad$ Amount of exposure time required for the masses emitted into the headspace vial to be $5 \%$ of the initial emitted masses for dry and wet filters. The decay time was not calculated for triacetin and nicotine, since their mass change with time didn't follow an exponential decay.

\subsubsection{Conditioning in large chamber}

The SPHERE chambers described above operated at relatively high air change rates $\left(35 \mathrm{~h}^{-1}\right.$ for the dark chamber and $150 \mathrm{~h}^{-1}$ for the UV chamber) compared to air change rates in buildings. The large, walk-in chamber was used to examine the influence of air change rates $(\lambda)$ that butts might experience in an indoor environment. A description of the air change rate measurement can be found in Appendix A.4.

\subsubsection{Influence of air change rate}

The masses of the eight target chemicals emitted from cigarette butts conditioned in the large walkin chamber at two different outdoor air change rates $\left(\lambda_{0}\right.$ : flow rate from outdoor air divided by chamber volume, $0.54 \mathrm{~h}^{-1}$ and $0.99 \mathrm{~h}^{-1}$ ) and curve fits to the measured data are shown in Figure 3.9 (a) through (h). The RSDs of each triplicate data for $89 \%$ of the time points in Figure 3.9 are less than $30 \%$, while the RSDs for the other $11 \%$ of points range from $31 \%$ to $68 \%$.

Similar to the data sets in Figure 3.3 and Figure 3.5, the emitted masses for all of the target chemicals other than triacetin and nicotine decayed to less than $5 \%$ of the initial masses by $48 \mathrm{~h}$. 
In contrast, the emitted masses of nicotine and triacetin decayed slower with the measured emitted mass at $48 \mathrm{~h}$ being $31 \%$ to $40 \%$ of the initial emitted mass. The $\mathrm{R}^{2}$ values of the curve fits are higher than 0.94 for furfural, ethylbenzene, styrene, 2-methyl-2-cyclopenten-1-one, and limonene. However, the $\mathrm{R}^{2}$ value for the other three chemicals, i.e., naphthalene, triacetin, and nicotine, are lower, ranging from 0.71 to 0.87 .

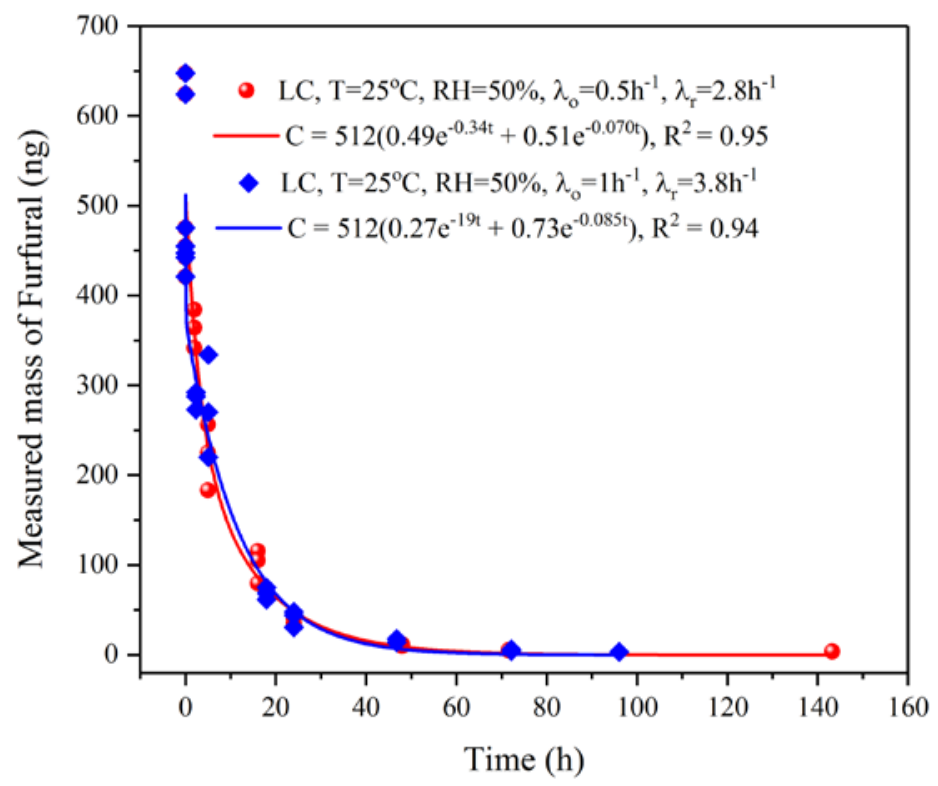

(a)

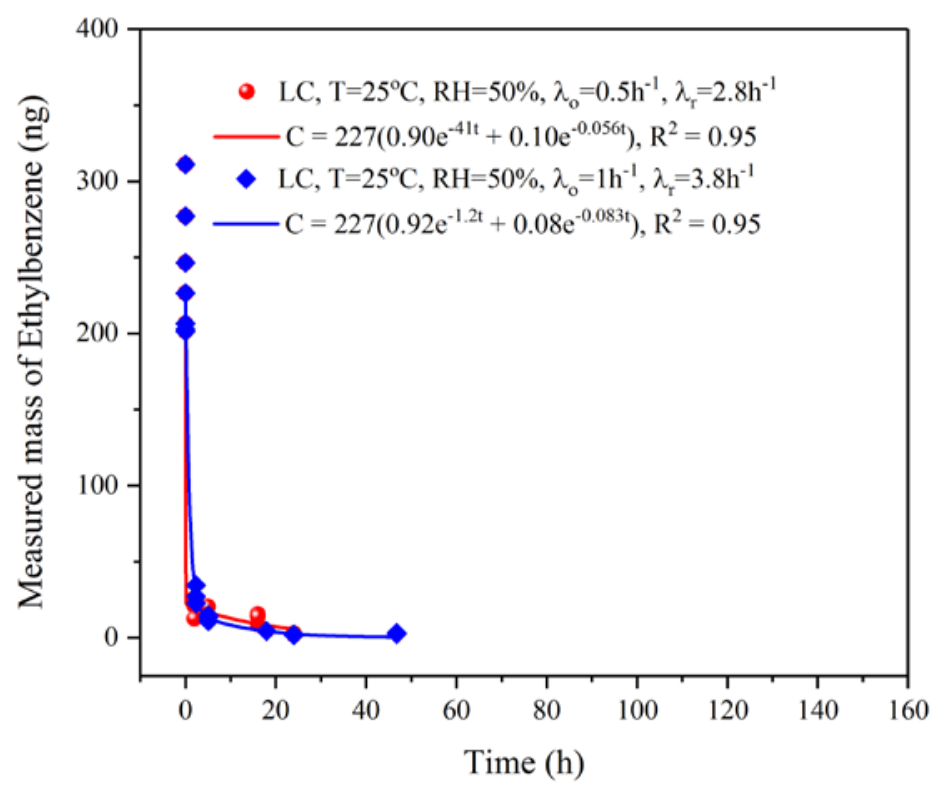


(b)

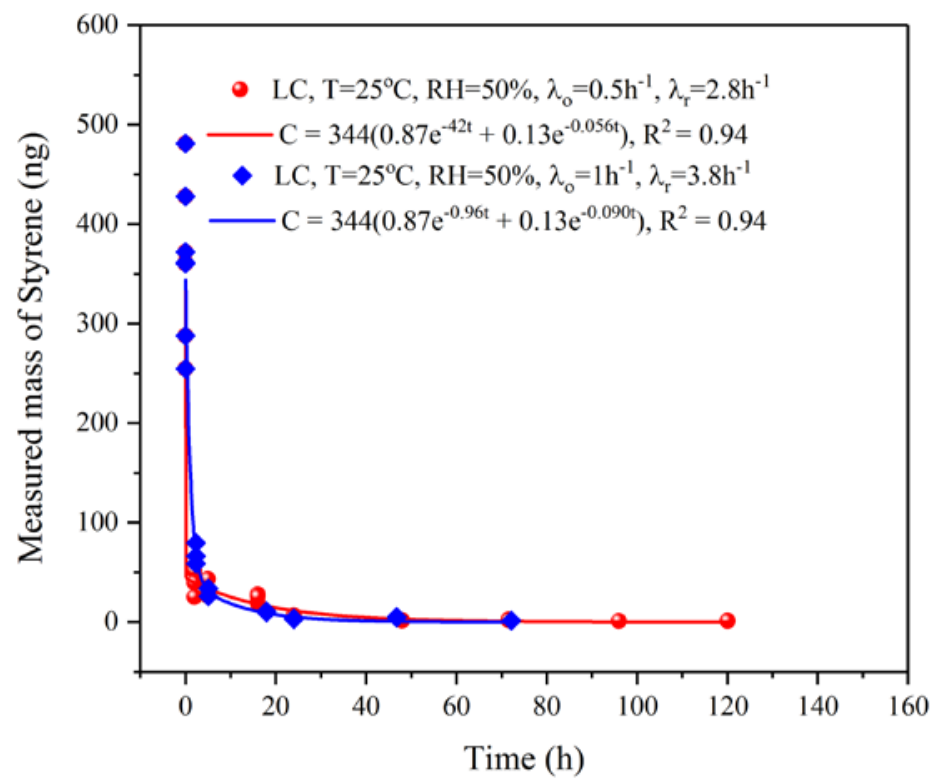

(c)

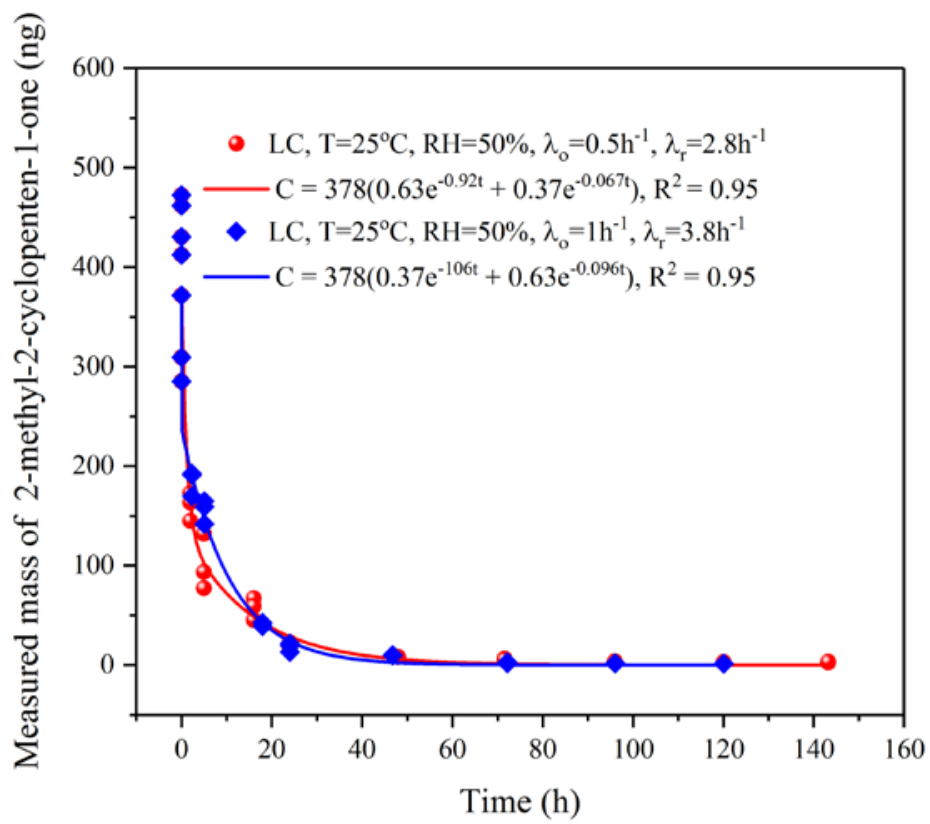

(d) 


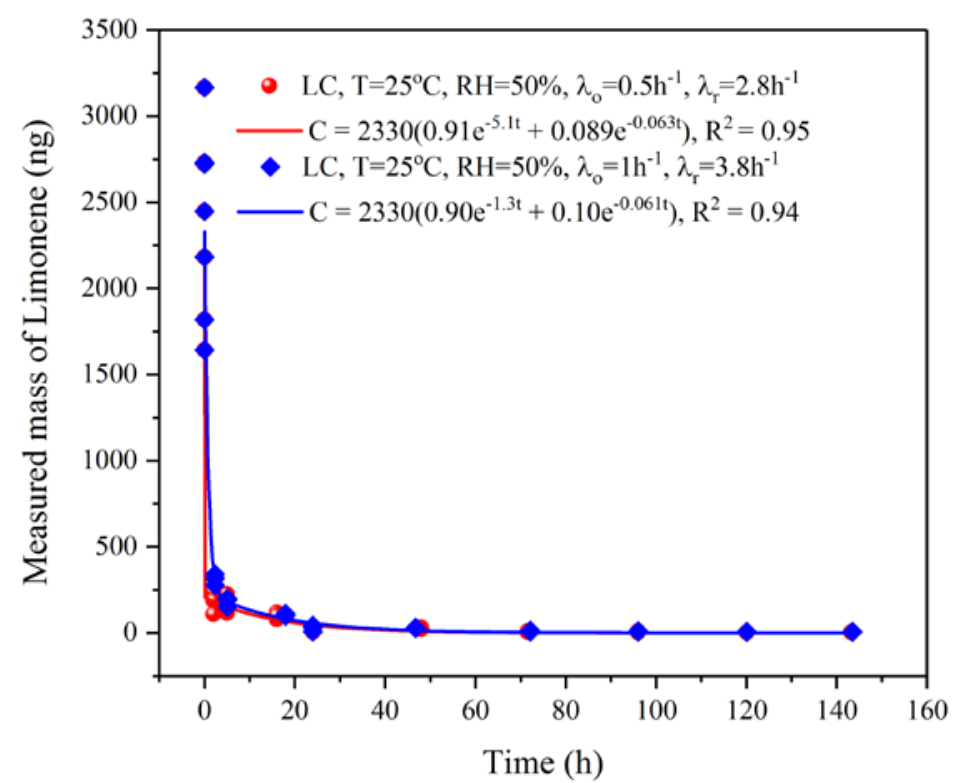

(e)

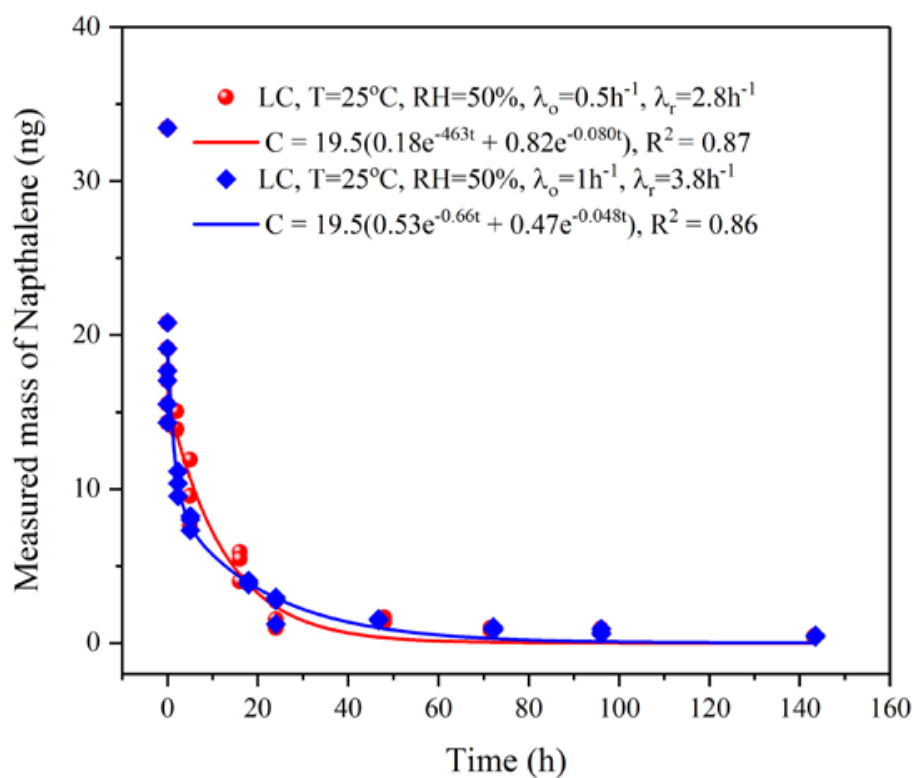

(f) 


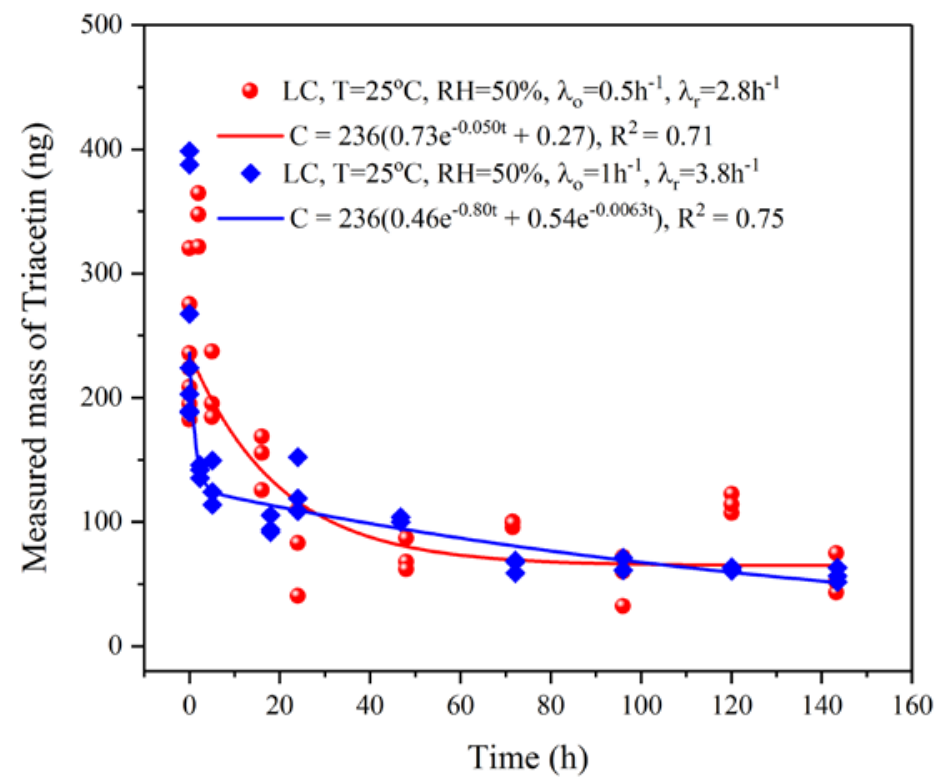

(g)

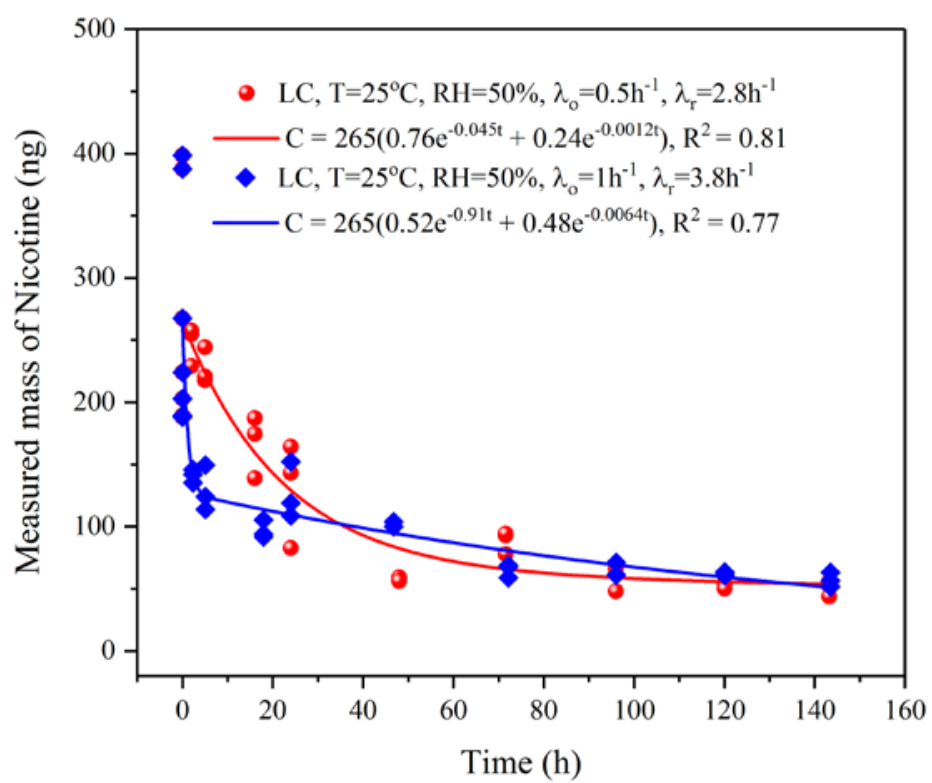

(h)

Figure 3.9: $\quad$ Measured emitted mass of the target chemicals from each cigarette butt conditioned in the large walk-in chamber at the same temperature $(T)$ and relative humidity $(R H)$, but different air change rate $\left(\lambda_{0}\right)$. $\lambda_{0}$ : flow rate from outdoor air divided by chamber volume; $\lambda_{r}$ : recirculation flow rate divided by chamber volume. 
To examine the influence of $\lambda_{o}$ on the emitted masses, the decay times were calculated and are shown in Figure 3.10 (a) and (b). Among the target chemicals, those with higher vapor pressures (i.e. $\mathrm{V}_{\mathrm{p}}>10^{-4}(\mathrm{~atm})$ : furfural, ethylbenzene, styrene, limonene, 2-methyl-2-cyclopenten-1-one, and naphthalene) show a percentage change in decay time at $\lambda_{\mathrm{o}}$ of $0.54 \mathrm{~h}^{-1}$ to decay time at $\lambda_{\mathrm{o}}$ of $1 \mathrm{~h}^{-1}$ of $-5 \%,-52 \%, 4 \%,-28 \%, 24 \%$ and $33 \%$. Given the inconsistent decay time differences between the two conditions, the air change rate doesn't seem to influence the emission rate of cigarette butts for these chemicals under the test conditions. One possible reason is that under both tested conditions, the total air change rates, including recirculation, are high enough $\left(3.3 \mathrm{~h}^{-1}\right.$ and $4.8 \mathrm{~h}^{-1}$ ) so that the rate limiting process for butt emissions would be the diffusion in the cigarette butts not the convective mass transfer around the butts. Therefore, increasing the air change rate didn't increase the emission rates in these tests.

For triacetin and nicotine, the decay times calculated from the curve fits (shown in Figure 3.10) do not describe the data in Figure 3.9 well. The decay in emitted mass at the higher air change rate was faster in the first $18 \mathrm{~h}$ and then became similar around $24 \mathrm{~h}$. In contrast to other volatile target chemicals, triacetin and nicotine may adsorb to chamber walls. Hence, as the air change rate increases, the adsorption rate to the chamber wall would increase, since the airborne transport of these heavier chemicals is likely limited by the air movement. Adsorption to the chamber walls could result in lower concentrations in the chamber, increasing the driving force for triacetin and nicotine to emit from the butts. After the adsorption to the chamber wall reaches equilibrium, the air change rate doesn't continue to influence the emission rate from the butts, as the airborne concentrations in both air change rates would be similar. At that point, the emission rates under both conditions would become similar.
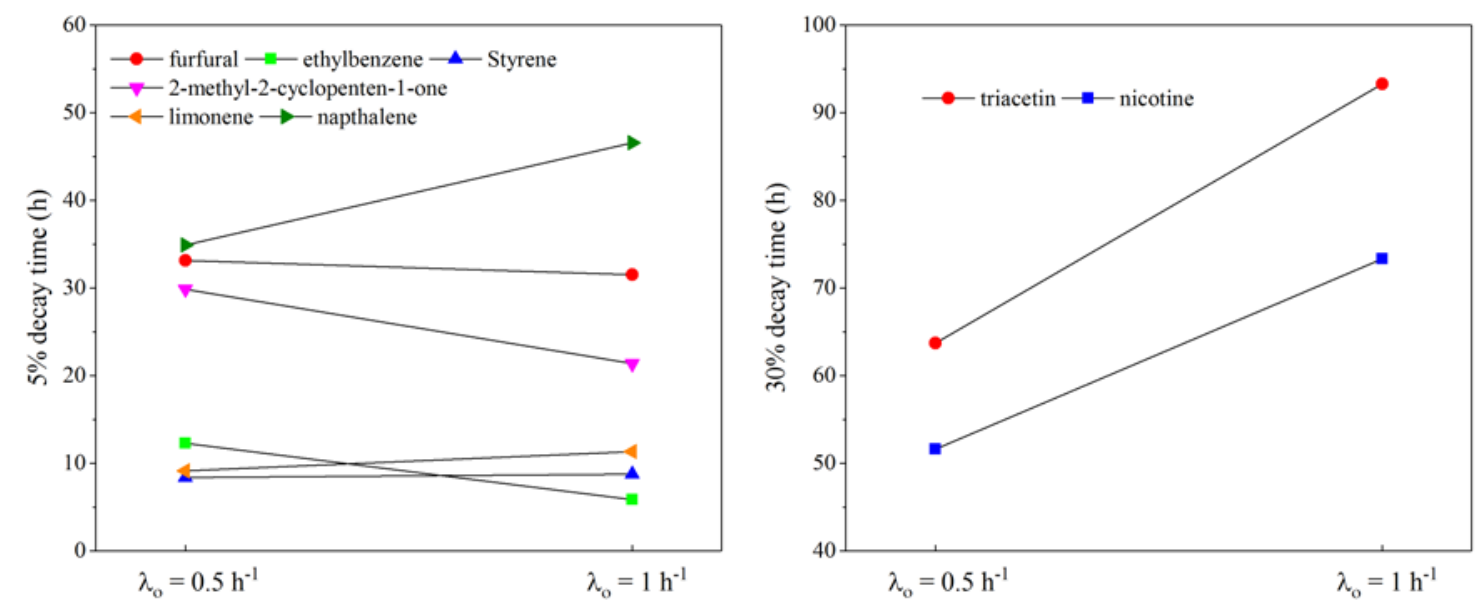

Figure 3.10: Exposure time required for the masses emitted into the headspace vial to be $5 \%$ or $25 \%$ or $30 \%$ of the initial emitted masses under conditions with $\lambda_{0}$ (flow rate from outdoor air divided by chamber volume) of $0.5 \mathrm{~h}^{-1}$ and $1 \mathrm{~h}$ ${ }^{-1}$. Note that $30 \%$ decay times were calculated for triacetin and nicotine, instead of $25 \%$ decay times. This is because the curve fit for triacetin mass change in Figure $3.9 \mathrm{~g}$ ) shows that the mass would reach steady state at $27 \%$ of the initial mass emitted. 


\subsubsection{Conditioning on rooftop}

The previous experiments examined the influence of the specific parameters under controlled chamber conditions. However, cigarette butts are often discarded outdoors experiencing a wide range of experimental conditions. The emitted masses were measured after the cigarette butts were conditioned on the roof of a building on the NIST campus during both summer and winter periods. The butts were exposed to temperatures ranging from $-2.4^{\circ} \mathrm{C}$ to $32.3^{\circ} \mathrm{C}$, relative humidity ranging from $38.6 \%$ to $93.2 \%$, wind speed ranging from $0.1 \mathrm{~m} \mathrm{~s}^{-1}$ to $15.7 \mathrm{~m} \mathrm{~s}^{-1}$, and solar radiation ranging from $0 \mathrm{~W} \mathrm{~m}^{-2}$ to $1271 \mathrm{~W} \mathrm{~m}^{-2}$ for the six-day exposure periods. In addition, rain and/or snow also fell at various times during each experimental period.

\subsubsection{Comparison of winter and summer}

Unlike the chamber datasets (Figure 3.3, Figure 3.5, and Figure 3.9), the emitted masses did not always decay to less than $5 \%$ of the initial masses by $48 \mathrm{~h}$. The masses from winter samples typically decayed slower than the masses from summer samples. As noted in Section 3.2.2.2 (Figure 3.6), a $10{ }^{\circ} \mathrm{C}$ increase in temperature and a $25 \%$ change in relative humidity resulted in roughly the same increase in emitted mass for most of the target chemicals under controlled chamber conditions. The overall average temperatures were nearly the same for the two summer experiments $\left(25.1^{\circ} \mathrm{C} \pm 3.0^{\circ} \mathrm{C}\right.$ and $\left.24.4^{\circ} \mathrm{C} \pm 3.3^{\circ} \mathrm{C}\right)$ and two winter experiments $\left(3.7^{\circ} \mathrm{C} \pm 2.7^{\circ} \mathrm{C}\right.$ and $3.5^{\circ} \mathrm{C} \pm 4.2^{\circ} \mathrm{C}$, Table 2.4). Hence, there was roughly a $20^{\circ} \mathrm{C}$ difference between the seasonal experiments. The overall average relative humidity was also nearly the same for the two summer experiments ( $72.6 \% \pm 14.1 \%$ and $72.8 \% \pm 12.1 \%)$ and two winter experiments $(64.6 \% \pm 14.1 \%$ and $64.5 \% \pm 17.1 \%$ ). There was roughly an $8 \%$ change in the average relative humidity between the samples. Given that the temperature change between summer and winter experiments was twice as big as in the chamber experiments, and the relative humidity change was one-third of the change in the chamber experiments, one would expect the temperature change to have more of an influence on the emitted mass.

However, even though the overall averages for temperature and relative humidity were similar for the two summer events and for the two winter events, the daily values were different. Specifically, the temperatures during the first $48 \mathrm{~h}$ were different for the two winter events. The average temperature during the first $48 \mathrm{~h}$ of the first winter experiment was $2.8^{\circ} \mathrm{C} \pm 2.5^{\circ} \mathrm{C}$, while in the second experiment it was $-0.2{ }^{\circ} \mathrm{C} \pm 1.4^{\circ} \mathrm{C}$. In addition, the maximum relative humidity in the first $48 \mathrm{~h}$ was $87.2 \%$ for Winter 1 and $59.5 \%$ for Winter 2 (91.1 \% for Summer 1, 87.0 \% for Summer 2). Together these factors (higher temperature and higher relative humidity) indicate, as seen in Section 3.2.2.2, that for most of the target chemicals the emitted mass during the first $48 \mathrm{~h}$ should reduce faster for the Winter 1 experiment as compared to Winter 2 experiment. This was seen for furfural, ethylbenzene, styrene, 2- methyl-2-cyclopenten-1-one, limonene and naphthalene (Figure 3.11 (a) through (f)). Only data for these six chemicals were curve fitted, with decay times being faster for the Winter 1 experiment for five of these six chemicals (Figure 3.12). The variability in the triacetin and nicotine data are discussed below. 


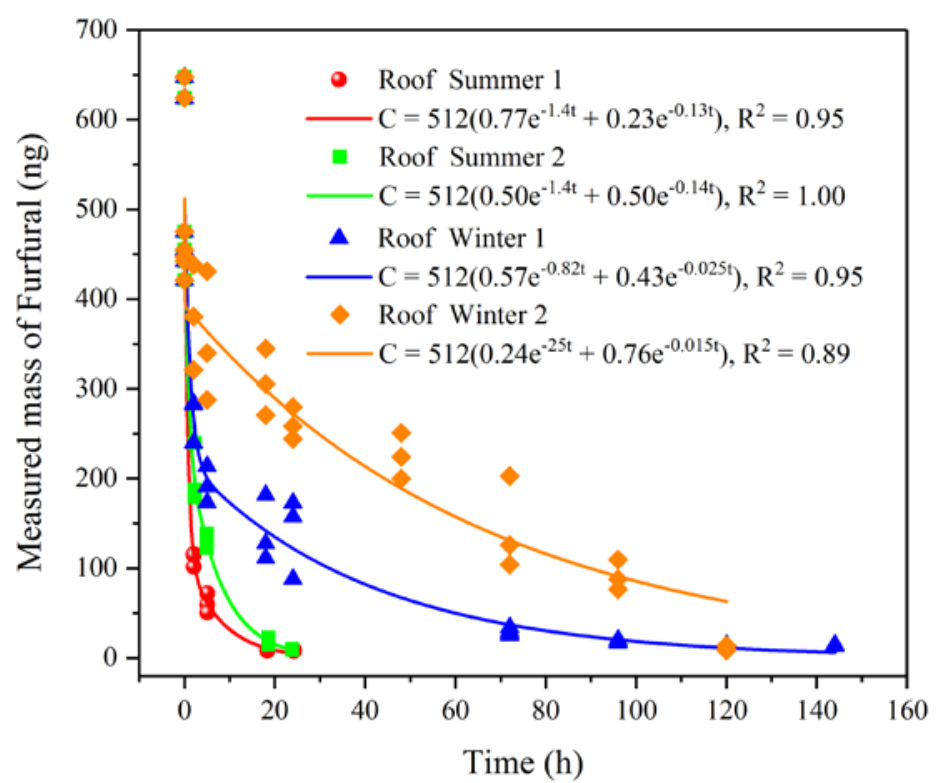

(a)

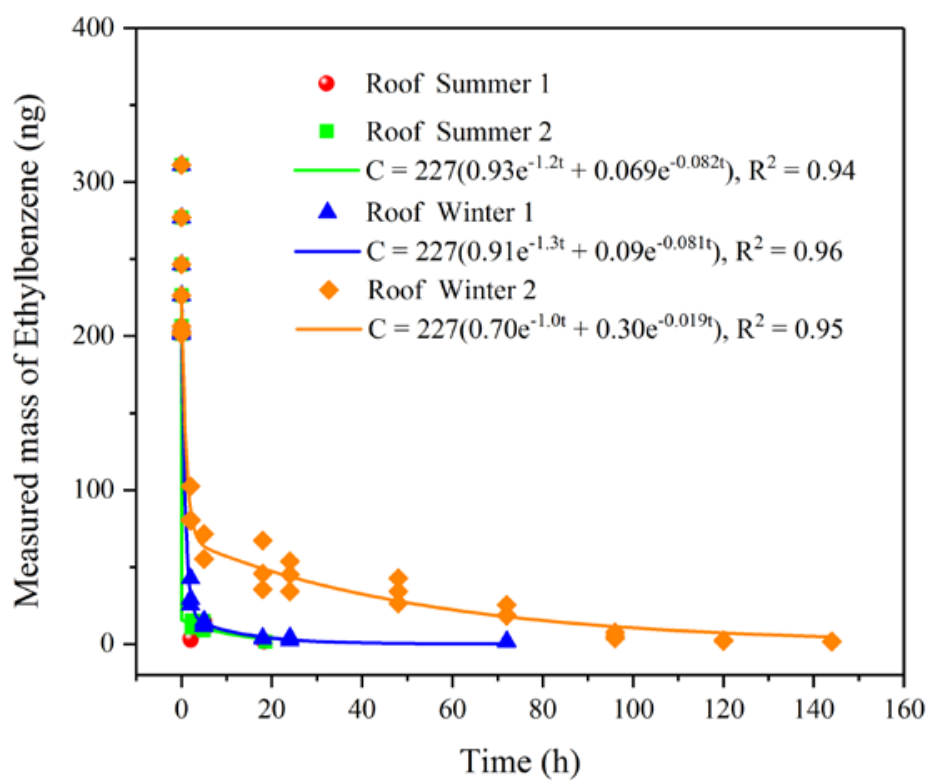

(b) 


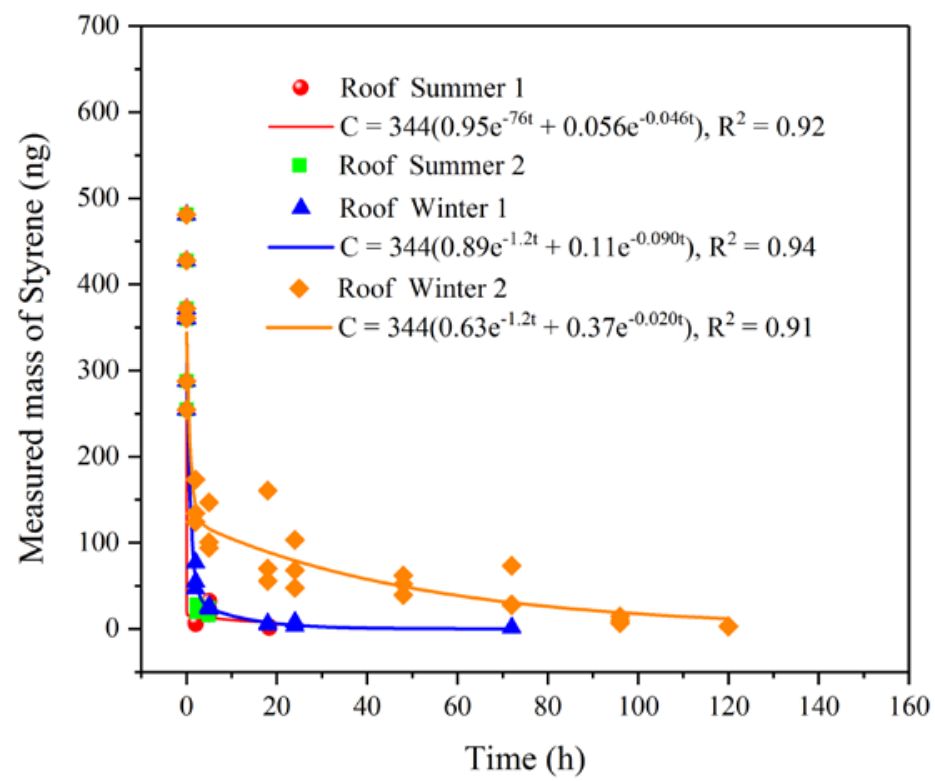

(c)

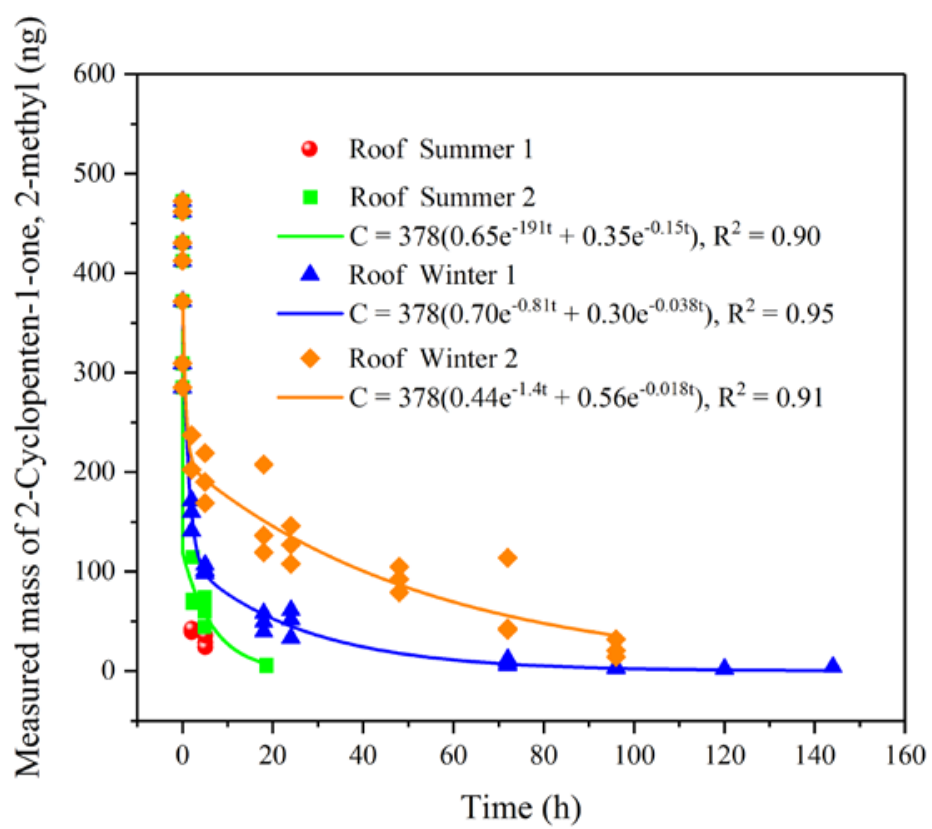

(d) 


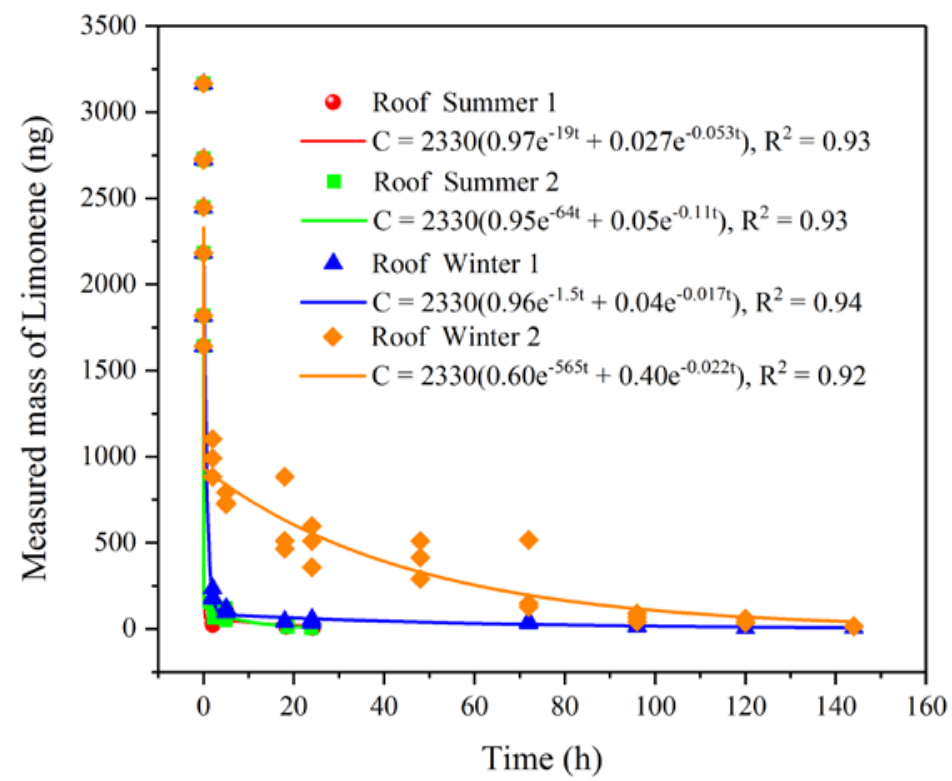

(e)

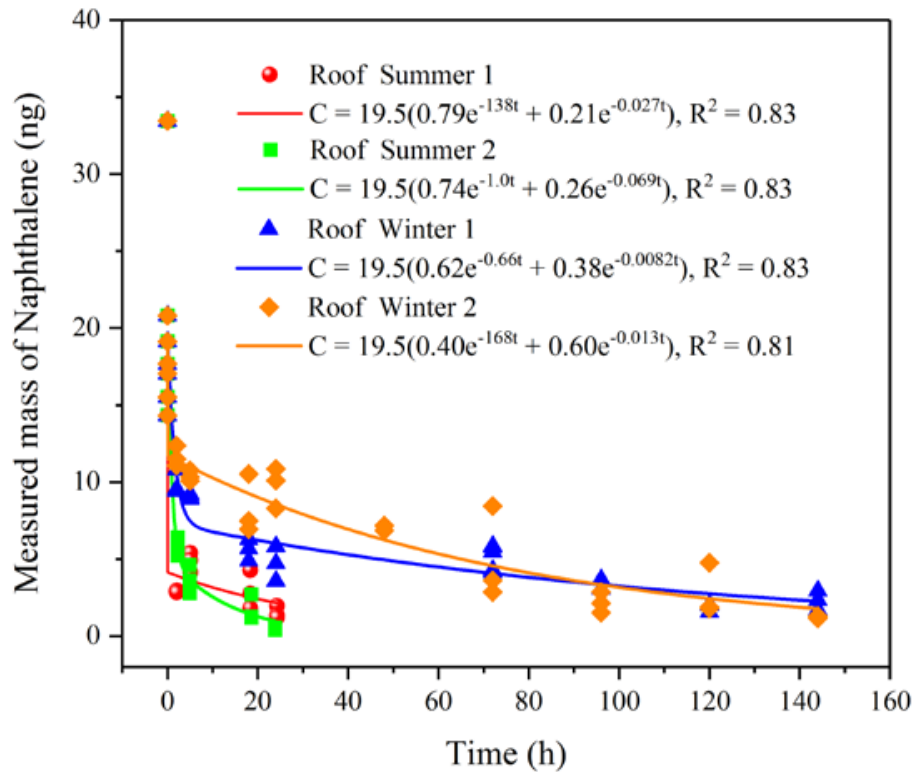

(f) 


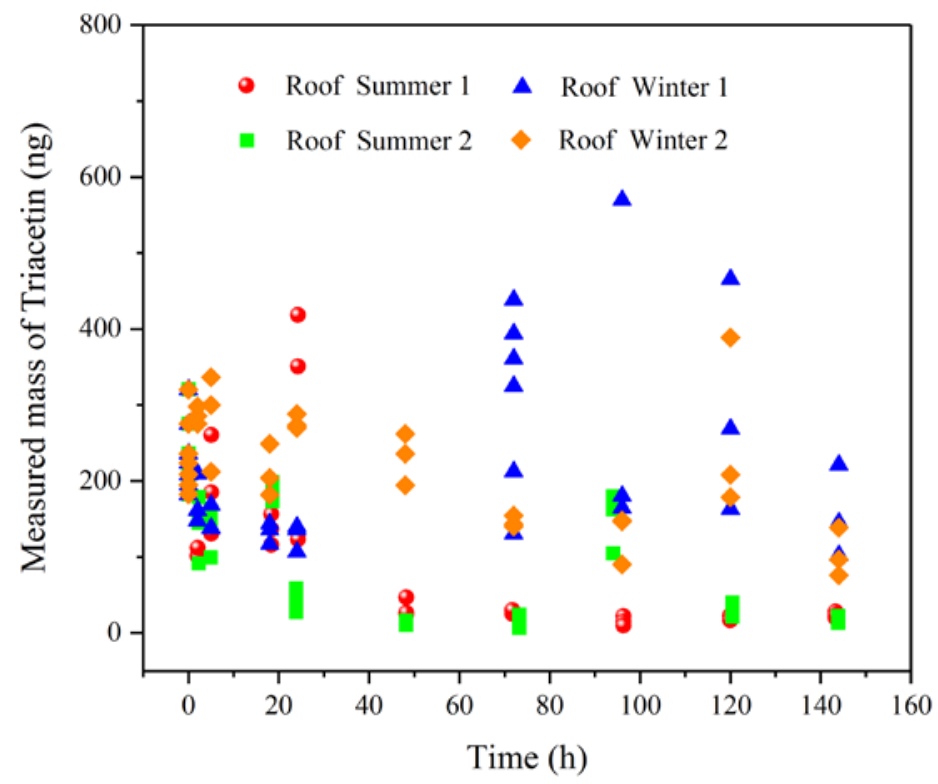

(g)

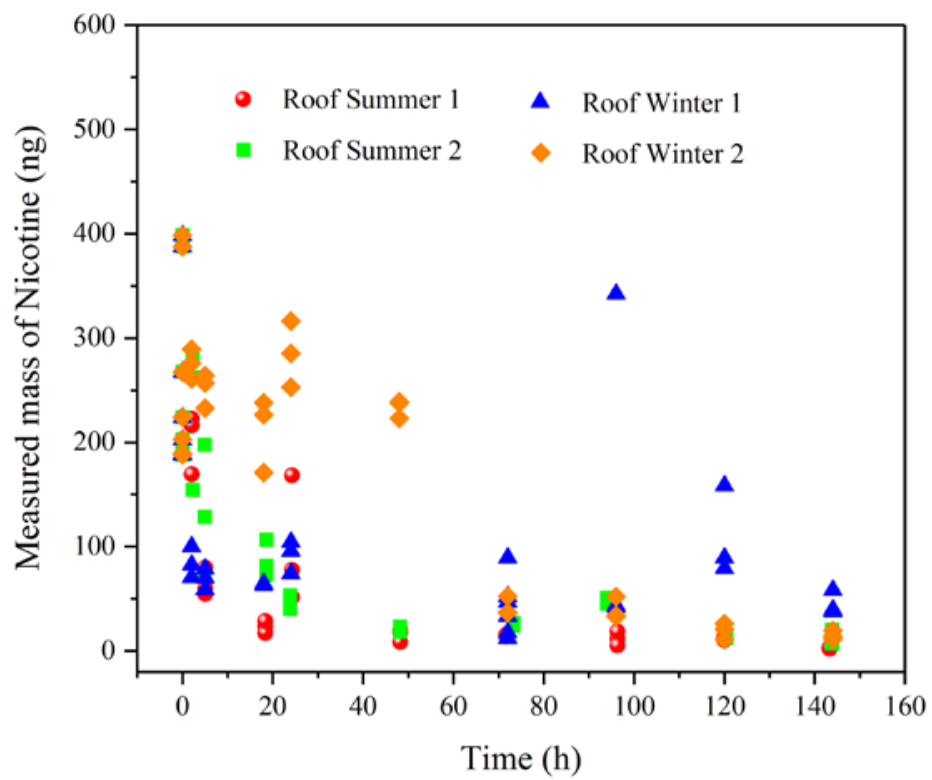

(h)

Figure 3.11: $\quad$ Measured emitted masses of target chemicals from each cigarette butt conditioned on roof of a NIST building in both summer and winter. 


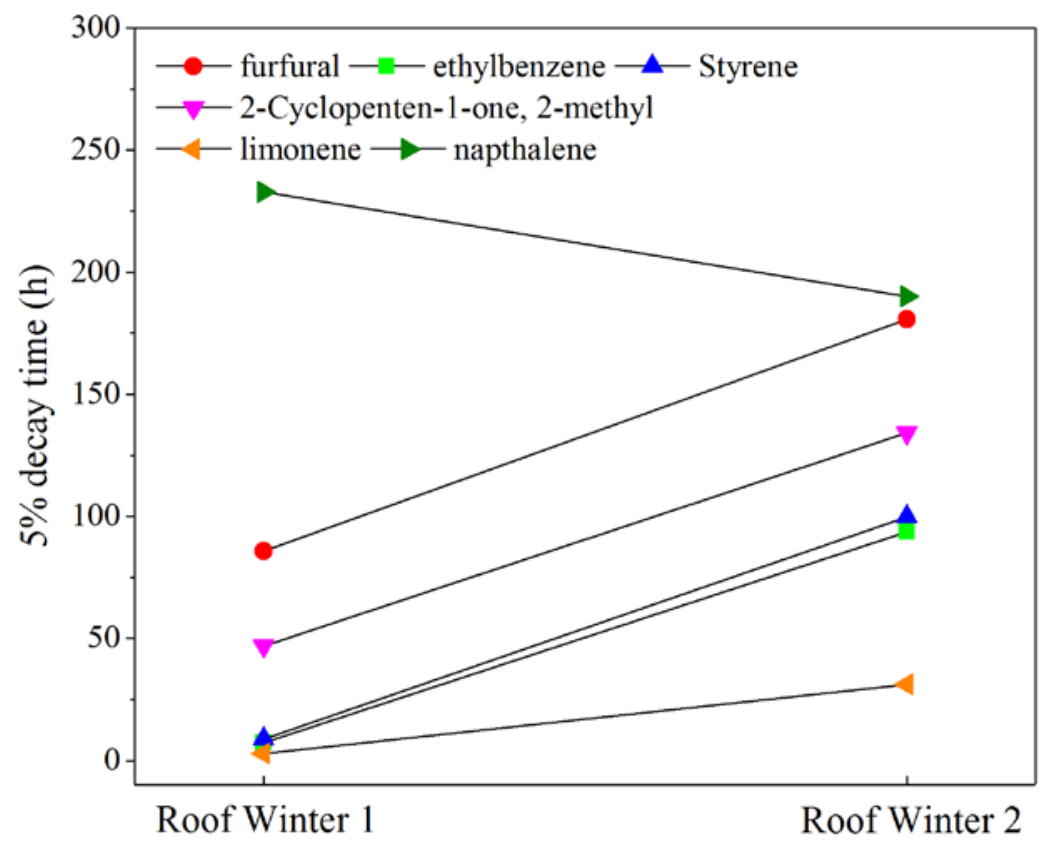

Figure 3.12: $\quad$ Exposure time required for the masses emitted into the headspace vial to be $5 \%$ of the initial emitted masses. Lefthand values are from the Roof Winter 1 samples. Right-hand values are from the Roof Winter 2 samples.

\subsubsection{Impacts of Water Saturation}

The data from triacetin and nicotine are more erratic than the other chemicals, with emitted masses at several time points after $72 \mathrm{~h}$ being higher than the masses after $2 \mathrm{~h}$ (Figure $3.11(\mathrm{~g})$-(h)), which may be partly resulted from the precipitation events described below. Triacetin and nicotine are three orders of magnitude more water soluble than four of the six other target chemicals and have one to six orders of magnitude higher $K_{\text {wa }}$ than the other chemicals (Table 2.3). In addition, as noted in Section 3.2.2.3, nicotine protonates in the presence of acidic water. Hence, it would be expected that the masses emitted from triacetin and nicotine would be more dependent upon water saturation of butts due to precipitation.

The timing of water saturation can be deduced from precipitation data (Figure 2.19). For each experiment a major rainfall event $\left(0.01 \mathrm{~mm} \mathrm{~min}^{-1}\right.$ for longer than $\left.30 \mathrm{~min}\right)$ or major snow event $\left(0.01 \mathrm{~mm} \mathrm{~min}{ }^{-1}\right.$ intermittently for more than $1 \mathrm{~h}$ ) was correlated with an increase in butt mass between placement on the roof and removal from the roof (Figure 3.13, colored vertical bars show the approximate timeframes of the precipitation events). The emitted masses for triacetin and nicotine from samples taken after these precipitation events were significantly higher than the masses from samples taken immediately before these precipitation events (Figure 3.11 (g) and (h)): Roof Summer 1, 96h to 122h; Roof Summer 2, 72 h to 85 h; Roof Winter 1, 46 h to 62 h; and Roof Winter 2, $96 \mathrm{~h}$ to $116 \mathrm{~h}$. 


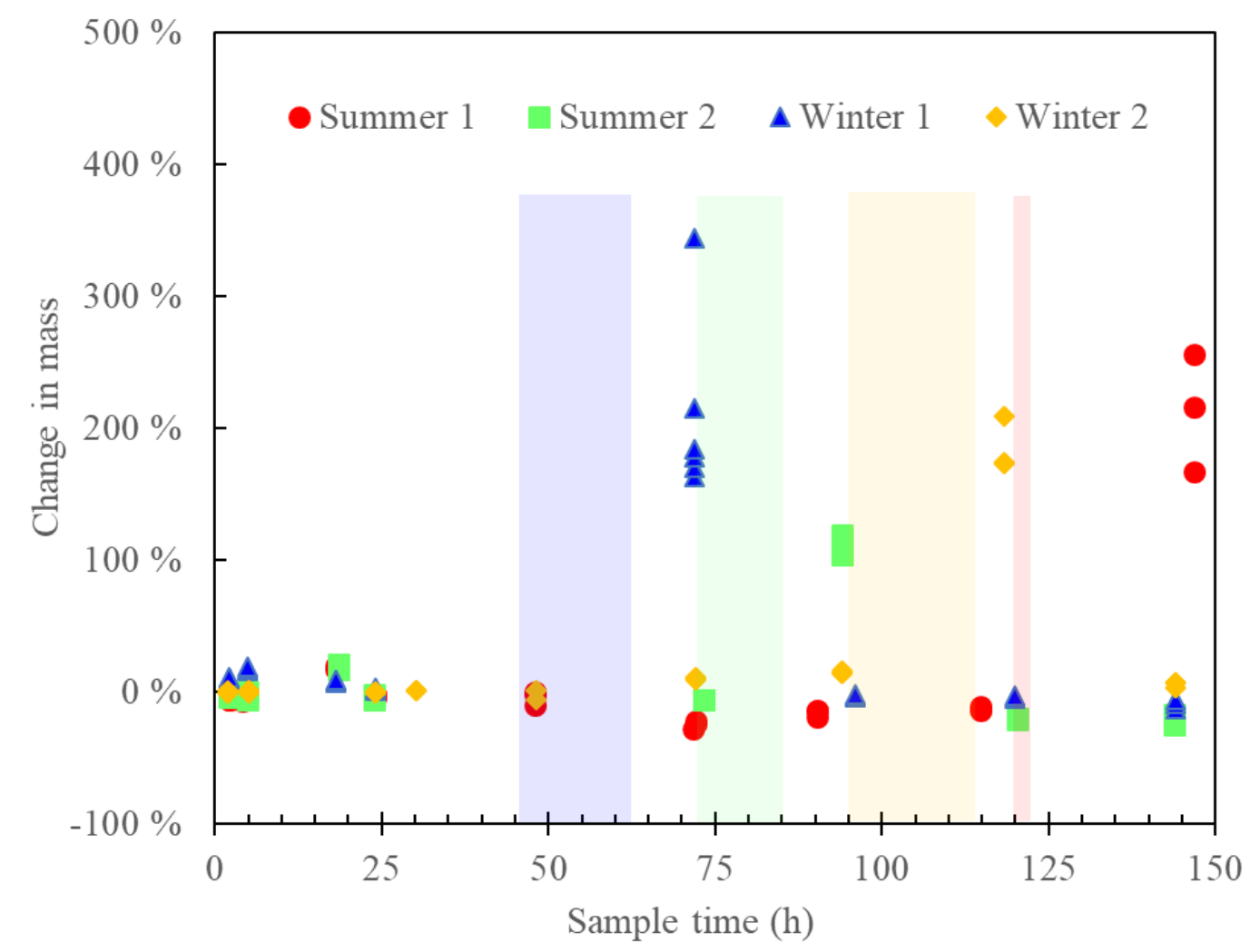

Figure 3.13: Change in butt mass between placement on roof and removal from roof. No data for Roof Summer 2 or Roof Winter 1 at $48 \mathrm{~h}$. Vertical bars show major rain and snow events. The pink bar is for the Summer 1 sample. The green bar for the Summer 2 sample. The blue bar is for the Winter 1 sample. The yellow bar is for the Winter 2 sample.

For the 15 butts sampled after the first major precipitation event, the average butt mass increase was $185 \%$ (standard deviation of $60 \%$ ). The average mass change of the butts removed prior to each major rainfall/snow event was $0 \%$ (standard deviation $11 \%, \mathrm{n}=72$ ). Hence, the precipitation events likely saturated the butts (as opposed to adsorbing water from the high relative humidity that occurred throughout the experiments). The mass data for roof butts were more variable than the data for the 179 comparable butts that were placed in conditioned chambers for roughly the same time periods which had a standard deviation $=1 \%$ (average change $=-1 \%$ ). For chemicals other than triacetin and nicotine, most of the major precipitation events occurred after the calculated $5 \%$ decay times (Figure 3.12). Exceptions included the Winter 2 data for furfural and 2- methyl-2-cyclopenten-1-one, and both Winter naphthalene datasets.

Not only were the butts gaining mass from precipitation, their physical appearance after major precipitation events also changed. Figure 3.14 shows butts collected after a major rainfall event during a preliminary experiment. Noticeable discoloration occurred to the butts, indicating that water soluble chemicals had migrated from the interior of the butts to the exterior paper or the concrete below. Some butts were more discolored than others, and some of the concrete below the 
butts was also more stained than others. Most of the discoloration was on the paper wrapping the unburned tobacco and ash as opposed to the filter. Given the solubility of triacetin and nicotine in water, it is likely that some of these chemicals initially present inside the butts migrated to the surface of the butts during saturation with water.
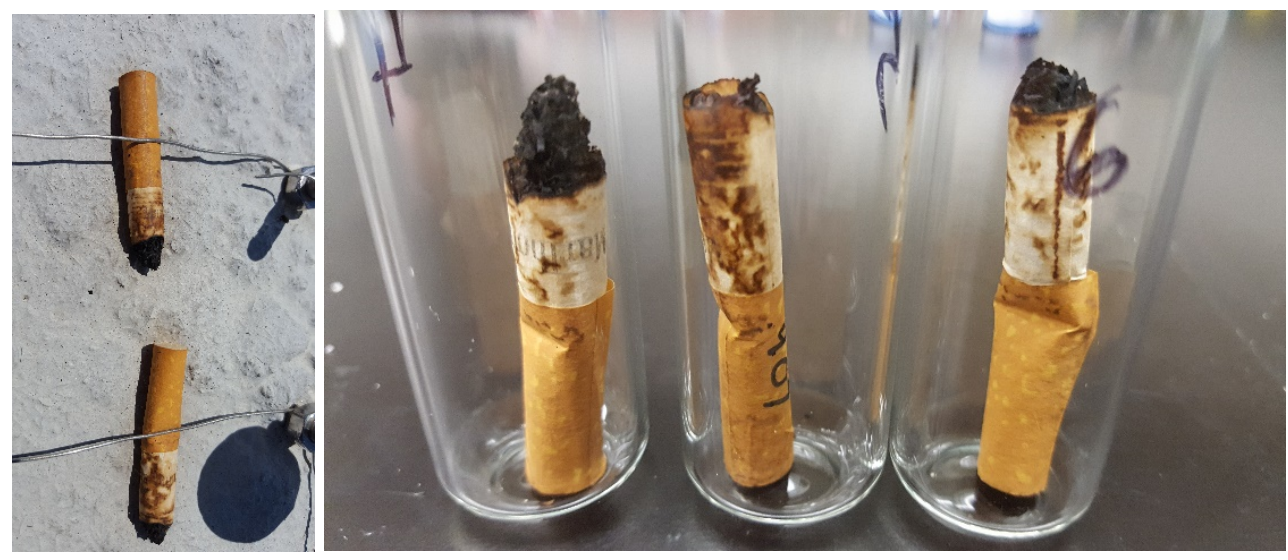

Figure 3.14: Change in butt appearance after rain event on roof.

Other researchers have demonstrated that aqueous emission of nicotine from cigarette butts into water can be a relatively fast process. Standardized cigarette butts produced with a smoking machine leached $7.3 \mathrm{mg}$ of nicotine per g of butts into $1 \mathrm{~L}$ of purified water, of which $50 \%$ was released in the first 27 min during the experiment (Green et al. 2014). The same study also found that the cumulative nicotine release from fifteen consecutive rainfall events each with $1.4 \mathrm{~mm}$ of precipitation was $3.8 \mathrm{mg}$ of nicotine per g butt, of which $47 \%$ was released during the first event (Green et al. 2014).

Factors other than the major precipitation events also contributed to butt mass variability. In time periods unrelated to the major precipitation events, the change in butt mass was smaller for the summer samples than the winter samples, indicating the butts were drying out in the summer heat (Figure 3.15, same data as in Figure 3.13 with vertical axis zoomed in). In addition to the major precipitation event, there were four minor precipitation events (Summer 1: $2 \mathrm{~h}$ and $88 \mathrm{~h}$; Summer 2: $77 \mathrm{~h}$; Winter 1: $3 \mathrm{~h}$ ). The Winter 1: $3 \mathrm{~h}$ and Summer 1: $88 \mathrm{~h}$ precipitation events appear to correspond to roughly $10 \%$ increases in butt mass. However, this moisture may not be enough to saturate the butts, so there was no corresponding increase in triacetin and nicotine mass emitted at those sampling times.

The water adsorbed to the butts can also increase in a non-linear manner as the relative humidity increases. An increase in the adsorbed water could increase competition of adequate sorption sites for the target chemicals (Laskar et al. 2019). The summer samples taken at $18 \mathrm{~h}$ were taken prior to the sun rising and experiencing nearly $90 \% \mathrm{RH}$ (Figure 2.16). These summer butts experienced wet-dry cycles (though not saturation) throughout the day and night. The average change in mass was $-4 \%$ at the $5 \mathrm{~h}$ sample (typically about $5 \mathrm{pm}$ ), $19 \%$ at the $18 \mathrm{~h}$ sample (typically at 6 a.m.) and $-4 \%$ again at the $24 \mathrm{~h}$ sample (typically at noon). In contrast, the Winter 2 samples stayed 
relatively consistent in moisture content throughout the first $48 \mathrm{~h}$, while the Winter 1 samples dried out during the first $48 \mathrm{~h}$ after experiencing a mist with fine water droplets in the air in the first $3 \mathrm{~h}$.

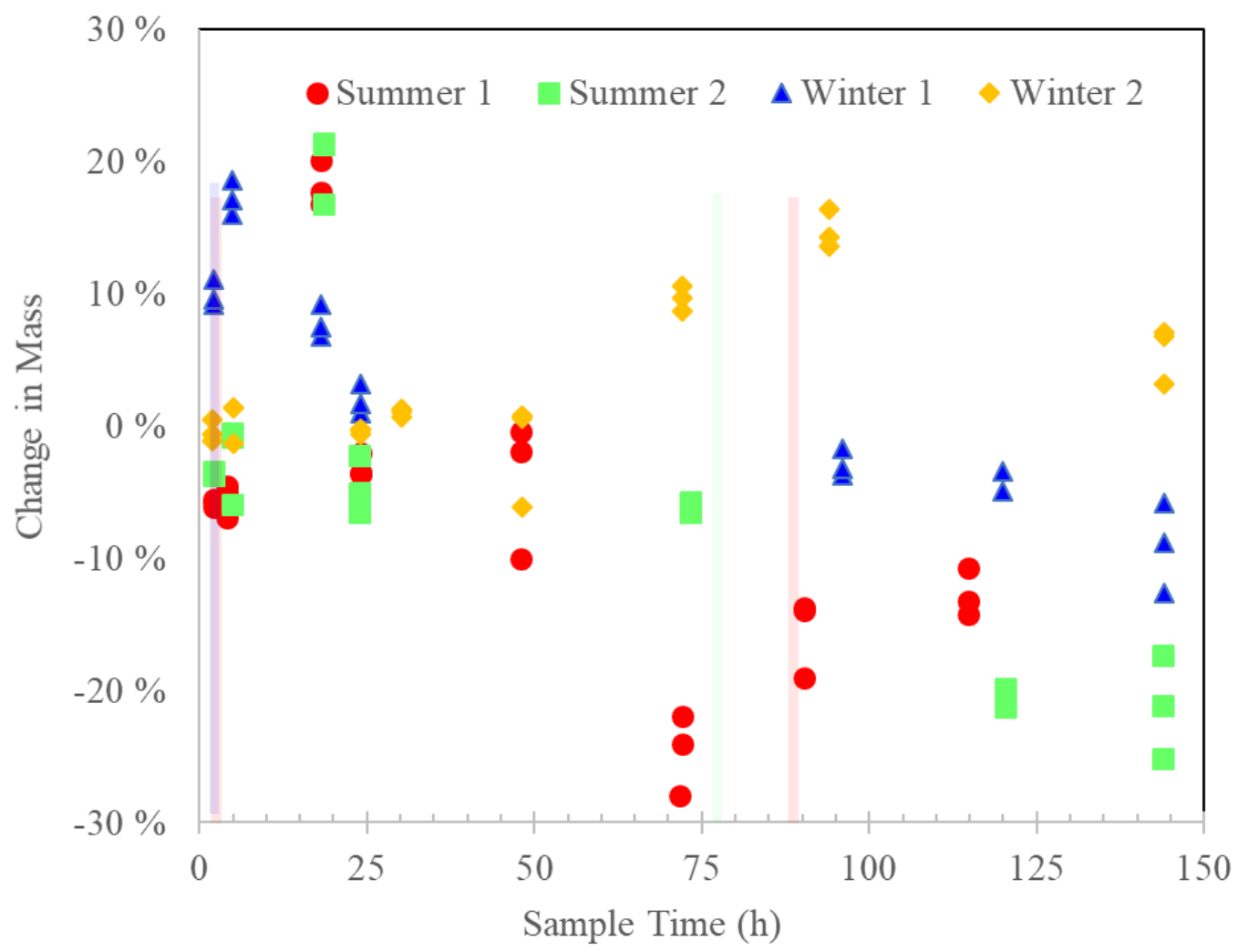

Figure 3.15: Change in butt mass between placement on roof and removal from roof. No data for Roof Summer 2 or Roof Winter 1 at $48 \mathrm{~h}$. Vertical bars show minor rain and snow events. The pink bar is for the Summer 1 sample. The green bar for the Sumer 2 sample. The purple bar is for the Summer 1 and Winter 1 sample

In summary, the butts got wet when exposed on the roof, and there was visible chemical migration on the butts after major precipitation events. Hence, exposure to water could result in elevated airborne emitted mass during the headspace analysis and be responsible for much of the variation seen in the emitted masses for triacetin and nicotine during the roof experiments.

Furfural and 2-methyl-2-cyclopenten-1-one also have high solubility in water (Table 2.3), but their masses are less erratic than triacetin and nicotine. The 2- methyl-2-cyclopenten-1-one mass emitted was at or near detection limits by the time the major precipitation events occurred during all experiments. The only experiment where there was significant furfural mass remaining prior to a major precipitation event was conducted during Winter 2 . The furfural mass emitted immediately fell after the major precipitation event (96 h to $116 \mathrm{~h}$ ) (Figure 3.11 (a)). The fact that furfural fell after a major precipitation event while triacetin and nicotine increased is likely because the $K_{\text {wa }}$ of furfural is 1.5 orders of magnitude lower than triacetin and nicotine. The precipitation event mobilized all three chemicals, but furfural volatilized faster than triacetin and nicotine during the winter sampling events. 


\subsubsection{Conditioning Experiments Summary}

The experiments described in Section 3.2 were intended to determine the influence of different parameters on the emitted masses of target chemicals in headspace vials. Based on these measurements, the following general conclusions can be made:

- The emitted mass from six of the eight target chemicals (furfural, ethylbenzene, styrene, 2methyl-2-cyclopenten-1-one, limonene, naphthalene) decayed rapidly in all environments, reaching $5 \%$ of their initial emitted mass within $24 \mathrm{~h}$ in most cases. Given these results, discarded butts may be significant sources of these chemicals in the first $24 \mathrm{~h}$ after smoking. After $24 \mathrm{~h}$, these chemicals are more likely to emit at a comparatively lower rate, except when butts are discarded in low temperatures $\left(<5^{\circ} \mathrm{C}\right)$.

- The emitted mass from triacetin and nicotine decayed slower and more erratically than the other six chemicals in most of the test environments. Butts are more likely to be sources of these two chemicals for prolonged periods (greater than $24 \mathrm{~h}$ ), which may be a concern for butts disposed in enclosed spaces such as cars.

- Exposure to intense UV light can increase the emissions from butts by either increasing the temperature of the butts or enhancing the degradation of cellulose acetate.

- The air change rate under the test conditions only influenced the emissions of triacetin and nicotine in the first 24 hours.

- Increasing temperature increased the chemical emission rates from the butts in both the chamber and outdoor experiments. Butts discarded in the summer at high temperatures may be significant sources of these chemicals.

- Water has considerable influence on the chemical emission rates from butts.

o For butts discarded in dry environments, increasing the relative humidity may result in water competition for sorption sites with the target chemicals, which would enhance the emission rate of target chemicals into the air. Seven of the eight chemicals were emitted at higher rates at $50 \% \mathrm{RH}$ compared to $25 \% \mathrm{RH}$ (with triacetin being the exception).

o When butts are saturated with water, pore spaces in the butts are filled with liquid water and the water solubility of each target chemical along with its partition from water into air will impact the rate at which the target chemicals are emitted into headspace air. During the saturation process, the chemicals with high water solubility and $K_{\text {wa }}$, like triacetin and nicotine, may migrate into the surrounding environment via aqueous rather than airborne routes. Other less soluble chemicals likely emit into air from saturated butts and to greater extents as the $K_{\text {wa }}$ increases. For these chemicals, the ratios of initial emitted mass for dry-to-wet butts/filters increases with increasing $K_{\text {wa. }}$

o Water saturation enhances the decay rate of measured emitted masses for the two carbonyl chemicals: furfural and 2-methyl-2-cyclopenten-1-one, while it decreased the decay rate for the three hydrocarbons (styrene, limonene, and naphthalene). When butts get saturated by a precipitation event and then dry out, the airborne emissions of triacetin and nicotine can increase. In the roof experiments, the emitted mass of triacetin and nicotine both increased after a saturation-drying cycle during 
both summer and winter. This is likely the result of chemical redistribution in the butts when wet, which enhanced the emissions once the butts were dried out.

\subsection{EMISSION RATES FROM CIGARETTE BUTTS IN LARGE CHAMBER}

One experiment was performed to measure the average emission rates of the target chemicals from cigarette butts in a walk-in chamber. In this experiment, the airborne concentrations from cigarette butt emissions were measured, rather than quantifying the mass remaining on the butt via headspace analysis. The challenge with this approach is that the concentration can decay to levels below quantification limits quickly. To overcome this issue, eighteen cigarette butts were placed simultaneously in the large walk-in chamber during the test to increase the total emission rate and hence the concentrations in the chamber air. Four Tenax samples were taken during each sampling period, of which two were from the inlet air, one was from the middle of the chamber and one was from the outlet of the chamber (Figure 1.3). Nine sets of samples were taken at different times over the 27-h emission test. Emission rates were then calculated from the measured concentrations using a mass balance approach in section 2.5.4.

\subsubsection{Air sample concentrations in the chamber}

This section summarizes the concentration measurement results in the chamber. Detailed chemical concentrations measured in the chamber air as a function of location and time are shown in Table B.7.

Background. Chemical concentrations in background samples taken prior to the introduction of the 18 butts to the chamber were generally below quantification limits. Chemical concentrations in the inlet air samples were higher than the quantification limits for ethylbenzene (in one of two samples) and nicotine. Chemical concentrations in the middle of the chamber and outlet air samples were below quantification limits except for ethylbenzene (2 samples), styrene (1), limonene (1), naphthalene (2), and nicotine (2). However, these background concentrations were about ten times lower than the concentrations in the first air sample during the emission study (highest measured experimental concentrations), and comparable or less than the concentration in air samples taken during the last sampling period (lowest experimental concentrations).

Inlet. All air entering the chamber went through a prefilter, a HEPA filter, and an activated charcoal filter (see flow path in Figure A.8). During these experiments, the chamber ventilation system was operated with $85 \%$ recirculation of return air from the chamber into the supply airstream. Under these conditions, the concentrations in the inlet were much lower than the concentrations at the middle and outlet of the chamber, indicating the effectiveness of the filtration system. On average for all sampling times and all chemicals except ethylbenzene, the inlet concentrations were $13 \%$ of the middle and outlet samples. The notable exception was ethylbenzene, where the inlet concentrations after the first $5 \mathrm{~h}$ were $61 \%$ to $99 \%$ of the concentrations measured in the middle and outlet of the chamber, respectively. Inlet concentrations were accounted for in the calculation of emission rates, as described in Section 2.5.4. 
Chamber. Figure 3.16 shows the chemical concentrations at the outlet and in the middle of the chamber with the 18 cigarette butts placed in the center of the chamber. Triacetin and nicotine concentrations reached a plateau within about $5 \mathrm{~h}$ and stayed fairly consistent for the remainder of the experimental period $(27 \mathrm{~h})$, while the other chemical concentrations decreased with time. For all chemicals except nicotine, the percentage difference of concentration in the middle of the chamber and the outlet of the chamber was less than $37 \%$ at each sample time. More than $80 \%$ of the middle of the chamber-outlet sample pairs differed by less than $25 \%$. These data indicate that the chamber air concentration was relatively uniform and that there was no significant adsorption to the chamber surfaces for these chemicals. In a study by Singer et al. (2003), only small differences in emission rates for ethylbenzene, styrene and naphthalene in a ventilated (with an air change rate of $2 \mathrm{~h}^{-1}$ ) and unventilated stainless steel chamber (with air change rate of less than $0.02 \mathrm{~h}^{-1}$ ) were seen, indicating that the adsorption of these chemicals to stainless steel surfaces was insignificant. For nicotine in the present study, the chemical concentrations at the outlet are about 1.0 to 2.6 times lower than the concentrations in the middle, which could be the result of significant adsorption of nicotine onto the chamber surfaces. Nicotine sorption was accounted for mathematically as described in Section 2.5.4.

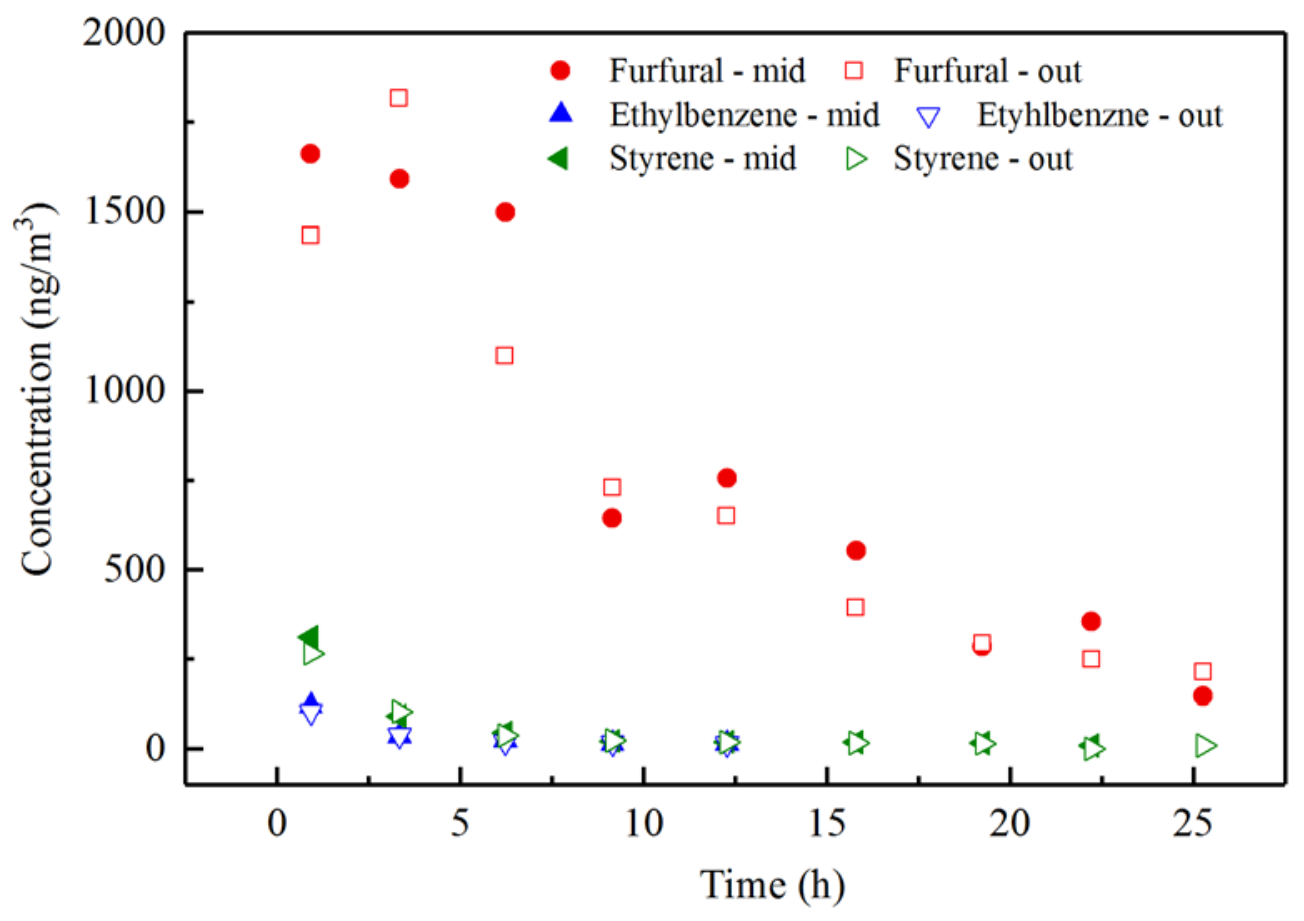

(a) 


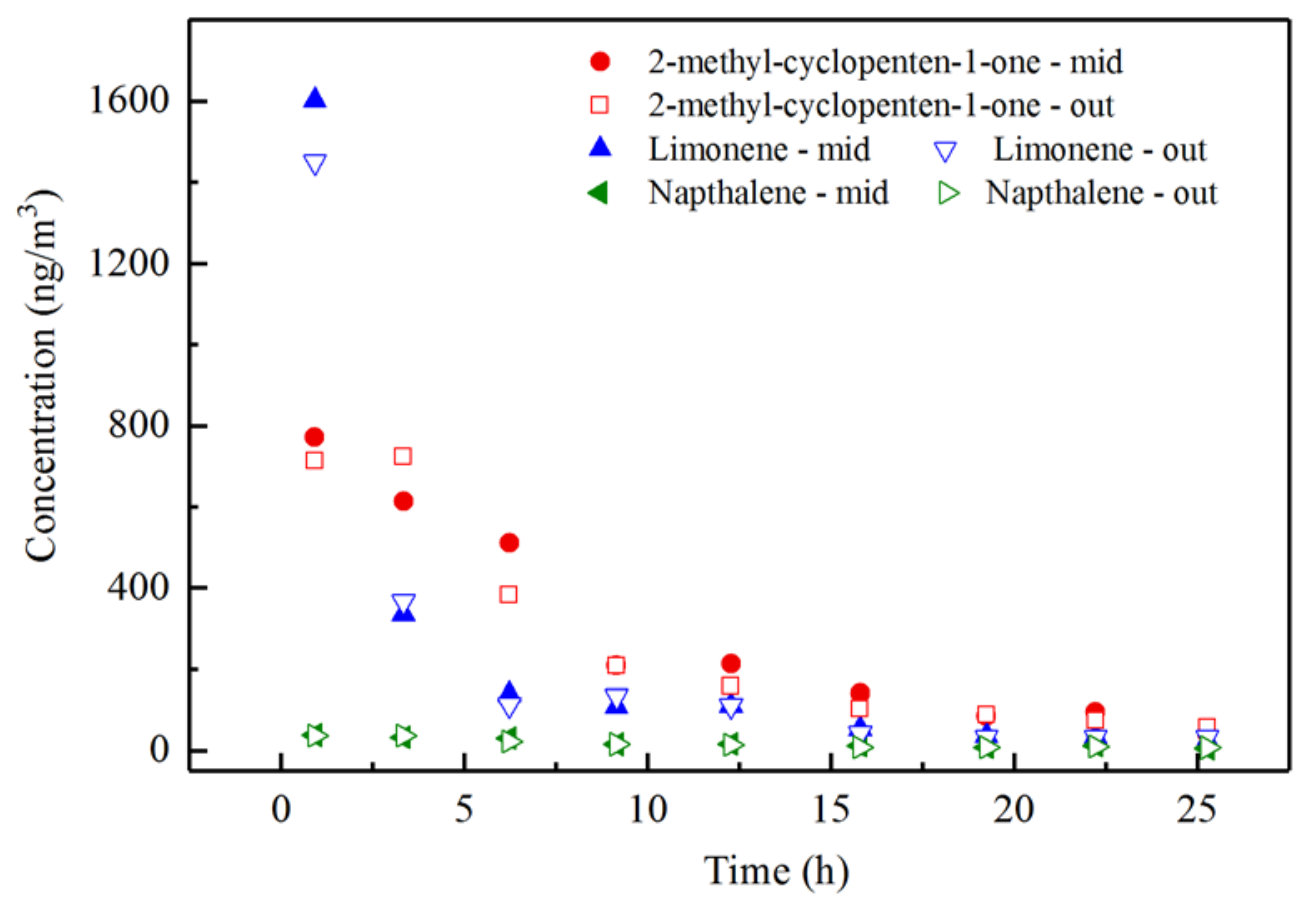

(b)

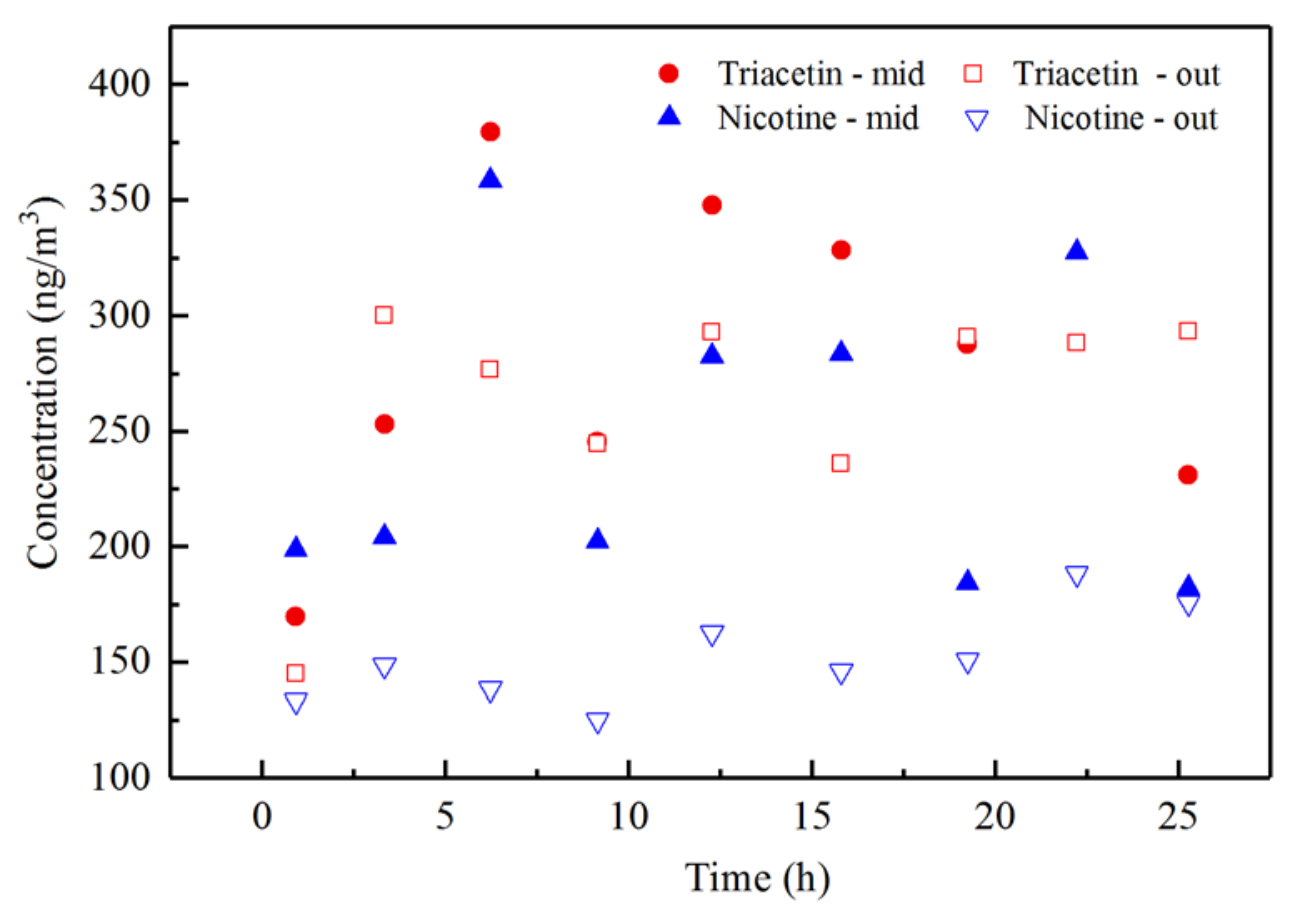

(c)

Figure 3.16 Target chemical concentrations in the middle (mid) and outlet (out) of the chamber. The time corresponding to each concentration point is the middle of the sampling period. 


\subsubsection{Calculated emission rates}

The emission rates were calculated using the method described in Section 2.5.4. For the concentrations in the chamber air ( $C$ in equation (1) and (2)), the average of the concentrations in the middle and at the outlet were used after subtracting the background concentrations. Also, adsorption to chamber surfaces was only considered in the emission rate calculation of nicotine. Nicotine was the only chemical that had consistently higher concentrations measured in the middle of the chamber compared to the outlet, indicating that sorption was occurring. Values of the

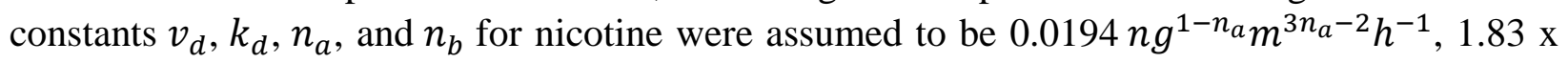
$10^{-9} n g^{1-n_{d}} m^{3 n_{d^{-2}}} h^{-1}, 1.22$, and 2.15 (from Table 1 of Van Loy et al.(1997)).

The calculated emission rates for different chemicals, normalized per cigarette butt are shown in Figure 3.17. Consistent with the concentrations, the emission rates for triacetin and nicotine reached a plateau after the first sampling period and stayed relatively constant for the rest of the experimental period, while the emission rates decreased with time for the other chemicals. Nicotine typically is present at $10 \mathrm{mg}$ to $15 \mathrm{mg}$ per unburned cigarette (of which the smoker intake is $1 \mathrm{mg}$ to $2 \mathrm{mg}$ per cigarette) (Benowitz and Henningfield 2013). A total of $36 \mu \mathrm{g}$ of nicotine per cigarette was released during the 24-h large chamber study, or roughly $0.3 \%$ of the mass present in unburned cigarettes used in this study. Even if burning releases a large amount of nicotine, there is still likely a significant mass remaining in a butt. Triacetin is normally the major plasticizer in the filter, which can account for about $6 \%$ to $10 \%$ of the filter weight (8 $\mathrm{mg}$ to $14 \mathrm{mg}$ of triacetin per filter) (Branton et al. 2017). A total of $48 \mu \mathrm{g}$ of triacetin per cigarette was released during the 24-h large chamber study, or roughly $0.5 \%$ of the mass present before burning based on the results of Branton et al. (2017). Significant triacetin mass is likely to remain in a butt after burning. Hence, nicotine and triacetin are expected to continue to emit for a long time after $24 \mathrm{~h}$ due to their significant masses in the butt and low vapor pressure.

The other six chemicals are mainly the result of combustion and pyrolysis in the cigarette (see discussion in Section 3.1). Hence, the initial mass of these chemicals in a fresh cigarette butt is likely much less than for nicotine and triacetin and may be on the same order of magnitude as the emitted mass ( $2 \mu \mathrm{g}$ to $98 \mu \mathrm{g}$ per cigarette). In addition, these chemicals are more volatile (higher vapor pressure, Table 2.3) than nicotine and triacetin. With higher vapor pressures and less initial mass, the emission rates of these six chemicals decayed more quickly than nicotine and triacetin. 


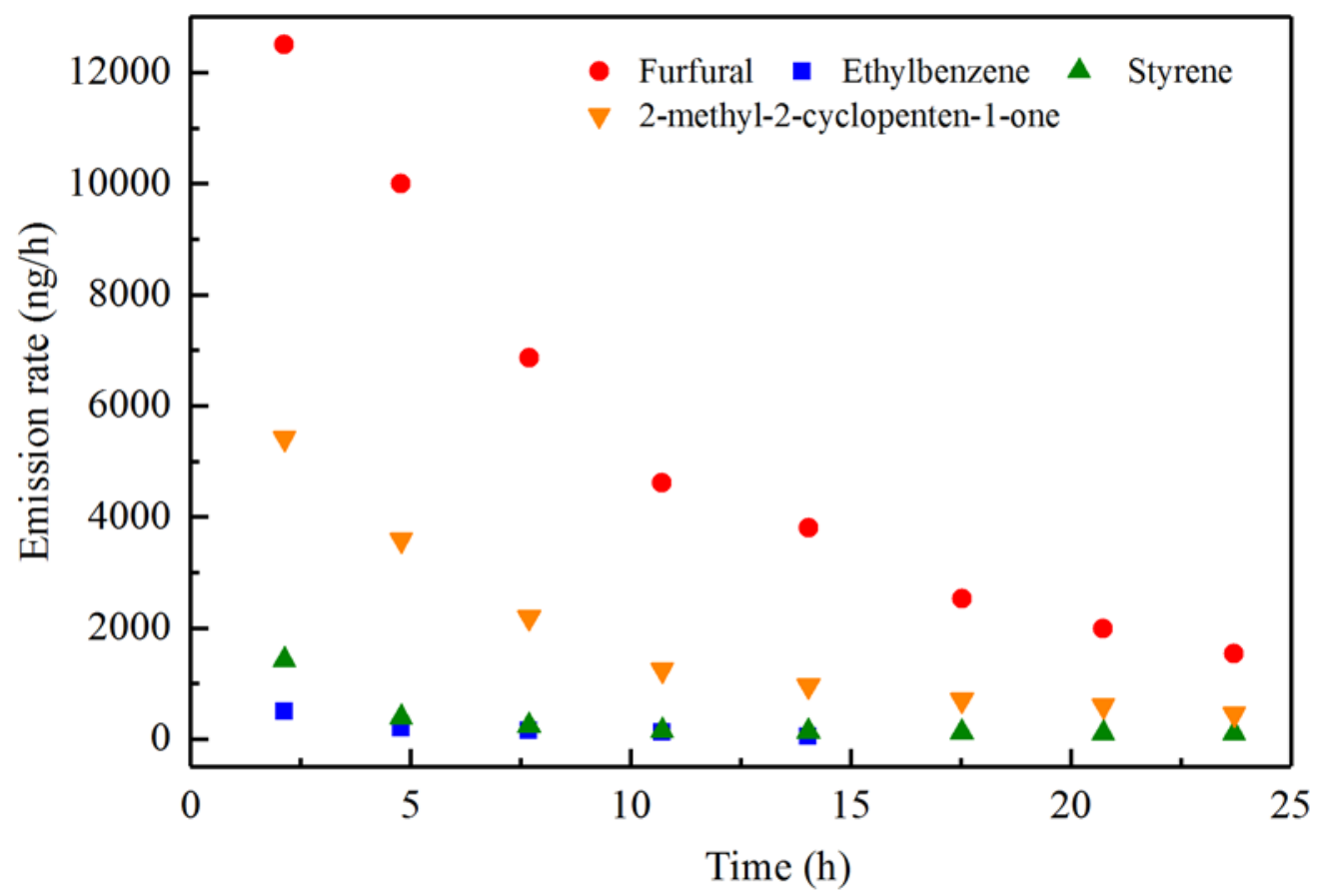

(a)

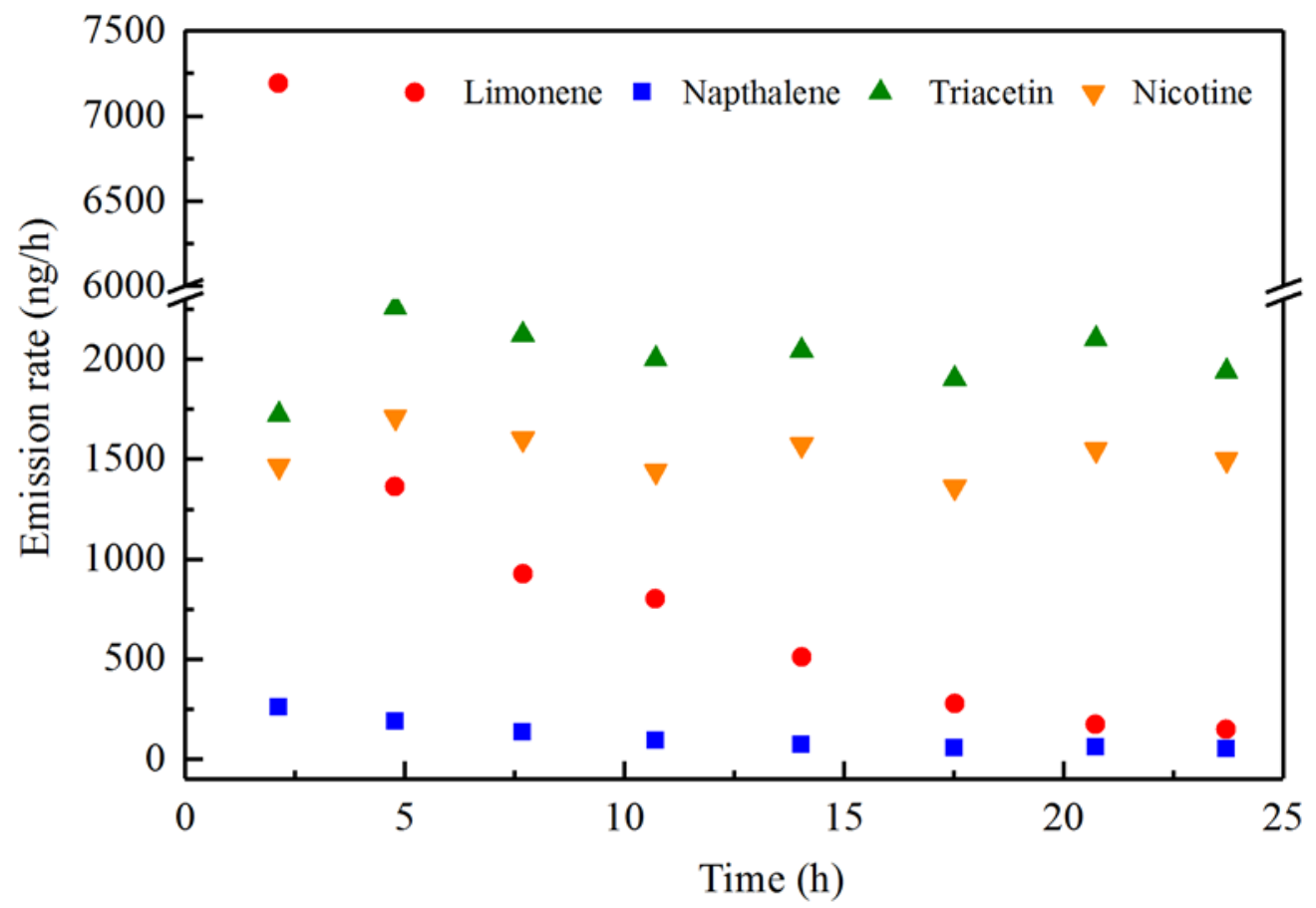

(b)

Figure 3.17. Calculated emission rates for six chemicals per cigarette butt in a walk-in chamber (ng/h). 
Exposure to airborne chemicals from smoking has included a major focus on environmental tobacco smoke, which is primarily from the burning tip of tobacco products between puffs (i.e. sidestream smoke) and the smoke that is puffed through the cigarette and exhaled by the smoker (i.e. mainstream smoke). The Surgeon General has determined that environmental tobacco smoke causes various adverse health effects including lung cancer, lower respiratory illness and impaired lung function in children, stroke, and heart disease (United States Department of Health and Human Services 2006, United States Department of Health and Human Services 2010, United States Department of Health and Human Services 2014). To put the emission rates from cigarette butts measured in the chamber in context, it is meaningful to compare the emissions from extinguished cigarette butts with the cigarette emissions during active cigarette burning (i.e., the combination of mainstream and sidestream smoke). Table 3.4 shows that the $24 \mathrm{~h}$ emitted masses per cigarette butt are about $1 \%$ to $10 \%$ of the emitted mass per active cigarette burning for ethylbenzene, styrene, limonene, and naphthalene and about $1 \%$ to $15 \%$ of the emitted mass per cigarette for nicotine. To our knowledge, no emission rates for furfural, 2-methyl-2-cyclopenten1-one, and triacetin for cigarette smoking have been reported in the literature. It is noteworthy that the $24 \mathrm{~h}$ emitted mass for nicotine from a cigarette butt could be up to $15 \%$ of the emitted mass from a burning cigarette. Hence, the long-term emitted mass could be comparable to mainstream and sidestream smoke if the cigarette butt were left longer than $24 \mathrm{~h}$ in a room or at higher temperature (e.g., in a car, where the temperature can be over $55^{\circ} \mathrm{C}$ (Lahimer et al. 2017). 
Table 3.4: Mass of chemical emitted from a cigarette butt (this study, $\mu \mathrm{g} /$ cigarette butt, first row) compared mass of chemicals emitted during active cigarette burning ( $\mu \mathrm{g} /$ cigarette)

\begin{tabular}{|c|c|c|c|c|c|c|c|c|c|}
\hline Reference & Sampling description & Furfural & Ethylbenzene & Styrene & $\begin{array}{c}\text { 2-methyl-2- } \\
\text { cyclopenten-1-one }\end{array}$ & Limonene & Naphthalene & Triacetin & Nicotine \\
\hline This study ${ }^{\mathrm{a}}$ & $\begin{array}{l}\text { Air sampling from a } 31 \mathrm{~m}^{3} \\
\text { stainless steel chamber with } \\
\text { air change rate of } 0.54 \mathrm{~h}^{-1} \\
\text { and } 18 \text { cigarette butts in the } \\
\text { middle of the chamber }\end{array}$ & 120 & 2.5 & 6.7 & 40 & 28 & 2.5 & 48 & 36 \\
\hline $\begin{array}{l}\text { Charles et al. } \\
\text { (2008) }\end{array}$ & $\begin{array}{c}\text { Mainstream and sidestream } \\
\text { smoke sampling from a } \\
\text { smoking machine } \\
\end{array}$ & $一^{\mathrm{b}}$ & 114 & 134 & - & 476 & 13 & 一 & 241 \\
\hline $\begin{array}{l}\text { Bi et al. } \\
\text { (2005) }\end{array}$ & $\begin{array}{c}\text { Environmental tobacco } \\
\text { smoke sampling in a } \\
75.5 \mathrm{~m}^{3} \text { unoccupied office }\end{array}$ & 一 & 79 & 146 & 一 & 269 & 一 & - & 323 \\
\hline $\begin{array}{c}\text { Baek and } \\
\text { Jenkins (2004) }\end{array}$ & $\begin{array}{c}\text { Environmental tobacco } \\
\text { smoke sampling in a } 30 \mathrm{~m}^{3} \\
\text { stainless steel chamber }\end{array}$ & 一 & 107 & 107 & 一 & 305 & - & - & 552 \\
\hline $\begin{array}{l}\text { Singer et al. } \\
\text { (2003) }\end{array}$ & $\begin{array}{c}\text { Environmental tobacco } \\
\text { smoke sampling in a } 45 \mathrm{~m}^{3} \\
\text { stainless steel chamber with } \\
\text { air change rate of } 2 \mathrm{~h}^{-1}\end{array}$ & - & 165 & 186 & - & - & 39 & - & 3370 \\
\hline $\begin{array}{l}\text { Daisey et al. } \\
\text { (1998) }\end{array}$ & $\begin{array}{c}\text { Environmental tobacco } \\
\text { smoke sampling in an } \\
\text { unventilated } 20 \mathrm{~m}^{3} \text { stainless } \\
\text { steel chamber with air } \\
\text { filtration rate of } 0.03 \mathrm{~h}^{-1}\end{array}$ & - & 130 & 147 & - & 一 & 一 & - & 919 \\
\hline $\begin{array}{l}\text { Martin et al. } \\
\text { (1997) }\end{array}$ & $\begin{array}{c}\text { Environmental tobacco } \\
\text { smoke sampling in an } 18 \mathrm{~m}^{3} \\
\text { unventilated stainless-steel } \\
\text { chamber }\end{array}$ & - & 80 & 94 & - & - & - & 一 & 1580 \\
\hline
\end{tabular}




\subsubsection{Association of chamber emission rates and headspace analysis mass measurements}

The association between the measured airborne emission rates from the large chamber emission test and the measured emitted masses by headspace analysis of butts placed in the large chamber were examined. For furfural, ethylbenzene, styrene, 2-methyl-2-cyclopenten-1-one, limonene, and naphthalene, both the large chamber emission rates and headspace emitted masses decayed very quickly. This is likely due in part to their relatively low initial masses in the cigarette butts and high volatility. Furthermore, the emission rates measured from chamber air concentrations and the emitted masses measured in the headspace vials after conditioning in the chamber had statistically significant linear correlations for all chemicals except for nicotine and triacetin (Figure 3.18 (a) through (f)) ( $\mathrm{p}=0.06$ for ethylbenzene, $\mathrm{p}<0.05$ for styrene, 2-methyl-2-cyclopenten-1-one, limonene, and naphthalene from Pearson correlation analysis)). Hence, when the emitted masses are measured by headspace analysis, the correlation curves can be used to estimate the emission rates in an environment under similar conditions. These correlations also suggest that the trend of the influence of environmental conditions on emitted mass by headspace analysis reported in Section 3.2 should be similar to the trend of the influence of environment conditions on emission rates under real conditions.

However, the association between emission rates and the emitted masses for triacetin and nicotine were not statistically significant (Figure $3.18(\mathrm{~g})$ and $(\mathrm{h}))(\mathrm{p}>0.2$ from Pearson correlation analysis), exhibiting a negative correlation. In the emission test, the high content of nicotine in the butts and the low volatility resulted in the nicotine and triacetin emission rates remaining steady over the $24 \mathrm{~h}$ test period. But, in the headspace analysis study, where only three butts were placed in the large chamber, the remaining masses that were emitted from the butts decreased with time (similar to the data in Figure 3.9) during the headspace analysis study. It is possible that the number and proximity of the butts in the chamber influenced the emission rates for low vapor pressure chemicals like nicotine and triacetin. More butts in the basket appear to lead to lower emission rates, which supports this explanation. If this is the case, the emission rates calculated for the chamber test may be conservative. Further emission rate studies varying the number of butts in the basket could help to understand this issue. It is also possible that other unknown experimental errors contributed to the fact that the emission rates and the emitted masses for triacetin and nicotine are not significantly correlated. 

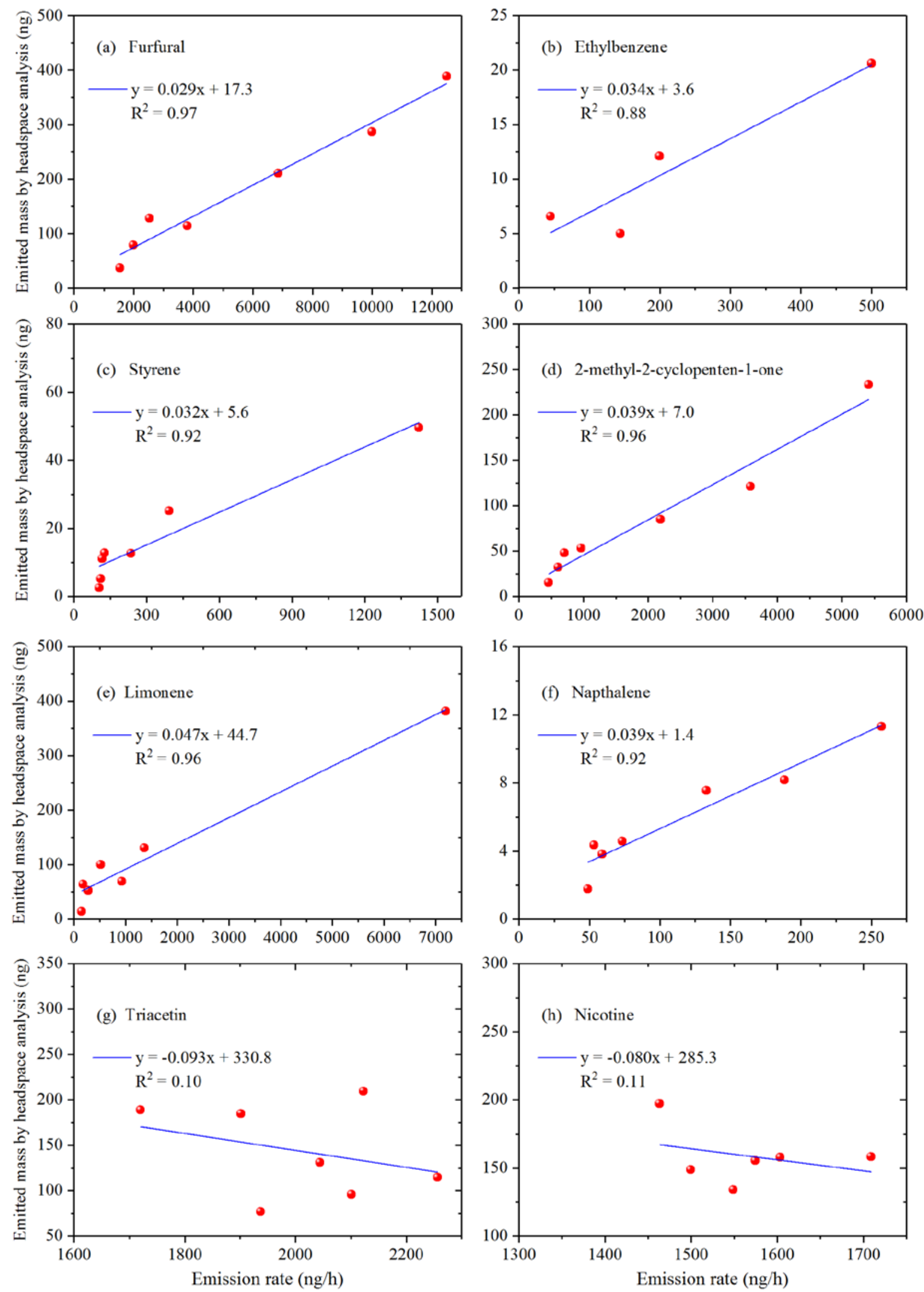

Figure 3.18: Correlation between calculated emission rates and measured emitted masses by headspace analysis. 


\section{CONCLUSIONS}

The global disposal of five trillion cigarette butts every year presents a potentially significant environmental issue. Although there is a body of knowledge on aqueous emissions from cigarette butts, the environmental impact of cigarette butts due to airborne emissions is not well-studied (Gong et al. 2017).

This research studied airborne emissions of eight target chemicals from cigarette butts systematically for the first time. The eight target chemicals were furfural, ethylbenzene, styrene, 2-methyl-2-cyclopenten-1-one, limonene, naphthalene, triacetin, and nicotine. Specifically, this research determined the relative distributions of the target chemicals in freshly smoked, nonsmoldering butts to understand which parts of the butts emitted chemicals. This study also examined the influence of various environmental factors (i.e., temperature, relative humidity, ultraviolet radiation, water saturation, and air change rate) on airborne emissions from cigarette butts. In addition, this study compared the airborne emissions for butts placed outdoors in summer and winter. Lastly this research included measurements of the chemical emission rates into air from cigarette butts in a walk-in chamber.

Based on the results and discussions above, the following conclusions can be drawn:

- Most of the target chemicals released from the butt were the result of the burning process (including both combustion and pyrolysis). Burning also increased the emitted masses for triacetin and nicotine, two chemicals present in unburned cigarettes. Most of the other target chemicals were primarily emitted from the filter of the burned cigarette butt.

- Results from the experiments on conditioned butts showed discarded butts are likely to be significant sources of furfural, ethylbenzene, styrene, 2-methyl-2-cyclopenten-1-one, limonene, and naphthalene in the first $24 \mathrm{~h}$ after smoking. After $24 \mathrm{~h}$, the emissions of these chemicals decrease significantly. In contrast, butts are likely to be sources of triacetin and nicotine for longer time periods (greater than $24 \mathrm{~h}$ ), which may be relevant for butts disposed in indoor spaces such as cars.

- Increased temperature increased the rate at which all target chemicals were emitted from the butts in both chamber and outdoor experiments.

- Water has considerable influence on the emission rates from butts. Seven of the eight chemicals were emitted faster from butts at a 50 \% RH compared to a $25 \% \mathrm{RH}$. For butts discarded in dry environments, increasing the relative humidity can result in water competition for sorption sites with the target chemicals, which would enhance the emission rate of target chemicals. During the saturation process under conditions of exposure to liquid water, the chemicals with high water solubility and $K_{\text {wa }}$ e.g., triacetin and nicotine, can migrate into the surrounding environment via aqueous rather than airborne routes. Other less soluble chemicals are more likely to be emitted from saturated butts into air as $K_{\text {wa }}$ increases. For these chemicals, the ratios of initial emitted mass for both dry butts to wet butts and dry filters to filters increases with increasing $K_{\text {wa. }}$. Water saturation increased the decay rate of emitted mass measured in headspace analysis for the two carbonyl 
chemicals: furfural and 2-methyl-2-cyclopenten-1-one, while it decreased the decay rate for the three hydrocarbons (styrene, limonene, and naphthalene).

- Exposure to intense UV light can increase the emission from butts by either increasing the temperature of a butt or enhancing the degradation of cellulose acetate.

- The air change rate under the conditions tested only influenced the emissions of triacetin and nicotine in the first 24 hours.

- Emission rates of target chemicals from cigarette butts were measured in a walk-in chamber at $25{ }^{\circ} \mathrm{C}$ and $50 \% \mathrm{RH}$. The average emitted mass of the target chemicals over the first $24 \mathrm{~h}$ ranged from $2.5 \mu \mathrm{g} / \mathrm{butt}$ to $120 \mu \mathrm{g} / \mathrm{butt}$. The total emitted mass over $24 \mathrm{~h}$ for nicotine from a cigarette butt in this study could be up to $15 \%$ of the literature reported emitted mass from a burning cigarette.

- The associations between the emission rates from the large chamber emission test and the emitted masses by headspace analysis were examined. Furfural, ethylbenzene, styrene, 2methyl-2-cyclopenten-1-one, limonene, and naphthalene demonstrated significant correlations. These correlations indicate that for these chemicals the trends of the influence of environmental conditions on emitted mass measured by headspace analysis should be similar to the trends of environment conditions on emission rates under real conditions.

Overall, these measurements demonstrated that cigarette butts can be a significant source of the eight target chemicals to the environments in which they are disposed, with the emission rates depending on environmental factors including temperature, relative humidity, and water saturation.

This study has several limitations and much additional work remains to be done to more completely understand airborne emissions from cigarette butts. Only one brand of cigarette was tested in this study, which limits the generalizability of the present study. The cigarette butts were produced using a custom-built smoking apparatus at one target length. Thus, the cigarette butts tested in this study may be different from the varied butts produced by human smoking. Studies comparing different brands and characterizing differences between smoking by human and smoking apparatus would be valuable. The environmental conditions tested in this study (two each for temperature, relative humidity, UV, and air change rate) are limited. More tests under various conditions are needed to more fully understand the environmental impacts on butt emissions. Also, the emission rate test in the chamber was only conducted once for 24 hours. More experiments are needed to evaluate variability of the chemical emission rates. Furthermore, repeated long-term emission testing would contribute to better understanding emissions, especially for triacetin and nicotine. Given that adsorption parameters found in the literature were used for calculating the emission rates for nicotine, an adsorption study using the same chamber as the emission test would help to estimate the nicotine emission rate more accurately. In addition, when examining the influence of various factors, the emitted masses into headspace of a vial were measured, not the actual emission rates. More studies directly examining the influence of environmental conditions on emission rates would help us gain a better quantitative understanding of the influence of environmental conditions on airborne cigarette butt emissions. 


\section{DISCLAIMER}

Certain commercial equipment, instruments, or materials are identified in this paper in order to specify the experimental procedure adequately. Such identification is not intended to imply recommendation or endorsement by the National Institute of Standards and Technology, nor is it intended to imply that the materials or equipment identified are necessarily the best available for the purpose.

\section{ACKNOWLEDGEMENTS}

This work was funded by the United States Food and Drug Administration under the Interagency Agreement \#224-15-9012. This publication represents the views of the author(s) and does not represent the U.S. Food and Drug Administration/Center for Tobacco Products position or policy.

The authors would like at acknowledge the assistance of $\mathrm{Vu}$ Pham in conducting numerous experiments. In addition, the authors thank Elizabeth Tom, Havishk Tripathi and Stephen Smith for helping with preliminary experiments.

\section{REFERENCES}

ASTM (2012). Standard tables for reference solar spectral irradiances: direct normal and hemispherical on $37^{\circ}$ tilted surface. West Conshohoken, PA, ASTM International. G173-03 (2012).

ASTM (2017). Standard test method for determining air change in a single zone by means of a tracer gas dilution. West Conshohocken, PA, ASTM International. E741-11 (2017).

ASTM (2018). Standard practice for full-scale chamber determination of volatile organic emissions from indoor materials/products. West Conshohoken, PA, ASTM International. D6670-18.

Baek, S.-O. and R. A. Jenkins (2004). "Characterization of trace organic compounds associated with aged and diluted sidestream tobacco smoke in a controlled atmosphere-volatile organic compounds and polycyclic aromatic hydrocarbons." Atmospheric Environment 38(38): 6583-6599.

Baker, R. R. (1987). "A review of pyrolysis studies to unravel reaction steps in burning tobacco." Journal of Analytical and Applied Pyrolysis 11: 555-573.

Becherucci, M. E. and J. P. S. Pon (2014). "What is left behind when the lights go off? Comparing the abundance and composition of litter in urban areas with different intensity of nightlife use in Mar del Plata, Argentina." Waste Management 34(8): 1351-1355.

Benowitz, N. L. and J. E. Henningfield (2013). "Reducing the nicotine content to make cigarettes less addictive." Tobacco Control 22(suppl 1): i14-i17. 
Bi, X., G. Sheng, Y. Feng, J. Fu and J. Xie (2005). "Gas-and particulate-phase specific tracer and toxic organic compounds in environmental tobacco smoke." Chemosphere 61(10): 1512-1522.

Bonanomi, G., G. Incerti, G. Cesarano, S. A. Gaglione and V. Lanzotti (2015). "Cigarette Butt Decomposition and Associated Chemical Changes Assessed by C-13 CPMAS NMR." Plos One 10(1).

Boyd, M. (2016). "NIST Technical Note 1913: NIST Weather Station for Photovoltaic and Building System Research." National Institute of Standards and Technology, Department of Commerce. http://dx.doi.org/10.6028/NIST.TN.1913

Branton, P., M. Leistner, M. Wöllner and S. Kaskel (2017). "An innovative technique for rapid screening of cigarette filter adsorbents." Chemical Engineering \& Technology 40(1): 71-75.

Cardoso, C. R. and C. H. Ataíde (2013). "Analytical pyrolysis of tobacco residue: Effect of temperature and inorganic additives." Journal of Analytical and Applied Pyrolysis 99: 49-57.

Chapman, S. (2006). "Butt clean up campaigns: wolves in sheep's clothing?" Tobacco Control 15(4).

Charles, S. M., C. Jia, S. A. Batterman and C. Godwin (2008). "VOC and particulate emissions from commercial cigarettes: analysis of 2, 5-DMF as an ETS tracer." Environmental Science \& Technology 42(4): 1324-1331.

Chevalier, Q., H. El Hadri, P. Petitjean, M. Bouhnik-Le Coz, S. Reynaud, B. Grassl and J. Gigault (2018). "Nano-litter from cigarette butts: Environmental implications and urgent consideration." Chemosphere 194: 125-130.

Chin, J., E. Byrd, N. Embree, J. Garver, B. Dickens, T. Finn and J. Martin (2004). "Accelerated UV weathering device based on integrating sphere technology." Review of Scientific Instruments 75(11): 49514959.

Claereboudt, M. R. (2004). "Shore litter along sandy beaches of the Gulf of Oman." Marine Pollution Bulletin 49(9-10): 770-777.

Clark, M. A., S. P. Dunlap and C. K. Banerjee (2017). Filtered cigarette incorporating an adsorbent material, Google Patents.

Code of Federal Regulations (2003). Definition and procedure for the determination of the method detection limit - Revision 1.11. CFR 40, Ch. 1, Pt. 136.

Daisey, J., K. Mahanama and A. Hodgson (1998). "Toxic volatile organic compounds in simulated environmental tobacco smoke: emission factors for exposure assessment." Journal of Exposure Analysis and Environmental Epidemiology 8(3): 313-334.

Egerton, G. S. and K. M. Shah (1968). "The Effect of Temperature on the Photochemical Degradation of Textile Materials: Part I : Degradation Sensitized by Titanium Dioxide." Textile Research Journal 38(2): 130-135.

Fukuhara, K., T. Sakaki, H. Sakuma and S. Sugawara (1985). "Odor analysis of cigarette butts by a headspace technique." Agricultural and Biological Chemistry 49(7): 2177-2179. 
Gong, M., S. Khurshid and D. Poppendieck (2017). "What's in a butt? Environmental contamination from airborne cigarette butt emissions." Integrated Environmental Assessment and Management 13(3): 549-551.

Green, A. L. R., A. Putschew and T. Nehls (2014). "Littered cigarette butts as a source of nicotine in urban waters." Journal of Hydrology 519: 3466-3474.

Hawthorne, S. B., D. G. Poppendieck, C. B. Grabanski and R. C. Loehr (2001). "PAH release during water desorption, supercritical carbon dioxide extraction, and field bioremediation." Environmental Science \& Technology 35(22): 4577-4583.

Healton, C. G., K. M. Cummings, R. J. O'Connor and T. E. Novotny (2011). "Butt really? The environmental impact of cigarettes." Tobacco Control 20: I1-I1.

Hertz, R., T. Streibel, C. Liu, K. McAdam and R. Zimmermann (2012). "Microprobe sampling-Photo ionization-time-of-flight mass spectrometry for in situ chemical analysis of pyrolysis and combustion gases: Examination of the thermo-chemical processes within a burning cigarette." Analytica Chimica Acta 714: 104-113.

Hosono, K., A. Kanazawa, H. Mori and T. Endo (2007). "Photodegradation of cellulose acetate film in the presence of benzophenone as a photosensitizer." Journal of Applied Polymer Science 105(6): 3235-3239.

Huang, H., H. Liang, X. Liu and Y. Yu (2014). "Determination of VOCs in cigarette tipping paper by HSGC/MS." Acta Tabacaria Sinica 20(1): 15-20.

Ishizu, Y. and Y. Ishizu (2013). "A New Diffusive Sampler for Determining Nicotine and 3-Ethenylpyridine Contents in Second-Hand Smoke." Indoor and Built Environment 22(3): 520-527.

ISO3308 (2012). "Routine analytical cigarette-smoking machine - Definitions and standard conditions." International Standard.

Ji, H., J. Man, J. Liu, N. Liu, F. Wang and W. Han (2015). "Determination of benzene compounds in mainstream cigarette smoke entrapped by filter using static headspace GC/MS method." Acta Tabacaria Sinica 21(2): 23-28.

John, E., S. Coburn, C. Liu, J. McAughey, D. Mariner, K. McAdam, Z. Sebestyén, I. Bakos and S. Dóbé (2018). "Effect of temperature and humidity on the gas-particle partitioning of nicotine in mainstream cigarette smoke: A diffusion denuder study." Journal of Aerosol Science 117: 100-117.

Lahimer, A., M. Alghoul, K. Sopian and N. Khrit (2017). The effect of solar reflective cover on soak air temperature and thermal comfort of car parked under the sun. E3S Web of Conferences, EDP Sciences.

Laskar, II, Z. Hashisho, J. H. Phillips, J. E. Anderson and M. Nichols (2019). "Modeling the Effect of Relative Humidity on Adsorption Dynamics of Volatile Organic Compound onto Activated Carbon." Environmental Science \& Technology. 
Liang, C. K. and J. F. Pankow (1996). "Gas/particle partitioning of organic compounds to environmental tobacco smoke: Partition coefficient measurements by desorption and comparison to urban particulate material." Environmental Science \& Technology 30(9): 2800-2805.

Markowicz, P. and L. Larsson (2015). "Influence of relative humidity on VOC concentrations in indoor air." Environmental Science and Pollution Research 22(8): 5772-5779.

Martin, P., D. L. Heavner, P. R. Nelson, K. C. Maiolo, C. H. Risner, P. S. Simmons, W. T. Morgan and M. W. Ogden (1997). "Environmental tobacco smoke (ETS): a market cigarette study." Environment International 23(1): 75-90.

Nelson, P. R., F. W. Conrad, S. P. Kelly and R. J. Reynolds (1998). "Comparison of environmental tobacco smoke to aged and diluted sidestream smoke." Journal of Aerosol Science 29: 281-282.

Novotny, T. E. and F. Zhao (1999). "Consumption and production waste: another externality of tobacco use." Tobacco Control 8(1): 75-80.

Ohara, K., T. Ujihara, T. Endo, F. Sato and K. Yazaki (2003). "Limonene production in tobacco with Perilla limonene synthase cDNA." J Exp Bot 54(393): 2635-2642.

Patel, V., G. W. Thomson and N. Wilson (2013). "Cigarette butt littering in city streets: a new methodology for studying and results." Tobacco Control 22(1): 59-62.

Poppendieck, D. G., S. S. Khurshid and S. J. Emmerich (2016). "Measuring Airborne Emissions from Cigarette Butts: Literature Review and Experimental Plan Final Report to U.S. Food and Drug Administration." National Institute of Standards and Technology Department of Commerce. NISTIR 8147. NISTIR 8147. https://nvlpubs.nist.gov/nistpubs/ir/2016/NIST.IR.8147.pdf

Puls, J., S. A. Wilson and D. Holter (2011). "Degradation of Cellulose Acetate-Based Materials: A Review." Journal of Polymers and the Environment 19(1): 152-165.

Purkis, S. W., V. Troude, G. Duputie and C. Tessier (2010). "Limitations in the characterisation of cigarette products using different machine smoking regimes." Regulatory Toxicology and Pharmacology 58(3): 501-515.

Seco Pon, J. P. and M. E. Becherucci (2012). "Spatial and temporal variations of urban litter in Mar del Plata, the major coastal city of Argentina." Waste Management 32(2): 343-348.

Singer, B. C., A. T. Hodgson and W. W. Nazaroff (2003). "Gas-phase organics in environmental tobacco smoke: 2. Exposure-relevant emission factors and indirect exposures from habitual smoking." Atmospheric Environment 37(39-40): 5551-5561.

Smith, S. D. A., C. L. Gillies and H. Shortland-Jones (2014). "Patterns of marine debris distribution on the beaches of Rottnest Island, Western Australia." Marine Pollution Bulletin 88(1-2): 188-193.

St Charles, F. K., A. A. Kabbani and M. F. Borgerding (2010). "Estimating tar and nicotine exposure: Human smoking versus machine generated smoke yields." Regulatory Toxicology and Pharmacology 56(1): 100-110. 
Torikai, K., S. Yoshida and H. Takahashi (2004). "Effects of temperature, atmosphere and pH on the generation of smoke compounds during tobacco pyrolysis." Food and Chemical Toxicology 42(9): 1409-1417.

United States Center of Disease Control and Prevention (2017). "Tobacco Brand Preferences." Accessed 6/17/19. https://www.cdc.gov/tobacco/data statistics/fact sheets/tobacco industry/brand preference/ index.htm

United States Department of Health and Human Services (2006). "The Health Consequences of Involuntary Exposure to Tobacco Smoke: A Report of the Surgeon General." Centers for Disease Control and Prevention, National Center for Chronic Disease Prevention and Health Promotion and Office on Smoking and Health. Alanta. Accessed 6/17/19. https://www.cdc.gov/tobacco/data statistics/sgr/2006/index.htm

United States Department of Health and Human Services (2010). "A Report of the Surgeon General: How Tobacco Smoke Causes Disease: What It Means to You." Centers for Disease Control and Prevention, National Center for Chronic Disease Prevention and Health Promotion and Office on Smoking and Health. Alanta. Accessed 6/17/19. https://www.cdc.gov/tobacco/data statistics/sgr/2010/consumer booklet/index.htm

United States Department of Health and Human Services (2014). "The Health Consequences of Smoking50 Years of Progress: A Report of the Surgeon General." Centers for Disease Control and Prevention, National Center for Chronic Disease Prevention and Health Promotion and Office on Smoking and Health. Atlanta. Accessed 6/17/19. https://www.cdc.gov/tobacco/data statistics/sgr/50th-anniversary/index.htm

United States Food and Drug Administration (2009). Family Smoking Prevention and Tobacco Control Act. Public Law 111-31 [H.R. 1256]. https://www.fda.gov/tobacco-products/rules-regulations-andguidance/family-smoking-prevention-and-tobacco-control-act-table-contents

United States Food and Drug Administration (2012). "Harmful and Potentially Harmful Constituents in Tobacco Products and Tobacco Smoke: Established List." Accessed 6/12/2019. https://www.fda.gov/tobacco-products/rules-regulations-and-guidance/harmful-andpotentially-harmful-constituents-tobacco-products-and-tobacco-smoke-established-list

Van Loy, M. D., V. C. Lee, L. A. Gundel, J. M. Daisey, R. G. Sextro and W. W. Nazaroff (1997). "Dynamic behavior of semivolatile organic compounds in indoor air. 1. Nicotine in a stainless steel chamber." Environmental Science \& Technology 31(9): 2554-2561.

Wilson, N., J. Oliver and G. Thomson (2014). "Smoking close to others and butt littering at stops: pilot observational study." Peerj 2.

You, J., G. Zhu, Y. Zhang and J. Ni (2014). "Determination of menthol in mentholated cigarettes by headspace gas chromatography." Tobacco Science \& Technology(8): 51-54. 


\section{Appendix A METHOD DEVELOPMENT DATA}

This appendix presents data that were collected during the method development phase of the project. Appendix A.1 includes the data used to determine which chemicals were chosen as target chemicals. Appendix A.2 describes how the time the butt spent in the transport vial between removal from the conditioning environment and the TD-GC-MS sample analysis impacted the measured emitted masses from cigarette butts. Appendix A.3 demonstrates how the time the butt spent in the transport vial between generation and placement in the conditioning environment impacted the response. Appendix A.4 describes the measurement of the outdoor air change rate for the walk-in chamber. Appendix A.5 show the breakthrough data for $3 \mathrm{~h}$ Tenax tube sampling of the walk-in chamber.

\section{A.1 CHEMICALS IDENTIFIED EMITTING FROM FOUR FRESH CIGARETTE BUTTS}

Over 157 different chemicals were identified in each of the tested butts as having peak responses larger than $1 \%$ of the largest peak (Table A.1). The target chemicals, which served as the focus of the study, were selected primarily from chemicals with response areas ranking in the top 30 among the identified chemicals. A total of 44 different chemicals were in the top 30 responses for the four cigarette butts analyzed (Table A.2). These chemicals can be characterized by functional groups (Table A.3).

Table A.1: $\quad$ Number of chemicals identified in four fresh cigarette butts with peak response larger than $1 \%$ of the largest peak.

\begin{tabular}{|c|c|c|c|c|}
\hline Group & Fresh 1 & Fresh 2 & Fresh 3 & Fresh 4 \\
\hline \# Total identified & 157 & 166 & 170 & 157 \\
\hline
\end{tabular}


Table A.2: Summary of observed chemicals in four fresh cigarette butts that had response areas ranking in the top 30 response area plus chemicals listed in HPHC by FDA (target chemicals are highlighted in bold).

\begin{tabular}{|c|c|c|c|c|c|c|c|c|c|c|c|}
\hline \multirow{2}{*}{ Groups } & \multirow{2}{*}{ Structure } & \multirow{2}{*}{$\begin{array}{l}\text { RT } \\
\text { Time } \\
\text { (min) }\end{array}$} & \multicolumn{2}{|r|}{ Fresh 1} & \multicolumn{2}{|r|}{ Fresh 2} & \multicolumn{2}{|r|}{ Fresh 3} & \multicolumn{2}{|r|}{ Fresh 4} & \multirow{2}{*}{$\begin{array}{l}\text { Response } \\
\text { Relative } \\
\text { Standard } \\
\text { Deviation }\end{array}$} \\
\hline & & & CAS No. & Chemical name & CAS No. & Chemical name & CAS No. & Chemical name & CAS No. & Chemical name & \\
\hline \multirow{3}{*}{ Cyclohexene } & & 7.561 & & & & & $138-86-3$ & $\begin{array}{l}\text { Cyclohexene, 1-methyl- } \\
\text { 4-(1-methylethenyl)- }\end{array}$ & $138-86-3$ & $\begin{array}{l}\text { Cyclohexene, 1- } \\
\text { methyl-4-(1- } \\
\text { methylethenyl)- }\end{array}$ & \\
\hline & & 8.339 & $138-86-3$ & Limonene & $138-86-3$ & Limonene & $138-86-3$ & Limonene & $138-86-3$ & Limonene & $19 \%$ \\
\hline & & 8.755 & $138-86-3$ & $\begin{array}{l}\text { Cyclohexene, 1-methyl- } \\
\text { 4-(1-methylethenyl)- }\end{array}$ & $138-86-3$ & $\begin{array}{l}\text { Cyclohexene, 1-methyl- } \\
\text { 4-(1-methylethenyl)- }\end{array}$ & $138-86-3$ & $\begin{array}{l}\text { Cyclohexene, 1-methyl- } \\
\text { 4-(1-methylethenyl)- }\end{array}$ & $138-86-3$ & $\begin{array}{l}\text { Cyclohexene, 1- } \\
\text { methyl-4-(1- } \\
\text { methylethenyl)- }\end{array}$ & $15 \%$ \\
\hline \multirow{6}{*}{ Piridine } & & 3.699 & 108-99-6 & 3-methyl-pyridine & $108-99-6$ & 3-methyl-pyridine & $108-99-6$ & 3-methyl-pyridine & $108-99-6$ & 3-methyl-pyridine & $9 \%$ \\
\hline & & 4.080 & $110-86-1$ & Pyridine & $110-86-1$ & Pyridine & $110-86-1$ & Pyridine & $110-86-1$ & Pyridine & $12 \%$ \\
\hline & & 5.164 & & & $109-06-8$ & Pyridine, 2-methyl- & $109-06-8$ & Pyridine, 2-methyl- & $109-06-8$ & Pyridine, 2-methyl- & \\
\hline & & 5.299 & & & $504-29-0$ & 2-Pyridinamine & & & & & \\
\hline & & 5.887 & $108-99-6$ & 3-methyl-pyridine & $108-99-6$ & 3-methyl-pyridine & $108-99-6$ & 3-methyl-pyridine & $108-99-6$ & 3-methyl-pyridine & $8 \%$ \\
\hline & & 13.49 & $54-11-5$ & Nicotine & $54-11-5$ & Nicotine & $54-11-5$ & Nicotine & $54-11-5$ & Nicotine & $20 \%$ \\
\hline \multirow[t]{8}{*}{ Benzene } & & 4.128 & $108-38-3$ & Benzene, 1,3-dimethyl- & & & & & & & \\
\hline & & 4.859 & & & $100-42-5$ & Benzene, ethenyl- & $100-42-5$ & Benzene, ethenyl- & & & \\
\hline & & 5.925 & $100-41-4$ & Benzene, ethyl- & $100-41-4$ & Benzene, ethyl- & $100-41-4$ & Benzene, ethyl- & $100-41-4$ & Benzene, ethyl- & $26 \%$ \\
\hline & & 6.074 & $106-42-3$ & Benzene, 1,4-dimethyl- & $106-42-3$ & Benzene, 1,4-dimethyl- & $106-42-3$ & Benzene, 1,4-dimethyl- & $106-42-3$ & $\begin{array}{c}\text { Benzene, 1,4- } \\
\text { dimethyl- }\end{array}$ & $24 \%$ \\
\hline & & 6.434 & $100-42-5$ & Styrene & $100-42-5$ & Styrene & $100-42-5$ & Styrene & $100-42-5$ & Styrene & $12 \%$ \\
\hline & & 6.453 & & & & & $106-42-3$ & Benzene, 1,4-dimethyl- & $106-42-3$ & $\begin{array}{c}\text { Benzene, 1,4- } \\
\text { dimethyl- }\end{array}$ & \\
\hline & & 6.806 & $98-82-8$ & $\begin{array}{l}\text { Benzene, (1- } \\
\text { methylethyl)- }\end{array}$ & $\begin{array}{l}2000382- \\
84-3\end{array}$ & $\begin{array}{c}\text { 2-Hydroxy-2-phenyl-N- } \\
\text { (1-phenyl-ethyl)- } \\
\text { acetamide }\end{array}$ & $\begin{array}{l}2000074- \\
44-2\end{array}$ & $\begin{array}{c}\text {.BETA.-D2-2- } \\
\text { PHENYLNITROETHANE }\end{array}$ & $\begin{array}{l}2000382- \\
84-3\end{array}$ & $\begin{array}{l}\text { 2-Hydroxy-2- } \\
\text { phenyl-N-(1- } \\
\text { phenyl-ethyl)- } \\
\text { acetamide }\end{array}$ & \\
\hline & & 7.594 & $873-49-4$ & Benzene, cyclopropyl- & & & & & & & \\
\hline
\end{tabular}




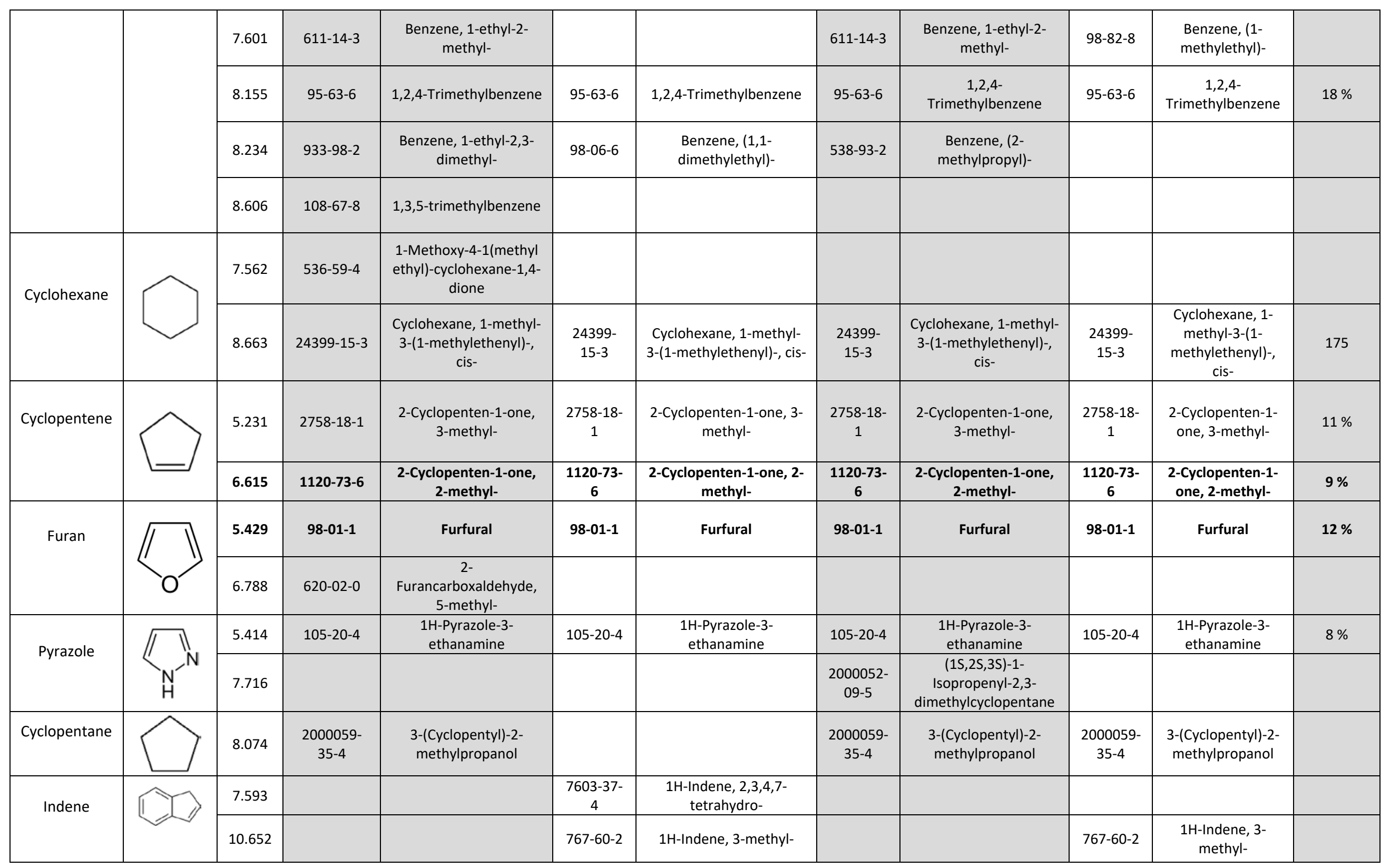




\begin{tabular}{|c|c|c|c|c|c|c|c|c|c|c|}
\hline \multirow{11}{*}{ Others } & 2.584 & & & & & & & $\begin{array}{c}58795- \\
35-0\end{array}$ & $\begin{array}{l}\text { Cyclobutanone, } \\
\text { 3,3-dimethyl-2-(1- } \\
\text { propenyl)-, (E)- }\end{array}$ & \\
\hline & 4.213 & & & $\begin{array}{l}2000008- \\
26-3\end{array}$ & $\begin{array}{l}\text { 2-Cyano-1- } \\
\text { cyclobutanone }\end{array}$ & & & & & \\
\hline & 4.443 & $765-46-8$ & $\begin{array}{l}\text { SPIRO[2.4]HEPTA-2,6- } \\
\text { DIENE }\end{array}$ & $765-46-8$ & $\begin{array}{c}\text { SPIRO[2.4]HEPTA-2,6- } \\
\text { DIENE }\end{array}$ & $765-46-8$ & $\begin{array}{c}\text { SPIRO[2.4]HEPTA-2,6- } \\
\text { DIENE }\end{array}$ & $765-46-8$ & $\begin{array}{c}\text { SPIRO[2.4]HEPTA- } \\
\text { 2,6-DIENE }\end{array}$ & $13 \%$ \\
\hline & 7.563 & & & $\begin{array}{c}54346- \\
06-4\end{array}$ & $\begin{array}{c}\text { 1(3H)-Isobenzofuranone, } \\
\text { 3a,4,5,7a-tetrahydro-4- } \\
\text { hydroxy-3a,7a-dimethyl-, } \\
\text { (3a.alpha.,4.beta.,7a.alp } \\
\text { ha.)-(.+/-.)- }\end{array}$ & & & & & \\
\hline & 7.718 & $2609-23-6$ & $\begin{array}{c}\text { 2,6-Octadiene, 2,6- } \\
\text { dimethyl-, (E)- }\end{array}$ & & & & & $\begin{array}{c}2609-23- \\
6 \\
\end{array}$ & $\begin{array}{c}\text { 2,6-Octadiene, 2,6- } \\
\text { dimethyl-, (E)- }\end{array}$ & \\
\hline & 8.002 & & & $\begin{array}{l}2000016- \\
29-3\end{array}$ & $\begin{array}{c}\text { Tricyclo[5.1.0.0(1,3)]oct3 } \\
\text {-ene }\end{array}$ & $\begin{array}{c}2609-23- \\
6\end{array}$ & $\begin{array}{c}\text { 2,6-Dimethyl-2-trans-6- } \\
\text { octadiene }\end{array}$ & & & \\
\hline & 8.076 & & & $105-85-1$ & $\begin{array}{l}\text { 6-Octen-1-ol, 3,7- } \\
\text { dimethyl-, formate }\end{array}$ & & & & & \\
\hline & 8.149 & & & $\begin{array}{l}2000017- \\
52-3\end{array}$ & $\begin{array}{c}\text { 6-Methoxyhex-2-en-4- } \\
\text { yne }\end{array}$ & & & & & \\
\hline & 8.205 & $\begin{array}{l}2000030- \\
34-6\end{array}$ & $\begin{array}{c}1,8,9- \\
\text { Triazabicyclo[4.3.0]non } \\
\text { a-6,8-diene } \\
\end{array}$ & & & & & & & \\
\hline & 8.215 & $\begin{array}{l}2000051- \\
87-3\end{array}$ & $\begin{array}{c}\text { trans- } \\
\text { Bicyclo[4.3.0]nonan-2- } \\
\text { one } \\
\end{array}$ & & & $\begin{array}{l}2000051- \\
87-3\end{array}$ & $\begin{array}{c}\text { trans- } \\
\text { Bicyclo[4.3.0]nonan-2- } \\
\text { one } \\
\end{array}$ & $\begin{array}{l}2000045- \\
36-2\end{array}$ & $\begin{array}{c}\text { 1(7),5,8-0- } \\
\text { Menthatriene }\end{array}$ & \\
\hline & 8.429 & $13466-78-9$ & 3-Carene & 3-Carene & 3-Carene & 3-Carene & 3-Carene & 3-Carene & 3-Carene & $19 \%$ \\
\hline Acetate $^{a}$ & 8.429 & $102-76-1$ & $\begin{array}{c}\text { 1,2,3-Propanetriol, } \\
\text { triacetate }\end{array}$ & $102-76-1$ & $\begin{array}{c}\text { 1,2,3-Propanetriol, } \\
\text { triacetate }\end{array}$ & $102-76-1$ & $\begin{array}{c}\text { 1,2,3-Propanetriol, } \\
\text { triacetate }\end{array}$ & $102-76-1$ & $\begin{array}{c}\text { 1,2,3-Propanetriol, } \\
\text { triacetate }\end{array}$ & $31 \%$ \\
\hline Phenol $^{b}$ & 7.832 & & & $108-95-2$ & Phenol & $108-95-2$ & Phenol & $108-95-2$ & Phenol & \\
\hline Naphthalene ${ }^{b}$ & 11.237 & 91-20-3 & Naphthalene & $91-20-3$ & Naphthalene & $91-20-3$ & Naphthalene & $91-20-3$ & Naphthalene & $17 \%$ \\
\hline
\end{tabular}

a. Response is not within top 30, but acetate is the main component of filter and can be used to examine long term emission.

b. Response is not within top 30 , but phenol and naphthalene belong to the HPHC by FDA. 
Table A.3: $\quad$ Summary of number of identified chemicals with response areas ranking the top 30

\begin{tabular}{|c|c|c|c|c|}
\hline Groups & Fresh 1 & Fresh 2 & Fresh 3 & Fresh 4 \\
\hline Cyclohexene & 2 & 2 & 3 & 3 \\
\hline Pyridine & 4 & 6 & 10 & 9 \\
\hline Benzene & 11 & 8 & 1 & 1 \\
\hline Cyclohexane & 2 & 1 & 2 & 2 \\
\hline Cyclopentene & 2 & 2 & 1 & 1 \\
\hline Furan & 2 & 1 & 1 & 1 \\
\hline Pyrazole & 1 & 1 & 2 & 1 \\
\hline Cyclopentane & 0 & 2 & 0 & 6 \\
\hline Indene & 5 & 7 & 5 & 30 \\
\hline Others & $\mathbf{3 0}$ & $\mathbf{3 0}$ & 30 \\
\hline Sum & & & & 1 \\
\hline
\end{tabular}

\section{A.2 EVALUATION OF INJECTION TIME ON EMITTED MASSES FROM CIGARETTE BUTTS}

A total of 84 butts were generated and placed in vials as described in Section 2.1. The vials were then analyzed within $48 \mathrm{~h}$ of generation according to the analysis methods described in Section 2.4.5. Figure A.1 through Figure A.3 show that the mass emitted during headspace analysis conducted zero to $46 \mathrm{~h}$ after butt generation did show a slight decay trend for 6 of the 8 of the chemicals, but not for triacetin and nicotine. However, for the times that most of the butts were analyzed from the conditioned environment $(9.8 \mathrm{~h}$ to $32.9 \mathrm{~h}$, average value \pm one standard deviation) the mass emitted was relatively stable for all chemicals. 
- Furfural • Ethylbenzene

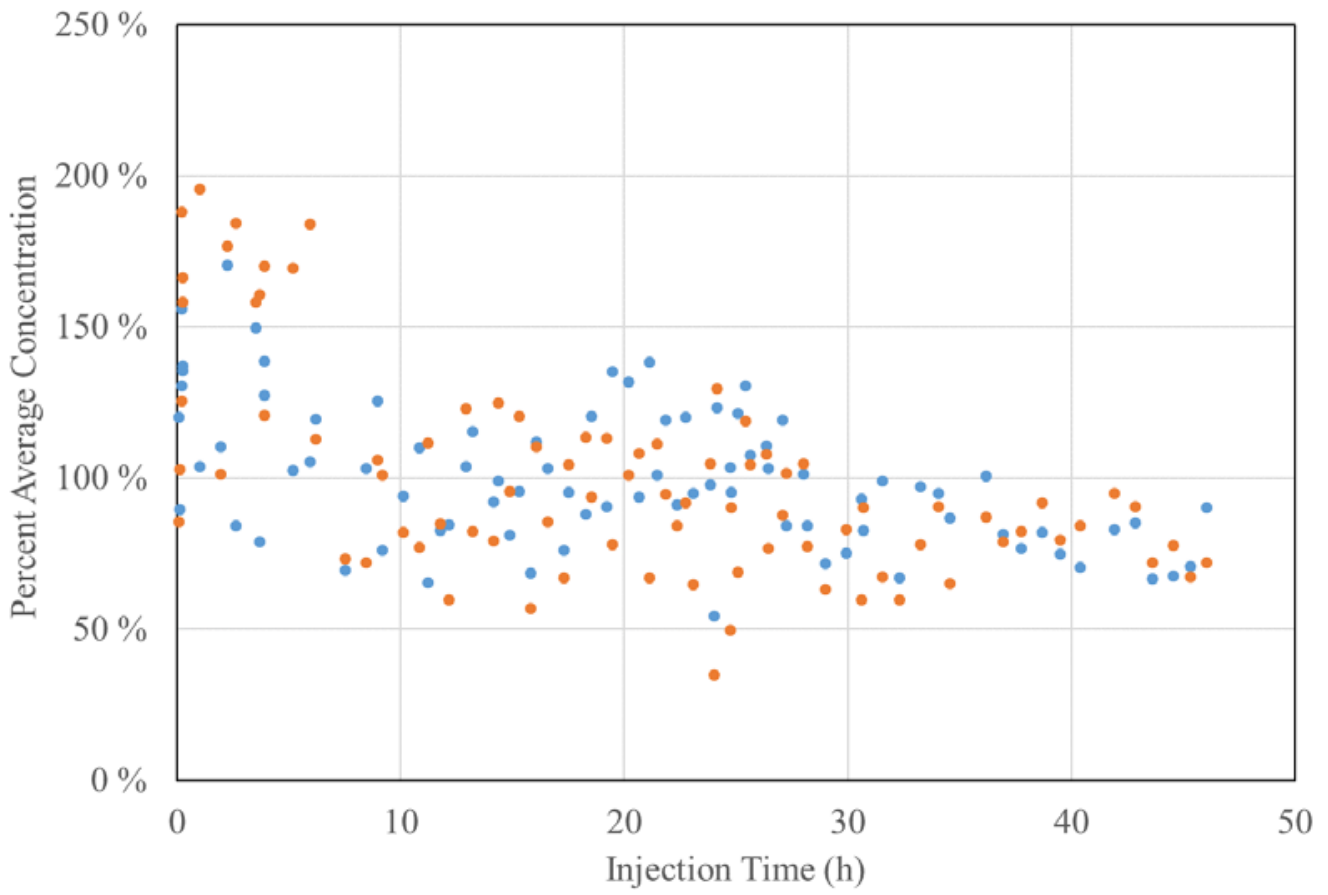

Figure A.1: $\quad$ Percent of average initial concentration for furfural and ethylbenzene mass emitted during headspace analysis conducted $0 \mathrm{~h}$ to $46 \mathrm{~h}$ after butt generation.

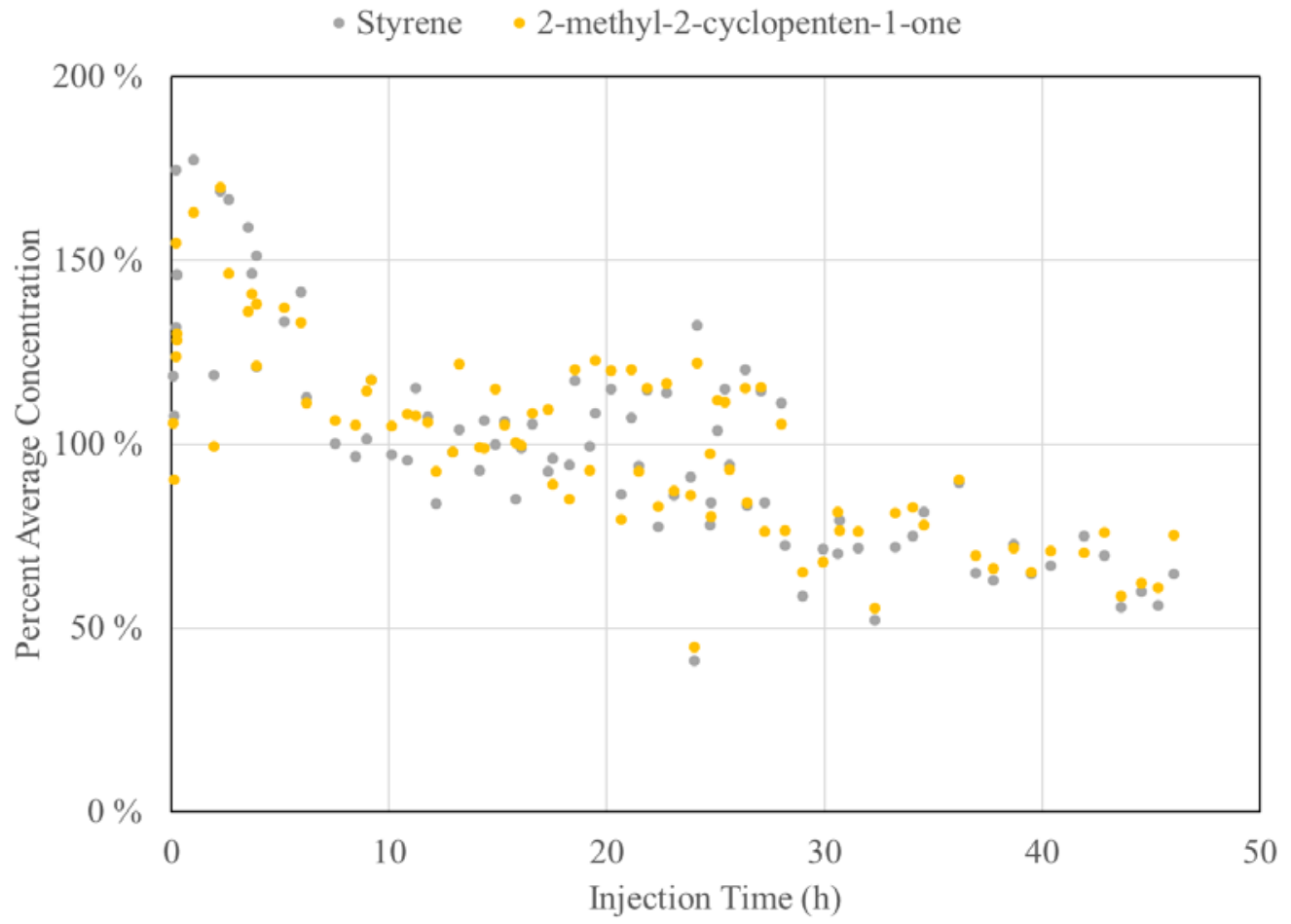

Figure A.2: $\quad$ Percent of average initial concentration for styrene and 2-methyl-2-cyclopenten-1-one mass emitted during headspace analysis conducted $0 \mathrm{~h}$ to $46 \mathrm{~h}$ after butt generation. 
- Triacetin - Nicotine

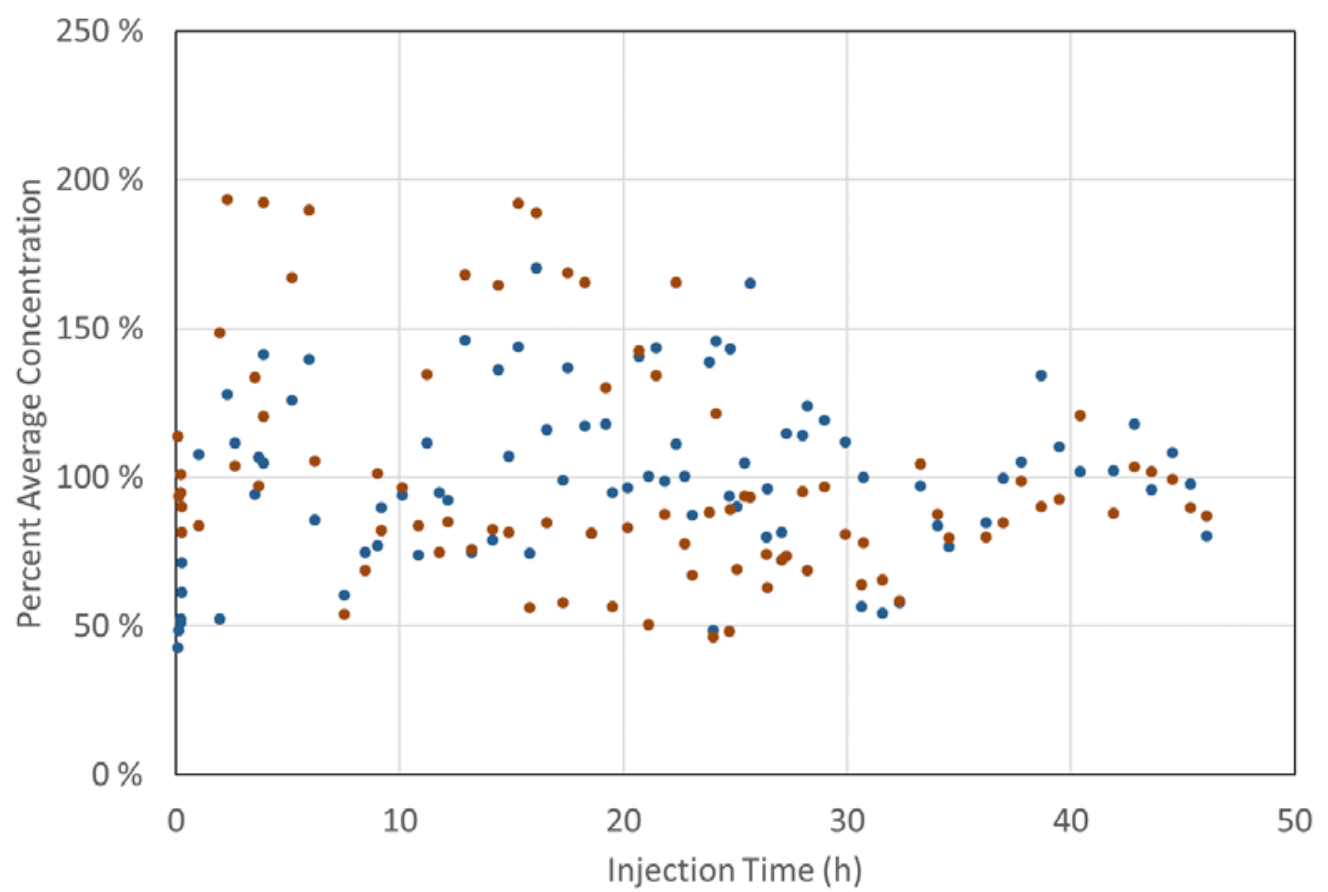

Figure A.3: $\quad$ Percent of average initial concentration for triacetin and nicotine mass emitted during headspace analysis conducted $0 \mathrm{~h}$ to $46 \mathrm{~h}$ after butt generation. 


\section{A.3 EVALUATION OF TRANSPORTATION ON EMITTED MASSES FROM CIGARETTE BUTTS}

A total of 14 butts were generated and placed in vials as described in Section 2.1. The vials were then analyzed within $4 \mathrm{~h}$ of generation according to the analysis methods described in Section 2.4.5. Figure A.4 through Figure A.7 show that the mass emitted during headspace analysis conducted $0 \mathrm{~h}$ to $4 \mathrm{~h}$ after butt generation was relatively constant. This consistency indicates that placing the butts in the transport vials for less than $4 \mathrm{~h}$ prior to placing in the conditioning environment had minimal impact on the future emissions.

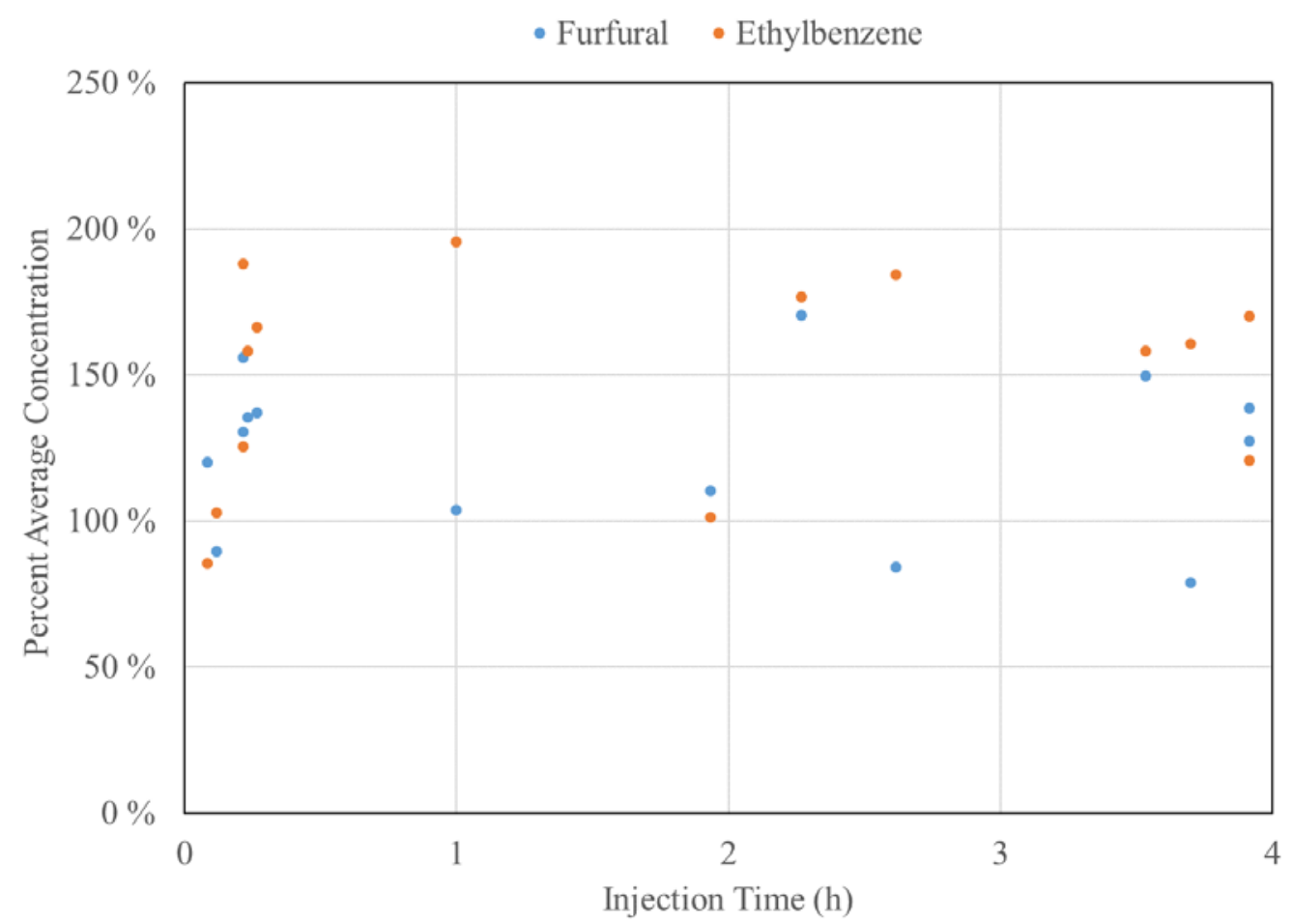

Figure A.4: $\quad$ Percent of average initial concentration for furfural and ethylbenzene mass emitted during headspace analysis conducted $0 \mathrm{~h}$ to $4 \mathrm{~h}$ after butt generation. 
- Styrene - 2-methyl-2-cyclopenten-1-one

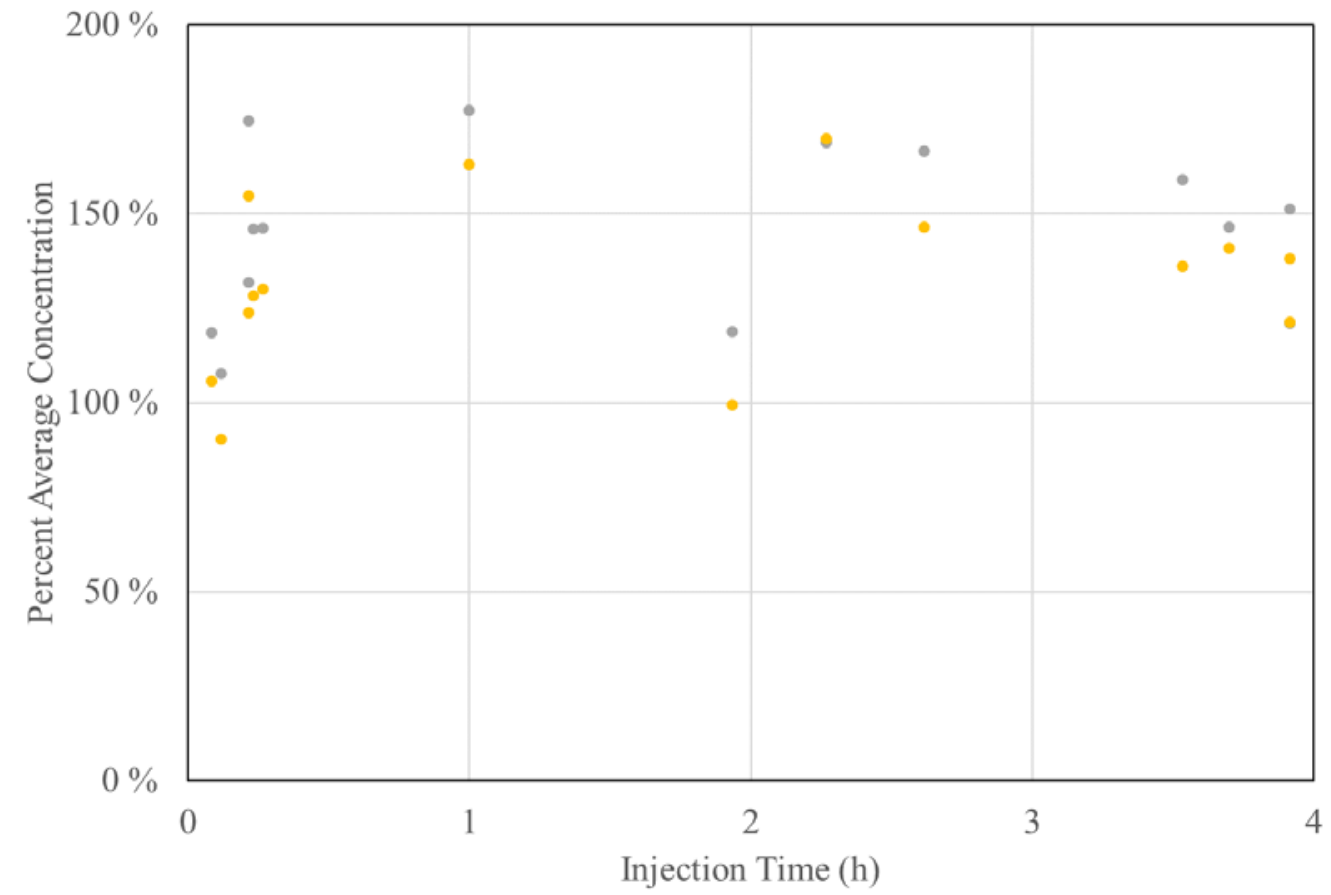

Figure A.5: $\quad$ Percent of average initial concentration for styrene and 2 methyl-2-cyclopenten-1-one mass emitted during headspace analysis conducted $0 \mathrm{~h}$ to $4 \mathrm{~h}$ after butt generation.

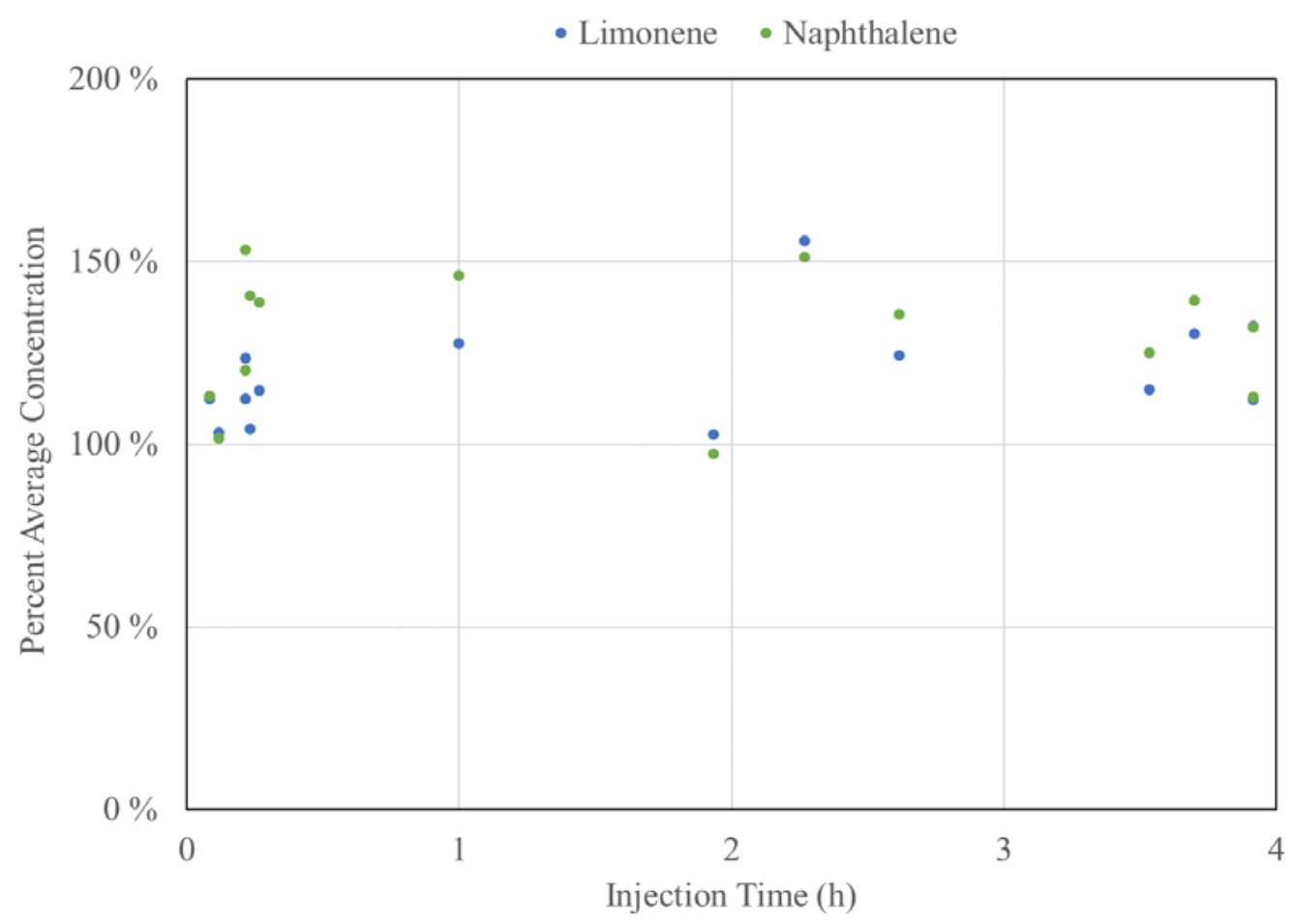

Figure A.6: $\quad$ Percent of average initial concentration for limonene and naphthalene mass emitted during headspace analysis conducted $0 \mathrm{~h}$ to $4 \mathrm{~h}$ after butt generation. 
- Triacetin • Nicotine

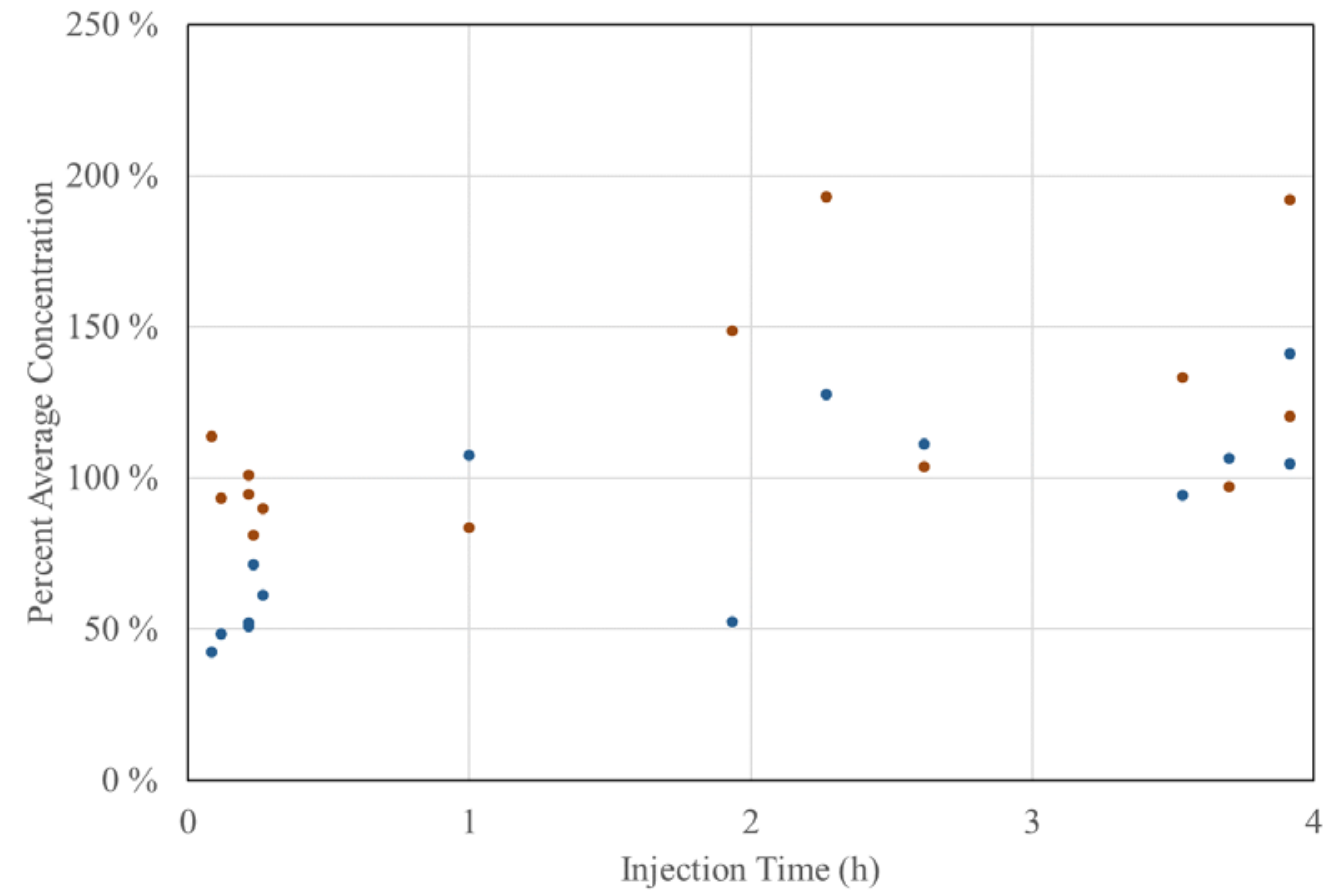

Figure A.7: $\quad$ Percent of average initial concentration for triacetin and nicotine mass emitted during headspace analysis conducted $0 \mathrm{~h}$ to $4 \mathrm{~h}$ after butt generation. 


\section{A.4 MeAsurement of air ChANGe RATE In the LARGe CHAMBER}

The large chamber is a double wall stainless steel chamber with internal size of $3.6 \mathrm{~m}$ length by $3.6 \mathrm{~m}$ wide by $2.4 \mathrm{~m}$ tall, located at NIST in room A316 of Building 226. The walls, the ceiling and the floor are thermally insulated with a thickness of $10 \mathrm{~cm}$. The chamber is connected by $15.2 \mathrm{~cm}$ (6 in.) insulated stainless steel ducts to the "ESPEC" system in the attic (Figure A.8). The ESPEC system controls the temperature, relative humidity, pressure and flow rate in the chamber. The air to the chamber is provided by a variable speed fan with a variable frequency device and a computer controlled, modulating damper (Damper IV) and three manually-modulated dampers (Damper I, II, III) as shown in the schematic below (Figure A.8). Damper IV (recirculation damper) also controls the recirculation of air to the chamber.

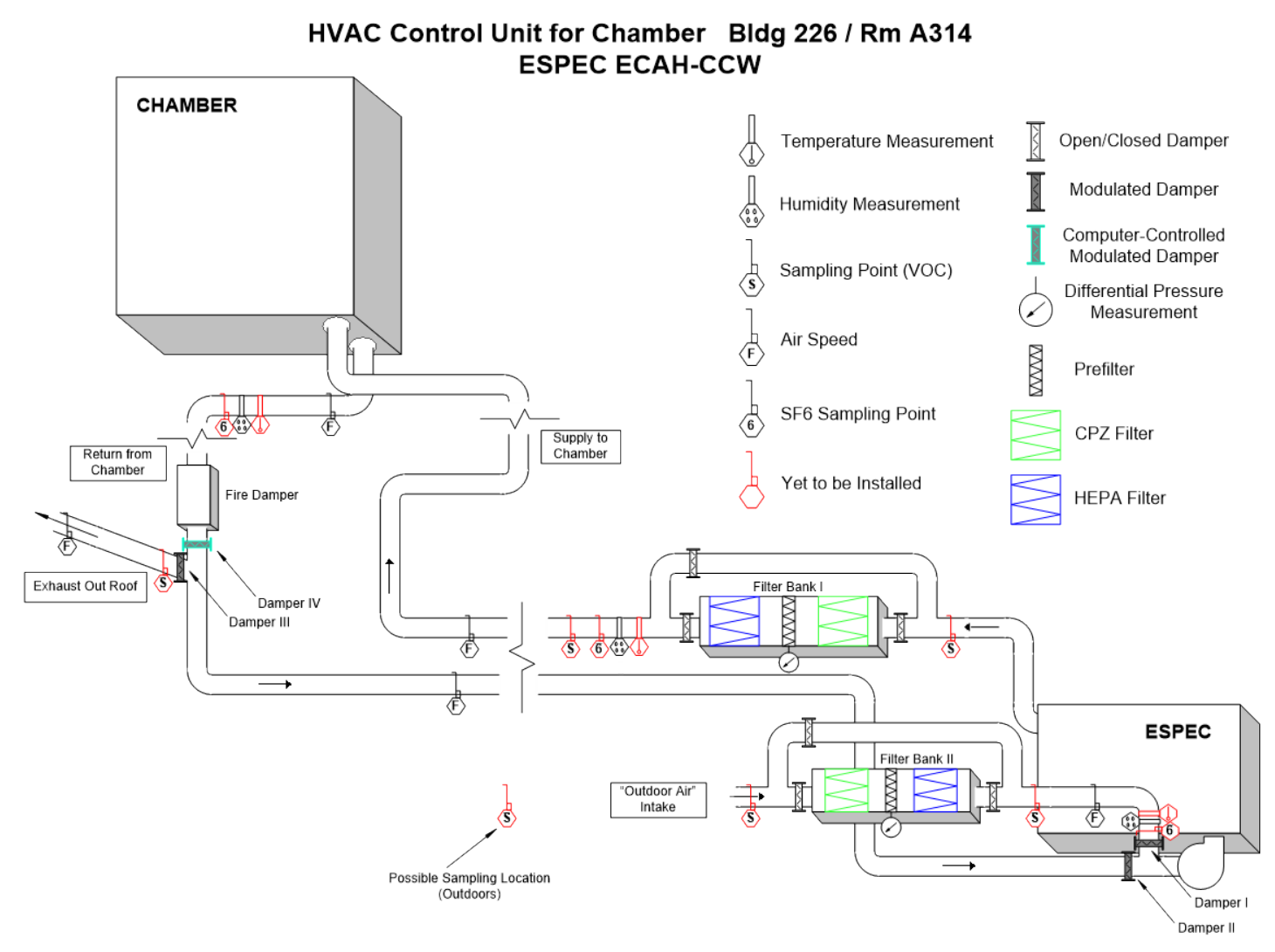

Figure A.8: Measurement locations in the large chamber/ESPEC system

In this study, fan speed was set to the lowest value at $36 \mathrm{~Hz}$ and the modulated dampers were fixed. The outdoor air change ratea was controlled with the recirculation damper and measured using the tracer gas decay method. Sulfur hexafluoride $\left(\mathrm{SF}_{6}\right)$ was used as the tracer gas. For each test, $3.5 \mathrm{~L}$ of $5 \% \mathrm{SF}_{6}$ (by mass) was injected into the chamber manually with one $2 \mathrm{~L}$ syringe and one $1.5 \mathrm{~L}$ syringe. The decay of the $\mathrm{SF}_{6}$ was monitored using a photoacoustic infrared (PAIR) tracer gas monitoring system. The PAIR was calibrated between $0.6 \mathrm{ppm}$ and $3 \mathrm{ppm}$, and only data in this range were used for the air change rate calculation. Based on ASTM E741-11 (2017) (ASTM 
2017), the slope of the log of $\mathrm{SF}_{6}$ concentration versus sampling time equals the negative of the air change rate. An example of the measured $\mathrm{SF}_{6}$ concentration in a test with a $79 \%$ opening of recirculation damper is shown in Figure A.9. The linear curve fitting in Figure A.9 shows the air change rate was $0.99 \mathrm{~h}^{-1}$. In total, eight decay tests were conducted, lasting $2 \mathrm{~h}$ to $3 \mathrm{~h}$ each. The opening of recirculation damper was linearly correlated with the calculated outdoor air change rates (Figure A.10). The curve in Figure A.10 was used to set the position of the recirculation damper for each cigarette butt conditioning experiment and emission test. The outdoor air flow rate listed in Table 2.4 was calculated by the air change rate multiplied by the chamber volume.

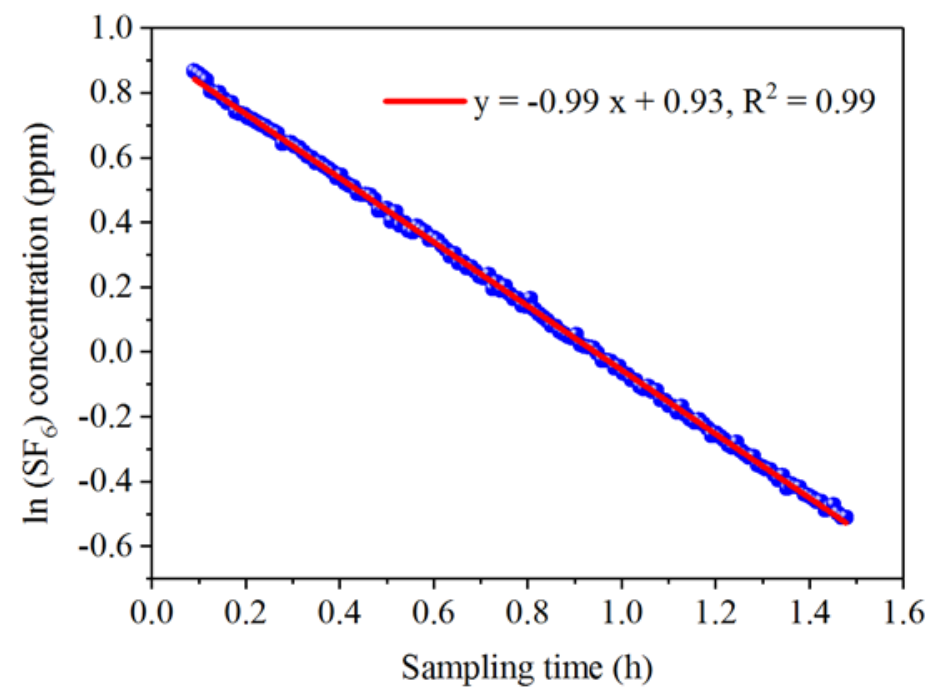

Figure A.9: $\quad S_{6}$ concentration in a decay test with $79 \%$ opening of recirculation damper

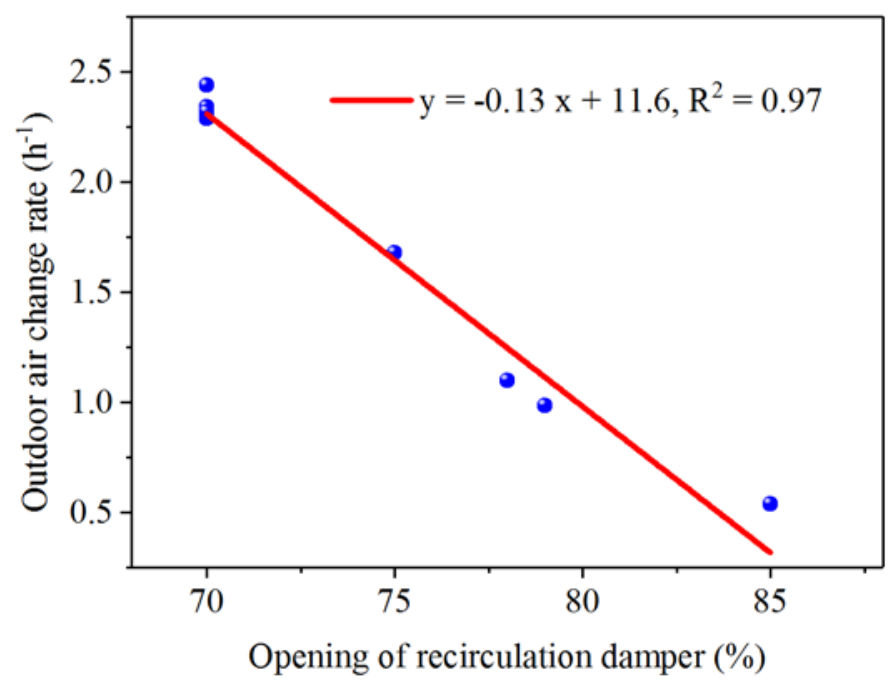

Figure A.10: Relation between outdoor air change rate and opening of recirculation damper. 
The total flow rate of supply air into the chamber was measured with a balometer. The manufacturers stated tolerance of the balometer measurements is $3 \%$ of reading plus $2.4 \mathrm{~L} \mathrm{~s}^{-1}$. Each of the three supply vents was measured and the total flow rate of air into the chamber was determined to be the sum of the three measurements. The re-circulation rate was determined by subtracting the outdoor airflow rate from the total flow rate. 


\section{A.5 EVALUATION OF BREAKTHROUGH DURING AIR SAMPLING IN THE CHAMBER EMISSION TEST}

To determine if the target chemicals breakthrough the sorbent tube during the $3 \mathrm{~h}$ sampling sorption tubes were spiked with the target chemical (roughly 50 to 100 times the instrument quantification limit listed in Table 2.7). Then, the spiked Tenax tube was connected to a clean Tenax tube as a backup tube, and purged with $99.99 \%$ nitrogen for $3 \mathrm{~h}$ at the same flow rate as that used for air sampling, i.e., $100 \mathrm{~mL} / \mathrm{min}$. A total of four tube pairs were analyzed. Masses measured for each tube are listed in Table A.4.

Table A.4: $\quad$ Breakthrough data for air sampling with Tenax tube.

\begin{tabular}{|c|c|c|c|c|c|c|c|c|}
\hline Sample & Furfural, ng & $\begin{array}{c}\text { Ethylbenzene, } \\
\text { ng }\end{array}$ & $\begin{array}{c}\text { Styrene, } \\
\text { ng }\end{array}$ & $\begin{array}{c}\text { 2-methyl-2- } \\
\text { cyclopenten-1-one, } \\
\text { ng } \\
\end{array}$ & $\begin{array}{c}\text { Limonene, } \\
\text { ng }\end{array}$ & $\begin{array}{c}\text { Naphthalene, } \\
\text { ng }\end{array}$ & $\begin{array}{c}\text { Triacetin, } \\
\text { ng }\end{array}$ & $\begin{array}{l}\text { Nicotine, } \\
\text { ng }\end{array}$ \\
\hline Front $^{\mathrm{a}} 1$ & 25.9 & 18.0 & 18.8 & 20.2 & 47.1 & 2.3 & 18.4 & 17.4 \\
\hline Front 2 & 23.5 & 15.7 & 16.3 & 17.8 & 39.3 & 2.0 & 16.3 & 15.8 \\
\hline Front 3 & 25.3 & 17.3 & 18.5 & 20.7 & 45.2 & 2.3 & 17.8 & 14.8 \\
\hline Front 4 & 22.4 & 15.1 & 16.3 & 18.2 & 40.3 & 2.1 & 17.3 & 17.3 \\
\hline Back-up ${ }^{b} 1$ & 0.75 & 0.47 & $\mathrm{ND}^{\mathrm{c}}$ & ND & ND & 0.14 & 0.38 & 0.33 \\
\hline Back-up 2 & 0.90 & 0.49 & 0.13 & ND & ND & 0.11 & 0.41 & 0.52 \\
\hline Back-up 3 & 1.13 & 0.65 & 0.30 & ND & ND & 0.12 & ND & 0.22 \\
\hline Back-up 4 & 1.78 & 1.38 & 0.58 & 0.34 & 0.55 & 0.09 & ND & 0.31 \\
\hline
\end{tabular}




\section{Appendix B EXPERIMENTAL DATA}

This appendix presents data that was collected for the experimental phase of the project. Appendix B.1 list the average initial emitted mass values of measured mass emitted from fresh cigarette butts used to analyze the data. Appendix B.2 lists the curve fitting parameters for each of the headspace experiments. Appendix B.3 lists the measured air concentrations in the chamber during the emission rate experiment. 


\section{B.1 MEASURED MASS EMITTED FROM FRESH CIGARETTE BUTTS}

Table B.1 list the average initial emitted mass values used to analyze the headspace data. These data are the average of the six data sets shown in Figure 2.21. Each dataset includes the analysis of at least 12 butts.

Table B.1: Measured emitted mass from each set of fresh cigarette butts (mean (standard deviation)).

\begin{tabular}{|c|c|c|c|c|c|c|c|c|c|c|c|}
\hline Sampling date & $\underset{\#}{\text { Sample }}$ & $\begin{array}{c}\text { Furural, } \\
\text { ng }\end{array}$ & $\begin{array}{c}\text { Ethylbenzene, } \\
\text { ng }\end{array}$ & $\begin{array}{l}\text { Styrene, } \\
\text { ng }\end{array}$ & $\begin{array}{c}\text { 2-methyl-2- } \\
\text { Cyclopenten- } \\
\text { 1-one, } \\
\text { ng }\end{array}$ & $\begin{array}{c}\text { Limonene, } \\
\text { ng }\end{array}$ & $\begin{array}{c}\text { Naphthalene, } \\
\text { ng }\end{array}$ & $\begin{array}{c}\text { Triacetin, } \\
\text { ng }\end{array}$ & $\begin{array}{l}\text { Nicotine, } \\
\text { ng }\end{array}$ & $\begin{array}{c}\text { Temperature, } \\
{ }^{\circ} \mathrm{C}\end{array}$ & $\begin{array}{c}\text { Relative } \\
\text { humidity, } \\
\%\end{array}$ \\
\hline $2 / 28 / 2018$ & 12 & $\begin{array}{l}647.5 \\
(89.2)\end{array}$ & $\begin{array}{l}226.4 \\
(42.7)\end{array}$ & $\begin{array}{l}361.2 \\
(49.9)\end{array}$ & $\begin{array}{l}412.3 \\
(48.5)\end{array}$ & $\begin{array}{l}3165.6 \\
(505.3)\end{array}$ & $\begin{array}{l}33.5 \\
(3.7)\end{array}$ & $\begin{array}{l}320.4 \\
(40.3)\end{array}$ & $\begin{array}{l}398.5 \\
(83.8)\end{array}$ & $\begin{array}{l}23.4 \\
(0.1)\end{array}$ & $\begin{array}{c}20 \\
(2.1)\end{array}$ \\
\hline $8 / 15 / 2018$ & 12 & $\begin{array}{l}455.1 \\
(81.2)\end{array}$ & $\begin{array}{l}206.4 \\
(30.8)\end{array}$ & $\begin{array}{l}371.9 \\
(31.2)\end{array}$ & $\begin{array}{l}430.6 \\
(26.5)\end{array}$ & $\begin{array}{l}2447.6 \\
(259.8)\end{array}$ & $\begin{array}{l}17.7 \\
(1.1)\end{array}$ & $\begin{array}{l}182.4 \\
(34.3)\end{array}$ & $\begin{array}{l}189.2 \\
(33.3)\end{array}$ & $\begin{array}{l}24.4 \\
(0.2)\end{array}$ & $\begin{array}{l}46.1 \\
(0.5)\end{array}$ \\
\hline 8/21/2018 & 12 & $\begin{array}{l}624.2 \\
(52.8)\end{array}$ & $\begin{array}{l}246.5 \\
(48.6)\end{array}$ & $\begin{array}{l}427.7 \\
(27.2)\end{array}$ & $\begin{array}{l}461.6 \\
(20.1)\end{array}$ & $\begin{array}{l}2722.8 \\
(273.2)\end{array}$ & $\begin{array}{l}17.0 \\
(2.0)\end{array}$ & $\begin{array}{l}208.7 \\
(37.8)\end{array}$ & $\begin{array}{l}202.7 \\
(47.2)\end{array}$ & $\begin{array}{l}24.1 \\
(0.1)\end{array}$ & $\begin{array}{l}47.3 \\
(0.6)\end{array}$ \\
\hline 10/30/2018 & 18 & $\begin{array}{l}421.3 \\
(58.7)\end{array}$ & $\begin{array}{l}201.2 \\
(28.6)\end{array}$ & $\begin{array}{l}254.5 \\
(34.9)\end{array}$ & $\begin{array}{l}285.0 \\
(36.9)\end{array}$ & $\begin{array}{l}1642.4 \\
(139.7)\end{array}$ & $\begin{array}{l}15.5 \\
(1.8)\end{array}$ & $\begin{array}{l}195.0 \\
(45.4)\end{array}$ & $\begin{array}{l}224.1 \\
(39.5)\end{array}$ & $\begin{array}{l}23.8 \\
(0.1)\end{array}$ & $\begin{array}{l}33.8 \\
(0.2)\end{array}$ \\
\hline $11 / 2 / 2018$ & 12 & $\begin{array}{l}447.6 \\
(79.1)\end{array}$ & $\begin{array}{l}202.8 \\
(57.0)\end{array}$ & $\begin{array}{l}287.6 \\
(55.2)\end{array}$ & $\begin{array}{l}309.3 \\
(55.7)\end{array}$ & $\begin{array}{l}1818.5 \\
(254.6)\end{array}$ & $\begin{array}{l}14.3 \\
(1.4)\end{array}$ & $\begin{array}{l}235.9 \\
(63.9)\end{array}$ & $\begin{array}{l}188.1 \\
(41.7)\end{array}$ & $\begin{array}{l}23.8 \\
(0.3)\end{array}$ & $\begin{array}{l}43.5 \\
(0.4)\end{array}$ \\
\hline $11 / 16 / 2018$ & 12 & $\begin{array}{l}475.4 \\
(58.4)\end{array}$ & $\begin{array}{l}277.0 \\
(46.9)\end{array}$ & $\begin{array}{l}360.2 \\
(39.0)\end{array}$ & $\begin{array}{l}371.7 \\
(34.3)\end{array}$ & $\begin{array}{l}2183.1 \\
(162.4)\end{array}$ & $\begin{array}{l}19.1 \\
(1.8)\end{array}$ & $\begin{array}{l}275.3 \\
(44.4)\end{array}$ & $\begin{array}{l}387.6 \\
(75.1)\end{array}$ & $\begin{array}{l}23.8 \\
(0.1)\end{array}$ & $\begin{array}{l}33.7 \\
(0.4)\end{array}$ \\
\hline $\begin{array}{c}\text { Average (relative } \\
\text { standard deviation) of } \\
\text { mean values for each } \\
\text { date }(\mathrm{N}=7)\end{array}$ & & $\begin{array}{l}511.8 \\
(19 \%)\end{array}$ & $\begin{array}{c}226.7 \\
(18 \%)\end{array}$ & $\begin{array}{l}343.9 \\
(21 \%)\end{array}$ & $\begin{array}{c}378.4 \\
(19 \%)\end{array}$ & $\begin{array}{l}2330.0 \\
(23 \%)\end{array}$ & $\begin{array}{c}19.5 \\
(33 \%)\end{array}$ & $\begin{array}{l}236.3 \\
(21 \%)\end{array}$ & $\begin{array}{l}265.0 \\
(34 \%)\end{array}$ & $\begin{array}{c}23.9 \\
(1 \%)\end{array}$ & $\begin{array}{c}37.4 \\
(28 \%)\end{array}$ \\
\hline
\end{tabular}




\section{B.2 HeAdSPACE ANALYSIS CURVE FITTING PARAMETERS}

Table B.2 through Table B.6 list the two-stage curve fitting parameters $\left(M_{o}, F, k_{1}, k_{2}\right)$ and the $\mathrm{R}^{2}$ value for each of the headspace analysis experiments. The initial mass, $M_{o}$, values are the values shown in Table B.1 for all tables except Table B.4, which has different values due to the water saturation impacts on the initial masses.

Table B.2: $\quad$ Curve fitting parameters for experimental data examining influence of UV.

\begin{tabular}{|c|c|c|c|c|c|c|c|c|c|}
\hline & \multirow[b]{2}{*}{$M_{0}$} & \multicolumn{4}{|c|}{ UV on } & \multicolumn{4}{|c|}{ UV off } \\
\hline & & $F$ & $\boldsymbol{k}_{1}$ & $k_{2}$ & $\mathbf{R}^{2}$ & $F$ & $k_{1}$ & $k_{2}$ & $\mathbf{R}^{2}$ \\
\hline Furfural & 512 & 0.53 & 0.52 & 0.13 & 0.93 & 0.99 & 0.10 & 0.00 & 0.93 \\
\hline Ethylbenzene & 227 & 0.95 & 2.8 & 0.12 & 0.95 & 0.96 & 2 & 0.046 & 0.95 \\
\hline Styrene & 344 & 0.92 & 2.1 & 0.13 & 0.94 & 0.89 & 1.9 & 0.14 & 0.92 \\
\hline 2-methyl-2-cyclopenten-1-one & 378 & 0.74 & 0.99 & 0.12 & 0.94 & 0.35 & 80 & 0.12 & 0.94 \\
\hline Limonene & 2330 & 0.95 & 36 & 0.19 & 0.94 & 0.91 & 3.1 & 0.13 & 0.94 \\
\hline Naphthalene & 19.5 & 0.88 & 0.38 & 0.039 & 0.84 & 0.31 & 435 & 0.081 & 0.82 \\
\hline Triacetin & 236 & 0.36 & 0.29 & 0.0094 & 0.69 & 0.45 & 1918 & 0.0041 & 0.76 \\
\hline Nicotine & 265 & 0.68 & 0.075 & 0.0075 & 0.83 & 0.29 & 0.24 & 0.011 & 0.78 \\
\hline
\end{tabular}


Table B.3: $\quad$ Curve fitting parameters for experimental data examining influence of temperature (T) and relative humidity (RH).

\begin{tabular}{|c|c|c|c|c|c|c|c|c|c|c|c|c|c|c|c|c|c|}
\hline & \multirow[b]{2}{*}{$M_{0}$} & \multicolumn{4}{|c|}{$\begin{array}{c}\mathrm{T}=30^{\circ} \mathrm{C} \text {, relative humidity }= \\
50 \%\end{array}$} & \multicolumn{4}{|c|}{$\begin{array}{c}\mathrm{T}=40^{\circ} \mathrm{C} \text {, relative humidity } \\
=50 \%\end{array}$} & \multicolumn{4}{|c|}{$\begin{array}{c}\mathrm{T}=30^{\circ} \mathrm{C}, \text { relative humidity } \\
=25 \%\end{array}$} & \multicolumn{4}{|c|}{$\begin{array}{c}\mathrm{T}=40^{\circ} \mathrm{C} \text {, relative humidity } \\
=25 \%\end{array}$} \\
\hline & & $\boldsymbol{F}$ & $k_{1}$ & $k_{2}$ & $\mathbf{R}^{2}$ & $\boldsymbol{F}$ & $k_{1}$ & $k_{2}$ & $\mathbf{R}^{2}$ & $F$ & $k_{1}$ & $k_{2}$ & $\mathbf{R}^{2}$ & $F$ & $k_{1}$ & $k_{2}$ & $\mathbf{R}^{2}$ \\
\hline Furfural & 512 & 0.98 & 0.24 & 0.0046 & 0.92 & 0.62 & 0.83 & 0.190 & 0.95 & 0.47 & 71000 & 0.058 & 0.95 & 0.80 & 0.50 & 0.088 & 0.96 \\
\hline Ethylbenzene & 227 & & & & & & & & & 0.91 & 1.40 & 0.087 & 0.95 & & & & \\
\hline Styrene & 344 & & & & & & & & & 0.90 & 1.50 & 0.056 & 0.94 & 0.98 & 1.90 & 0.072 & 0.94 \\
\hline $\begin{array}{c}\text { 2-methyl-2- } \\
\text { cyclopenten-1-one }\end{array}$ & 378 & 0.91 & 0.63 & 0.065 & 0.94 & 0.83 & 1.48 & 0.160 & 0.95 & 0.70 & 1.70 & 0.062 & 0.95 & 0.96 & 0.82 & 0.014 & 0.95 \\
\hline Limonene & 2330 & 0.87 & 72 & 0.35 & 0.94 & & & & & 0.98 & 1.80 & 0.060 & 0.94 & 0.99 & 2.30 & 0.094 & 0.94 \\
\hline Naphthalene & 19.5 & 0.82 & 0.49 & 0.069 & 0.85 & 0.67 & 148 & 0.33 & 0.67 & 0.00 & -- & 0.076 & 0.82 & 0.83 & 0.49 & 0.088 & 0.86 \\
\hline Triacetin & 236 & 0.46 & 0.26 & 0.0048 & 0.81 & 0.71 & 0.40 & 0.0019 & 0.90 & 0.39 & 0.69 & 0.0069 & 0.77 & 0.79 & 0.047 & 0.00 & 0.81 \\
\hline Nicotine & 265 & 0.82 & 0.037 & 0.00 & 0.81 & 0.74 & 0.45 & 0.0080 & 0.85 & 0.00 & -- & 0.014 & 0.62 & 0.82 & 0.043 & 0.0024 & 0.79 \\
\hline
\end{tabular}

Table B.4: $\quad$ Curve fitting parameters for experimental data examining influence of water saturation.

\begin{tabular}{|c|c|c|c|c|c|c|}
\hline & \multicolumn{3}{|c|}{ Dry } & \multicolumn{3}{c|}{ Wet } \\
\hline & $\boldsymbol{M}_{\mathbf{0}}$ & $\boldsymbol{k}$ & $\boldsymbol{R}^{\mathbf{2}}$ & $\boldsymbol{M}_{\mathbf{0}}$ & $\boldsymbol{k}$ & $\boldsymbol{R}^{\mathbf{2}}$ \\
\hline Furfural & 689 & 0.35 & 0.98 & 777 & 0.55 & 0.99 \\
\hline Ethylbenzene & 301 & 1.8 & 0.98 & 191 & - & - \\
\hline Styrene & 402 & 1.5 & 0.99 & 291 & 1.1 & 1.0 \\
\hline 2-methyl-2-Cyclopenten-1-one & 358 & 0.51 & 0.98 & 301 & 0.62 & 0.97 \\
\hline Limonene & 2320 & 1.5 & 1.0 & 1448 & 0.87 & 1.0 \\
\hline Naphthalene & 14 & 0.36 & 0.95 & 12 & 0.35 & 0.96 \\
\hline Triacetin & 373 & - & - & 159 & - & - \\
\hline Nicotine & 146 & - & - & 13 & - & - \\
\hline Dashes (-) indicate when curve fit parameters were not determined due to lack of data.
\end{tabular}


Table B.5: $\quad$ Curve fitting parameters for experimental data examining influence of air change rate $(\lambda)$.

\begin{tabular}{|c|c|c|c|c|c|c|c|c|c|}
\hline & & \multicolumn{4}{|c|}{$\lambda_{0}=0.54 \mathrm{~h}^{-1}, \lambda_{\mathrm{r}}=3.5 \mathrm{~h}^{-1}$} & \multicolumn{4}{|c|}{$\lambda_{0}=0.99 \mathrm{~h}^{-1}, \lambda_{\mathrm{r}}=3.0 \mathrm{~h}^{-1}$} \\
\hline & $M_{0}$ & $\boldsymbol{F}$ & $k_{1}$ & $k_{2}$ & $\mathbf{R}^{2}$ & $M_{0}$ & $\boldsymbol{F}$ & $\boldsymbol{k}_{1}$ & $k_{2}$ \\
\hline Furfural & 512 & 0.49 & 0.34 & 0.07 & 0.95 & 0.27 & 19 & 0.085 & 0.94 \\
\hline Styrene & 344 & 0.87 & 42 & 0.056 & 0.94 & 0.87 & 0.96 & 0.09 & 0.94 \\
\hline 2-methyl-2-cyclopenten-1-one & 378 & 0.63 & 0.92 & 0.067 & 0.95 & 0.37 & 106 & 0.096 & 0.95 \\
\hline Naphthalene & 19.5 & 0.18 & 463 & 0.08 & 0.87 & 0.53 & 0.66 & 0.048 & 0.86 \\
\hline Triacetin & 236 & 0.73 & 0.05 & 0.0 & 0.71 & 0.46 & 0.8 & 0.0063 & 0.75 \\
\hline Nicotine & 265 & 0.76 & 0.045 & 0.0012 & 0.81 & 0.52 & 0.91 & 0.0064 & 0.77 \\
\hline
\end{tabular}

Table B.6: $\quad$ Curve fitting parameters for experimental data comparing summer and winter.

\begin{tabular}{|c|c|c|c|c|c|c|c|c|c|c|c|c|c|c|c|c|c|}
\hline & \multirow[b]{2}{*}{$M_{0}$} & \multicolumn{4}{|c|}{ Roof Summer 1} & \multicolumn{4}{|c|}{ Roof Summer 2} & \multicolumn{4}{|c|}{ Roof Winter 1} & \multicolumn{4}{|c|}{ Roof Winter 2} \\
\hline & & $F$ & $k_{1}$ & $k_{2}$ & $\mathbf{R}^{2}$ & $F$ & $k_{1}$ & $k_{2}$ & $\mathbf{R}^{2}$ & $F$ & $k_{1}$ & $k_{2}$ & $\mathbf{R}^{2}$ & $F$ & $k_{1}$ & $k_{2}$ & $\mathbf{R}^{2}$ \\
\hline Furfural & 512 & 0.77 & 1.4 & 0.13 & 0.95 & 0.50 & 1.4 & 0.14 & 1.0 & 0.57 & 0.82 & 0.025 & 0.95 & 0.24 & 25 & 0.015 & 0.89 \\
\hline Ethylbenzene & 227 & - & - & - & - & 0.93 & 1.2 & 0.082 & 0.94 & 0.91 & 1.3 & 0.081 & 0.96 & 0.70 & 1.0 & 0.019 & 0.95 \\
\hline Styrene & 344 & 0.95 & 76 & 0.046 & 0.92 & - & - & - & - & 0.89 & 1.2 & 0.09 & 0.94 & 0.63 & 1.2 & 0.020 & 0.91 \\
\hline $\begin{array}{c}\text { 2-methyl-2- } \\
\text { cyclopenten-1-one }\end{array}$ & 378 & - & - & - & - & 0.65 & 191 & 0.15 & 0.90 & 0.70 & 0.81 & 0.038 & 0.95 & 0.44 & 1.4 & 0.018 & 0.91 \\
\hline Limonene & 2330 & 0.97 & 19 & 0.053 & 0.93 & 0.95 & 64 & 0.11 & 0.93 & 0.96 & 1.5 & 0.017 & 0.94 & 0.60 & 565 & 0.022 & 0.92 \\
\hline Naphthalene & 19.5 & 0.79 & 138 & 0.027 & 0.83 & 0.74 & 1.0 & 0.069 & 0.83 & 0.62 & 0.66 & 0.0082 & 0.83 & 0.40 & 168 & 0.013 & 0.81 \\
\hline Triacetin & 236 & - & - & - & - & - & - & - & - & - & - & - & - & - & - & - & - \\
\hline Nicotine & 265 & - & - & - & - & - & - & - & - & - & - & - & - & - & - & - & - \\
\hline
\end{tabular}




\section{B.3 AIR SAMPLE CONCENTRATIONS IN THE CHAMBER}

Table B.7 lists the measured air concentrations in the chamber during the emission rate experiment. Four Tenax sample tubes were taken at each sampling time (Front inlet, Back inlet, Middle, Outlet) as illustrated in Figure 1.3.

Table B.7: Chemical concentrations in chamber air at different locations and different times for emission test in large chamber.

\begin{tabular}{|c|c|c|c|c|c|c|c|c|c|c|}
\hline Sample & $\begin{array}{c}\text { Sampling } \\
\text { start } \\
\text { time }^{\mathrm{a}}, \mathbf{h} \\
\end{array}$ & $\begin{array}{c}\text { Sampling } \\
\text { duration, } \\
\text { h }\end{array}$ & $\begin{array}{c}\text { Furfural, } \\
\mathbf{n g} / \mathbf{m}^{3}\end{array}$ & $\begin{array}{c}\text { Ethylbenzene, } \\
n g / \mathbf{m}^{3}\end{array}$ & $\begin{array}{c}\text { Styrene, } \\
\mathbf{n g} / \mathbf{m}^{3}\end{array}$ & $\begin{array}{c}\text { 2-methyl-2- } \\
\text { cyclopenten-1-one, } \\
\mathbf{n g} / \mathbf{m}^{3}\end{array}$ & $\begin{array}{c}\text { Limonene, } \\
\mathbf{n g} / \mathbf{m}^{3}\end{array}$ & $\begin{array}{c}\text { Naphthalene, } \\
\mathbf{n g} / \mathbf{m}^{3}\end{array}$ & $\begin{array}{c}\text { Triacetin, } \\
\mathbf{n g} / \mathbf{m}^{3}\end{array}$ & $\begin{array}{c}\text { Nicotine, } \\
\mathbf{n g} / \mathrm{m}^{3}\end{array}$ \\
\hline Front inlet & $-3^{b}$ & 2.7 & $-^{\mathrm{c}}$ & - & - & - & - & - & - & 21.4 \\
\hline Back inlet & $-3^{b}$ & 2.7 & - & 13.6 & - & - & - & - & - & 23.1 \\
\hline Middle & $-3^{b}$ & 2.7 & - & 15.3 & - & - & - & 6.0 & - & 23.3 \\
\hline Outlet & $-3^{b}$ & 2.7 & - & 15.6 & 14.8 & - & 33.1 & 6.4 & - & 24.4 \\
\hline Front inlet & 0 & 1.8 & 104.5 & 37.7 & 39.1 & 61.0 & 188.1 & 7.0 & - & 32.8 \\
\hline Back inlet & 0 & 1.8 & 106.6 & 38.3 & 44.9 & 60.2 & 195.8 & 6.9 & - & 33.5 \\
\hline Middle & 0 & 1.8 & 2613.7 & 188.7 & 488.2 & 1215.2 & 2518.9 & 59.8 & 266.9 & 312.5 \\
\hline Outlet & 0 & 1.8 & 2256.1 & 164.6 & 417.7 & 1122.6 & 2279.6 & 58.0 & 227.9 & 209.5 \\
\hline Front inlet & 2 & 2.9 & 77.5 & 14.6 & 14.3 & 36.6 & 34.7 & 4.1 & - & 22.1 \\
\hline Back inlet & 2 & 2.9 & 73.3 & 14.9 & 16.2 & 35.0 & 39.6 & 4.2 & - & 20.2 \\
\hline Middle & 2 & 2.9 & 1407.5 & 32.3 & 80.3 & 542.8 & 296.6 & 29.5 & 223.9 & 180.4 \\
\hline Outlet & 2 & 2.9 & 1606.6 & 34.5 & 91.8 & 639.4 & 324.2 & 33.1 & 265.5 & 131.3 \\
\hline Front inlet & 5 & 2.6 & 56.4 & 14.8 & & 27.8 & - & - & - & 25.6 \\
\hline Back inlet & 5 & 2.6 & 74.1 & 16.0 & 16.2 & 34.6 & - & 5.1 & - & 24.0 \\
\hline Middle & 5 & 2.6 & 1722.7 & 26.8 & 52.8 & 586.5 & 158.1 & 35.5 & 436.6 & 412.3 \\
\hline Outlet & 5 & 2.6 & 1261.3 & 23.3 & 43.1 & 439.0 & 130.2 & 26.4 & 318.2 & 159.2 \\
\hline Front inlet & 7.8 & 2.9 & 36.3 & 12.6 & - & 16.6 & - & - & - & 22.2 \\
\hline Back inlet & 7.8 & 2.9 & 38.9 & 12.6 & - & 17.1 & - & - & - & 20.9 \\
\hline Middle & 7.8 & 2.9 & 659.3 & 16.4 & 22.7 & 212.6 & 111.0 & 15.9 & 251.2 & 206.9 \\
\hline Outlet & 7.8 & 2.9 & 746.5 & 18.2 & 24.1 & 212.7 & 135.7 & 15.6 & 249.9 & 127.9 \\
\hline Front inlet & 10.8 & 3.0 & 28.8 & - & - & 17.4 & - & - & 16.6 & 21.6 \\
\hline Back inlet & 10.8 & 3.0 & 31.5 & - & - & 18.0 & - & - & - & 19.5 \\
\hline Middle & 10.8 & 3.0 & 734.5 & 14.8 & 19.9 & 207.0 & 106.8 & 15.9 & 338.1 & 274.7 \\
\hline
\end{tabular}




\begin{tabular}{|c|c|c|c|c|c|c|c|c|c|c|}
\hline Outlet & 10.8 & 3.0 & 632.3 & 14.9 & 19.0 & 154.1 & 108.6 & 14.2 & 284.8 & 158.2 \\
\hline Front inlet & 14.8 & 2.9 & 25.8 & - & - & 17.4 & - & - & - & 21.7 \\
\hline Back inlet & 14.8 & 2.9 & 27.5 & 12.6 & - & 13.6 & - & - & - & 20.3 \\
\hline Middle & 14.8 & 2.9 & 543.4 & 14.2 & 18.2 & 138.7 & 51.8 & 12.1 & 322.8 & 278.7 \\
\hline Outlet & 14.8 & 2.9 & 385.1 & 13.5 & 16.0 & 101.1 & 42.3 & 8.5 & 232.0 & 143.3 \\
\hline Front inlet & 17.9 & 2.9 & - & - & - & 13.0 & - & - & 18.8 & 21.8 \\
\hline Back inlet & 17.9 & 2.9 & - & - & - & 14.1 & - & - & 19.6 & 21.1 \\
\hline Middle & 17.9 & 2.9 & 279.9 & 13.9 & 16.7 & 84.1 & 35.9 & 8.7 & 282.7 & 180.9 \\
\hline Outlet & 17.9 & 2.9 & 288.3 & 13.4 & 15.5 & 86.0 & 32.9 & 8.4 & 285.7 & 147.9 \\
\hline Front inlet & 20.9 & 2.8 & 37.2 & 13.8 & 14.7 & 16.3 & - & - & 26.2 & 30.6 \\
\hline Back inlet & 20.9 & 2.8 & - & - & - & 13.0 & - & - & 21.3 & 20.6 \\
\hline Middle & 20.9 & 2.8 & 353.9 & 13.9 & 15.8 & 95.9 & 35.0 & 12.2 & 389.9 & 327.6 \\
\hline Outlet & 20.9 & 2.8 & 265.0 & 14.0 & 15.2 & 78.7 & 33.9 & 11.2 & 307.0 & 200.3 \\
\hline Front inlet & 23.8 & 3.0 & - & - & - & - & - & - & 17.8 & 21.7 \\
\hline Back inlet & 23.8 & 3.0 & - & - & - & 13.3 & - & - & 18.7 & 20.2 \\
\hline Middle & 23.8 & 3.0 & 147.8 & 12.2 & 13.7 & 41.5 & - & 5.9 & 231.1 & 182.2 \\
\hline Outlet & 23.8 & 3.0 & 214.3 & - & 14.8 & 56.6 & 32.9 & 7.7 & 293.2 & 175.4 \\
\hline
\end{tabular}

a: time interval from the start of the emission test; b: background samples were taken 3 h before the start of the emission test; c: mass in the sample was less than the quantification limit in Table 2.7. 